NASA CR- 1.35264

MCR-77-2:3

\title{
NAS \\ National \\ Aeronautics and \\ Space \\ Administration
}

\section{EFFECT OF VIBRATION ON \\ RETENTION CHARACTERISTICS OF SCREEN ACQUISITION SYSTEMS}

\author{
Final Report \\ October 1977 \\ by J. R, Tegart and A. C. Park \\ (NASA-CL-1352E4) EFEECI CF HIERATICH CH \\ RETENTICA CEREACTEEISIICS CE SCEEEN \\ ACQCISITICA SYETENS Final Fefort, Nay 1976 \\ - Lur. 1977 (Nartin Narietta (crp.) $167 \mathrm{f}$ unclas \\ EC ACE/ME AC1 CSCI $20[\quad$ G3/34 53556 \\ MARTIN MARIETTA CORPORATION \\ Denver Division
}

prepared for

NATIONAL AERONAUTICS AND SPACE ADMINISTRATION

NASA Lewis Research Center

Contract NAS3-20097

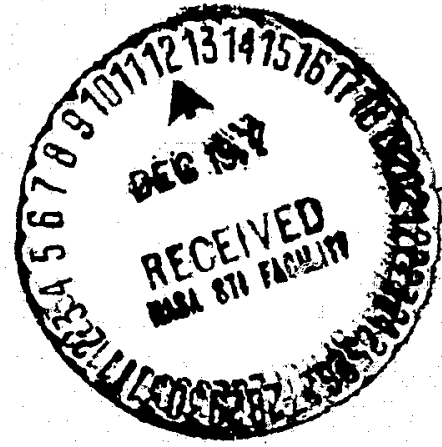




\begin{tabular}{|c|c|c|}
\hline $\begin{array}{l}\text { 1. Report No. } \\
\text { NASA CR - } 135264\end{array}$ & 2. Government Accession No. & 3. Recipient's Cotalog No. \\
\hline \multirow{2}{*}{\multicolumn{2}{|c|}{$\begin{array}{l}\text { 4. Tillo and Subtille } \\
\text { Effect of Vibration on Retention Character- } \\
\text { istics of Screen acquijition systems }\end{array}$}} & $\begin{array}{l}\text { 5. Report Doto } \\
\text { October } 1977\end{array}$ \\
\hline & & 6. Performing Organization Coda \\
\hline \multicolumn{2}{|c|}{$\begin{array}{l}\text { 7. Author(s) } \\
\text { J. R. Tegart, A. C. Park }\end{array}$} & $\begin{array}{l}\text { 8. Performing Orgonization Report No. } \\
\text { MCR }-77-253\end{array}$ \\
\hline \multirow{3}{*}{\multicolumn{2}{|c|}{$\begin{array}{l}\text { 9. Performing Organization Nome and Address } \\
\text { Martin Marietta Corporation } \\
\text { P. 0. Box } 179 \\
\text { Denver, Colorado } 80201\end{array}$}} & 10. Work Unil No. \\
\hline & & $\begin{array}{l}\text { 11. Contract or Grant No. } \\
\text { NAS3 - } 20097 \\
\end{array}$ \\
\hline & & $\begin{array}{l}\text { 13. Type of R.jport and Period Coyered } \\
\text { Final Report }\end{array}$ \\
\hline \multirow{2}{*}{\multicolumn{2}{|c|}{$\begin{array}{l}\text { 12. Sponsoring Agency Name and Address } \\
\text { NASA Lewis Research Center } \\
\text { Cleveland, Ohio }\end{array}$}} & $\begin{array}{l}\text { Fina } 1 \text { Report } \\
\text { May } 1976 \text { to June } 1977\end{array}$ \\
\hline & & 14. Sponsoring Agency Code \\
\hline \multicolumn{3}{|l|}{ 15. Supplementary Nates } \\
\hline
\end{tabular}

16. Abstroct

An analytical and experimental investigation of the effect of vibration on the retention characteristics of screen acquisition systems was performed. Vibration contributes to the pressure differential acting on a surface tension device, which could lead to gas ingestion through the fine-mesh screen. A survey was conducted to establish the range of the vibration environments to be expected. Analytical methods to predict the pressure differential due to vibration and the screen response were developed. An extensive test program, considering the many variables that influence the screen response, was performed. Through a direct evaluation of the test data the effect of tactors such as weave orientation, vibration orientation, screen support method, screen mesh, liquid flow and liquid subcooling was determined. Prediction of the effect of random and sine vibration for certain conditions was possible.

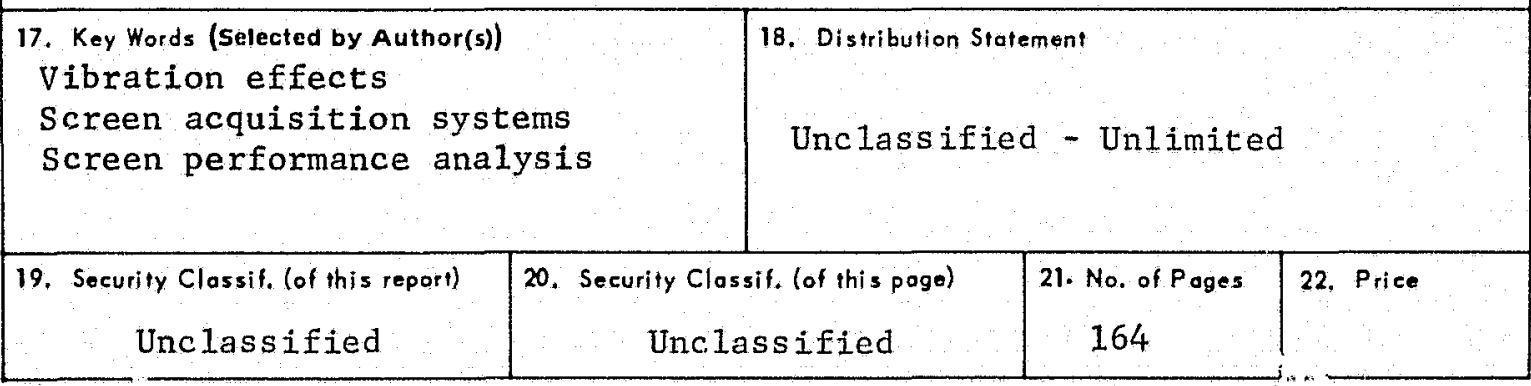


This report was prepared by the Martin Marietta Corporation, Denver Division, under Contract NAS3-20097. The contract was administered by the Lewis Researci Center of the National Aeronautics and Space Administration, Cleveland, Ohio. The study was performed from May 1976 to June 1977 and the NASA-LeRC Project Manager was Mr. John C. Aydelott.

The authors wish to acknowledge the contributions of the following individuals to this program: D. A. Fester and A. J. Villars for their suggestions in formulating the apl oach to the study, and W. J. Kacena for the development of the s'ructural dynamics model. 


\section{Page intentionally left blank}


LIST OF FIGURES . . . . . . . . . . . . . . . . . vii vi

LIST OF TABLES . . . . . . . . . . . . . . . . . .

SUMMARY ........................

I. INTRODUCTION ..................... 1

II. SURVEY OF VIBRATIONAL EFFECTS . . . . . . . . . . 5

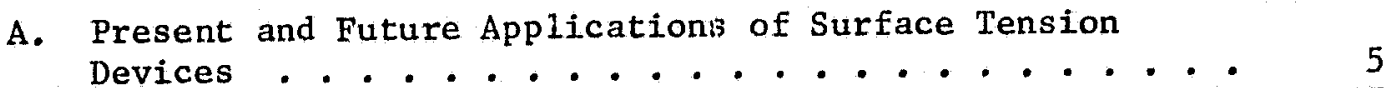

B. Vibration Environment ............ 17

C. Compilation of Survey Results . . . . . . . . 30

III. VIBRATIONAL EFFECTS ANALYSIS . . . . . . . . . . 35

A. Hydrostatic Model ............. 35

B. Screen Dynamics Approach ............ 36

IV. EXPERIMENTAL INVESTIGATION .................... 45

A. Approach ................. . . 45

1. Test Liquids.............. . . 46

2. Screen Mesh .............. 46

3. Screen Mounting ............ 49

4. Configuration ............ . . 51

5. Applied Vibration ............ . . 54

B. Test Apparatus . . . . . . . . . . . 54

1. Test Model ............... 55

2. Test System ..................... 60

3. Instrumentation ............. 60

C. Test Program................ 65

1. Test Mat ix ............... 65

2. Test Procedure ............... 70

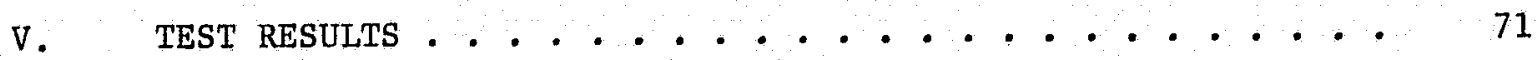

A. Discussion of Results . . . . . . . 71

1. Basic Screen Response ........... . . 71

2. Screen Breakdown ............. 80

3. Effect of Weave Orientation ........ 85 
V. A. 4. Effect of Model Crientation . . . . . . . . 87

5. Effect of Screen Support Method ......... 89

6. Effect of Screen Mesh .............. 96

7. Effect of Liquid Flow ............... . 97

8. Effect of Dual Screen Elements . . . . . . . 100

9. Effect of Liquid Subcooling . . . . . . . . . . 101

10. Miscellaneous Effects ............ 103

B. Data Correlation .............. 105

1. Hydrostatic Mode1 . . . . . . . . . 106

2. Structural Dynamics Mode1 ........... 113

VI. CONCLUSIONS AND RECOMMENDATIONS . . . . . . . . . 123

APPENDIX A Bubble Growth Mode1 . . . . . . . . . . 125

APPENDIX B Test Data ................. 141

APPENDIX C Symbols ............................... 151

APPENDIX D References . . . . . . . . . . . 153 
II-1 Space Shuttle Orbital Maneuvering System Acquisition

Device.................. 6

II-2 Space Shutt1e Reaction Control System Acquisition Device

for Aft Tanks ................ 9

II-3 Space Shuttle Reaction Control System Acquisition Device for Forward Tanks ............. 10

II-4 Viking Orbite: Surface Tension Device . . . . . . . 11

II-5 Surface Tension Device for Agena . . . . . . . . 13

II-6 Trap Assembly, Transtage Main Tanks . . . . . . . 14

II-7 Pressurization Inlet Capillary Barrier, Transtage Main

Tanks ...................... 15

II-8 Dual Screen Liner Concept for Cryogenic Orbiter . . . . 16

II-9 Start Tank Concept for Cryogenic Orbiter . . . . . . 16

II-10 Trap with Liner for Space Tug Oxidizer Tank . . . . . 18

II-11 Start Tank with Surface Tension Device for Space Tug Fue 1

Tank .................... 19

II-12 Integrated APS Zero-G Reservoir for Space Tug . . . . 20

II-13 Surface Tension Device for Orbit Adjust Propulsion

System ..................... 20

II-14 Space Shuttle Randum Viuration Environments . . . . 22

II-15 Viking Random Vibration Environment . . . . . . 23

II-16 Viking Orbiter Launch Sinusoidal Vibration . . . . . . 24

II-17 Random Vibration Acceptance Levels, Space Boosters . . . 25

II-18 Sinusoidal Vibration Flight Acceptance Levels, Space

II-19 Effect of Liquid Leve1 in a Tank on the Vibration

Environment during Static Firing . . . . . . . 27

II-20 Upper Stage Engines ................... 28 
II-21 Lunar Module Primary Structure Random Vibration

Criteria................. 29

II-22 Power Spectral Density Due to Arm Flapping . . . . . . 31

III-1 Screen Dynamics Approach . . . . . . . . . . 37

III-2 Elemental Liquid/Container System . . . . . . . . 38

IV $-1 \quad$ Hydrostatic Screen Retention . . . . . . . . 49

IV-2 Screen Mounting Configiration ........... 50

IV $-3 \quad$ Special Screen Specimens ............ 52

IV $-4 \quad$ Model and Vibration Orientation . . . . . . . . 53

IV-5 Components of Test Mode1, Single Element Configuration . . 5.6

I

IV-7 Supported by Perforated P1ate . . . . . . . . 58

IV-8 Unsuppurted ............................ 58

IV-9 Pleated screen . . . . . . . . . . . . 58

IV-10 Internal Ribs ...................... 59

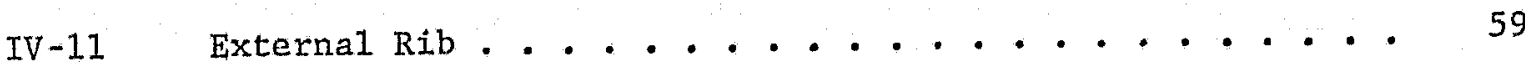

IV-12 Specimens 1,2 and 3 (from Left to Right) . . . . . 59

IV-13 Model Mounted on Shaker ................... 61

IV-14 Close Up View of Mode1 . . . . . . . . . 62

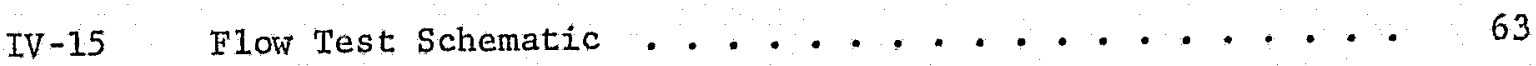

$\mathrm{V}-1 \quad$ Pressure Waveforms ....................... 73

V-2 Variation of Differential Pressure with Frequency . . . 75

V-3 Variation of Pressure with Position in Liquid . . . . 77

V $-4 \quad$ Screen Response to Sinusoidal Vibration . . . . . 78

V $-5 \quad$ Effect of Liquid Height on Screer Response . . . . . 82 
V-6 Random Vibration spectrum .............. 90

V-7 Influence of Screen Support Method on Response to

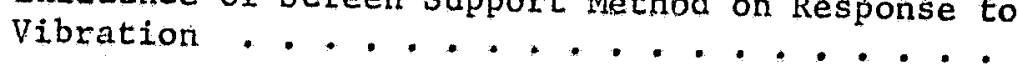

V-8 Saturation Curves for Freon 11 and Freon 113 ..... 102

V-9 Random Vibration Spectra ............ 107

V-10 Influence of Random Vibration Spectrum . . . . . . . 109

V-11 Influence of Random Vibration Based on Spectral Density . 110

V-12 Correlation with Hydrostatic Mode1 . . . . . . . 112

V-13 Test Results, Specimens 1 and $2 \ldots \ldots$........... 119

V-14 Amplification Parameter, Specimens 1 and 2....... 121

A-1 Simplified Screen Pore ............. 126

A-2 Variation of Capillary Pressıre with Bubble Volume . . . 129

A-3 Unstable Response to Sinusoidal Pressure Variation . . . . 135

A-4 Effective Pressure for Sinusoidal Pressure Variation . . 136 
IIST OF TABLES

Page

I-1 Prior Studies . . . . . . . . . . . . . . . . . . 2

II-1 Configuration and Operational Environment . . . . . . . $\quad 7$

IV-1 Properties of Test Liquids at $20^{\circ} \mathrm{C}\left(58^{\circ} \mathrm{F}\right) . . . . . .47$

IV-2 Screen Mesh . . . . . . . . . . . . . . . . 48

IV-3 Screen Specimens . . . . . . . . . . . . . . . . 66

IV -4 Test Matrix . . . . . . . . . . . . . . . . 67

V-1 Predicted Screen Stiffness . . . . . . . . . . . . . 86

V-2 Effect of Flow on Screen Response . . . . . . . . . . . 99

V-3 Summary of Test Results, Specimen $1 . \bullet^{-} \cdot \bullet^{-} \cdot \bullet^{-} \cdot \bullet^{-} 115$

V-4 Summary of Test Results, Specimen 2 . . . . . . . . . 117

V-5 Test Results, External Rib Configurations . . . - • • $\quad$ - 122

A-1 Screen Parameters . . . . . . . . . . . . . . 128

A-2 Coefficients for Flow Loss . . . . . . . . . . . $\quad \cdot \quad \cdot 132$

A-3 Bubble Detachment for Liquid Oxygen . . . . . . . . 139 
An analytical and experimental investigation of the effect os vibration on the retention characteristics of screen acquisition systems was performed. The functioning of surface tension devices using fine-mesh screens requires that the pressure differential acting on the screen be less than its pressure retention capability. When exceeded, screen breakdown will occur and gas-free expulsion of propellant will no longer be possible. Vibration, inherent in any spacecraft operational environment, is a means by which that pressure differential is increased.

In order to establish the range of the vik, a survey was conducted. This survey considered present and future applications of surface tension devices and the vibration environments that they would experience.

An analytical approach to predicting the effect of vibration was developed. This approach considers the transmission of the vibration to the screens of the device and the coupling of the liquid and the screen in establishing the screen response. A method of evaluating the transient response of the gas/ liquid interface within the screen was also developed. Also considered was a hydrostatic mode1, developed under previous studies.

A test program that would verify the analytical models and evaluate the effects of vibration was performed. A total of 551 vibration tests were performed, considering the many variables that effect the screen response. The pressure differential due to the vibration ant the acceleration of the screen were measured during the test's.

Through a direct evaluation of the test results, an understanding of many of the factors influencing the vibration response was gained. The pressure differential data allcwed the harmonics, waveforms and amplitudes to be studied. It was found that the screen responds to the positive peak pressure (lowering the liquid pressure with respect to the gas on the opposite side of the screen) due to the vibration. The effects of screen weave orientation, vibration orientation, screen support method, screen mesh, liquid flow, single and dual screen elements, and liquid subcooling were evaluated. The hydrostatic model is capable of predicting the effect of low frequency sine vibration and the effect of random vibration by using empirical coefficients for specific screen support methods and vibration spectra. Limited verification of the structural dynamics model was achieved.

Continued investigation of the effects of vibration, considering both empirical and theoretical based approaches, is recommended. 
The application of surface tension systems to propellant acquisition and control has increased significantly in recent years. These applications include both high- and low-g environments, and boost anl ozbital mission phases. Most of these recent applications have employed tine-mesh screen systems, as opposed to sheet-netal vane devices, due to the high adverse acceierations encountered during the missions, Proper design of these fine-mesh screen devices requires a delicate balance beiween the bubble point of the screen and the pressure losses in the system. To preclude gas ingestion into the controlled liquid region, i.e., screen breakdown, and assure delivery of single-phase liquid to the propulsion system, the bubble point of the screen must exceed the pressure differential imposed on the device during all phases of the mission.

The pressure differential is composed of many contributions. Gravity forces produce hydrostatic pressures. Propellant flow produces viscous losses and changes in the velocity head. Vibration is another means by which the pressure differential can be increased.

A surface tension devic will be subjected to some form of vibration. It could be from a booster or from the main engines and attitude control engines of a space vehicle, even the movement of a crew can produce vibration. Vibration accelerates the liquid mass within a surface tension device in much the same way as a steady acceleration. However, due to the periodic nature of the vibration, interaction between the liquid, screen and surface tension device structure influences tive pressure differential produced.

Previous investigations have shown that vibration can contribute significantly to the pressure differential acting on a surface tension device and have attempted to characterize the effect. Table I-1 summarizes the important prior studies. A large part of this work (Ref. I 1, I-3 and I-4) has been performed on a screen acquisition/expulsion device (tank plus screen system) to determine the impact of sine and random vibrations on expulsion capability. Initial tests performed by orton were run with a spherical liner made of pleated screen and encased in an outer shell of plexiglass (Ref. I-1). These tests were conducted with both sine and random vibrations in the horizontal and vertical axes. Results showed good agreement with a hydrostatic model for vibration (see Chapter III for a discussion of this modeling technique) when applied to random and low frequency sine tests. Failure to correlate at higher sinusoidal frequencies was attributed to resonant conditions, i.e., attenuation and amplification of input. However, instrumentation was not placed on the device and a quantitative evaluation was not obtained.

Similar tests were run by Martin Marietta using a cylindrical dual-screenliner system (Ref. I-3). Accelerometers were located on the plexiglass tank at various positions. Again, good correlation was obtained during 
Table I-1. Prior Studies

\begin{tabular}{|c|c|c|c|c|c|c|c|}
\hline 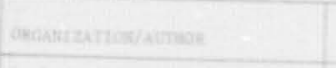 & 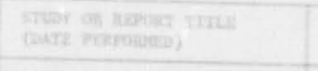 & Tor suricas & 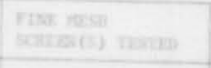 & Inser melus & vesume & wastiless abe comcanstows & consenss \\
\hline a. he prean & 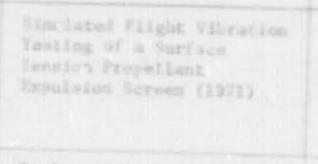 & 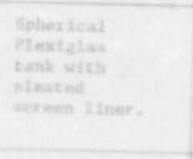 & $257 \times 13208.25$ & 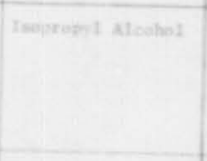 & 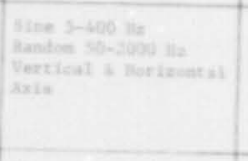 & 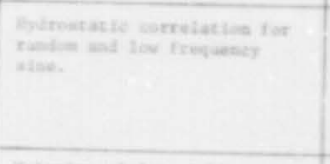 & 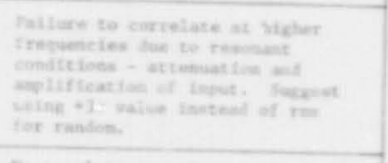 \\
\hline 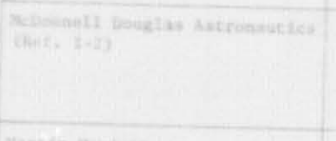 & 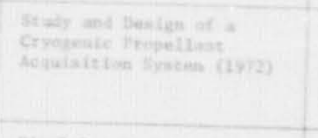 & 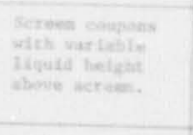 & 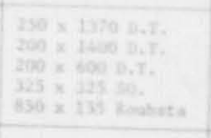 & Inofropyl xa wobet & 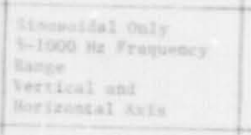 & 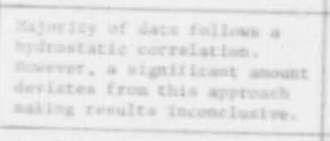 & 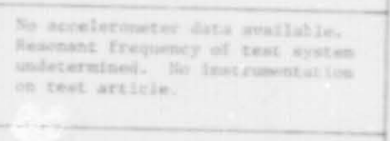 \\
\hline Wartin Maxistes & 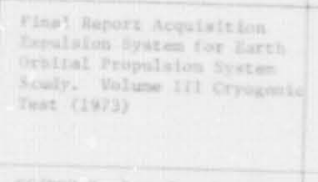 & 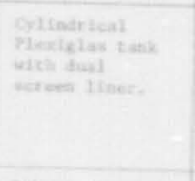 & 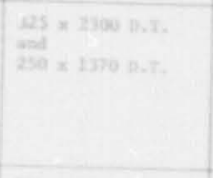 & Kecthanas & 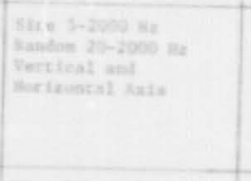 & 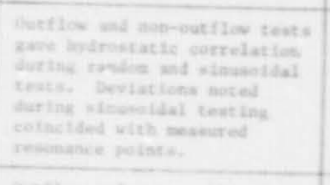 & 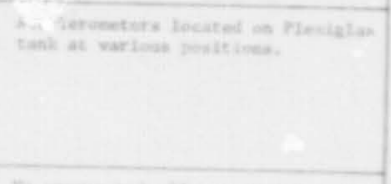 \\
\hline 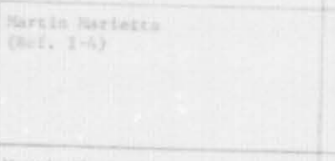 & 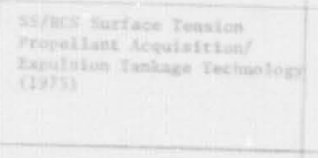 & 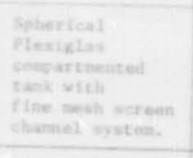 & $324=2306$ b.5. & Preme in & 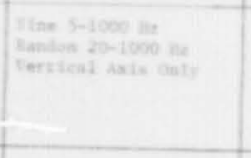 & 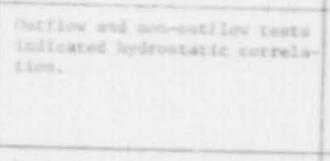 & 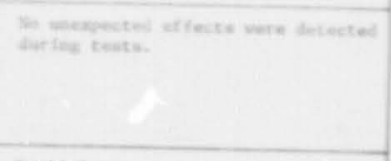 \\
\hline 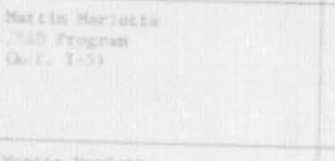 & 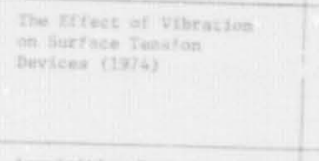 & 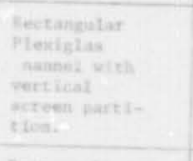 & $123 \times 2300$ p. 1. & |werthenel & 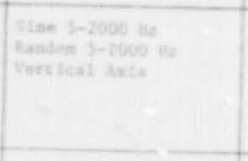 & 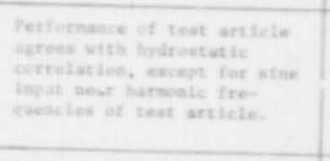 & 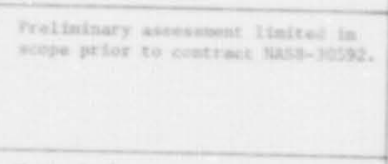 \\
\hline Verring Martats & 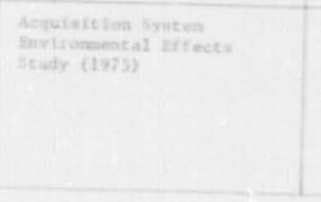 & 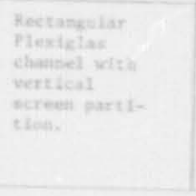 & 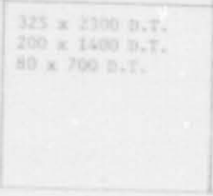 & Inothengl Aleako: & 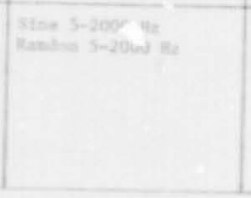 & 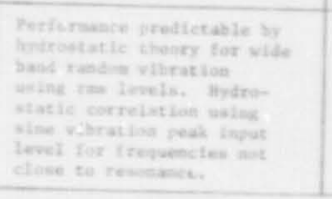 & 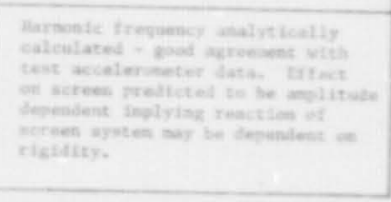 \\
\hline
\end{tabular}

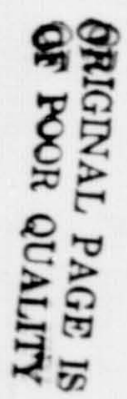


random and sine tests based on kydrostatic theory except at certain discrete frequencies during sinusoidal inputs. However, these deviations coincided with resonance points indicatsd by accelerometer readouts where the amplified g-level was high enough to produce screen instability based on hydrostatic theory. In contrast, some periods of resonance were observed at higher frequencies when screen instability was not observed, indicating a time or amplitude dependency. A spherical compartmented tank with a fine-mesh screen channel system was also tested by Martin Marietta during a subscale verification test program (Ref. I-4). Results showed no unexpected vibration effects on the system during a series of outflow and non-outflow tests.

In contrast, some tests have been performed on discrete screen elements. McDonne11 Douglas (Ref. I-2) subjected individual screen coupons with variable liquid column heights to sine vibration. A total of five different screens were tested, Although a large part of the data was correlated by hydrostatic analysis, a significant amount deviated from this approach. These deviations were attributed to resonance conditions of the system. However, since accelerometers were not located on the test article, evaluation of screen dynamics was not possible and results were inconclusive.

The most significant prior study was performed by Martin Marietta (Ref. I-6). The effect of vibration on the capillary stability of a screen and the resultant hydrostatic pressure head due both to the rigid-body motion and screen dynanics were investigated during this work. Extensive vibration testing of a vertical, transparent channel was conducted for both random and sinusoidal vibration environments. Accelerometers were located on the channel and screen to allow a quantitative evaluation of test results. With the exception of the sinusoidal vibration at frequencies near the screen resonance, gas ingestion across the screen was found to occur when the tota? the static $:$ drth gravity was approximately equal to the screen bubble tevint.

The effective level for sine vibration was the peak value while that for random vibration was the rms value. For sine vibrations near the natural frequency of the systems, a departure from the hydrostatic effect due to the large accelerations and amplitudes was noted. A comparison of calculated and experimental data for the natural frequency of the system showed good agreement. The analysis considered screen, perforated plate, liquid, and accelerometer masses.

This program continued the investigation of the effects of vibration on the retention capability of fine-mesh screens. Using what has been learned from the previous studies, this program made an in-depth study of the many factors that can influence the response of the screen to vibration.

First, a survey was performed to establish the range of the vibration environment to be expected for typical surface tension device applications. This survey is presented in Chapter II. Then an analytical method was 
deviloped that considers in detail the response of the screen of a surface tension device to vibration. The previously successful hydrostatic model was also considered as discussed in Chapter III. An experimental program that consilered the many factors that effect the vesponse of a screen device to vibration, such as screen mesh, screen support method, screen orientation and liquid flow, was devised. A test model with differential pressure and acceleration instrumentation was built and tested (Chapter IV).

The results of the testing, and the data analysis and correlation are presented in Chapter $V$. The conclusions and recommendations can be found in Chapter VI. 
A survey was performed to establish the range of the vibration environtient to be expected for present and future applications, within the U.S. space program, of liquid acquisition systems using fine-mesh woven screens. For each application the available information on the configuration, operational environment and other pertinent parameters were documented. Groups of systems with similar requirements were established and the range of vibrational effects to be expected for each group was determined. This information was used to define the regimes of intertst for the analytical and experimental efforts that followed.

This information is presented in three parts. First, the present and future applications of surface tension devices are presented along with available descriptions and mission requirements. Next the data collected on the vibrational environments of space vehicles and spacecraft is presented. Finally, the data is compiled and grouped to define the regimes of interest.

\section{A. Present and Future Applications of Surface Tension Devices}

Surface tension devices have "come of age" and are now flight operational and being considered for numerous near-future applications. It can be presumed that surface tension devices will be strong contenders for the acquisition system of any future liquid propulsion system.

The most prominent of the current applications'for surface tension devices is the Space Shuttle Orbiter. A surface tension device is used to supply propellant during the start of the Orbital Maneuvering system (OMS) engines (Figure II-1). The device must also be capable of supplying the thrusters of the Reaction Control System (RCS). The OMS performs the large $\Delta V$ translational maneuvers of the Space Shuttle Orbiter. The configuration and the operational environment for the OMS acquisition system is presented in Table II-1, as is the data for all the applications presented in this section.

Surface tension devices are also used in the tanks of the Space Shuttle RCS (Figures II-2 and II-3). This system controls the orbiter attitude and accomplishes small $\Delta V$ translational maneuvers. The system must function during a boost abort, on-orbit and during the initial phases of atmospheric entry.

A surface tension device was used in the tanks of the Viking orbiter main propulsion system (Figure II-4). This propulsion system performed the midcourse corrections, Mars orbit insertion and the orbital trims. The surface tension device was comprised of sheet metal vanes that took advantage of the liquid surface tension in positioning the propellant over the tank outlet. This program was only concerned with surface tension devices using fine-inesh screen, but the Viking system was of interest because it is representative of the environment for similar future spacecraft. 


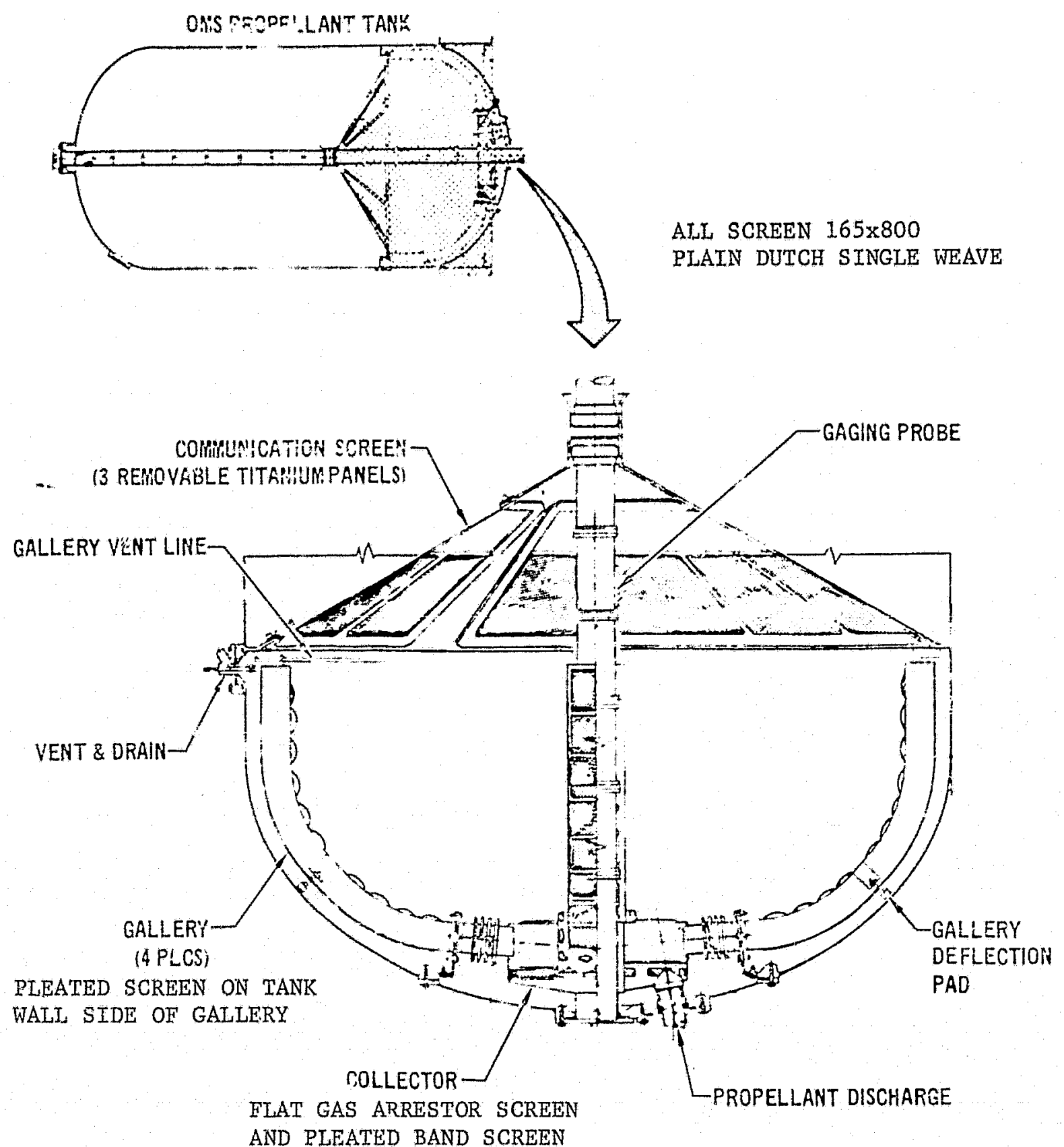

AND PLEATED BAND SCREEN

Figure II-1. Space Shuttle Orbital Maneuvering System Acquisition Device (from Ref. II-1) 
Table II-1. Configuration and Operational Environment

\begin{tabular}{|c|c|c|c|c|c|c|c|c|}
\hline \multirow[b]{2}{*}{$\begin{array}{l}\text { Spaceiraty/ } \\
\text { Whicle }\end{array}$} & \multirow[b]{2}{*}{ syate: } & \multirow[b]{2}{*}{ Ancelerasinas, if } & \multicolumn{4}{|c|}{ Mutits } & \multicolumn{2}{|c|}{ Cuet Iguratian } \\
\hline & & & sype & Mets & Pouncting, & 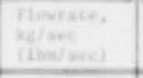 & fank, ois (fin.) & Acsuleittion Device \\
\hline \multirow[t]{4}{*}{ Spane slourtes } & \multirow[t]{2}{*}{ 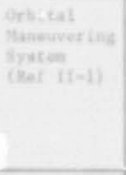 } & \multirow{2}{*}{ 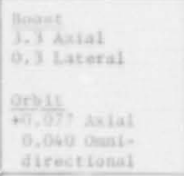 } & now & 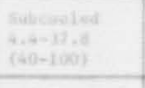 & $(2221)$ & $\begin{array}{l}6.36 \\
14+66) \\
\text { Masinum }\end{array}$ & \multirow{2}{*}{ 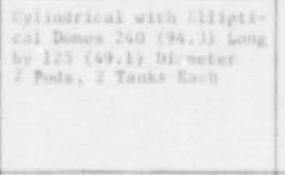 } & \multirow{2}{*}{ 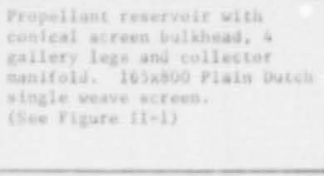 } \\
\hline & & & 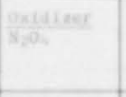 & 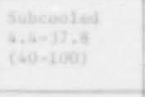 & $\left(\begin{array}{ll}2635 \\
(i n)\end{array}\right.$ & $\begin{array}{l}10,40 \\
(23,16) \\
\text { Masionse }\end{array}$ & & \\
\hline & \multirow[t]{2}{*}{ 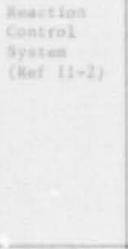 } & \multirow{2}{*}{ 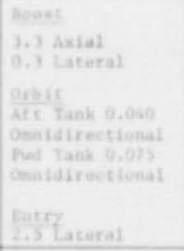 } & bail & 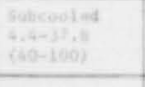 & $(922)$ & $\begin{array}{l}\text { 1.63 } \\
(8.127 \\
\text { Maximue }\end{array}$ & \multirow[t]{2}{*}{ 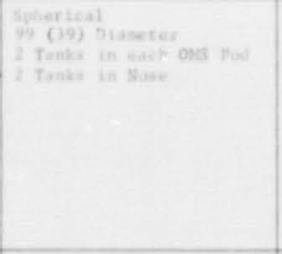 } & \multirow{2}{*}{ 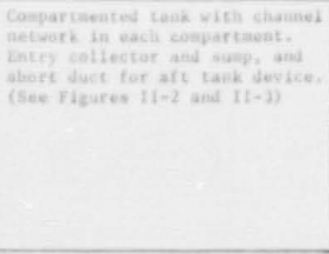 } \\
\hline & & & $\begin{array}{l}\text { Oondiver } \\
\text { wpos }\end{array}$ & 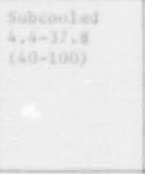 & (17) & $\begin{array}{l}3,8 y \\
(12,+5) \\
\text { Masiount }\end{array}$ & & \\
\hline \multirow[t]{2}{*}{ vikine } & \multirow{2}{*}{ 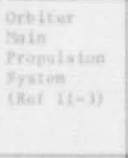 } & \multirow[t]{2}{*}{ 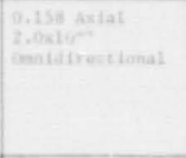 } & Dear & 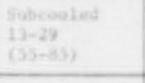 & $\begin{array}{l}961.6 \\
(1220)\end{array}$ & $\begin{array}{l}0.209 \\
(0,360) \\
\text { Masiene } \\
\end{array}$ & \multirow[t]{2}{*}{ 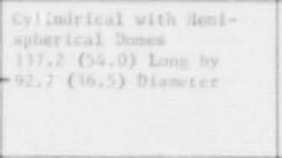 } & \multirow[t]{2}{*}{ 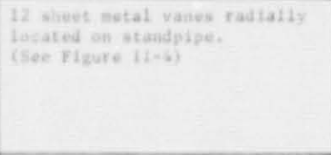 } \\
\hline & & & Whatiles & 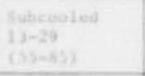 & $(1762)$ & $\begin{array}{l}9.297) \\
(0,65) \\
\text { Maxinum }\end{array}$ & & \\
\hline \multirow[t]{2}{*}{$\begin{array}{l}\text { Agena } \\
\text { (Wof } 11-6 \text { ) }\end{array}$} & \multirow{2}{*}{ 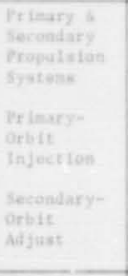 } & \multirow{2}{*}{ 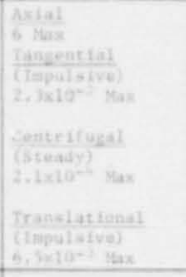 } & 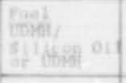 & 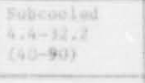 & $\begin{array}{l}7800 \\
(4+000)\end{array}$ & 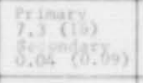 & 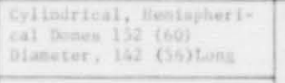 & \multirow{2}{*}{ 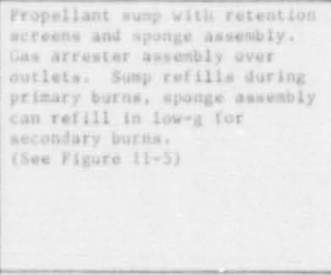 } \\
\hline & & & 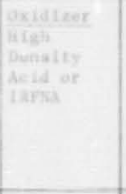 & $\begin{array}{l}\text { Sulcosolind } \\
4,2-12.2 \\
(40+90)\end{array}$ & $\begin{array}{l}4500 \\
(10,000)\end{array}$ & $\begin{array}{l}\text { grimary } \\
19(42) \\
\text { gienondary } \\
0.11(0.24)\end{array}$ & 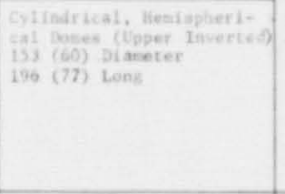 & \\
\hline \multirow[t]{3}{*}{$\begin{array}{l}\text { Transtage } \\
\text { (Ref If-5) }\end{array}$} & \multirow[t]{2}{*}{$\begin{array}{l}\text { Main } \\
\text { Engtaes (2) }\end{array}$} & \multirow[t]{2}{*}{ 3.9. Zlax dxial } & $\begin{array}{l}\text { Yusel } \\
\text { inoul }\end{array}$ & $\begin{array}{l}7.2-26 \cdot 7 \\
(45-80)\end{array}$ & $\begin{array}{l}3550 \\
(77820)\end{array}$ & $\begin{array}{l}4.01 \\
(8+43)\end{array}$ & 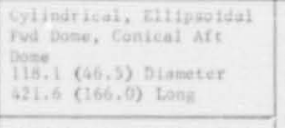 & \multirow{2}{*}{ 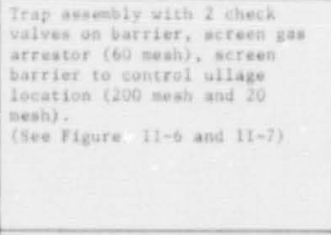 } \\
\hline & & & ostalizer & $\begin{array}{l}7,2-26,7 \\
(4)-80)\end{array}$ & $\begin{array}{l}7100 \\
(15,650)\end{array}$ & 8.01 & 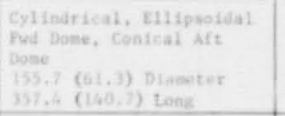 & \\
\hline & $\begin{array}{l}\text { Aecitude } \\
\text { Control } \\
\text { (12 } \\
\text { Ditruaterns) }\end{array}$ & $\begin{array}{l}\text { 0.03 Mas } \\
\text { Oimidirectional }\end{array}$ & $\begin{array}{l}\text { Mono- } \\
\text { Peopeltane } \\
\text { Hydrazsine }\end{array}$ & $\begin{array}{l}7,2-26.7 \\
(45-80)\end{array}$ & $\begin{array}{l}121 \\
(262)\end{array}$ & $\begin{array}{l}0.34 \\
\text { (1.23) } \\
\text { Maxisum }\end{array}$ & 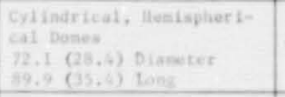 & $\begin{array}{l}\text { Ethylene Propylene Rubber } \\
\text { Diaphitago }\end{array}$ \\
\hline Viking & $\begin{array}{l}\text { lander } \\
\text { ics/Deorbit } \\
\text { (12 } \\
\text { Thnusters) }\end{array}$ & 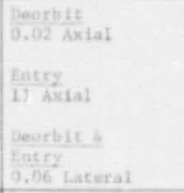 & 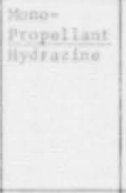 & $\begin{array}{l}\text { Siabreooled } \\
7.2-12.2 \\
(45-90)\end{array}$ & $\begin{array}{l}85.3 \\
(188)\end{array}$ & $\begin{array}{l}0.15 \\
(0.32) \\
\text { Maxineute }\end{array}$ & $\begin{array}{l}\text { Two Spherticat } \\
36.1(22,1) \text { paraseter }\end{array}$ & $\begin{array}{l}\text { Elastomer ic Diaphiragn } \\
\text { (ErT-10) }\end{array}$ \\
\hline $\begin{array}{l}\text { Interin } \\
\text { Upper } \\
\text { Stige }\end{array}$ & $\begin{array}{l}\text { Peection } \\
\text { Contral } \\
\text { Syices } \\
\text { (12 } \\
\text { Thirusters) }\end{array}$ & 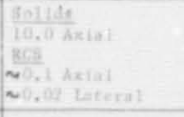 & $\begin{array}{l}\text { Nono- } \\
\text { Yrapelime } \\
\text { Hydraztine }\end{array}$ & $\begin{array}{l}\text { fiubcasied } \\
7,2-37.8 \\
(4,-106)\end{array}$ & $\begin{array}{l}120 \\
(26) 3]\end{array}$ & $\begin{array}{l}0.20 \\
(0.46) \\
\text { Maxinum }\end{array}$ & $\begin{array}{l}\text { Tyo } 5 \text { pherical } \\
36.1 \\
(22.1) \text { biasoter }\end{array}$ & Elastomeric Dfaphragin \\
\hline \multirow[t]{2}{*}{$\begin{array}{l}\text { Centaur } \\
\text { D-15 } \\
(\text { Ref } 11-6)\end{array}$} & \multirow[t]{2}{*}{$\begin{array}{l}\text { Mats } \\
\text { Eneine }\end{array}$} & \multirow{2}{*}{$\begin{array}{l}\frac{\text { Axial }}{2.51} \operatorname{Max} \\
\text { sctitude } \\
\frac{\text { Control }}{1.9 \times 10^{-7}} \operatorname{lax}\end{array}$} & $\begin{array}{l}\text { Fued } \\
\text { Linguld } \\
\text { ilydregen }\end{array}$ & $\begin{array}{l}\text { Saturated } \\
-251 \\
(-620)\end{array}$ & $\left(\begin{array}{cc}35 \\
(5229)\end{array}\right.$ & $\begin{array}{l}4.89 \\
(10.8)\end{array}$ & 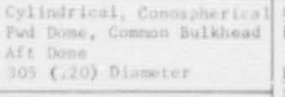 & \multirow{2}{*}{ 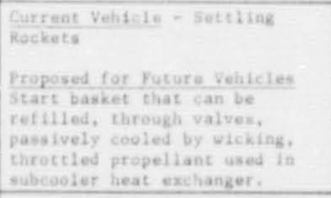 } \\
\hline & & & $\begin{array}{l}\text { oxidizer } \\
\text { itingis } \\
\text { onygen }\end{array}$ & $\begin{array}{l}\text { Saturated } \\
-187 \\
(-297)\end{array}$ & $\begin{array}{l}11,354 \\
(25,450)\end{array}$ & $\begin{array}{l}25.9 \\
(57.1)\end{array}$ & 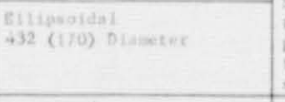 & \\
\hline \multirow[t]{2}{*}{$\begin{array}{l}\text { Space } \\
\text { Storable } \\
\text { Propulation } \\
\text { Module } \\
\text { (Ref } 11-7 \text { \& } \\
11-3)\end{array}$} & \multirow[t]{2}{*}{$\begin{array}{l}\text { Jain } \\
\text { Engina s } \\
\text { Atcilsude } \\
\text { Control }\end{array}$} & \multirow[t]{2}{*}{$\begin{array}{l}\text { Mein fingting } \\
0.068-0.19 \\
\text { Actutude } \\
\text { Control } \\
7 \times 10^{-1} \operatorname{Max}\end{array}$} & 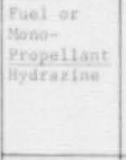 & $\begin{array}{l}\text { Fibcooled } \\
4.4=37, \text { h } \\
(40-1000)\end{array}$ & $\begin{array}{l}283 \\
(6264)\end{array}$ & $\begin{array}{l}\text { Yong-Yodt } \\
0.29 \\
(0.64) \\
\text { Biprop-8ode } \\
0.24 \\
(0.52) \\
\end{array}$ & \multirow[t]{2}{*}{ 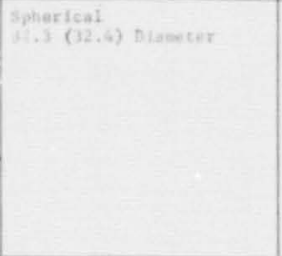 } & $\begin{array}{l}\text { Sheet metal vane type wurface } \\
\text { tension device (sialiar to } \\
\text { device in Yiking orbitar). }\end{array}$ \\
\hline & & & $\begin{array}{l}\text { Oxidizer } \\
\text { Yluorime }\end{array}$ & $\begin{array}{l}\text { Saturated } \\
-218 \text { to }-173 \\
(-360 \text { to } \\
-260)\end{array}$ & $\begin{array}{l}353 \\
(778)\end{array}$ & $\begin{array}{l}0.47 \\
(1.06)\end{array}$ & & \\
\hline
\end{tabular}


Table II-1. Configuration and Operational Environment (conc1)

\begin{tabular}{|c|c|c|c|c|c|c|c|c|}
\hline \multirow[b]{2}{*}{$\begin{array}{l}\text { Spacescraft/ } \\
\text { Vehicle }\end{array}$} & \multirow[b]{2}{*}{$5 y=t=$} & \multirow[b]{2}{*}{ Accelerat tone, is } & \multicolumn{4}{|c|}{ Fuids } & \multicolumn{2}{|c|}{ Conf Liveratien } \\
\hline & & & Fype: & 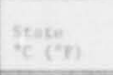 & $\begin{array}{l}\text { Vuanciky, } \\
\text { ke (Hin) }\end{array}$ & $\begin{array}{l}\text { Flowrate, } \\
\text { kelseed } \\
\text { (1berinec) }\end{array}$ & Zank, en (is.) & Aspuisition Derice \\
\hline \multirow{2}{*}{$\begin{array}{l}\text { Cryogende } \\
\text { Spare } \\
\text { shuttie } \\
\text { Orbiter } \\
\text { (Nef it-9) }\end{array}$} & \multirow{2}{*}{ 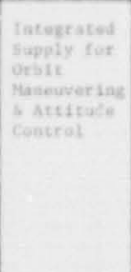 } & \multirow{2}{*}{ 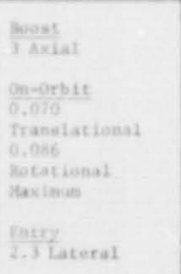 } & $\begin{array}{l}\text { heel } \\
\text { Liguid } \\
\text { indrogen }\end{array}$ & $\begin{array}{l}\text { Saturated } \\
-254 \\
(-420)\end{array}$ & $\begin{array}{l}3900 \\
(8600)\end{array}$ & $\begin{array}{l}2.7(6) \\
\text { zaximue }\end{array}$ & 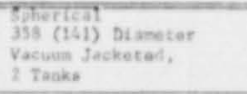 & \multirow{2}{*}{ 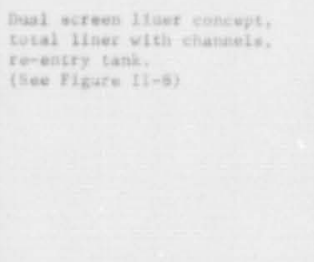 } \\
\hline & & & $\begin{array}{l}\text { Oxidizer } \\
\text { Liquili } \\
\text { Oxyigen }\end{array}$ & $\begin{array}{l}\text { saturated } \\
\left(\begin{array}{l}\text { sa } \\
(-79)\end{array}\right.\end{array}$ & $\begin{array}{l}18,000 \\
(40,000)\end{array}$ & $\begin{array}{l}\text { 13. (29) } \\
\text { Maximum }\end{array}$ & $\begin{array}{l}\text { Sphertial } \\
242(95,3) \text { Dimstar } \\
\text { Yaeuum Jacketed, } \\
2 \text { Tarks }\end{array}$ & \\
\hline \multirow{2}{*}{ 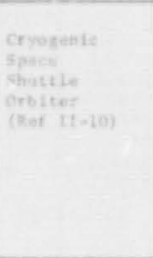 } & \multirow{2}{*}{ 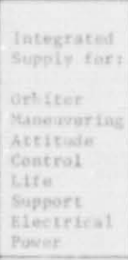 } & \multirow{2}{*}{ 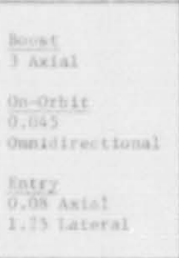 } & $\begin{array}{l}\text { Puet } \\
\text { Lifquid } \\
\text { itrdrogen }\end{array}$ & $\begin{array}{l}\text { Salurated } \\
-254 \\
(-420)\end{array}$ & $4720.600)$ & $\begin{array}{l}\text { W.S (10) } \\
\text { Maximing }\end{array}$ & $\begin{array}{l}\text { Cylindrical } \\
\text { Hemispherieal Dames } \\
366 \text { (154) Diamerer } \\
732 \text { (308) Long }\end{array}$ & \multirow{2}{*}{ 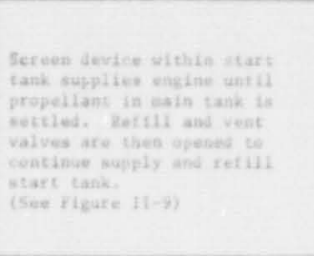 } \\
\hline & & & 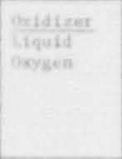 & $\begin{array}{l}\text { Sacuratud } \\
-131 \\
(-292)\end{array}$ & $17,0000)$ & $\begin{array}{l}23(50) \\
\text { Maxinus }\end{array}$ & 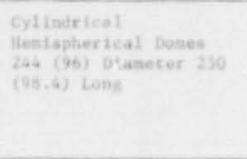 & \\
\hline $\begin{array}{l}\text { Communirationa } \\
\text { Satullite }\end{array}$ & $\begin{array}{l}\text { Ateitude } \\
\text { Controt }\end{array}$ & 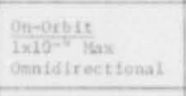 & $\begin{array}{l}\text { Mono- } \\
\text { Prapullant } \\
\text { Hydewatine }\end{array}$ & $\begin{array}{l}46-600 \\
(60-160)\end{array}$ & $\begin{array}{l}59 \\
(5130) \\
\text { Per Tank }\end{array}$ & $\begin{array}{l}0.016 \\
\text { (0.01) } \\
\text { Moximu= }\end{array}$ & $\begin{array}{l}\text { Cylinifical } \\
\text { Healipherical Dones } \\
244(96) \text { Diametex } \\
250(98.4) \text { Long }\end{array}$ & $\begin{array}{l}\text { Total Combunicatios Serface } \\
\text { Tension Device }\end{array}$ \\
\hline \multirow[t]{5}{*}{ 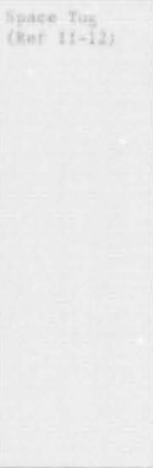 } & \multirow[t]{2}{*}{ 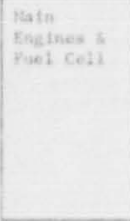 } & \multirow{5}{*}{ 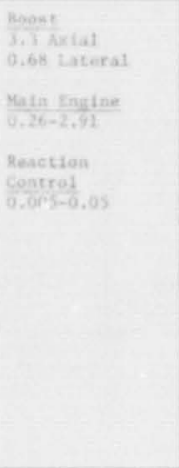 } & $\begin{array}{l}\text { Puel } \\
\text { Fintrogen }\end{array}$ & $\begin{array}{l}\text { Sacurated } \\
-253 \\
(-629)\end{array}$ & $\begin{array}{l}3230 \\
(7130)\end{array}$ & $\begin{array}{l}2.1+2 / 2 \\
\text { Maximing }\end{array}$ & $\begin{array}{l}\text { Spherleal } \\
57,2(22,5) \text { Diameter }\end{array}$ & \multirow[t]{2}{*}{ 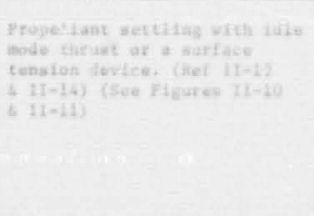 } \\
\hline & & & Oxdidizer & $\begin{array}{l}\text { Saturated } \\
-183 \\
(-297)\end{array}$ & $\begin{array}{l}19,600 \\
(42,800)\end{array}$ & $\begin{array}{l}12,8 \\
(28,2) \\
\text { Kaxinue }\end{array}$ & $\begin{array}{l}\text { E11ipsoidal } \\
363.3(14 ., 09 \text { Dimeter } \\
258.6(102.8) \text { Long }\end{array}$ & \\
\hline & $\begin{array}{l}\text { Ausiliary } \\
\text { Proputision } \\
\text { systes }\end{array}$ & & $\begin{array}{l}\text { Mose- } \\
\text { Prupellans } \\
\text { bydratine }\end{array}$ & $\begin{array}{l}\text { Subcooled } \\
4.5-79 \\
(40-175)\end{array}$ & $\begin{array}{l}92.5 \\
\text { (206) } \\
\text { Per Taik }\end{array}$ & $\begin{array}{l}0,05-0,5 \\
(0,1-1,2)\end{array}$ & $\begin{array}{l}\text { Spherisal } \\
56.9(22,4) \text { Di aneter } \\
3 \text { Tanils }\end{array}$ & $\begin{array}{l}\text { Total cobounscation suriace } \\
\text { tension devite. }\end{array}$ \\
\hline & \multirow{2}{*}{$\begin{array}{l}\text { Integrated } \\
\text { Auxilfary } \\
\text { Propilision } \\
\text { Syntom } \\
\text { (Ret } 11-15 \text { ) }\end{array}$} & & $\frac{\text { thet }}{\text { Hydrogen }}$ & $\begin{array}{l}\text { Saturated } \\
-253 \\
(-423)\end{array}$ & 4.5 & $\begin{array}{l}0.096 \\
(0.21) \\
\text { Maximatim }\end{array}$ & \multirow[t]{2}{*}{$\begin{array}{l}\text { Spherieal } \\
50.8(20.0) \text { pianeter }\end{array}$} & \multirow{2}{*}{ 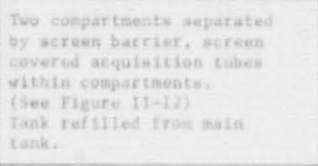 } \\
\hline & & & $\begin{array}{l}\text { Oxidizer } \\
\text { Donyzes }\end{array}$ & $\begin{array}{l}\text { Satwirated } \\
-183 \\
(-297)\end{array}$ & $\frac{9.1}{(20.1)}$ & $\begin{array}{l}\text { 0. } 31 \\
(0.069) \\
\text { Maximum }\end{array}$ & & \\
\hline 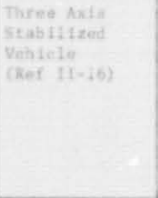 & $\begin{array}{l}\text { Orbit } \\
\text { Adyust } \\
\text { Propulation } \\
\text { Systen is } \\
\text { Retill of } \\
\text { Reacrion } \\
\text { Costzol } \\
\text { Bysten } \\
\text { Talaks }\end{array}$ & 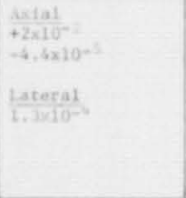 & $\begin{array}{l}\text { Mono- } \\
\text { Propeltans } \\
\text { ilydrazine }\end{array}$ & $\begin{array}{l}\text { Subcooted } \\
4+6-69 \\
(40-120)\end{array}$ & $\begin{array}{l}3059 \\
\text { (6560) } \\
\text { Muxianes }\end{array}$ & 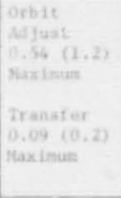 & $\begin{array}{l}\text { 5pherisal } \\
157(62) \text { Diamwier }\end{array}$ & 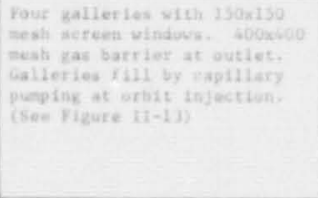 \\
\hline
\end{tabular}




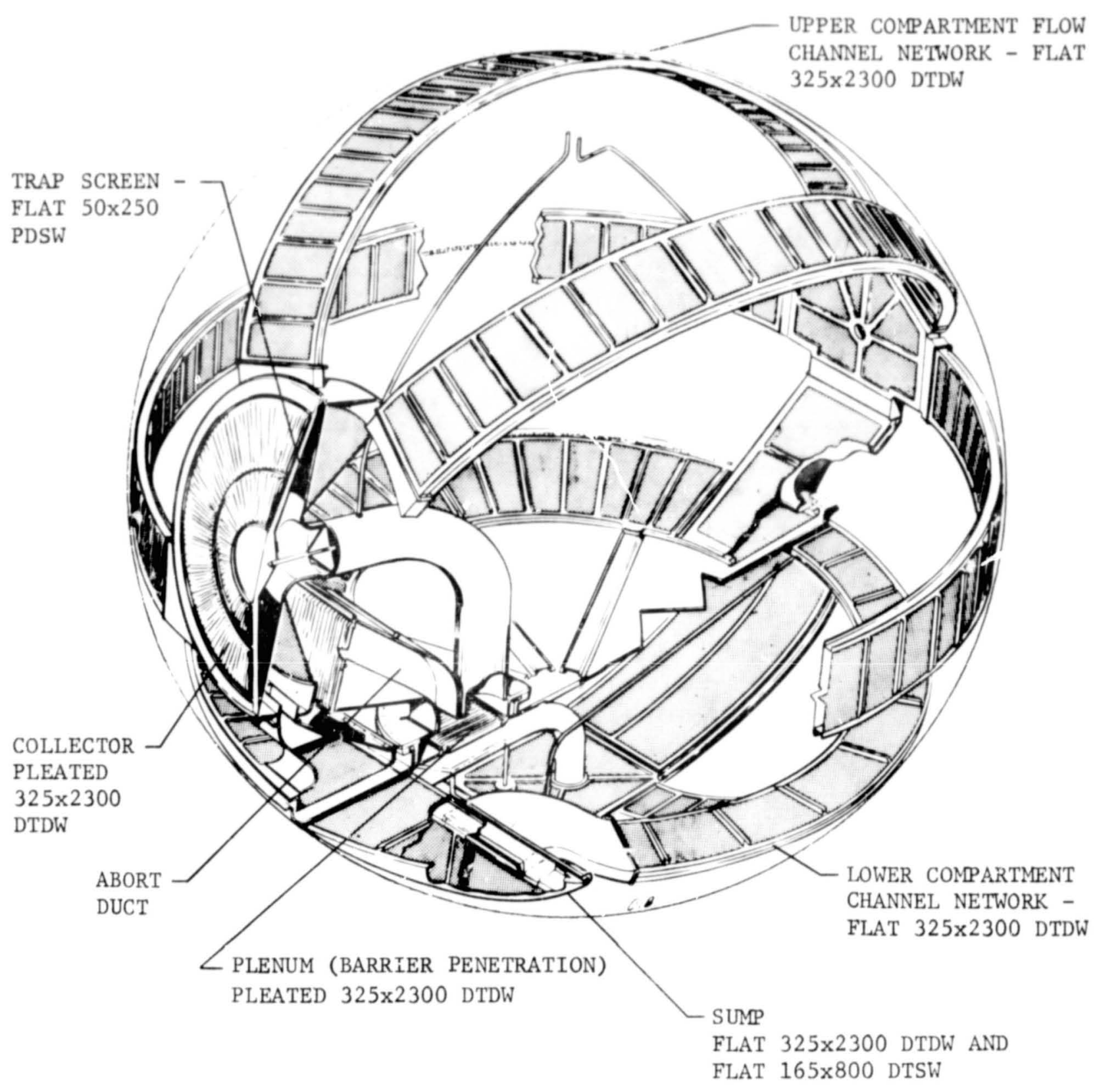

Figure II-2. Space Shuttle Reaction Contro1 System Acquisition Device for Aft Tanks

$$
\text { ORIGINAL PAGE QUALII }
$$




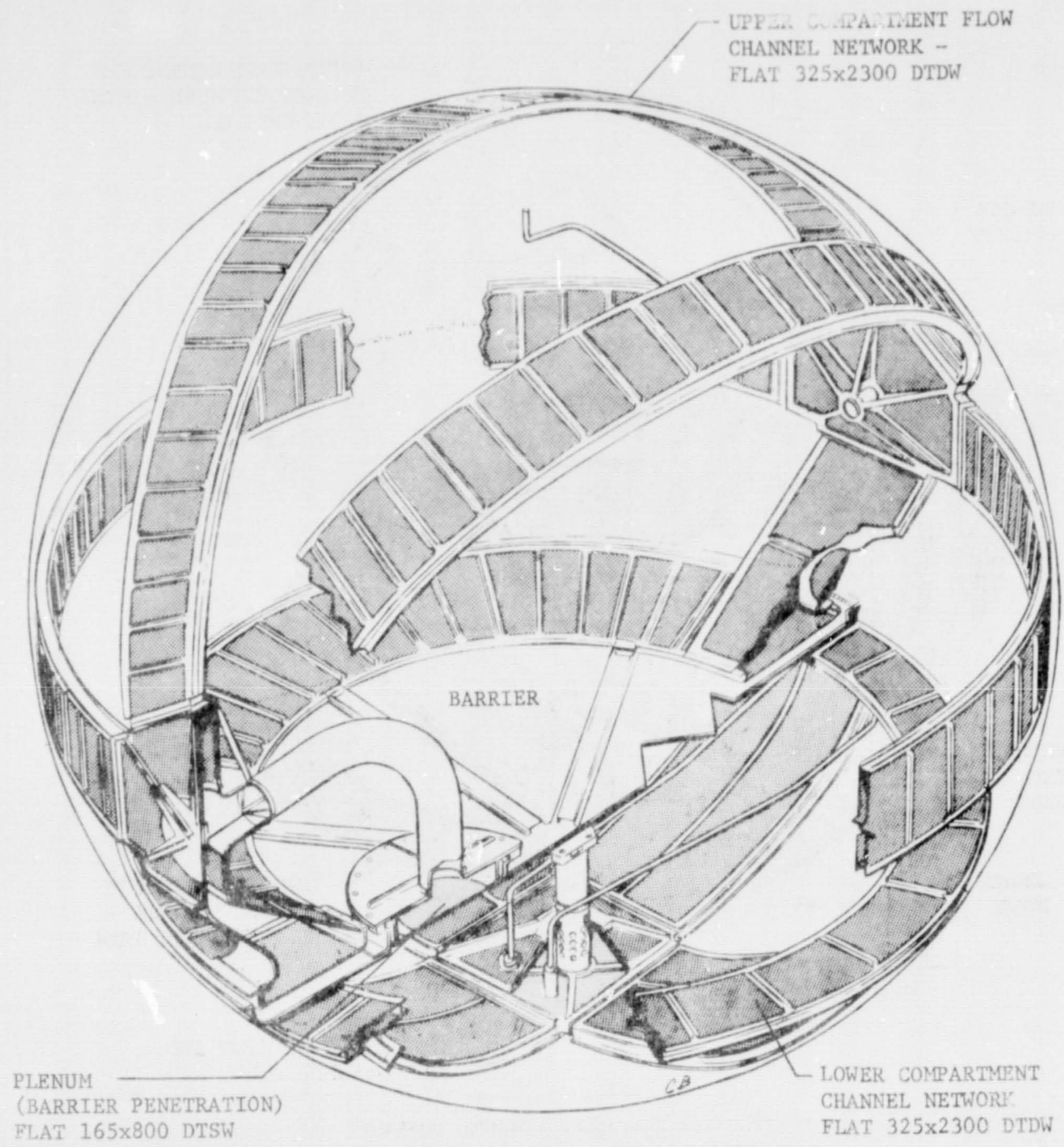

Figure :1-3. Space Shuttle Reaction Control System Acquisition Device for Forward Tanks 


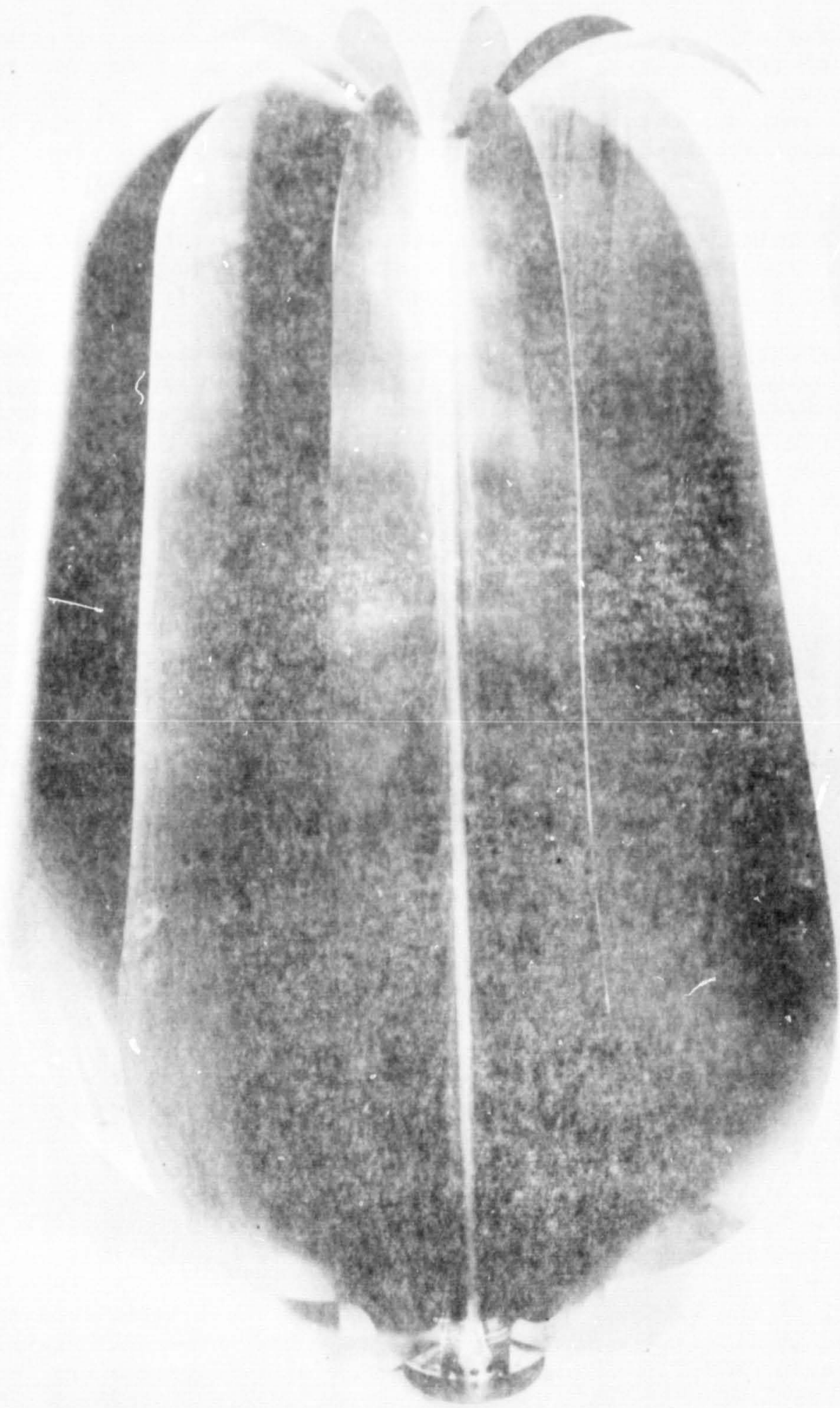

Figure II-4. Viking Orbiter Surface Tension Device 
Tits surface tension device for the Agena main engine has been operational for a number of years, having completed over 250 missions. Recently the device was improved so that it can supply both the primary and secondary propulsion systems and this device has flown six times. The details of this newer device are listed in Table II- 1 and shown in Figure II-5.

The Transtage is another application that has been flight proven, having successfully completed 24 missions. A screen barrier wi.thin a trap prevents bubbles from leaving the tank and another barrier keeps the pressurization diffuser clear of propellant (Figures II-6 and II-7).

Next, some current systems, in which surface tension devices could have been used but were not, are presented. Future systems, having similar missions to these current systems, would also nave similar requirements. The Viking deorbit system was mounted on the aeroshell of the lander. This system took the lander out of Mars oxbit and controlled attitude up until terminal descent began (Table II-1). The aeroshell was jettisoned when the parachute was opened. Propellants were settled while the terminal descent propulsion system (mounted on the lander) operated, so the system did not require propeliant acquisition.

The Interim Upper Stage, as it is presently defined, has solid main motors and a liquid attitude control system. The requirements for the attitude control system are listed in Table II-1.

A surface tension device has been suggested to replace settling rockets for an improved version of the Centaur. Since cryogenic propellants are involved, control of the thermodynamic state of the 1iquid within the surface tension device and the liquid delivered to the engine pumps are important factors (Table II-I).

A future system being developed by the Jet Propulsion Laboratory is a Space Storable Propulsion Module that is being considered as an orbiter of Mercury, Jupiter, Venus and Saturn and for a Mars surface sample return mission. Depending on the $\Delta V$ required, the engine can operate either in the monopropellant or bipropellant mode. A sheet metal vane device (similar to the Viking orbiter device) is currently baselined for this application. The long term compatibility of screen material with fluorine is a concern (Table IJ.-1).

The application of surface tension devices to a future cryogenic space Shuttle Orbiter has been evaluated. The criteria and the concepts from two such studies are Iisted in Table II-1 (Figures II-8 and II-9).

The capability of the propulsion systems of earth orbital satelittes continues to grow (Ref. II-I1). Many satelitites are now three-axis stabilized (rather than spin stabilized) so propellant acquisition systems are required. The requirements 1 isted in Table II-1 are for an Intelsat V communications satellite, now being developed. 

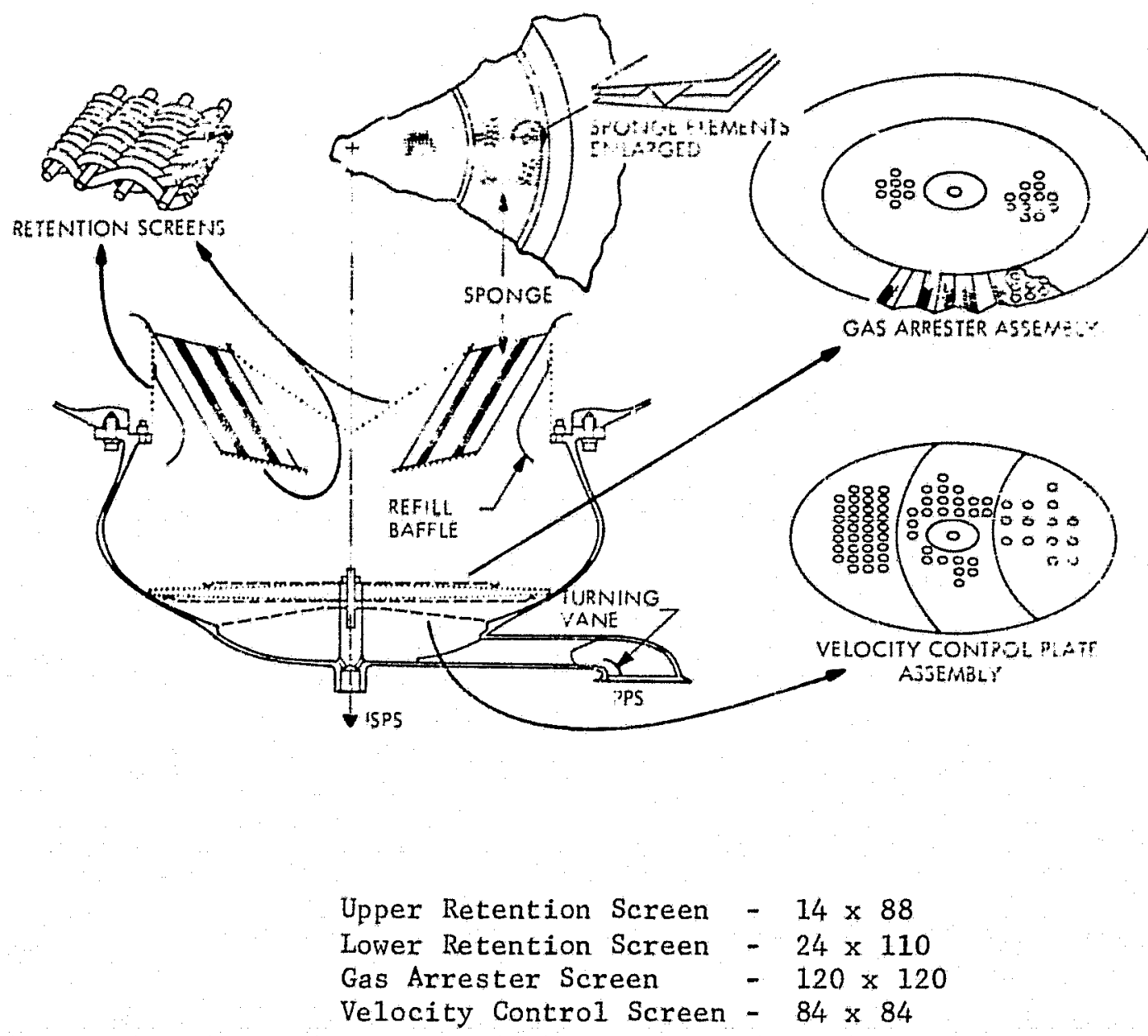

Figure II-5. Surface Tension Device for Agena (from Ref. II-4)

\section{ORIGINAL PAUE IS
OE POOR QUAITII}




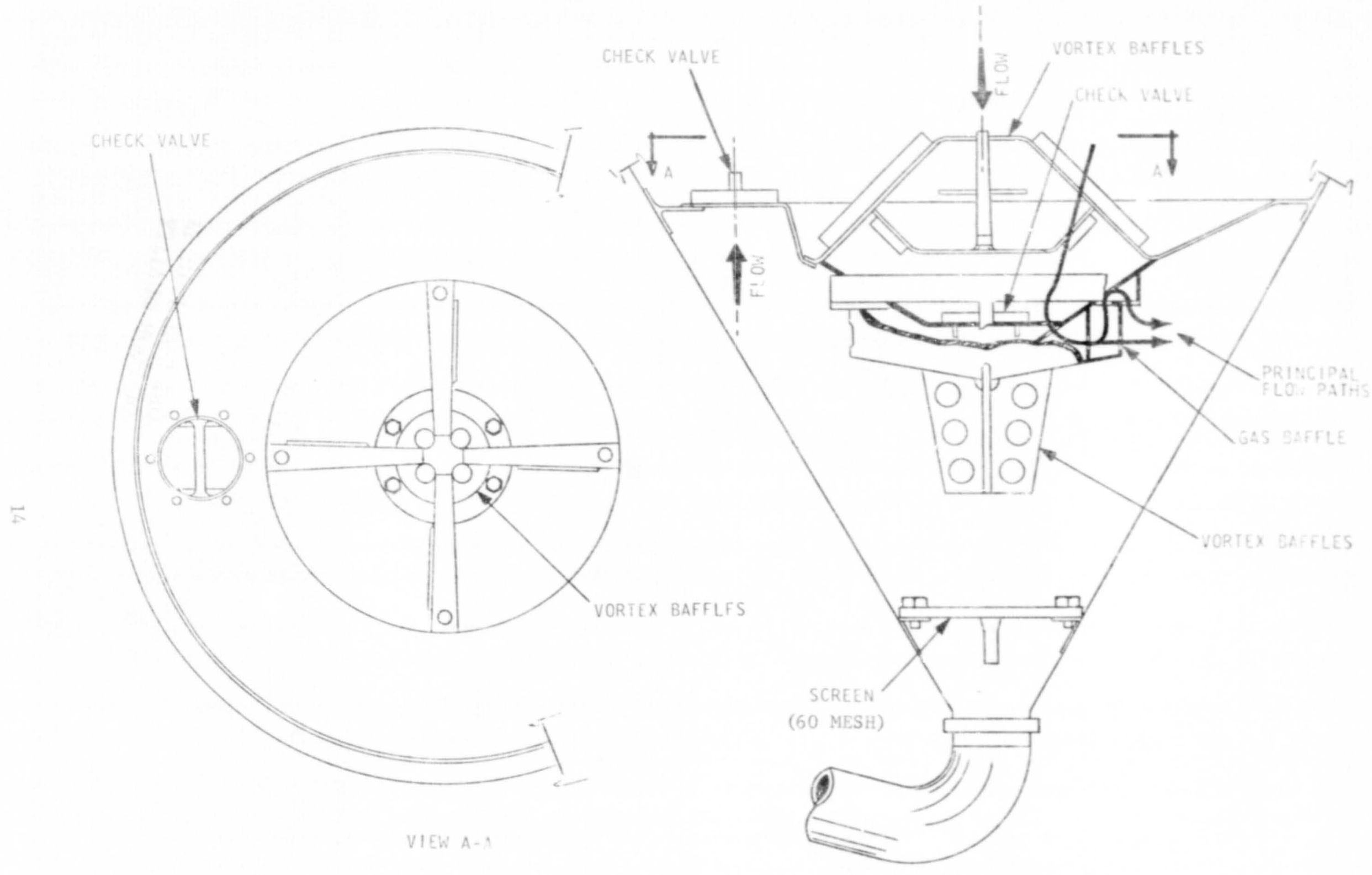

Figure II-6. Trap Assembly, Transtage Main Tanks 


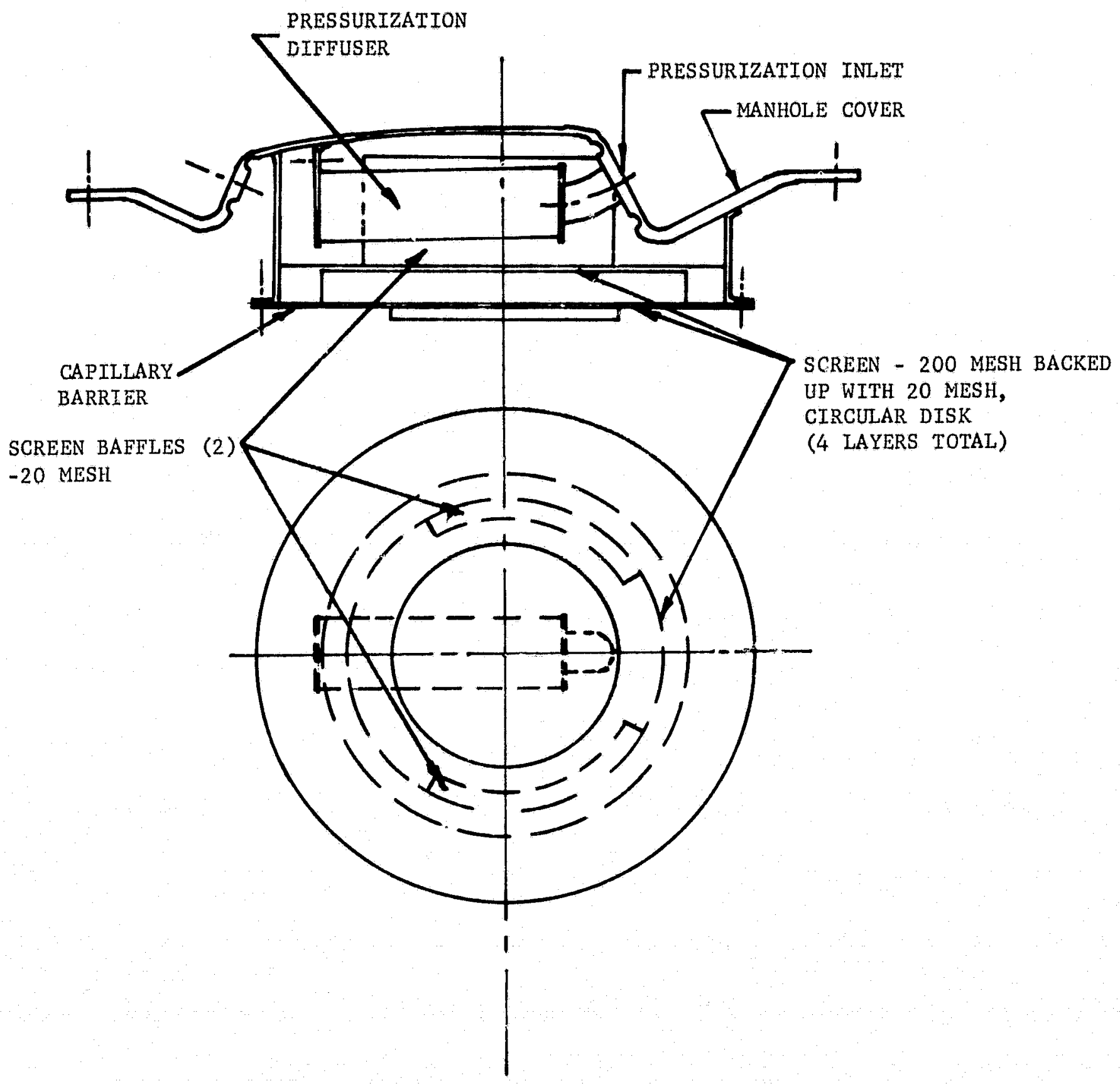

Figure II-7. Pressurization Inlet Capillary Barrier Transtage Main Tanks 


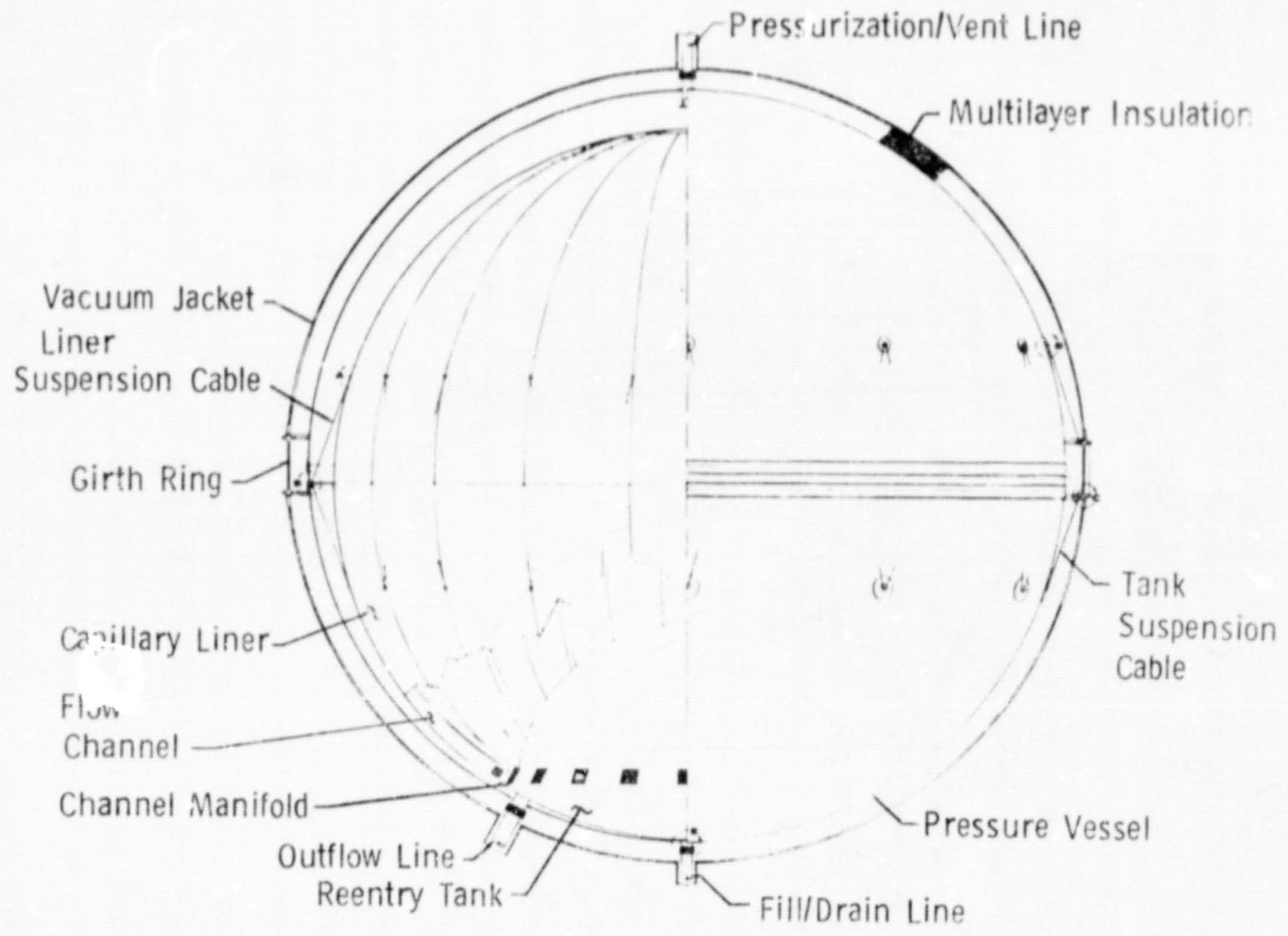

Figure II-8, Dual Screen Liner Concept for Cryogenic Orbiter (from Ref. II-9)

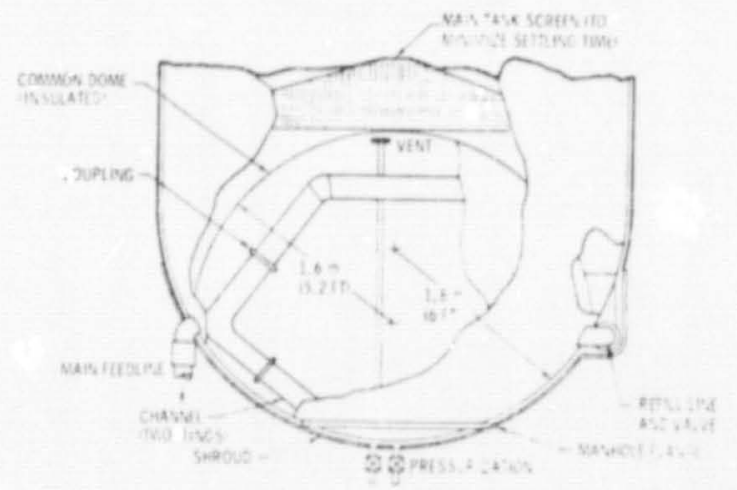

Figure II-9. Start Tank Concept for Cryogenic Orbiter (from Ref. I I-10) 
The Space Tug is a spacecraft that would be carried in the cargo bay of the Space Shuttle to deploy and retrieve payloads to orbits beyond the capability of the Shuttle. It is unmanned, has a cryogenic propulsion system and was to raplace the Interia Upper Stage now being developed. Current plans consider a manned orbit-to-orbit shuttle instead of the Space Tug.

The Space Tug, as it was defined (Ref. II-12), made use of the idle mode thrust from the main engine to settle propellants before an engine burn. However, the use of a surface tension device has been studied (Ref. II-13, II-14 and II-15). One concept (Table II-I and Figure II-10) has a screen trap at the tank outlet and uses a screen Iiner to form a vapor annulus that can be vented in low-g. Another concept (Figure II-11) uses a surface tension devire within a start tank. Fill and vent valves allow the start tank to refill during the engine burn.

The third approach is an integrated system, permitting the auxiliary propulsion system (APS) to be supplied from the main tanks. A reservoir tank with a surface tension device (Figure II-12) supplies propellant to the APS thrusters. During main propulsion system (MPS) and APS translational burns the reservoir tank is refilled by opening a vent valve. The APS is used to settle the main tank propellant prior to MPS burns.

Anotner current application for surface tension devices is the orbit adjust propulsion system of a classified space vehicle (Figure II-13). This system is presently operational, having performed six successful missions.

Another surface tension device is presently operational in the RCA Satcom (Ref. II-17). The device is of the sheet metal vane type. Two satellites are now in orbit and each has four tanks. The criteria for this system are similar to those for a "communications satellite" presented in Table II-1.

\section{B. Vibration Environment}

The most important aspect of this survey was to identify the vibration environments that could be experienced by a surface tension device. For this reason the survey concentrated on this parameter, somewhat independent of the applications.

The usual sources of space vehicle vibration are acoustic noise, aerodynamic noise and mechanically induced excitation. During the launch and ascent phase of the mission there are many signifir nt vibration sources: wind loads, propellant sloshing, transonic buffeting, supersonic flight, operation of engines, turbopump and auxiliary equipment, Pogo interaction and aeroelastic interaction (Ref. $i I-18$ ). Once in space, the primary source of vibration becomes the mechanical excitation of the spacecraft engine and any other operating machinery.

The vibrations produce a spectrum of frequency dependent accelerations. The sinusoidal and random components of the spectrum are used to define the environment. Rather than consider a11 the detailed variations with frequency, an envelope defines the manitudes of th vibration as they are 


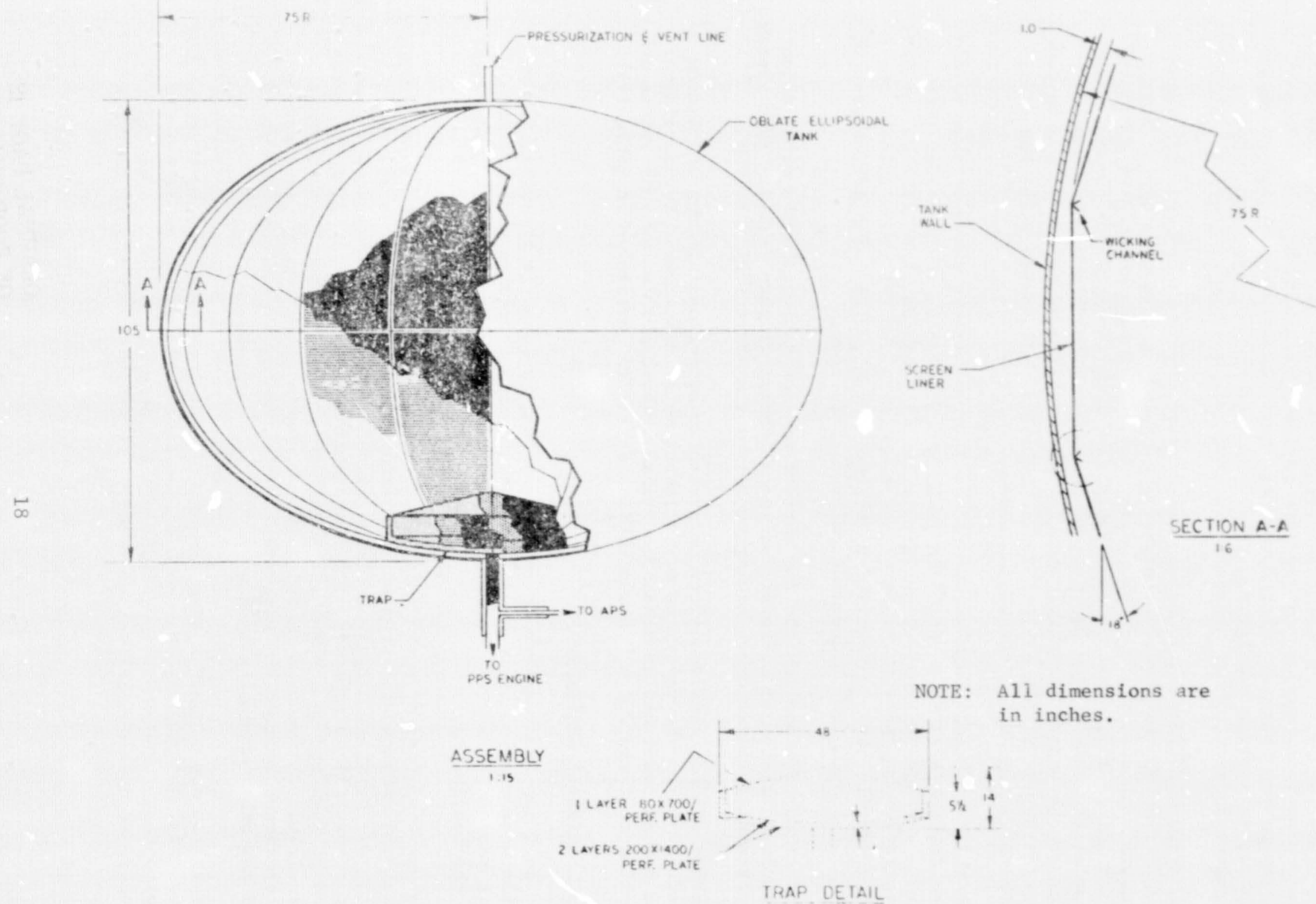

Figure II-10 Trap with Liner for Space Tug Oxidizer Tank (from Ref II-13) 


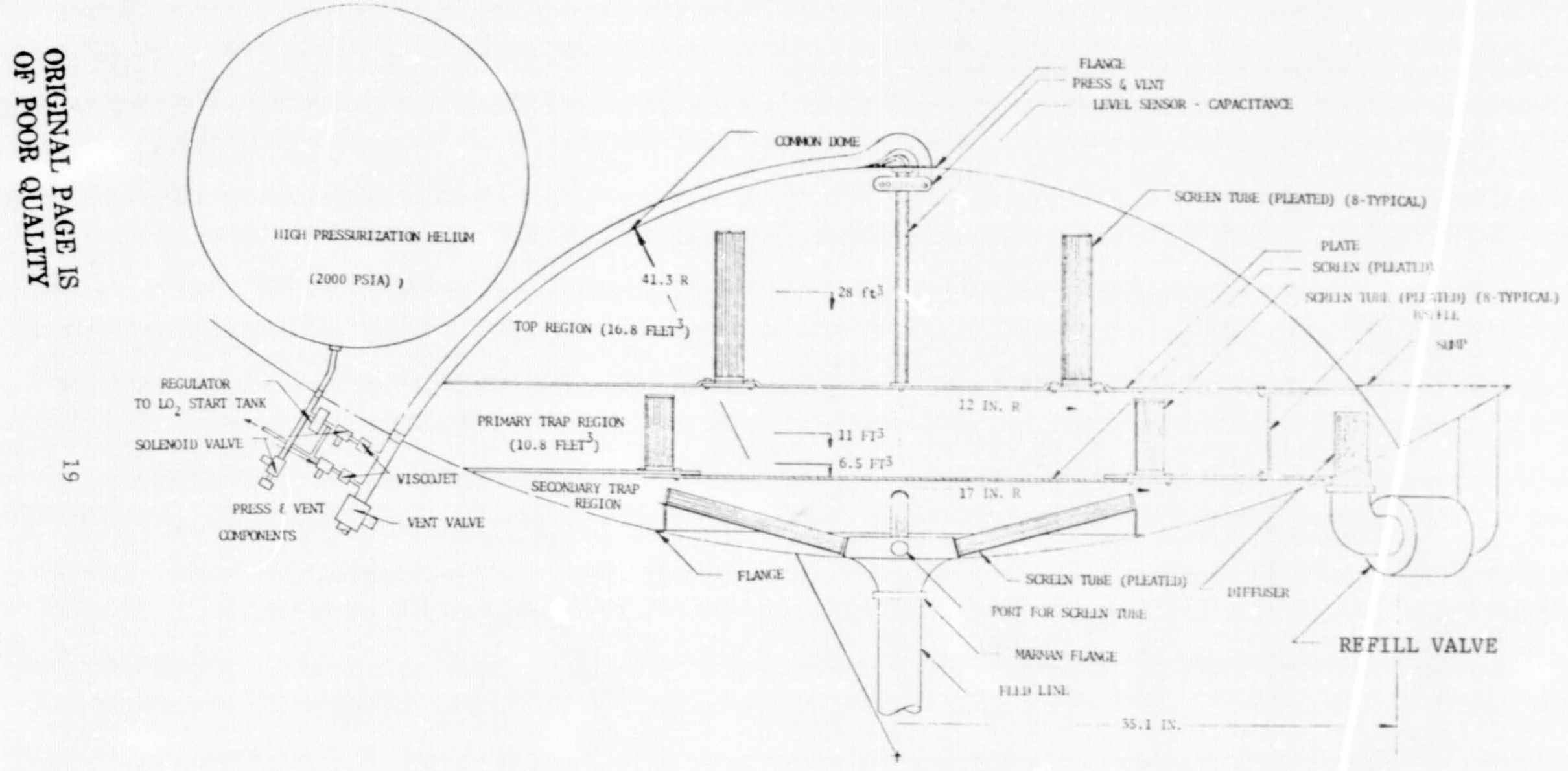

Figure II-11. Start Tank with Surface Tension Device for Space Tug Fuel Tank (from Ref. II-14) 


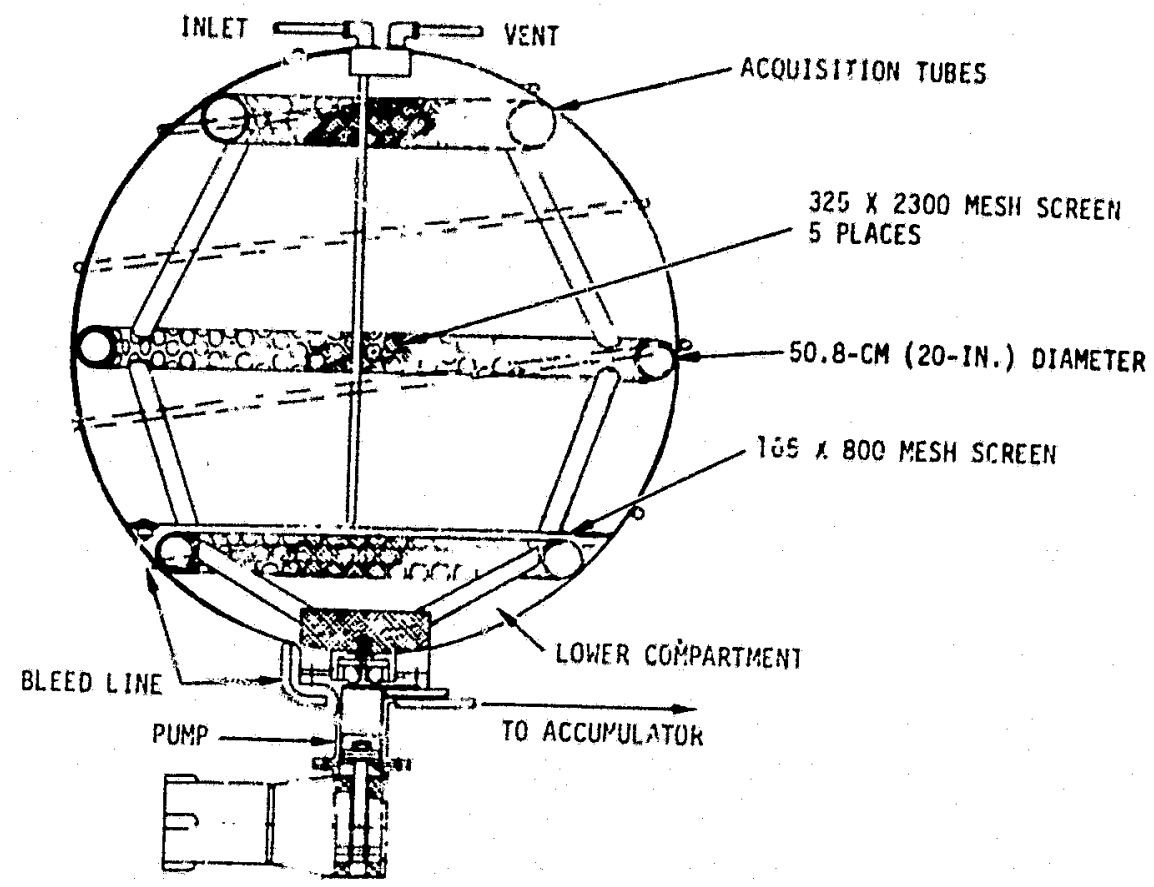

$\mathrm{LH}_{2}$ RESERVOIR SHOWN

Figure II-12. Integrated APS Zero-G Reservoir for Space Tug (Ref。II-15)

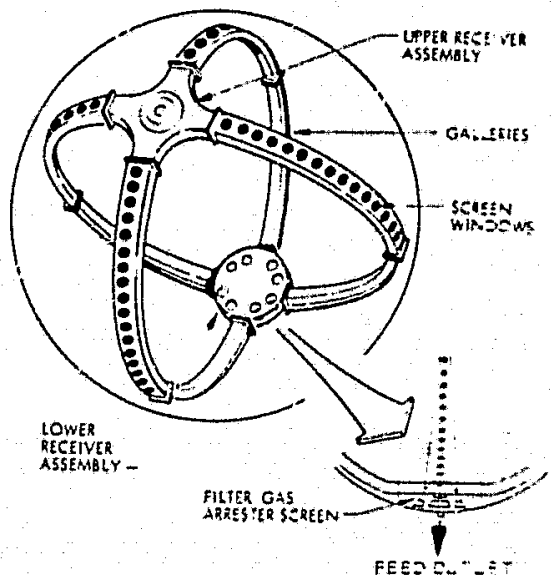

Figure II-13. Surface Tension Device for Orbit Adjust Propulsion System (from Ref. II-16) 
used in acceptance tests. Sinusoidal amplitude is specified in terms of the peak or RMS value of the sine wave at a given frequency. Random vibration is defined with the power spectral density as a function of frequency. Power spectral density (in units of $\mathrm{g}^{2} / \mathrm{Hz}$ ) is defined as the limiting meansquare value of a random variable, in this case, acceleration per unit bandwidth. An overall RMS g-level is defined for any given random vibration spectrum and is equal to the square root of the area under the spectral density versus frequency curve.

The largest magnitude vibration is usually produced during launch and ascent, due to the acoustic coupling of the high thrust engines. Using the Space Shuttle as an example, the vibration environments specified for the OMS and RCS acquisition systems are compared in Figure II-14 (Ref. II-1 and II-2). The structure of the tank and acquisition system is designed for the launch environment, the "worst-case" condition. Neither the OMS nor the RCS devices are fully operational during launch, so the boost vibration environment is not considered for their functional design. The devices do operate in the vibration environment produced by the OMS engines (OMS roll control is the case where the RCS maintains attitude if one of the two OMS engines should fail). The RCS operates during atmospheric entry until aerodynamic control is possible, so that vibration environment must also be considered.

This situation is typical of payload/booster vibration envirciar. nts. The booster produces the significant vibration environment that is specified for the structural design of the payload. This is usually not the "worstcase" condition for the operation of a surface tension device in the payload because they are not functional during launch. Either the device is completely submerged in propellant or breakdown of the screen has already been accepted as a consequence of the acceleration environment. Therefore, the in-space vibration environment, where the surface tension device is functional, is the prime concern.

The Viking spacecraft is another example of the varied vibration environments that can be encountered (Figures II-15 and II-16). Launch, transMars injection, Mars orbit, entry and termina1 descent environments were specified (Ref. II-19 and II-20).

The vibration environments that were collected fall into four general categories: (1) the environments produced by space boosters during the lift-off and ascent phase of the mission, (2) the envizonments produced by liquid upper stages and spacecraft main engines, (3) the environments produced by solid rocket motors, and (4) the environments produced by small thrusters and other miscellaneous disturbances.

1. Space Boosters - The vibration environments specified for the payload on the space boosters presently in use, are shown in Figures II-17 and II-18 (Ref. II-21) (the environment for the Titan III/Centaur is shown above in Figure II-15). The levels shown are for flight acceptance testing, which envelop the actual precilcted or measured flight vibration environment. Qualification levels are 1.5 to 2.0 times the flight acceptance leve1. These levels are typical, the actual vibration level experienced by the spacecraft propulsion system may vary, dependent on its location. and mounting in the spacecraft. 


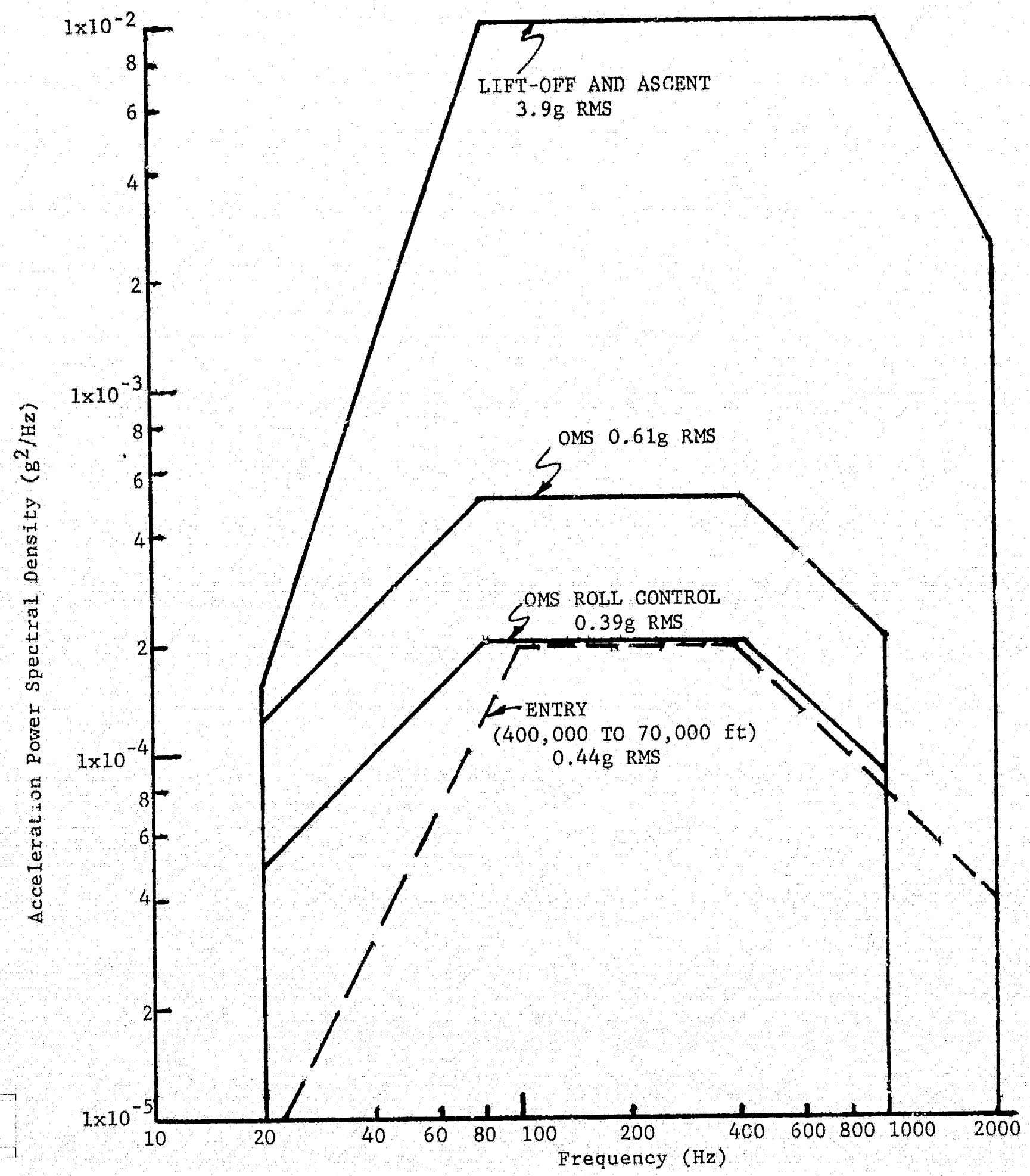

Figure II-14. Space Shuttle Random Vibration Environments 


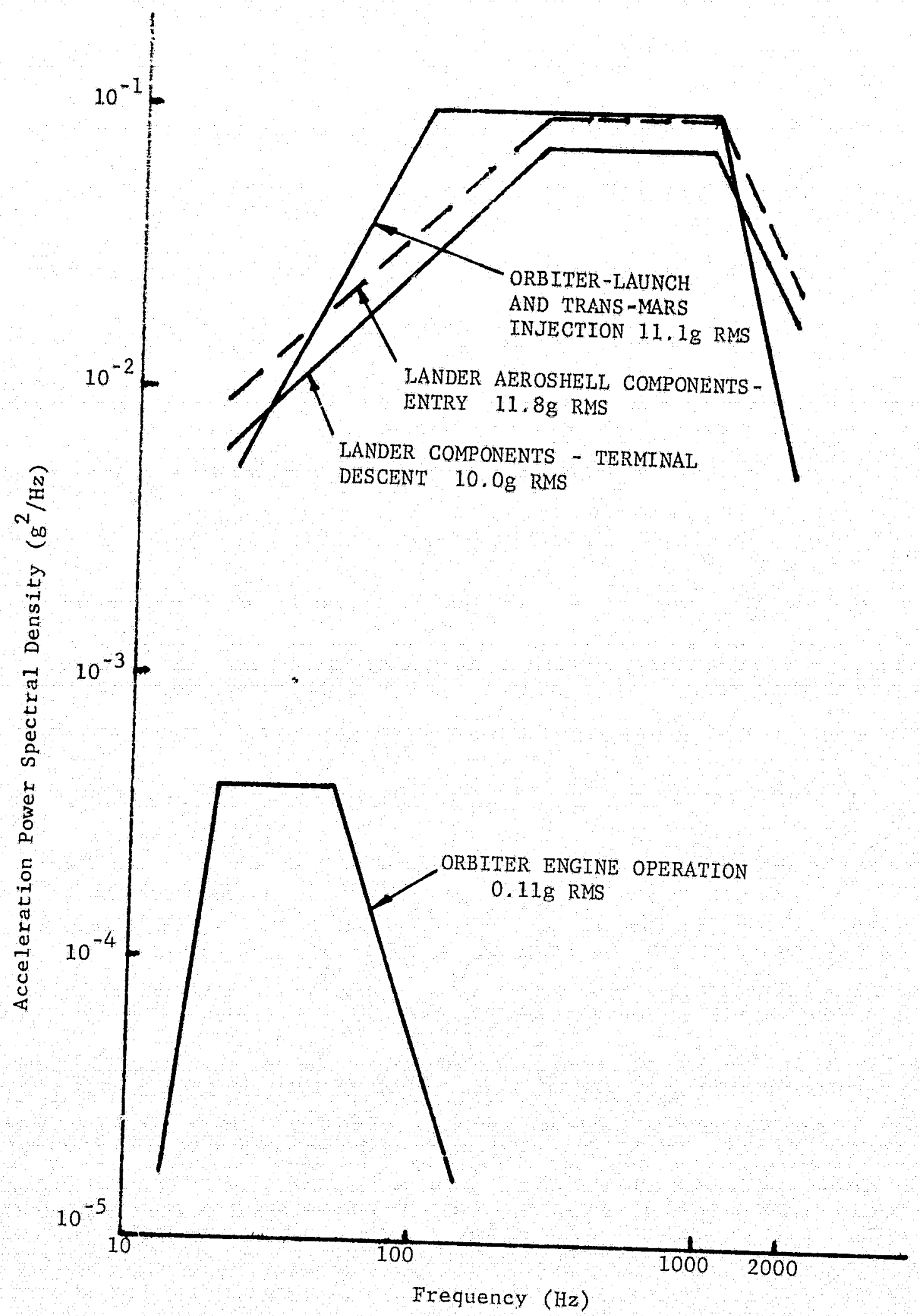

Figure II-15. Viking Random Vibration Environment 


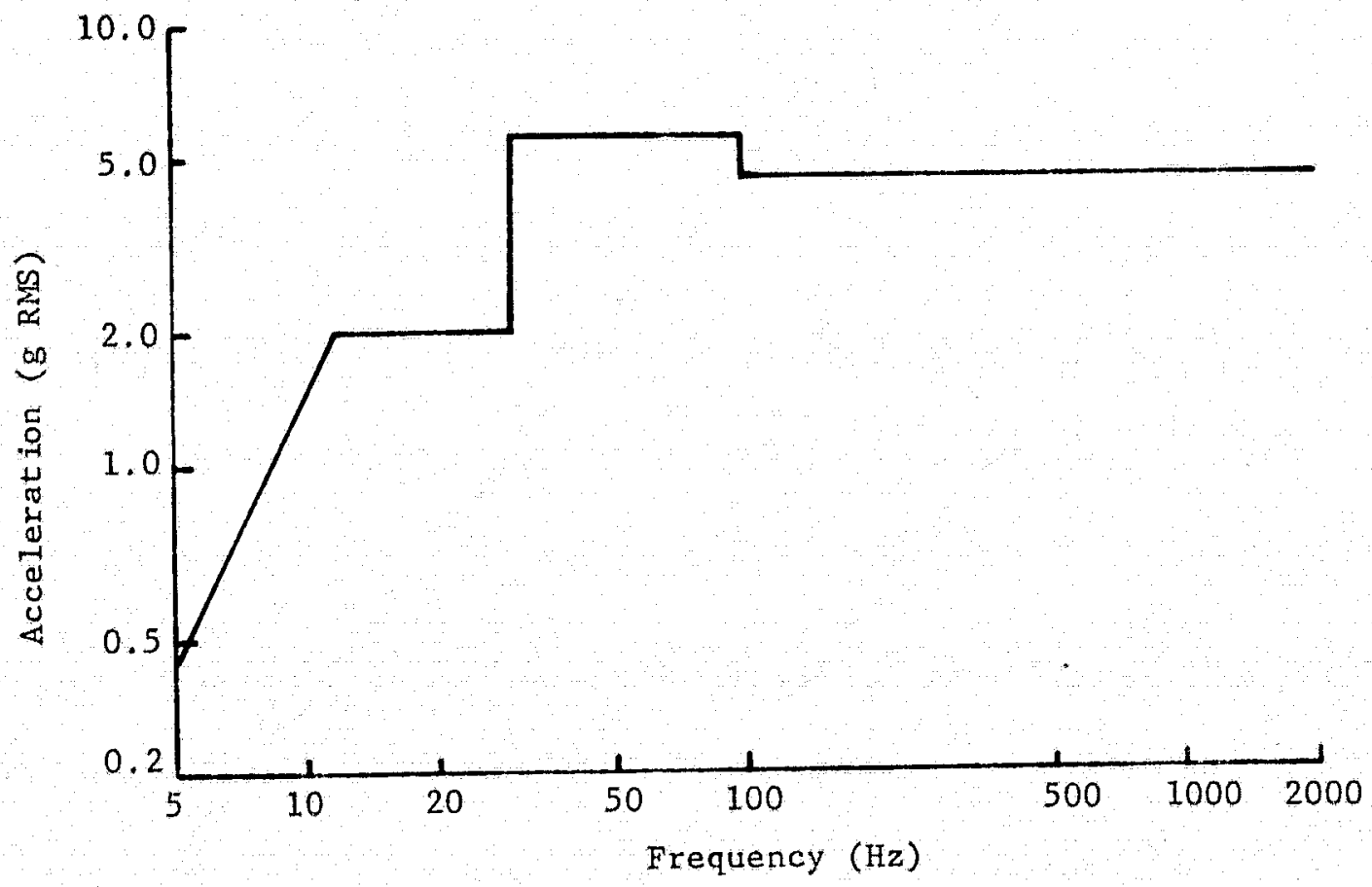

Figure II-16. Viking Orbiter Launch Sinusoidal Vibration 


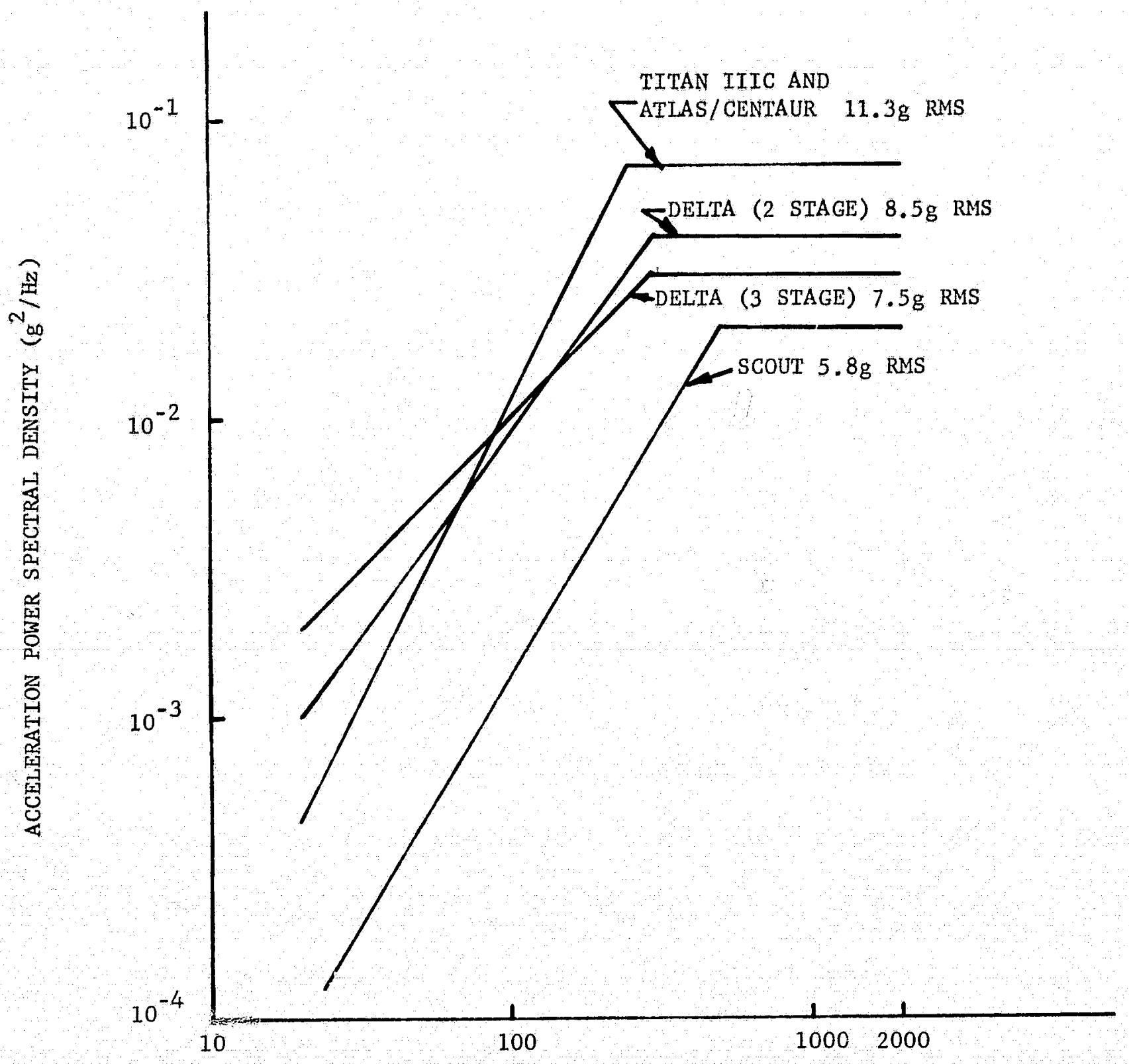

Figure II-17. Random Vibration Acceptance Leve 1s, Space Boosters 


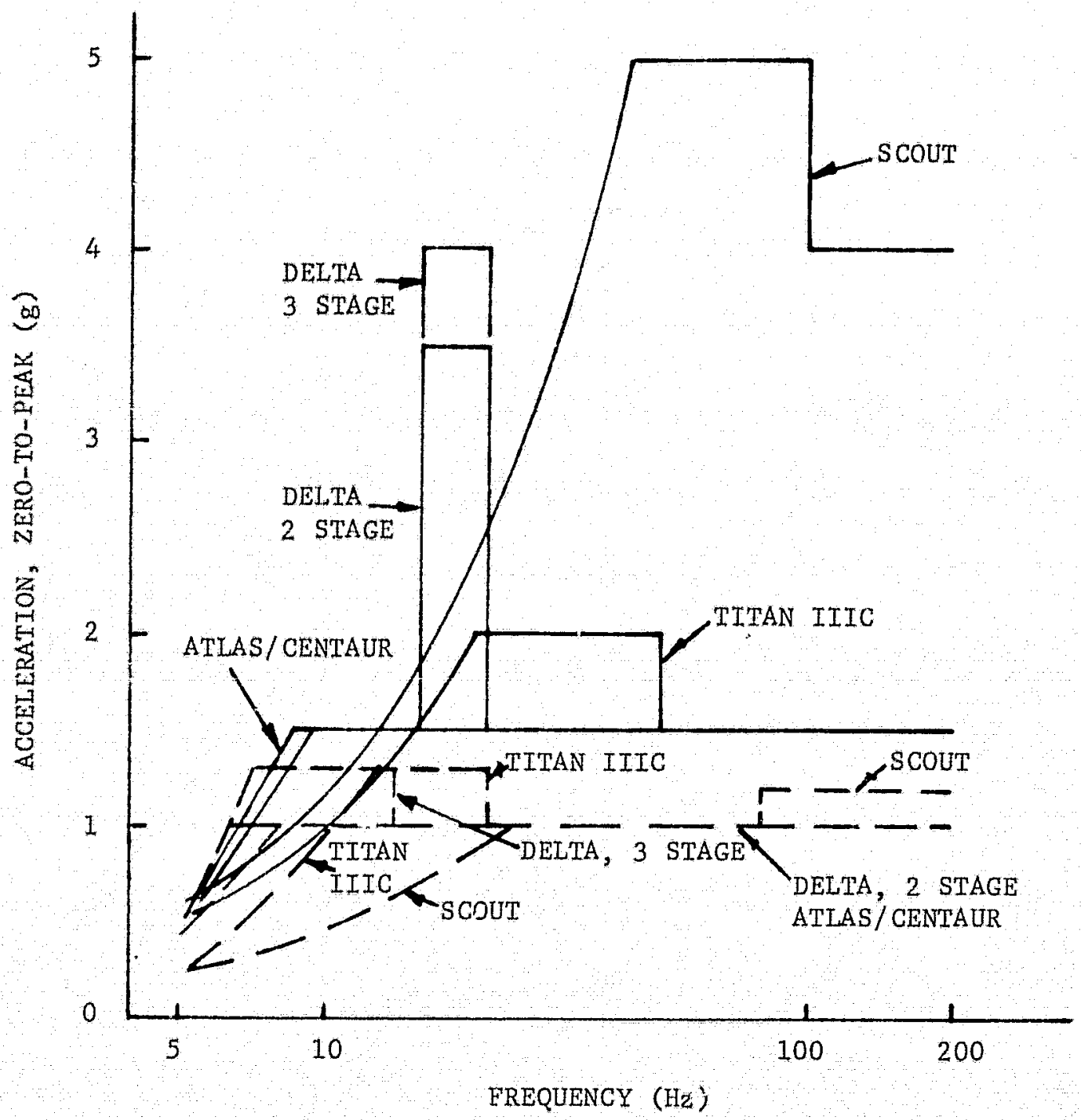

Figure II-18. Sinusoida1 Vibration Flight Acceptance Levels, Space Boosters 
The Satuin $V$ environment is representative of the environment for future large cryogenic boosters, such as a single stage to orbit booster. Reference II-22 presents a summary of the environments measured on the Saturn V. Figure II-19 shows the influence of the propellant volume on the vibration spectrum.

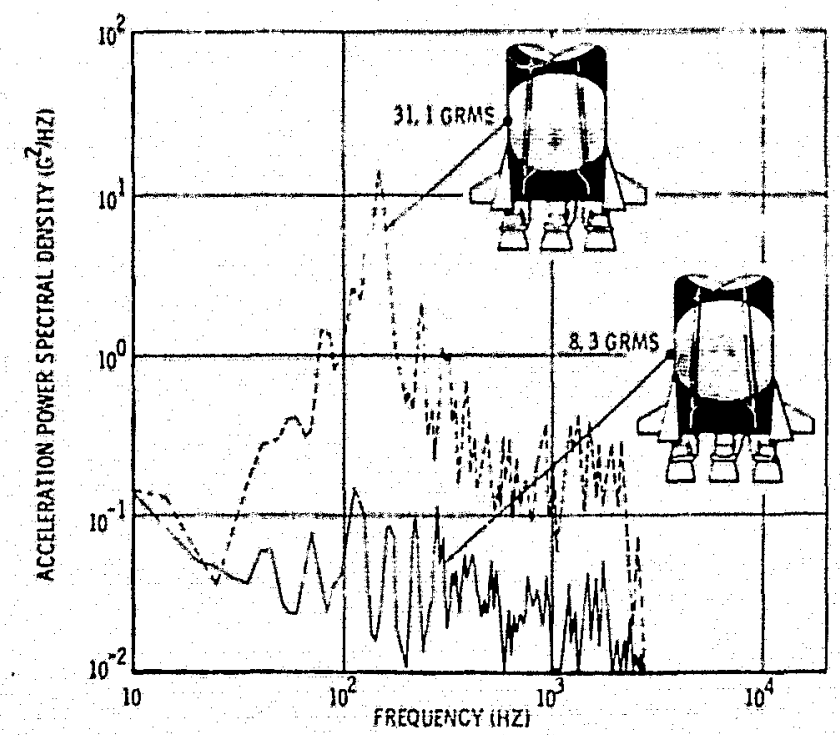

7igure II-19. Effect of Liquid Leve1 in a Tank on the Vibration Environment during Static Firing

2. Spacecraft Main Engines - The vibration environment produced by the Agena and Transtage engines is shown in Figure II-20 (Ref. II-23 and II-24). The environment for both descent and ascent of the Lunar Module is shown in Figure II-21 (Ref. II-25)。

3. Solid Rocket Motors - The vibration environment produced by solid rocket motors is of interest because liquid propulsion systems are also found on space vehicles with solid rocket motors. The Interim Upper Stage, with solid main engines and liquid attitude control, is a good example. Solids are also used as "kick stages" for spacecraft with liquid propulsion systems.

Acoustic pressure oscillations within the motor chamber of a solid rocket have been shown to cause a severe sinusoidal vibration environment (Ref. II-26 and II-27). Oscillatory burning produced high amplitude, narrow frequency band vibration with characteristics that vary rapidly with time. Accelerations exceeding $300 \mathrm{~g}$ have been mersured on the motor and $150 \mathrm{~g}$ at 


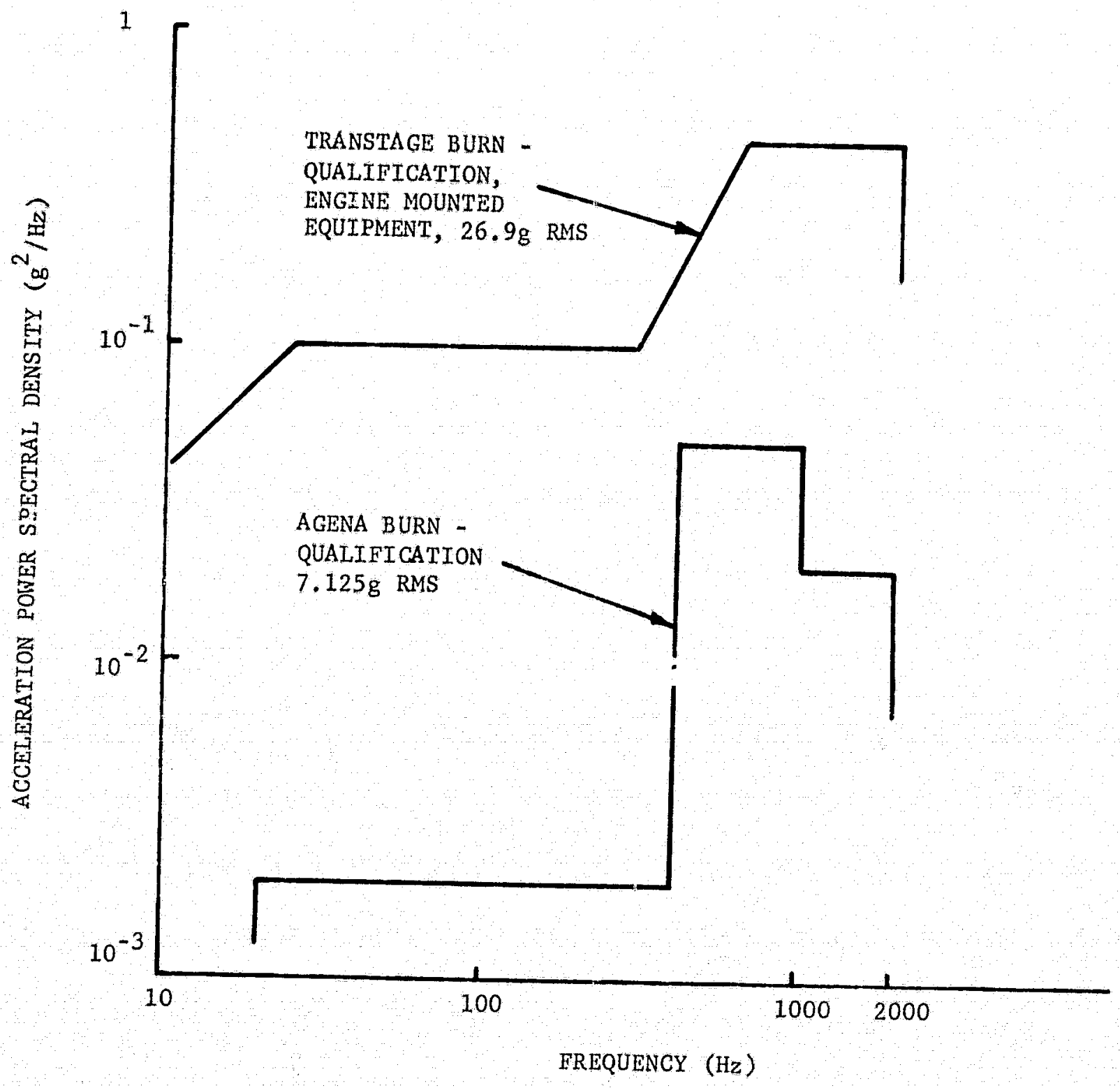

Figure II-20. Upper Stage Engines 


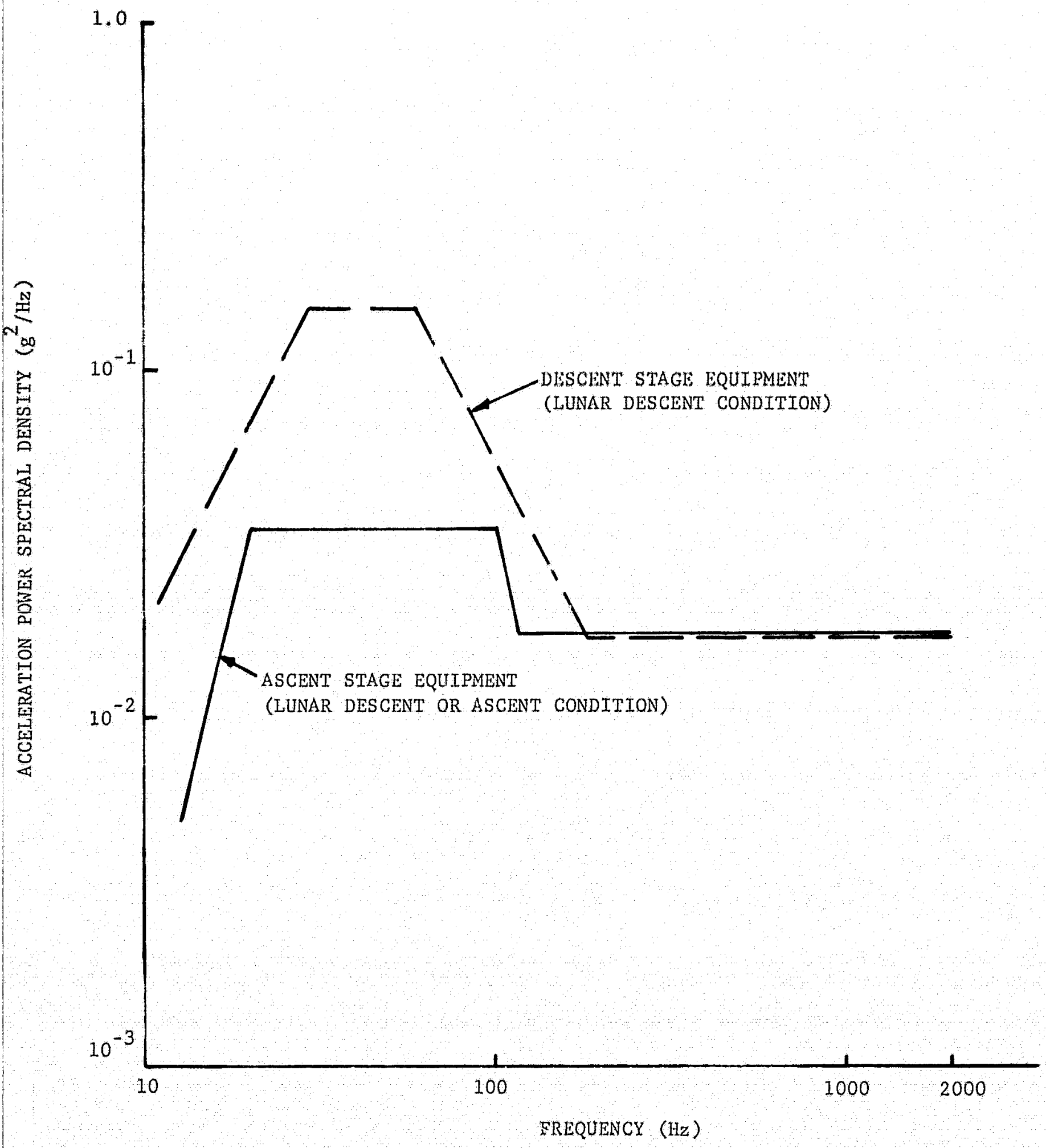

Figure II-21. Lunar Module Primury Structure Random Vibration Criteria 
a forward nounting adanter (Ref. IT-2h). However, these rocket motors are the fairly large engines of the Minuteman and Poseidon missiles.

With a somewhat smaller rocket motor (Nike, Ref. II-28), another unusual vibration envitronment was discovered, Oscillatory burning caused significant vibration in the frequency tange of 10 to $12.4 \mathrm{kHz}$. Vibration levels of $31.5 \mathrm{~g}$ RMS were measured in the first 1.2 seconds of burning, but then dropped to $7.4 \mathrm{~g}$ RMS.

"reket motors currently used for "kick stages" apparently burn with very little oscillation and do not produce a significant vibration environment. Specifications for the interface with the spacecraft require vibrations less than $2 \mathrm{~g}$, zero-to-peak. A $\mathrm{g}$-level of 0.018 was measured from 10 to 250 $\mathrm{Hz}$ for a Thioko1 TE-M-616-1 motor (Ref. II-29). Measurements made on a Thiokol TE-M-604 were al1 less than $10^{-5} \mathrm{~g}^{2} / \mathrm{Hz}$ over 5 to $3000 \mathrm{~Hz}$, and this appears to be typical of spacecraft solid motors (Ref. II-30). A TE-M-364-19 rocket motor for FLTSATCOM produced a maximum vibration of $3.16 \mathrm{~g}$ peak-topeak along a lateral axis over the frequency range of 0 to $5 \mathrm{KHz}$ (Ref. II -31 ).

4. Small Thrusters - Very little information is avallable on the in-space vibration environment produced by small thrusters and other small disturbances. A number of government agencies and aerospace companies were contacted and they confinmed this fact. The Shock and Vibration Information Center performed a literature search on this subject and they could not find any thing.

During the skylab missions some measurements of the spacecraft disturbances produced by crew motion, sere made (Ref. II-32). Shown in Figure II-22 is one of the more severe force spectra produced by the flapping of the astronauts' arms. The force can be converted to an accelexation for a given spacecraft mass. Accelerations as large at $10^{-3} \mathrm{~g}$ with a frequency spectrum of about one to several thousand Hertz trere experienced as the skylab coasted in space. These disturbances have been referred to as "G-Jitter" and could have a significant impact on processes or experiments that were intended to be performed in zero-g (Ref. II-33).

\section{Compilation of Survey Results}

The survey of the applications for surface tension acquisition systems included all the currently operational spacecraft using surface tension devices. They are:

Ageita - Screen trap in main tanks. Transtage - Screen trap and ullage barrier in main tanks. Viking orbiter - Vane device in main tanks. Three Axis stabilized Vehicle - Screen galleries in orbit adjust tank. RCA satcom - Vane device in attitude control tanks.

Surface tension devices presently being actively developed for flight systems consisted of the following: 


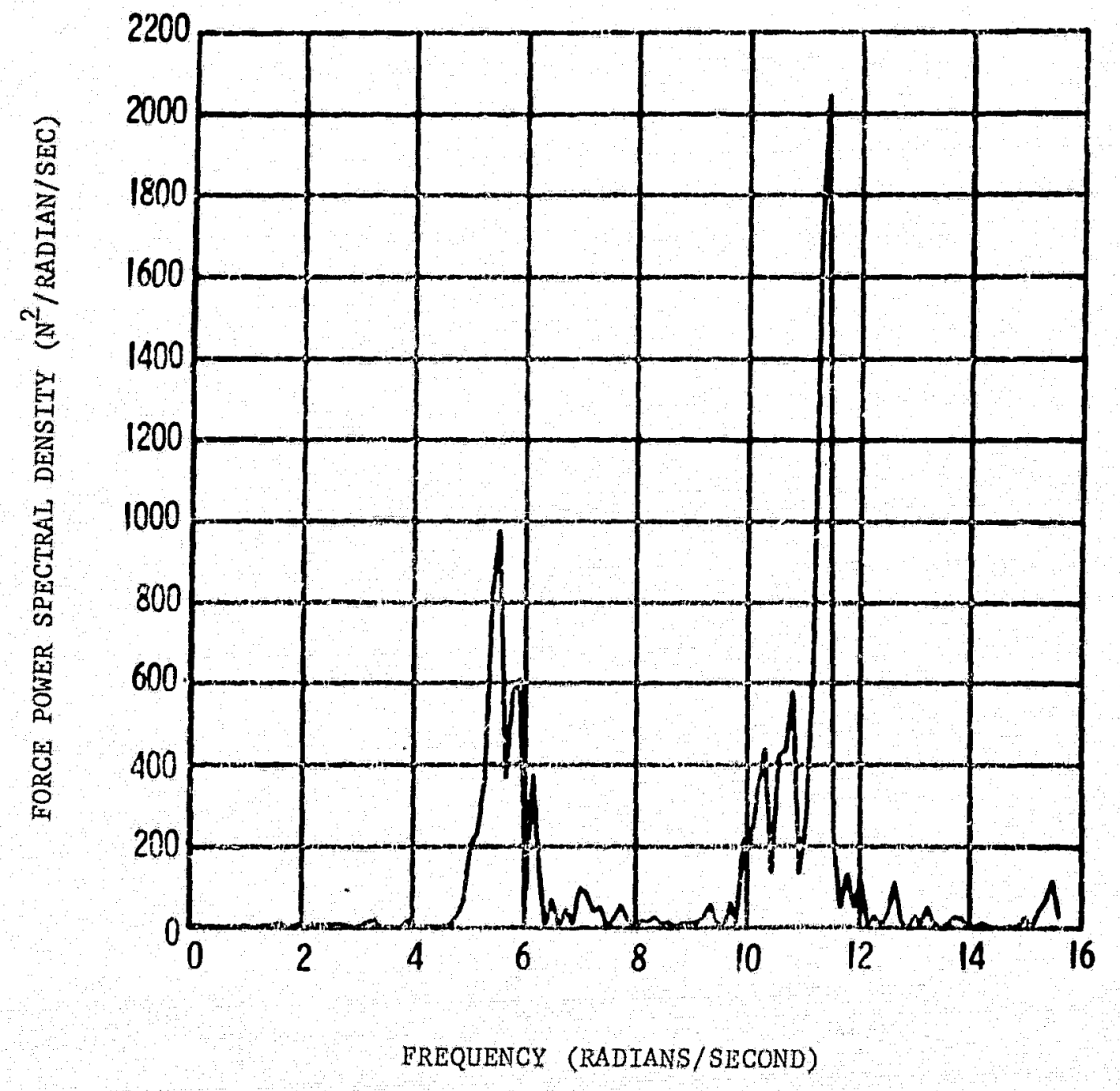

Figure II-22, Power Spectral Denulty Due to Arm Flapping (From Ref, II-32) 
Space Shuttle Reaction Control system - Swen channels with barrier in RCS tanks.

Space Shuttle Orbital Maneuvering System - Screen traps in OMS tanks.

Intelsat $\mathrm{V}$ Communications Satellite - Screen channels in attitude control system tanks.

Future applications include such systems as communications satellites, Space Tug and a cryogenic space Shuttle. This survey was intended to consider only applications of surface tension devices using fine-mesh screen within the U.S. Space Program. Some spacecraft falling outside those limits have been added because they are representative of future systems and contributed to the depth of the survey.

A similar survey was recently performed (Ref. II-34), except that it was directed toward flow thansients. The data from that survey was reviewed to insure that this survey was complete. Another recent survey of pocential receivers for in-orbit supply, provides a comprehensive list of future spacecraft, as envisioned by the NASA (Ref. II-35). The more sigtificant systems listed in that survey have been included in this survey. The scope of possible future spacecraft continues to grow. Large space stations for in-space manufacturing, solar energy collection, observation and communication are considered to be feasible future objectives within the next 25 years (Ref. II-36 and II-37).

Based on the results of this survey, the potential for surface tension device applications is unlimited. The possible applications cover a wide range of sizes, flow rates and acceleration environments. The fluids of interest are primarily $\mathrm{N}_{2} \mathrm{O}_{4}$, $\mathrm{MMH}$, oxygen, hydrogen and hydrazine. The screens being used ranged from a $60 \times 60$ square weave to a $325 \times 2300$ Dutch, twill.

In many cases the vibration environment specified for the applications collected in the first part of this survey was available. In other cases the information was not evailable or only the environment for a portion of the mission, when vibiation was a maximum (such as boost), was specified. Therefore, a wide ranging search for information on vibration environments was conducted, since this was the most significant parameter of the survey. The Shock and Vibration Information Center of the Naval Research Laboratory, and various NASA centers and aerospace companies were contacted during the survey.

The vibration environments were found to fall into four genera 1 categories, based on the source of the vibration. The categories are: (1) space boosters during lift-off and ascent operation, (2) main ergines of upper stages and spacecraft, (3) solid rocket motors, and (4) small thrusters and miscellaneous disturbances.

The environments produced by space boosters were found to be well documented. Some representative data was found for liquid main engines and solid rockets. Essentially no data could be found on the in-space operation of small 
thrusters, but some data on disturbances such as crew movement was found. Since the structural design of the spacecraft is usually the reason for the vibration specification, there has been little interest in low level vibration sources.

To summarize the vibration environments, they are of two types: random and sinusoidal. Random vibration is specified over a frequency range of 10 to $2,000 \mathrm{~Hz}$. The amplitude is stated in $\mathrm{g}$ RMS, taind on the power spectxal density. Amplitudes ranging from $0.11 \mathrm{~g}$ RMS fur a main engine to $11.3 \mathrm{~g}$ RMS for a booster were found. Sinusoidal vibrations range in frequency from 5 to $2,000 \mathrm{~Hz}$ with amplitudes up to $5 \mathrm{~g}$ zero-to-peak.

Care must be taken in using this collected data since the vibration level is a function of factors such as the location in the spacecraft and liquid levels. The environments presented are only typical of what may actually be experienced. In addition, some environments presented are as actually measured, some are acceptance test levels and some have safety factors applied to make the qualification test levels. 
Analytical models to predict the retention characteristics of a screen acquisition system in any given vibration environment we re developed. Two different analytical approaches were considered. One was to use the rather simple hydrostatic model that wa, developed under previous vibration studies. The second approach integrates two models, a structural dynamies model and a bubble growth model, to consider in more detail the factors involved in the response of the screen to vibration. In this chapter these two approaches are discussed.

\section{A. Hydrostatic Model}

Past studies have shown that the effects of vibration on the retention capability of a screen can be predicted with a simple hydrostatic model (see Chapter I, Intioduction, for a discussion of the previous vibration studies). The most recent and comprehensive of these studies (Ref. III-1) was used to define the state of development of the hydrostatic mode1. This model assumes the effect of the vibration to be hydrostatic in nature. The effect of the vibration is to create a pressure differential between the gas and liquid on opposite sides of the screen, with the liquid pressure being less than the gas pressure. This pressure differential has the form:

$$
\Delta \mathrm{P}_{\mathrm{V}}=\rho g h
$$

where the acceleration is due to the vibration and the height is a distance over which the vibration acts (a list of symbols can be found in Appendix B).

This model depends on test data to establish how the values of acceleration and height are defined. Data from previous tests (Ref. III-1) were correlated using this model when the acceleration was defined as the vibration amplitude input to the test model. For random vitration, it was the RMS level of the input. For sinusoidal vibration, the zero-to-peak amnlitude was used at high frequencies (frequencies greater than $200 \mathrm{~Hz}$ ). At lower frequencies, near the first harmonic of the structure, amplification must be taken into account. The height used was the length of screen exposed to the ullage, parallel to the direction of the vibration. The past verification of this model has been limited to fairly rigid screen specimens.

The model is applied to test data by predicting the contribution of vibration to the pressure differentials acting on the screen when screen breakdown occurs. At the point the retention capability of the screen is exceeded, the pressure differentials within the test system are related as follows:

$$
\Delta \mathrm{P}_{\mathrm{c}} \geq \Delta \mathrm{P}_{\mathrm{v}}+\Delta \mathrm{P}_{\mathrm{S}}+\Delta \mathrm{P}_{\mathrm{f}}
$$

The pressure differentials due to vibration, hydrostatic head and flow must exceed the retention capability of the screen when breakdown occurs. The retention capability of the screen is measured by the standard bubble point test. The hrdrostatic pressure differential due to one-g and the flow losses 
(if present) can be calculated from established theory. Therefore, the

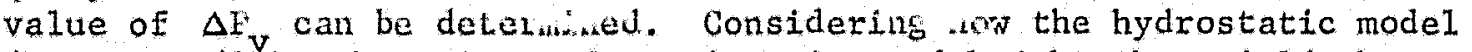
(Equation (I)), the values of acceleration and height that yield the proper value for $\Delta \mathrm{P}_{\mathrm{v}}$ can be determined. Empirical coefficients can also be applied to the model to account for various structural and screen support effects.

The hydrostatic model is applied to the design of surface tension devices in much the same way. If the model has been empirically verified for the surface tension device configuration of interest, the values of acceleration, height and coefficients are used to predict the value of $\Delta \mathrm{P}_{\mathrm{v}}$ for the specified vibration environment. This value is then used in conjunction with the other pressure differentials acting on the device to predict its performance.

\section{B. Screen Dyramics Approach}

This approach to the analysis of the effects of vibration considers in detail all aspects of the system response. The approach is outlined in Figure III-1. It consists of two analytical models; a structural dynamics model and a bubble growth mode1. The input vibration is defined at the tank support structure, so the transmission of the vibration to the surface tension device must be considered. For the purpose of this study, the input was considered to be directly applied to the surface tension devize, so an analysis of transmission of the vibration (box shown in dashed lines in Figure III-1) was not required.

The structural dynamics nodel predicts the pressure due to the vibration, taking into account the screen, its support structure, the liquid inass and liquid flow. The bubble growth model evaluates the pressure retention. capability of the screen to determine if screen breakdown will occur due to the oscillating pressure of the vibration. This model considers the screen geometry, liquid properties and the steady pressure differentials acting on the scres. These two models are discussed in the following sections.

1. Structural Dynamics Mode1 - Our development of a structural dynamics model to predict the oscillatory pressure environment in screen liquid acquisition systems is centered on a simple analog, namely a single degreeof-freedom elemental model applicable to a controlled set of test specimens. It is expected that knowledge gained from tests on the controlled specimens can be used to qualify this elemental approach and yield a prediction of the characteristic system parameters, i.e., mass, damping and stiffness. We expected that such insight, in conjunction with a continuously expanding test program, would then lend itself to gradual extensions of the elemental model to encompass more complex screen configurations. Additionally, it was anticipated that the expanded model would be useful in estimating the pressure environment in flight article hardware. The following text details development of the single degree-of-freedom elemental model.

a. Basic Equation of Motion - Consider a liquid/container system with a single compliant screen element as shown in Figure III-2. If we assume a linear single degree-of-freedom is representative of this system we have the basic equation 


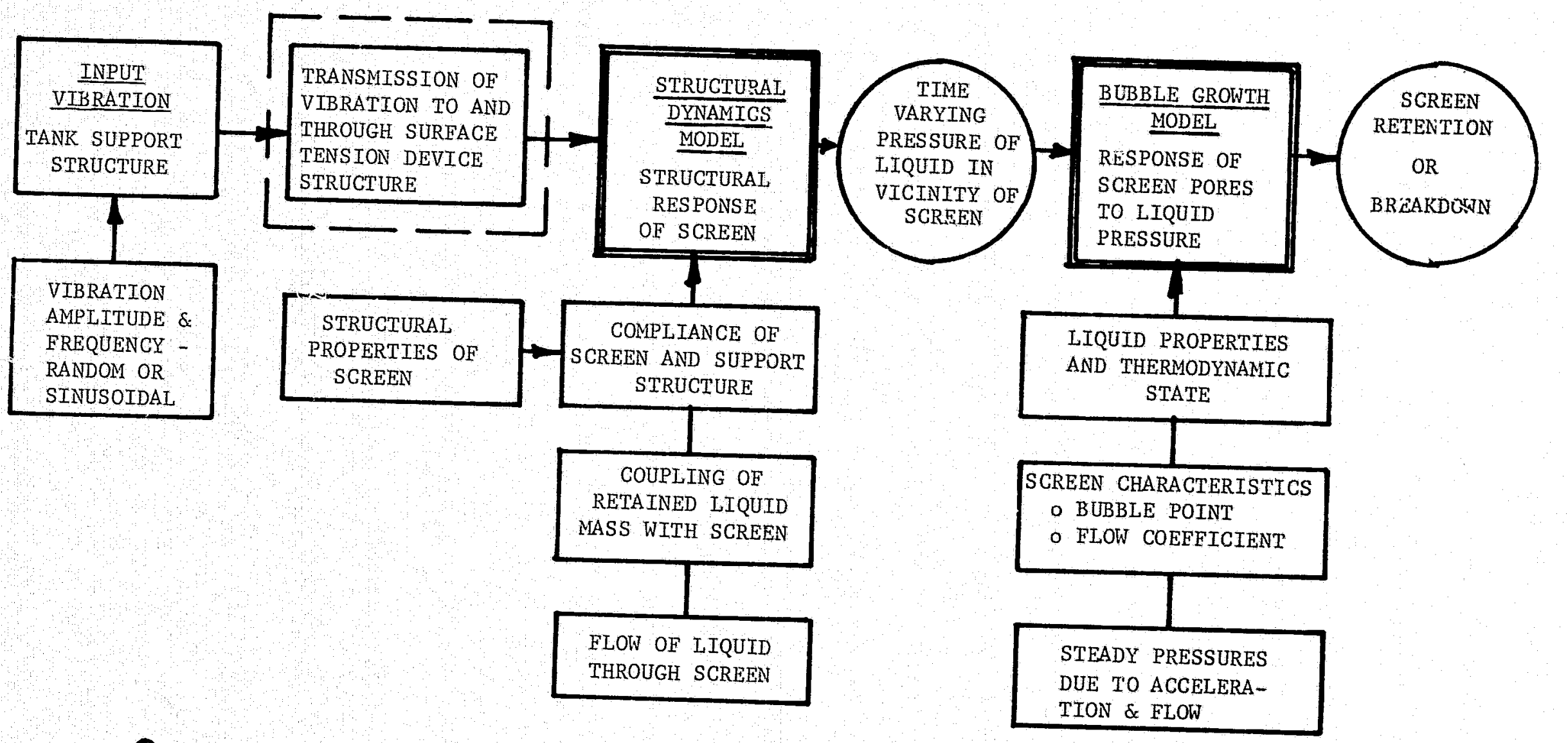

Figure III-1. Screen Dynamics Approach 


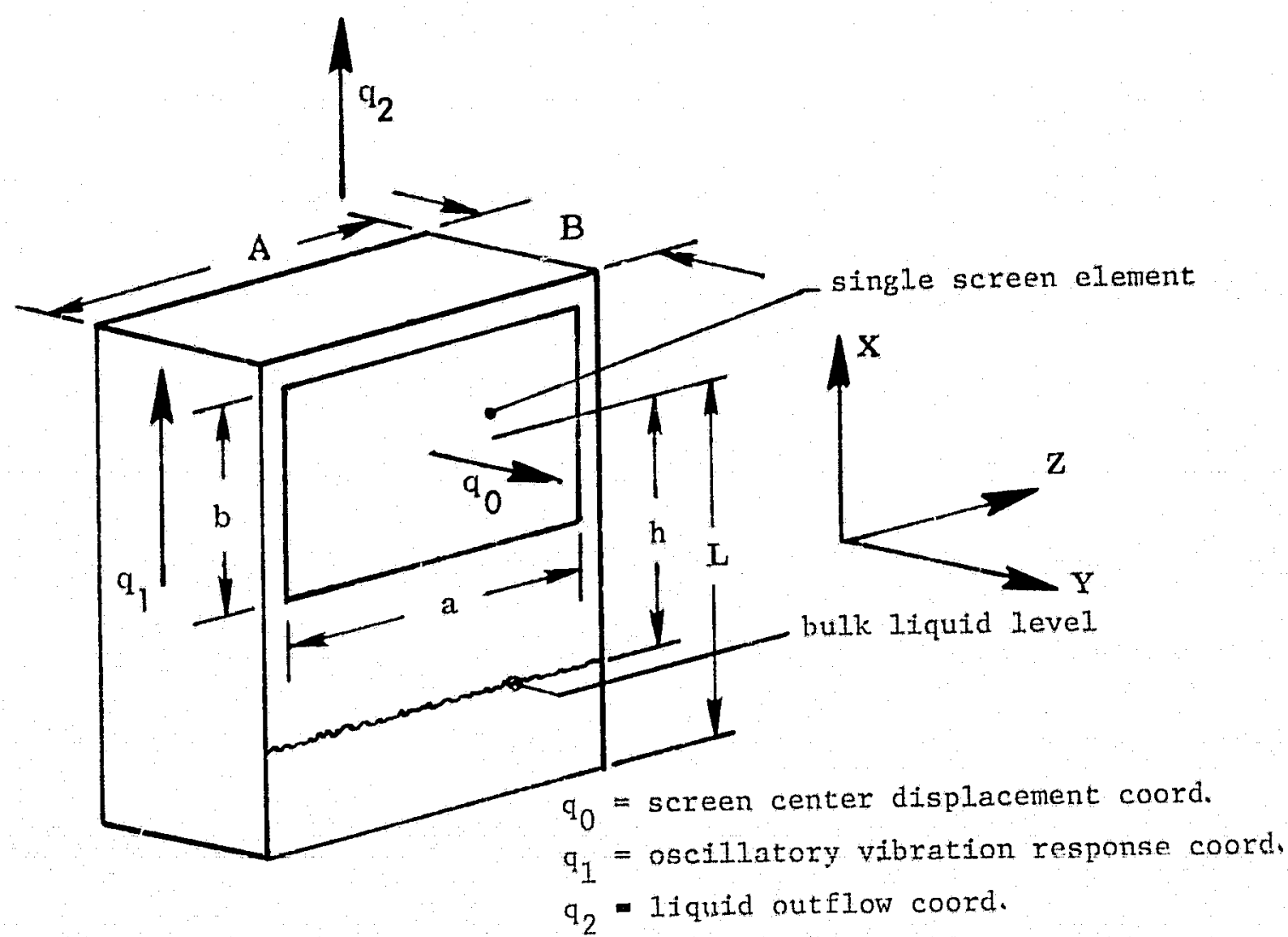

Figure III-2. Elemental Liquid/Container System

$$
m \ddot{q}+c \dot{q}+k q=F(t)
$$

and, letting $\omega_{0}=\sqrt{\mathrm{k} / \mathrm{m}}$, the natural frequency

$Q=\sqrt{\mathrm{km}} / \mathrm{c}$, the amplification

yields

$$
\ddot{q}+\frac{\omega_{0}}{Q} \dot{q}+\omega_{p}^{2} q=F(t) / m \text {. }
$$


Implementation of Equation (4) requires knowledge of the system governing parameters $(\mathrm{m}, \mathrm{c}, \mathrm{k})$ and an estimate of the forcing function $(\mathrm{F}(\mathrm{t}))$. This knowledge allows evaluation of the response acceleration which can then be expressed as a pressure.

b. Coordinate Transformation - A relationship between the screen center displacement coordinate, $\mathrm{q}_{0}$, and the oscillatory vibration response coordinate, $q_{1}$, can be obtained from considerations of continuity for an (assumed) incompressible flow. Assume that the screen deflection shape is of the form

$$
\begin{aligned}
& q(x, z)=q_{0} \sin \frac{\pi x}{b} \sin \frac{\pi z}{a} \\
& \dot{q}(x, z)=\dot{q}_{0} \sin \frac{\pi x}{b} \sin \frac{\pi z}{a}
\end{aligned}
$$

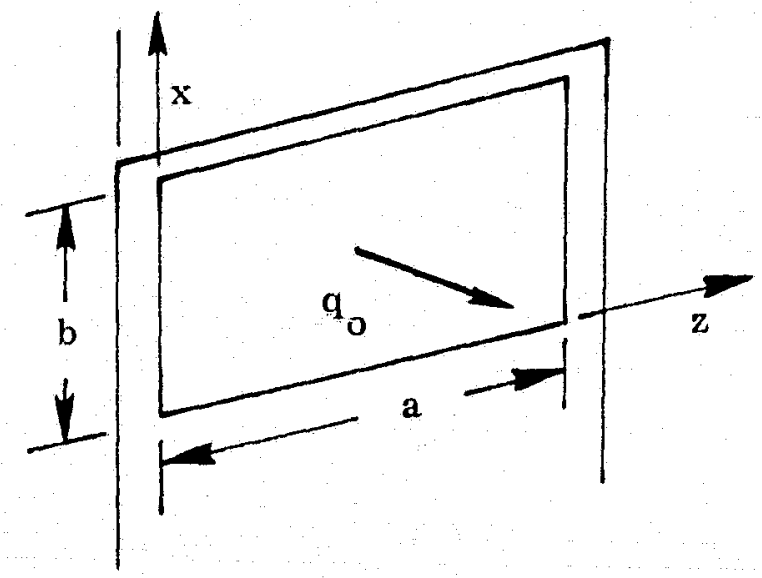

and, it follows that,

$$
A B \dot{q}_{1}=\dot{q}_{0} \iint_{\text {area }} \sin \frac{\pi x}{b} \sin \frac{\pi z}{a} d A=\frac{4 a b}{\pi^{2}} \dot{q}_{0} \cdot
$$

c. Mass Characteristics - The kinetic energy of the system as shown can be expressed in terns of the fluid mass density, $p$, the oscillatory vibration response coordinate, $q_{1}$, and the liquid outflow coordinate, $q_{2}$, as

$$
T=\frac{\rho}{2} \iiint_{V 01}\left(\dot{q}_{1}+\dot{q}_{2}\right)^{2} d V
$$

or

$$
T=\frac{\rho}{2} A B L\left(\dot{q}_{1}+\dot{q}_{2}\right)^{2}
$$

and it follows, through application of Lagrange's equation, that the effective mass, expressed in terms of the oscillatory vibration response coordinate, $q_{1}$, is

\section{ORIGLNAL PAGE IS OF POOR QUALITI}




$$
\frac{d}{d t}\left(\frac{\partial T}{\partial \dot{q}_{1}}\right)=\rho \text { ABL } \ddot{q}_{1}=M_{\text {eff }} \ddot{q}_{1}
$$

and $\quad M_{\text {eff }}=\rho A B L$.

Note that for steady flow, $\ddot{q}_{2}=0$. Alternatively, Equation (8) used in conjunction with Equation (6) yields the effective mass, expressed in terms of the screen center deflection coordinate, $\mathrm{q}_{0}$, as

$$
\begin{aligned}
& T=\frac{\rho}{2} A B L\left(\frac{4 a b}{\pi^{2} A B} \dot{q}_{0}+\dot{q}_{2}\right)^{2} \\
& \frac{d}{d t}\left(\frac{\partial T}{\partial \dot{q}_{0}}\right)=\rho A B L\left(\frac{16 a^{2} b^{2}}{\pi^{4} A^{2}{ }^{2}}\right) \ddot{q}_{0}=M_{\text {eff }} \ddot{q}_{0}
\end{aligned}
$$

and $\quad M_{\text {eff }}=\frac{16 \rho a^{2} b^{2} L}{\pi^{4} \mathrm{AB}}$.

Consideration must also be given the effective mass of the screen whose kinetic energy can be expressed in terms of the screen mass density, $P_{S}$, thickness, $t_{s}$, and screen center deflection coordinate, $q_{0}$, as

$$
\begin{aligned}
& T=\rho_{s} \frac{t_{S}}{2} \iint_{\text {area }} \dot{q}_{0}^{2} \sin ^{2} \frac{\pi x}{b} \sin ^{2} \frac{\pi z}{a} d A=\rho_{s} \frac{t_{s} a b}{8} \dot{q}_{0}^{2} \\
& \frac{d}{d t}\left(\frac{\partial T}{\partial \dot{q}_{0}}\right)=\rho_{S} \frac{t_{s} a b}{4} \quad \ddot{q}_{0}=M_{\text {eff }} \ddot{q}_{0}
\end{aligned}
$$

and $M_{\text {eff }}=\rho_{s} \frac{t_{s} a b}{4}$.

Thus, it is observed that the effective mass of the moving screen is one-quarter of its actual mass and the ratio of effective screen mass to effective fluid mass is 


$$
\frac{\left(M_{e f f}\right)_{\text {screen }}}{\left(M_{\text {eff }}\right)_{\text {Iiquid }}}=\frac{\pi^{4} \mathrm{~A}^{2} \mathrm{~B}^{2} \mathrm{M}_{\text {screen }}}{64 \mathrm{a}^{2} \mathrm{~b}^{2} M_{1 \text { iquid }}} \ll 1
$$

where $M_{\text {Screen }}$ and $M_{1 i q u i d}$ are the total mass of screen and 1iquid, respectively. Equation (17) indicates that the effective screen moss can be neglected with little error.

d. Forcing Function Determination - Equations of Motion.- If the fluid mass of Figure III-2 is excited with a base acceleration $\ddot{x}$, the flow acceleration applies a net force

$$
F(t)=-\curvearrowright A B h \ddot{x}
$$

and, malking use of Equations (10) and (4), yields the equation of motion,

$$
\ddot{q}_{1}+\frac{\omega_{0}}{Q} \dot{q}_{1}+\omega_{0}^{2} q_{1}=-\frac{h}{I} \ddot{x} .
$$

Determination of the applicable forcing functions for the other two directions of input excitation is not as straightforward. Reference to the sketch indicates the manner in which the pressure at the screen is determined as a function of base acceleration. For excitation in the $\mathrm{Y}-$ direction, $\Delta \mathrm{P}_{1}$, is likely to be zero when $\dot{\mathrm{Y}}>0$ and $\Delta \mathrm{P}_{2}$ is likely to be zero when $\ddot{\mathrm{Y}}<0$. An approximate representation is then

$$
F(t)=-\rho a b c \ddot{Y} / 2
$$

and, making use of Equation (10) and Equation (4) yields, the equation of motion

$$
\ddot{q}_{1}+\frac{\omega_{0}}{Q} \dot{q}_{1}+\omega_{0}^{2} q_{1}=-\frac{a b c \ddot{Y}}{2 A B I} .
$$

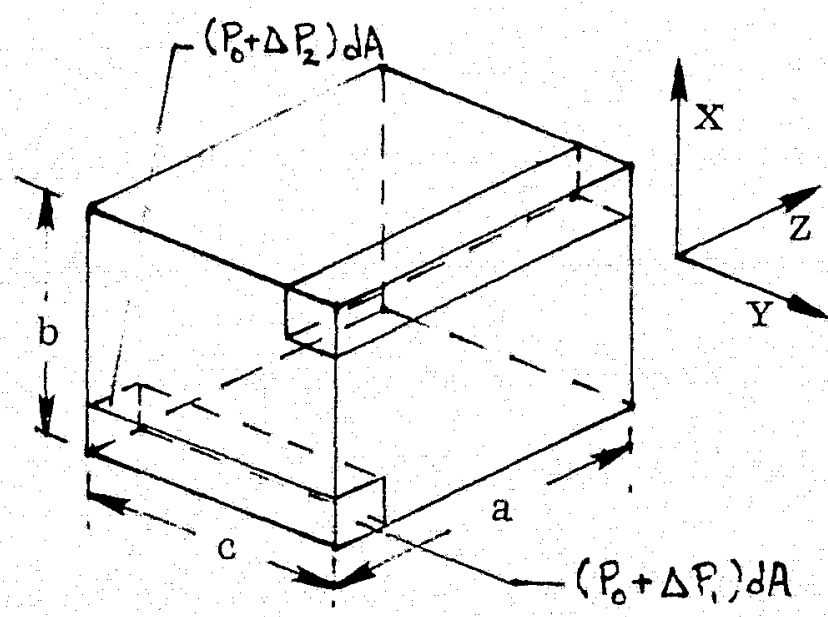


For excitation in the Z-direction, the distribution of the pressure varies linearly across the screen. Therefore, it seems approfiate to us the average value. Additionally, the excitation pressure does not go to zero when the acceleration changes sign but, rather, the reversal of the acceleration causes the same average screen differential pressure. Hence, the appropriate forcing function is

$$
F(t)=-\frac{\rho a^{2} b|\ddot{z}|}{2}
$$

and, making use of Equation (10) and Equation (4), yields the equation is motion

$$
\ddot{q}_{1}+\frac{\omega_{0}}{Q} \dot{q}_{1}+\omega_{0}^{2} q_{1}=-\frac{a^{2} b \ddot{z} \mid}{2 A B I} .
$$

Discussion to this point has evolved an fquation of motion for base excited vibration of a fluid column subjected to a restoring force arising from a single compliant screen element. The peak flow acceleration follows under the assumption of large dynamic amplification $(Q \geq 10)$ :

$$
\text { for the X-direction } \quad \ddot{q} \approx Q_{X} \frac{h}{L} \ddot{x}_{f}
$$

for the Y-direction

$$
\ddot{q} \approx \frac{Q C}{y}{a b \ddot{Y}_{F}}_{2 A L}
$$

for the $\mathrm{Z}$-direction

$$
\ddot{q} \approx \frac{Q C_{z} a^{2} b \ddot{z}_{I / 2}}{2 A B L}
$$

for sinusoidal vibration input of modulus $\ddot{x}, \ddot{z}$ and $\ddot{z}$ at the system natural frequency, $f$. The constants $C_{x}, C_{y}$ and $C_{z}$ are included in Equation (24) to account for the fact that uniform flow may not exist and that the input excitation itself may be affected by bulk liquid response. For uniform flow, $C_{x}=C_{y}=C_{z}=1$.

If random vibration input is considered, Equation (24a) becomes:

for the $\mathrm{X}$-direction

$$
\ddot{q} \approx \frac{x^{h}}{L}\left\{\frac{\pi}{2} Q \perp \operatorname{PSD}_{\mathrm{f}}\right\}^{\frac{1}{2}}
$$

for the $\mathrm{X}$-direction

$$
\ddot{q} \approx \frac{C_{y} a b}{2 A I}\left\{\frac{\pi}{2} Q \notin \operatorname{PSD}_{f}\right\}^{\frac{1}{2}}
$$

For the z-direction

$$
\ddot{q} \approx \frac{\mathrm{C}^{\mathrm{a}^{2}} \mathrm{~b}}{2 \mathrm{ABI}}\left\{\frac{\pi}{2} \mathrm{Q} \pm \mathrm{PSD}_{\mathrm{F} / 2}\right\}^{\frac{1}{2}}
$$


where $f$ is the natural frequency and ${ } D_{f}$ defines the acceleration spectral density at frequency, $f$.

e. Pressure Estimation - In a hydrostatic sense, the pressure at the screen element can be expressed as the sum of the static and dynamic contributions as

$$
\begin{aligned}
& \Delta \mathrm{P}_{\mathrm{s}}=\rho g h \\
& \Delta \mathrm{P}_{\mathrm{v}}=\rho g \mathrm{q}_{\mathrm{q}} \\
& \Delta \mathrm{P}_{\mathrm{t}}=\Delta \mathrm{P}_{\mathrm{s}}+\Delta \mathrm{P}_{\mathrm{v}}
\end{aligned}
$$

and it follows, for the three excitation directions, that:

for the X-direction

$$
\left(\Delta P_{t} / \rho g\right) / h_{s}=1+Q C_{x} \frac{h_{s}}{L} \ddot{X}_{f}
$$

for the Y-dirention

$$
\left(\Delta \mathrm{R}_{t} / \rho \mathrm{g}\right) / \mathrm{h}_{\mathrm{s}}=1+\frac{\mathrm{QC} \mathrm{y} \text { ab } \ddot{\mathrm{Y}}_{\mathrm{f}}}{2 \mathrm{AL}}
$$

for the Z-direction

$$
\left(\Delta \mathrm{P}_{t} / \rho \mathrm{g}\right) / \mathrm{h}_{s}=1+\frac{Q C_{z} \mathrm{a}^{2} \mathrm{~b} \ddot{z}_{\mathrm{f} / 2}}{2 \mathrm{ABL}}
$$

for sinusoidal input vibration, and

for the X-direction

$$
\left(\Delta \mathrm{P}_{t} / f g\right) / h_{s}=1+\frac{C_{x} h}{L}\left\{\frac{\pi}{2} \text { Qf } \operatorname{PSD}_{f}\right\} \frac{1}{2}
$$

for the Y-direction

$$
\left(\Delta \mathrm{P}_{t} / \rho g\right) / 1_{s}=1+\frac{C_{y} a b}{2 A L}\left\{\frac{\pi}{2} \text { Qf } \operatorname{PSD}_{f}\right\}
$$

for the Z-direction

$$
\left(\Delta \mathrm{P}_{t} / \rho g\right) / h_{s}=1+\frac{C_{z} a^{2} b}{2 A B L}\left\{\frac{\pi}{2} \text { Qf } P S D_{f / 2}\right\}^{\frac{1}{2}}
$$

for random input vibration where it has been assumed that $h=h_{S}$, the true static head.

The extension of the above developed elemental model to what certainly must be required for complex screen/liquid configurations is not at all straightforward. In fact, its possible extension is predicted solely upon a building-block approach using test data from increasingly more complex systems.

\section{ORIGINAL PAGE IS \\ OF POOR QUALIRY}


2. Bubble Growth Mode1 - The bubble growth nudal determines the time dependent response of $A$ screen to pressure transients. Screen breakdown is actually the growth and detachment of a bubble from a screen pore. The model analyzes the growth of a gas bubble at the pore of a screen to determine its response to time varying pressure differentials. The nodel was developed under a prior study and was applied to evaluating the response of a screen to flow transients (Ref. IIT-2). During this program the model was refined and applied to the specific problem of the periodic pressure oscillations produced by vibration.

There has been some evidence (RPE. III-1 and III-2) that pressure transients exceeding the retention capability of screen can be applied to a screen without causing breakdown. The screen tends to act as an accumulator, reducing the effect of short duration pressure transients. The purpose of the bubble growth model was to analyze this effect, so that the screen response to transients could be predicted.

Preliminary analyses performed under this program (refer to Appendix A) indicated that a screen would not respond to the peak pressure of a sinusoidally oscillating pressure, as could be produced by vibration. The screen would actually be responding as if the periodic pressure was a steady pressure 80 to $90 \%$ of the peak value, even at low frequencies ( $<50 \mathrm{~Hz}$ ). The test data that was acquired during this program have shown that this is not the case (see Chapter V). The screen responds to the peak value of the pressure. Therefore, the predicted pressures of the structural dynamics model can be used directly and the time dependent effects considered by the bubble growth model are not significant.

The key factor influencing the preliminary predictions was the orifice coefficient for a screen pore. The derived values for this coefficient (see Appendix A) must be much larger (indicating more flow resistance) thar is actually the case. Since it was concluded that the model was not applicable to the screen vibration problem, there was no effort to improve the coefficient values. The refinements added to the model during this progran are presented in Appendix A. 
An experimental investigation was performed to determine the effects of vibration on the retention capability of fine-mesh screens. The experimental program was composed to achieve this objective in two ways. First, the tests provided the data needed to verify the analytical models presented in Chapter III. Those models provide a means of predicting the effects of vibration. In addition, the tests were structured so that direct comparisons between various tests could be made, considering only one variable at a time. Through these direct comparisons the effects of vibration could also be established.

In this chapter the experimental investigation is described, including the approach, the test apparatus and the test matrix.

\section{A. Approach}

Vibration was applied to screen specimens and the conditions under which screen breakdown occurred were established. In an actual spacecraft, the vibration is transmitted from the source to the tank wall and then to the surface tension device mounted within the tank. In this study it was assumed that the vibration transmitted to the surface tension device structure was known. Our primary concern was the transmission of the vibration from the screen support structure to the screen and the resulting screen response.

Therefore, the test model consisted of a screen specimen, with its actual support structure, rigidly mounted within a container, The vibration was applied to the container.

A flat rectangular screer specimen was selected since its response is readily, analyzed and the results can be applied to any other screen configuration. The flat configuration for screen is found in most of the present and future surface tension devices, based on the survey presented in Chapter II. The screen is attached to the basic structure of the device and its span can be either unsupported, cr supported in some manner by ribs or perforated plate.

The basic purpose of the screen of a surface tension device is to exclude gas from a controlled liquid region. Liquid can then be expelled gas-free from the controlled region. A portion of a surface tension device was simulated for the tests by forming a controlled region with the screen specimen and the container. This region could be between a single screen and the container wall or between two parallel screens. When the retention capability of the screen was exceeded (screen breakdown), gas entered the controlled liquid region.

Having defined the basic configuration of the test mode1, there are a number of parameters that can influence the response of the screen to an applied vibration. The parameters considered are discussed in the following paragraphs. 


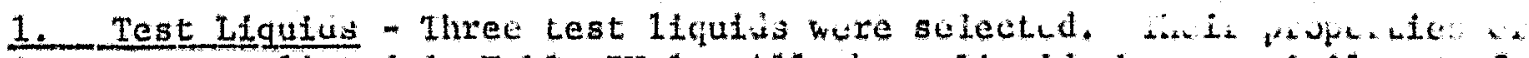
interest are listed in Table IV-1. All three liquids have a similar surface tension, but the density of the Freons is about twice that of the alcohol. This permitted a comparison of the influence of the liquid mass as it affected liquid pressure and the structural characterticics of the system. The alcohol has a high viscosity relative to that of the Freons, so viscous effects could also be compared.

The vapor pressures of the three liquids at ambient temperature cover a wis range. At atmospherice pressure $\left(\sim .8 \mathrm{~N} / \mathrm{cm}^{2}(12 \mathrm{psia})\right.$ in Denver) and a temperature of $20^{\circ} \mathrm{C}\left(68^{\circ} \mathrm{F}\right)$ the $i$ :opropy 1 alcohol is subcooled by $61^{\circ} \mathrm{C}$ $\left(110^{\circ} \mathrm{F}\right)$, the Freon 113 is subcnoler by $22^{\circ} \mathrm{C}\left(39^{\circ} \mathrm{F}\right)$ and the Freon 11 is at its boiling point. Test conditions with a small amount of subcooling were produced by controlling the system pressure. For comparison, large amounts of subcooling were obtained with the Freon 113 and isopropyl alcohol.

Another consideration in the selection of the liquids was their compatibility and hazardous hand1ing characteristics. A plastic window in the model was required so that screen breakdown could be observed. These liquids have sufficient compatibility with plastic for test purposes. The only hazard presented was the flammabjlity of the alcohol. The vapors are not toxic.

2. Screen Mesh - Eight screen moshes were selected, The parameters for these screens are listed in Table IV-2. The screens cover the full range of fine-mesh screen that would be applied to surface tension devices. The 32: $\because 2300$ Dutch twill is a practical limit for the smallest pore size. Screens that are coarser than $200 \times 200$ square weave have ilttle retention capabllity. Between these two extremes was an assortment of representative meshes. The $325 \times 2300,165 \times 800$ Dutch twill and the $50 \times 250$ are used in the Space Shuttle Reaction Control System propellant acquisition device and the $165 \times 800$ plain Dutch is used in the Space Shuttle Orbital Maneuvering system device. All of the typical weaves were represented in the selection.

The bubble point of the screens is presented in four different ways in Table IV-2. First, the water colunn height corresponding to the differential pressure necessary to produce breakdown of the screen when it is wet with isopropyl alcohol is listid (the standard bubble point test:). For the selected screens, there is a progression of the bubble point values from the coarsest to the finest, filling the entire range.

The last three columns of Table IV $\times 2$ list the height of the test liquids that could be supported in one-g $b$ a vertically oriented screen. When the test liquid level is lowcred on one side of the screen lo the listed height (see Figure IV -1 ), gas just begins to pass through the pores at the top of the screen.

The length of the model was selected based on data in Table IV-1. Hydrostatic pressure was used to "preload" the screen when it was oriented as in Figure IV-1. As the exposed screen height is increased, the hydrostatic pressure acting on the screen is increased, which brings the screen closer to the bubble print. Varying the hydrostatic pressure therefore varies the 
Table IV-1. Properties of Test Liquids at $20^{\circ} \mathrm{C}\left(68^{\circ} \mathrm{F}\right)$

\begin{tabular}{|c|c|c|c|c|}
\hline Liquid & $\begin{array}{l}\text { Surface } \\
\text { Tension } \\
\text { dynes/cm } \\
(1 \mathrm{bf} / \mathrm{ft})\end{array}$ & $\begin{array}{l}\text { Density } \\
\mathrm{gm} / \mathrm{Am}^{3} \\
\left(1 \mathrm{bm} / \mathrm{ft}^{3}\right)\end{array}$ & $\begin{array}{l}\text { Viscosity } \\
\text { Centipoise } \\
\text { (1bo/ft sec) }\end{array}$ & $\begin{array}{l}\text { Vapor Pressure } \\
\text { N/cm } \\
(\mathrm{psia)}\end{array}$ \\
\hline Isopropy 1 Alcohol & $\left(1.49 \times 10^{-3}\right)$ & $\begin{array}{l}0.786 \\
(49.0)\end{array}$ & $\left(1.68 \times 10^{-3}\right)$ & $\begin{array}{c}0.42 \\
(0.61)\end{array}$ \\
\hline Freon 113 & $\left(1.32 \times 10^{-3}\right)$ & $\begin{array}{l}1.58 \\
(98.4)\end{array}$ & $\left(\begin{array}{l}0.70 \\
\left(4.7 \times 10^{-4}\right)\end{array}\right.$ & $\begin{array}{c}3.7 \\
(5.3)\end{array}$ \\
\hline Freon 11 & $\left(1.30 \times 10^{-3}\right)$ & $\begin{array}{l}1.49 \\
(92.9)\end{array}$ & $\left(3.0 \times 10^{-4}\right)$ & $\begin{array}{l}8.8 \\
(12.8)\end{array}$ \\
\hline
\end{tabular}

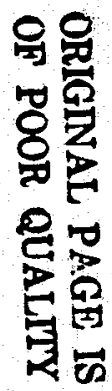


Table IV-2. Screen Mesh

\begin{tabular}{|c|c|c|c|c|c|c|c|}
\hline & & & & & Bubble Point at & $20^{\circ} \mathrm{C} \quad\left(68^{\circ} \mathrm{F}\right)$ & \\
\hline \multirow{2}{*}{$\begin{array}{l}\text { Screen Mesh } \\
\text { (wires per inch) }\end{array}$} & \multirow[b]{2}{*}{ Weave } & \multicolumn{2}{|c|}{$\begin{array}{c}\text { Wire Dianteter } \\
\text { mm (in.) }\end{array}$} & \multirow{2}{*}{$\begin{array}{l}\text { cm (in.) of } \\
\text { Water with } \\
\text { Isopropanol }\end{array}$} & \multirow{2}{*}{$\begin{array}{l}\text { cm (in.) of } \\
\text { Isopropanol/w } \\
\text { Isopropanol }\end{array}$} & \multirow{2}{*}{$\begin{array}{l}\text { cm (in.) of } \\
\text { F113 with } \\
\text { F113 }\end{array}$} & \multirow{2}{*}{$\begin{array}{l}\text { cm (in.) of } \\
\text { F11 with } \\
\text { F11 }\end{array}$} \\
\hline & & Warp & Shute & & & & \\
\hline $325 \times 2300$ & Dutch twill & $(.038)$ & $\begin{array}{l}.025 \\
(.0010)\end{array}$ & $\begin{array}{c}61.0 \\
(24.0)\end{array}$ & $\begin{array}{c}77.6 \\
(30.5)\end{array}$ & $\begin{array}{l}34.3 \\
(13.5)\end{array}$ & $\begin{array}{l}35.8 \\
(14.1)\end{array}$ \\
\hline $200 \times 1400$ & Dutch twill & $\begin{array}{c}.071 \\
(.0028)\end{array}$ & $\begin{array}{l}.041 \\
(.0016)\end{array}$ & $\begin{array}{c}41.4 \\
(16.3)\end{array}$ & $\begin{array}{c}52.7 \\
(20.7)\end{array}$ & $\begin{array}{l}23.3 \\
(9.2)\end{array}$ & $\begin{array}{l}24.3 \\
(9.6)\end{array}$ \\
\hline $165 \times 800$ & Dutch twil1 & $\begin{array}{l}.071 \\
(.0028)\end{array}$ & $\begin{array}{c}.051 \\
(.0020)\end{array}$ & $\begin{array}{l}19.6 \\
(7.7)\end{array}$ & $\begin{array}{l}24.9 \\
(9.8)\end{array}$ & $\begin{array}{l}11.0 \\
(4.3)\end{array}$ & $\begin{array}{l}11.5 \\
(4.5)\end{array}$ \\
\hline $165 \times 800$ & Plain Dutch & $\begin{array}{c}.051 \\
(.0020)\end{array}$ & $(.036)$ & $\begin{array}{l}24.1 \\
(9.5)\end{array}$ & $\begin{array}{c}30.7 \\
(12.1)\end{array}$ & $\begin{array}{l}13.6 \\
(5.3)\end{array}$ & $\begin{array}{l}14.2 \\
(5.6)\end{array}$ \\
\hline $80 \times 700$ & Dutch Twill & $\begin{array}{c}.102 \\
(.0040)\end{array}$ & $\begin{array}{l}.076 \\
(.0030)\end{array}$ & $\begin{array}{l}15.5 \\
(6.1)\end{array}$ & $\begin{array}{l}19.7 \\
(7.8)\end{array}$ & $\begin{array}{l}8.7 \\
(3.4)\end{array}$ & $\begin{array}{c}9.1 \\
(3.6)\end{array}$ \\
\hline $50 \times 250$ & Plain Dutch & $\begin{array}{l}.127 \\
(.0050)\end{array}$ & $\begin{array}{l}.114 \\
(.0045)\end{array}$ & $\begin{array}{c}8.9 \\
(3.5)\end{array}$ & $\begin{array}{l}11.3 \\
(4.5)\end{array}$ & $\begin{array}{c}5.0 \\
(2.0)\end{array}$ & $\begin{array}{c}5.2 \\
(2.1)\end{array}$ \\
\hline $850 \times 155$ & Robusta & $\begin{array}{l}.030 \\
(.0012)\end{array}$ & $\begin{array}{l}.102 \\
(.0040)\end{array}$ & $\begin{array}{c}28.4 \\
(11.2)\end{array}$ & $\begin{array}{c}36.1 \\
(14.2)\end{array}$ & $\begin{array}{l}15.9 \\
(6.3)\end{array}$ & $\begin{array}{l}16.8 \\
(6.6)\end{array}$ \\
\hline $200 \times 200$ & Square & $\begin{array}{l}.053 \\
(.0021)\end{array}$ & $\begin{array}{l}.053 \\
(.0021)\end{array}$ & $\begin{array}{c}9.7 \\
(3.8)\end{array}$ & $\begin{array}{l}12.3 \\
(4.8)\end{array}$ & $\begin{array}{c}5.4 \\
(2.1)\end{array}$ & $\begin{array}{c}5.7 \\
(2.2)\end{array}$ \\
\hline
\end{tabular}




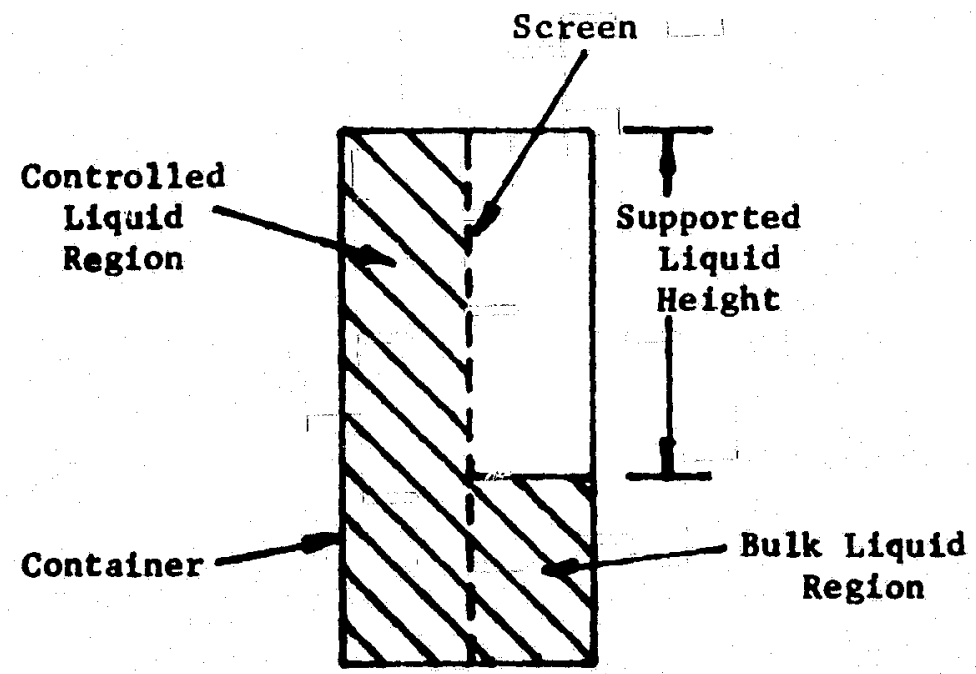

Figuze IV-1. Hydrostatic Screen Retention

susceptibility of the screen to breakdown due to a given vibration environment. In order to have low vibration level caused breakdown, the screen had to be long enough for hydrostatic pressures near the bubble point. However, a short screen length was desired from the standpoint of a simple shaker mounting that would permit good transmission of the input vibration. By using Freon 113 to "preload" the finer mesh screens, a vertical screen height of $38 \mathrm{~cm}(15 \mathrm{in})$ was adequate. By using the alcohol with the coarser screens the retention capability was Improved, allowing the effects of vibration to be better resolved.

3. Screen Mounting - Six different methods of supporting the screens were selected. The methods, shown with sketches in Figure IV-2, could give the screen total support, virtually no support or various degrees of support in between. A11 of these methods are proven techniques, based on fabricated prototype and flight surface tension devices.

In the following paragraphs, each of the support methods is described.

a. Bonded to Perforated Plate - This support method gave the most rigid screen of any of the selected methods. The screen and the backup perforated plate were diffusion bonded together, using a metallic bond that was formed in a furnace. The perforated plate had a high open area $147 \%$ open) so that the flow restriction was minimized. The only screen not supported was that over the round holes of the plate $(0.95 \mathrm{~cm}(3 / 8 \mathrm{in})$ diameter).

b. Supported by Perforated Plate - For this support method, the rectangular screen was resistance seam welded to a frame around its edges. The 

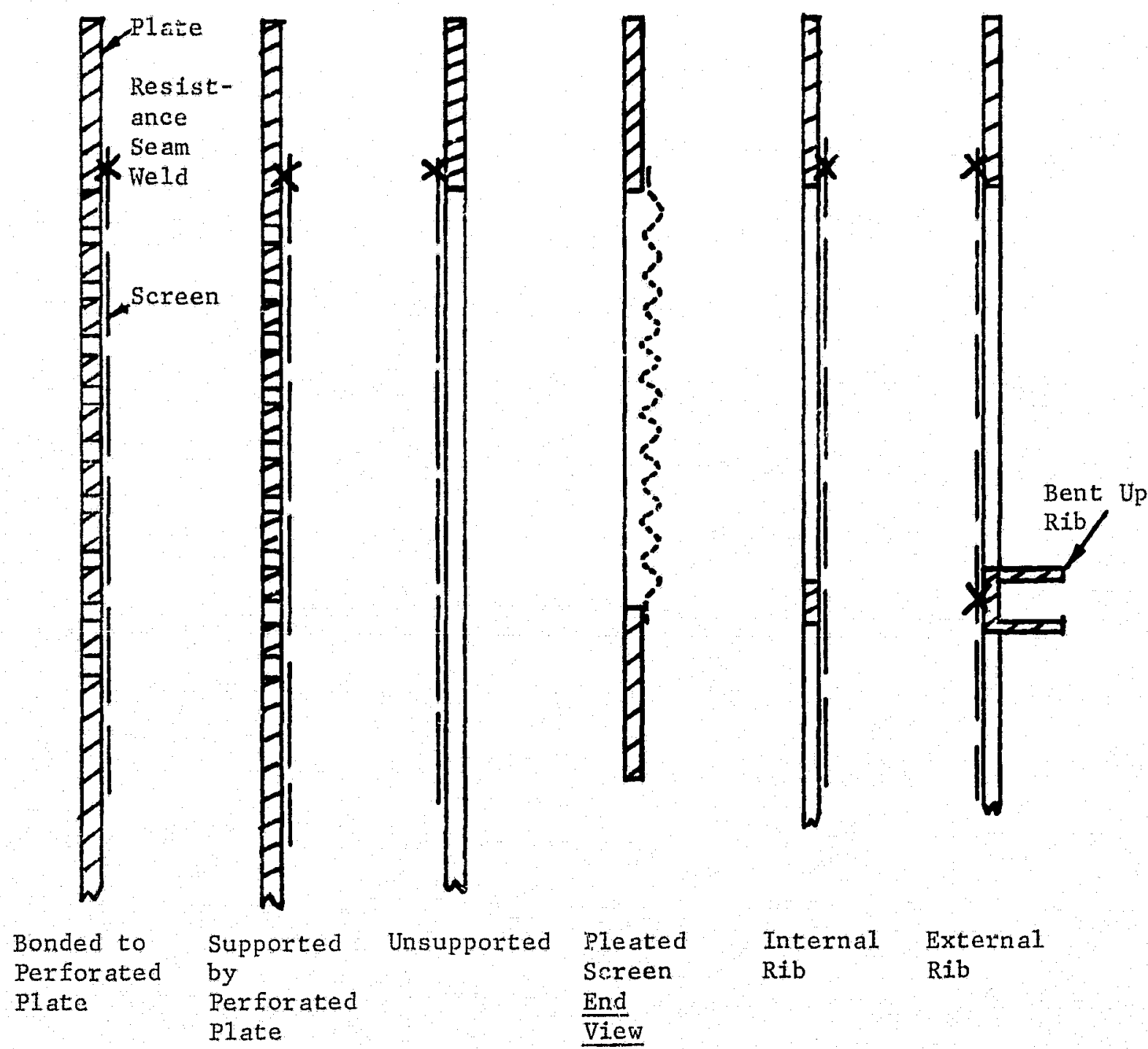

Internal Rib

Externa1 $\mathrm{Rib}$

Control Liquid Side on left Bulk Region on Right

Figlime IV-2 - Screen Mounting Configuration 
screen rested on perforated plate within the frame. Normal static pressure differentials reduce the pressure in the controlled liquid region with respect to the ullage, so the screen is forced against the perforated plate. The perforated plate offers no support if the pressure differential is reversed.

c. Unsupported - This method provides the least support of the screen. The edges of the screen were resistance welded to an open frame.

d. Pleated Screen - The screen was made somewhat self-supporting by pleating. Following the pleating, the screen was attached to an open frame.

e. Internal Rib - This method is essentially a modification to the unsupported configuration. Support ribs were added at fixed intervals on the controlled liquid side of the screen. The screen rested on the ribs, but was not joined to them. To prevent any interference with the flow path, the ribs need to be flat in cross section.

f. External Rib - These ribs were located on the bulk region side of the screen and the screen was seam welded to each rib. Since the rib was outside the flow passage, a "U" shape cross section was permissible.

Other than the $200 \times 200$ screen, the selected screens have different wire diameters and numbers of wires in the warp and shute directions. For most applications the screen is mounted so that the warp and shute wires run parallel and perpendicular to the support structure, giving two possible orientations of the screen. Since the screen structure is not uniform in every direction (orthotropic), its response could be dependent on orientation. This variable was considered in the testing.

Three special screen specimens were also tested to establish the basic response of screen to vibration. These specimens had simple square openings, rather than any of the above described support methods, to give an easily analyzed screen deflection. Each of the three specimens had a $7.6 \mathrm{~cm}$ (3.f in) square screen opening at the top (Figure IV-3). Specimen 1 had the same screen opening at the bottom, Specimen 2 had the opening at the bottom but no screen, and specimen 3 had a tube positioned half way through the plate at the bottom.

4. Configuration - The controlled liquid region could be represented by one or two screen specimens. One element represented a portion of a flow channel of which the other sides are solid and rigid. This also represented a portion of a screen barrier. Two parallel elements represented a portion of a flow channel that allows liquid to enter from either side. The opposite sides of this configuration had solid and rigid walls.

The vibration can act in any direction with respect to the screen. Steady accelerations can also act in any direction and can influence the response of the screen to vibration. Six possible orientations, in which the vibration and one-g were either parallel or perpendicular to the screen, were identified. These orientations are illustrated with respect to the model in Figure IV 4 . 


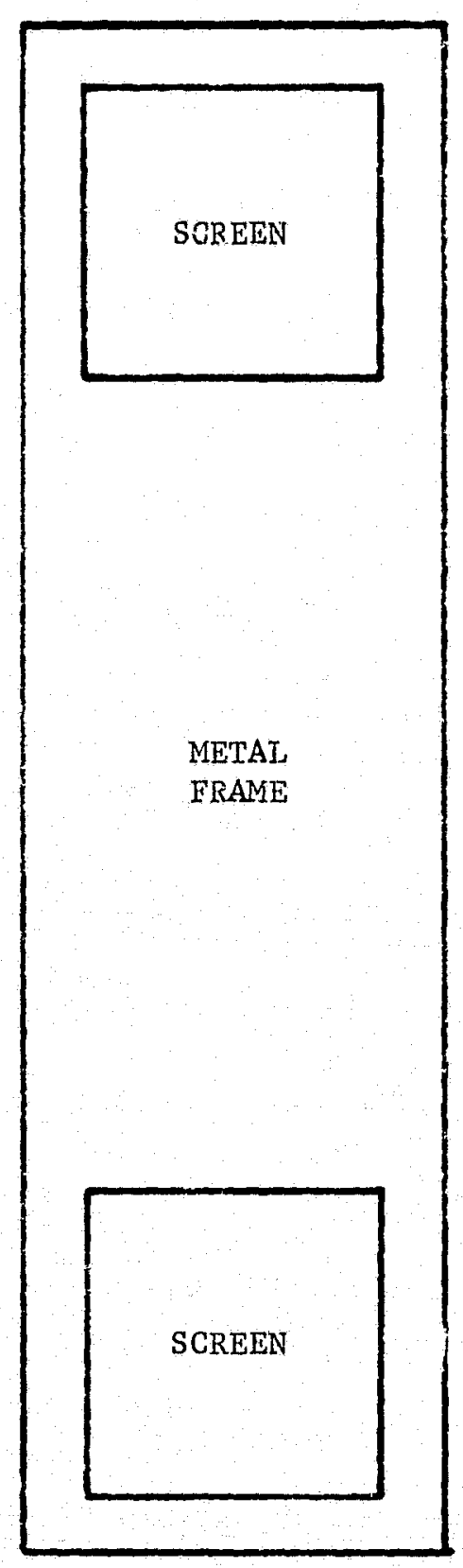

SPECIMEN 1

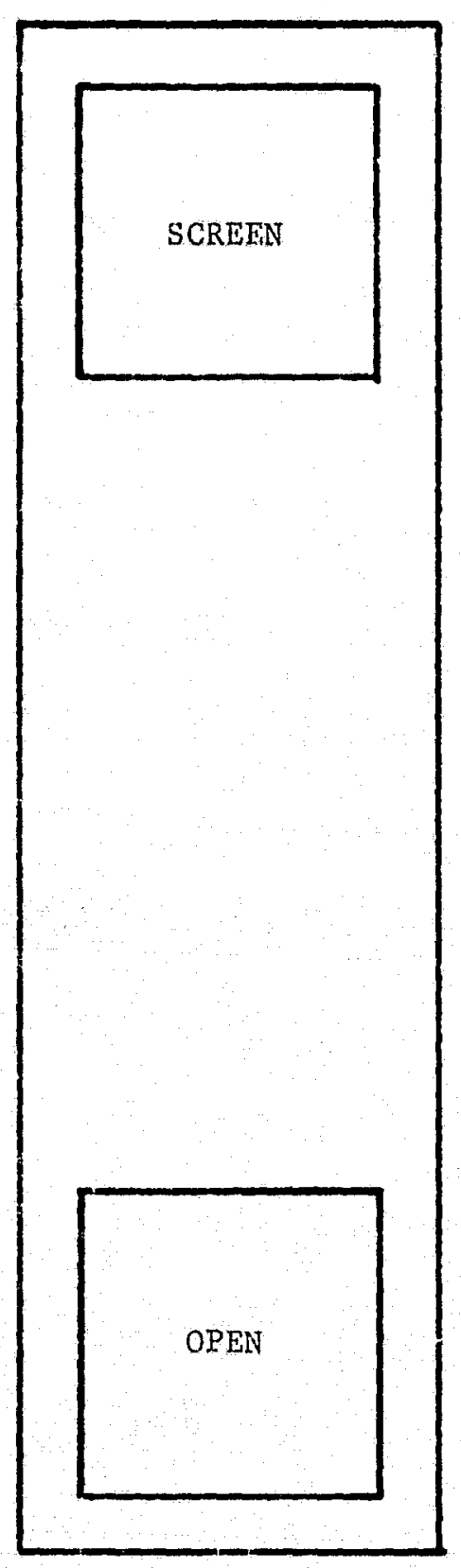

SPECIMEN 2

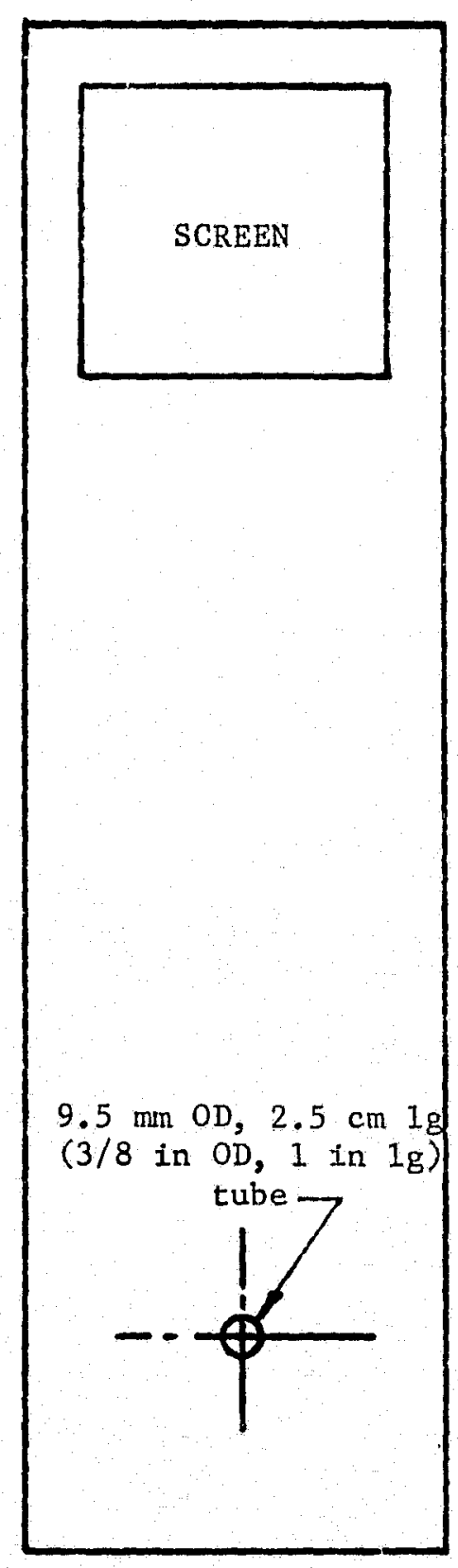

SPECIMEN 3

Figure IV-3. SPECIAL SCREEN SPECIMENS 
Figure IV-4. Model and Vibration Orientation

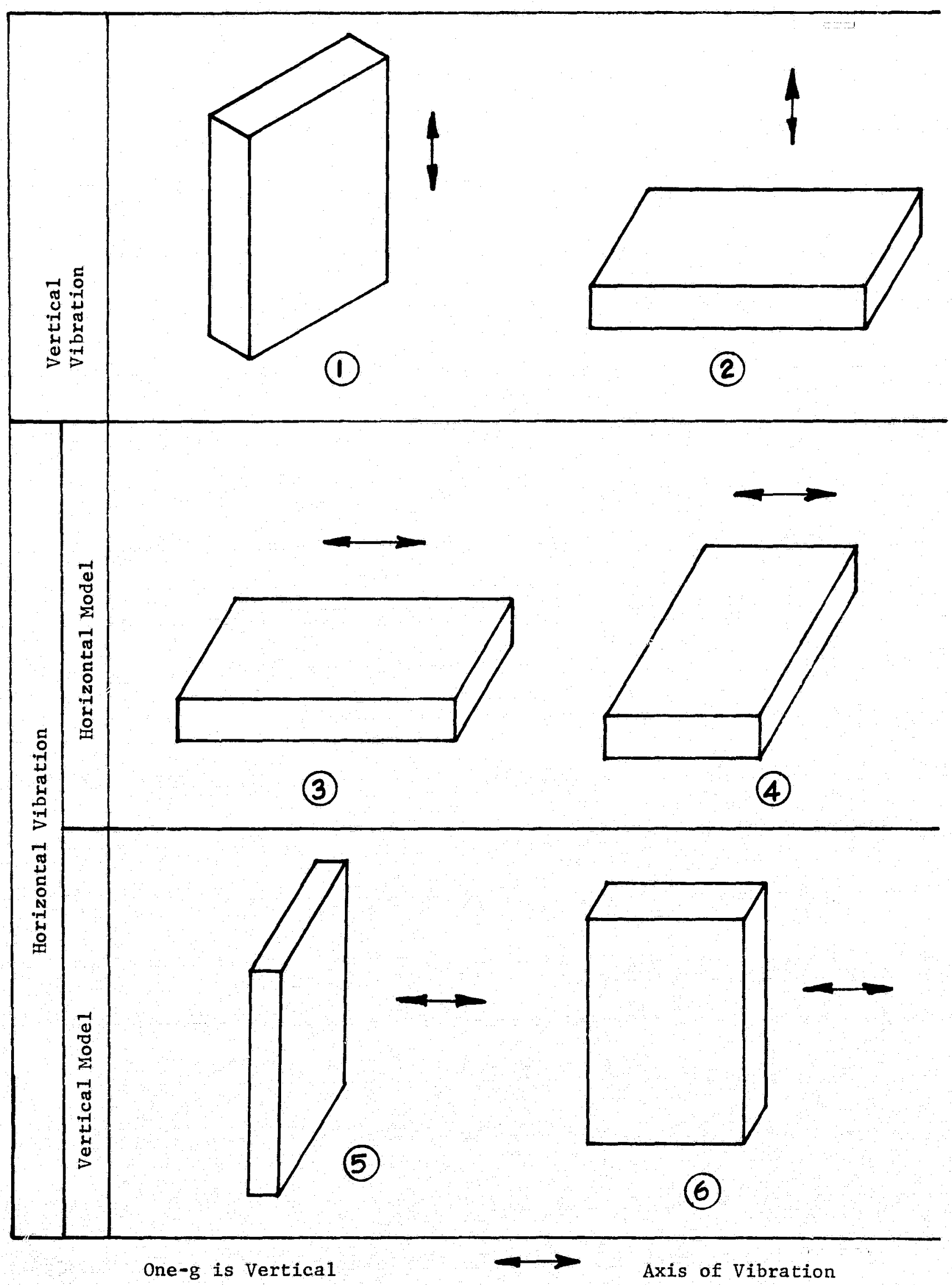


Orientations 2 and 5 were achieved by mounting the model directly to the shaker face plate (the shaker vibration axis is perpendicular to that plate). The shaker axis can be positioned either vertically (Orientation 2) or horizontally (Orientation 5). A thick inounting plate, to which the model was mounted, was bolted perpendicular to the shaker face plate to achieve Orientation 1 (Figure IV-13). For Orientation 6 the same mounting plate was used, but the shaker was posj.tioned horizontally. Orientations 3 and 4 required a slide plate. The slide plate rested on a large block and was bolted perpendicular to the horizonta1ly positioned shaker. Rotating the model 90 degrees on the slide plate changed the orientation from 3 to 4. When the model was vertical, the bulk region liquid level could be varied to change the hydrostatic pressure applied to the screen. When the model was horizontal, the controlled liquid region was above the screen and the bulk liquid was not in contact with the screen. This lack of bulk liquid contact is represertative of a barrier that positions the liquid in a tank. It can also represent a portion of a flow channel, far enough from the bulk liquid that liquid flow through the screen does not influence its response to vibration.

5. Applied Vibration - The vibration was in two forms: sinusoidal and random. Sinusoidal vibration was applied at a speci.fic frequency and peak amplitude. The usual method of performing sinusoidal tests is to sweep a range of frequencies, starting at some low value and incrementing at a fixed rate, keeping the amplitude constant. This technique can quickly identify the harmonics and the amplification of the system. Frequencies from 5 to $2000 \mathrm{~Hz}$ were covered. For any test configuration, an amplitude sufficient to cause screen breakdown was found, which ranged from 0.3 to $5.0 \mathrm{~g}$.

Random vibration was applied based on a spectrum of the power spectral density versus frequency. For a given spectrum, the RMS g-level can be defined. As the survey in Chapter II illustrated, there can be many possible spectra, but they usually ramp up from a low frequency to a constant level and then ramp down at around $1000 \mathrm{~Hz}$. A prime concern was where the system harmonies fall with respect to the power spectrum. The influence of the spectrum was evaluated by using various spectra as discussed in Chapter $\nabla$.

The shapo of the spectrum was held constant while the values of power were increased or decreased, varying the applied RMS g-level. For each configuration and spectrum, the RMS level was varied to find the point of screen breakdown. A range of 0.2 to $3.0 \mathrm{~g}$ RMS was covered.

\section{B. Test Apparatus}

The apparatus used to perform the tests is described in this section. The test system consisted of an electrodynamic shaker, the surface tension device model and the associated plumbing required to operate the model, The surface tension device model was a container jn which the screen specimen was mounted. 
1. Test Mode1 - The unassembled parts of the surface tension device model are shown in Figure IV-5. The container walls formed the controlled liquid region and the bulk region on opposite sides of the screen specimen. When sandwiched together with the back plate and the window, the model formed a sealed container. The volume between the back plate and the screen was the bulk region of the model, that contained varying amounts of liquid. The volume between the window and the screen was the controlled liquid region, that was completely full of liquid. The window permitted the passage of gas through the screen to be observed.

The wall was fabricated from aluminum stock. The volume formed by the wall was $39.4 \mathrm{~cm}(15.5 \mathrm{in})$ long, $8.9 \mathrm{~cm}(3.5 \mathrm{in})$ wide, and $2.4 \mathrm{~cm}(0.95 \mathrm{in})$ thick. Bolts passed through the window, one of the walls, the screen specimen and were screwed into the other wall to seal the container. A liquid gasket material was used to seal mating surfaces. A thin gasket was formed so the walls rigidly clamped the edges of the screen specimens. The outer, larger holes were for bolting the model to the shaker. The walls were drilled and tapped to accept all the necessary plumbing fittings. This was the configuration used when a single screen element was tested.

When two parallel screen specimens were tested, a spacer was added. The sandwich then consisted of: window - wall - screen specimen - spacer screen specimen - wall - back plate (Figure IV-6). The spacer had the same profile as the wall but was only $1.3 \mathrm{~cm}(0.5 \mathrm{in})$ thick. It was made of sheet plastic so that the controlled liquid region, which was between the screen specimens, could be observed for screen breakdown.

The screen specimens were all fabricated using a common frame that fit the model. Six versions of this frame, for each support method, were made. The frame was made of stainless steel sheet $0.69-\mathrm{mm}(0.027-\mathrm{in})$ thick. The screen opening, within the outer seam welds, for all the specimens was $7.6-\mathrm{cm}(3.0-\mathrm{in})$ wide and $38.1-\mathrm{cm}(15.0-1 \mathrm{n})$ 1ong.

A resistance seam weld was used to attach the screen to the plate. For each screen mesh a few trial welds were performed to obtain the correct welder settings. Leak-tight seam welds were produced for each of the eight screen meshes. Most of the screens were welded using a $0.13-\mathrm{mm}(0.005-\mathrm{in})$ thick foil strip that was located in top of the screen. This foil strip improves the penetration of the weld for the finer screen meshes. For the screens with larger wires $(80 \times 700,50 \times 250$ and $850 \times 155)$, no foil strip was necessary. There was some warping of the frames due to the welding. If the weld schedule had been optimized, a lower pressure could have been used and the warping could have been eliminated. The warping of the frame added some wrinkles to the screen, but when the specimen was mounted in the model the frame was flattened and these wrinkles were removed.

Front and back views of the various support methods for the screen specimens are shown in Figures $\mathrm{IV}-7$ through IV -11 . The screen is suppo:ed by the perforated plate in Figure IV-7. The bonded to perforated plate method used the same frame but the screen was diffusion welded to the plate. All perforated plate was the same: $47 \%$ open area and $0.95 \mathrm{~cm}(3 / 8 \mathrm{in})$ diameter holes. 


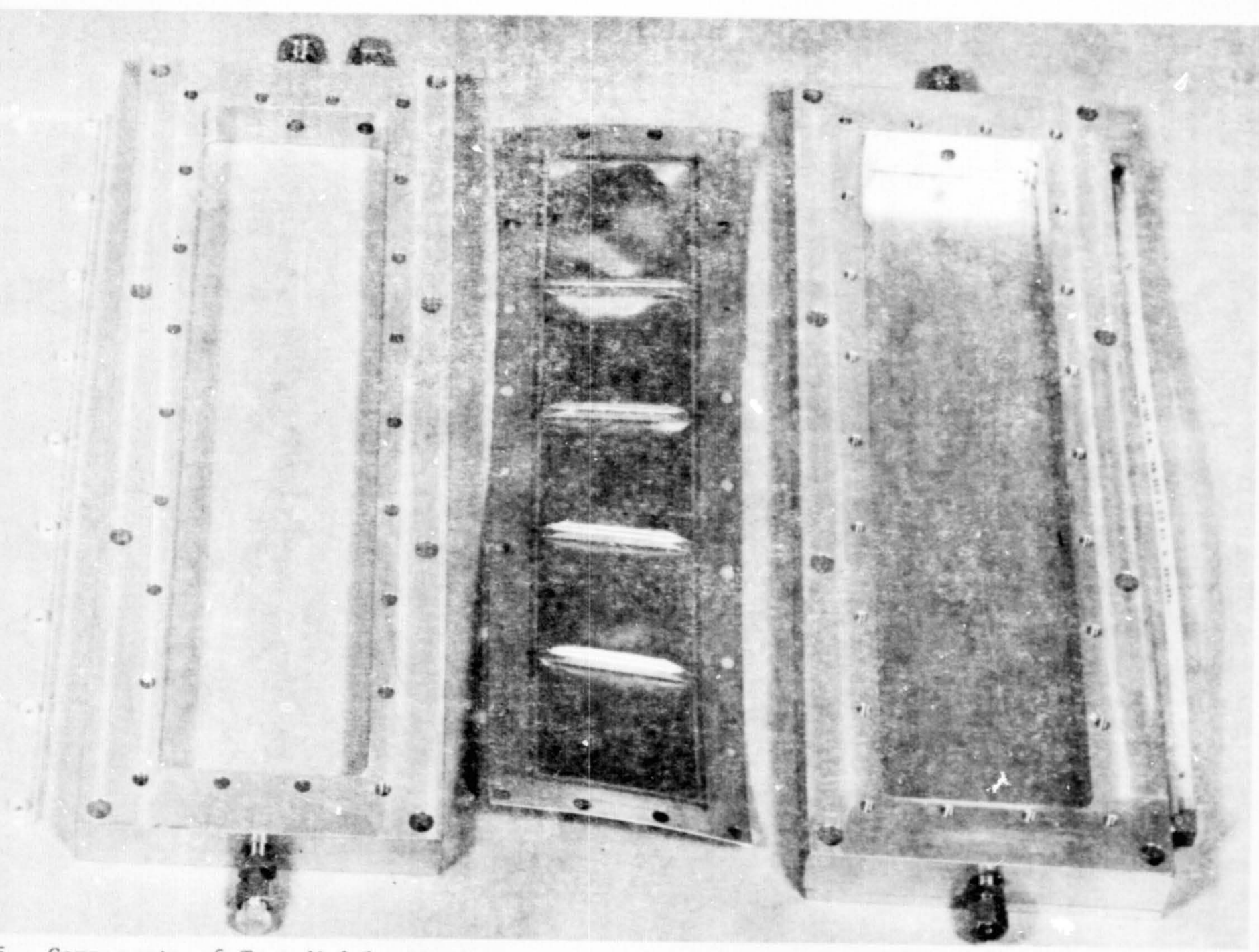

Figure IV-5. Components of Test Model, Single Element Configuration 

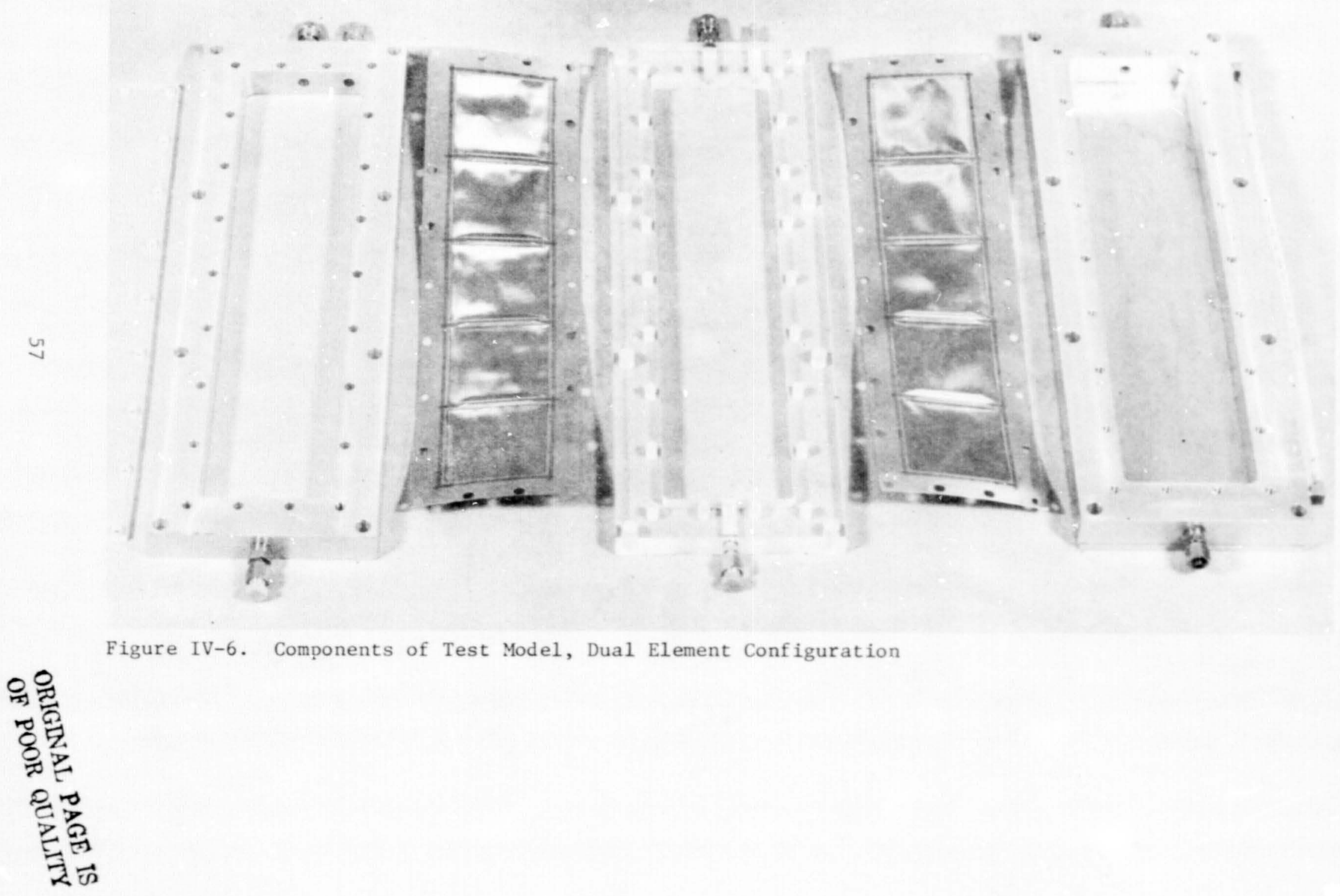

Figure IV-6. Components of Test Model, Dual Element Configuration 


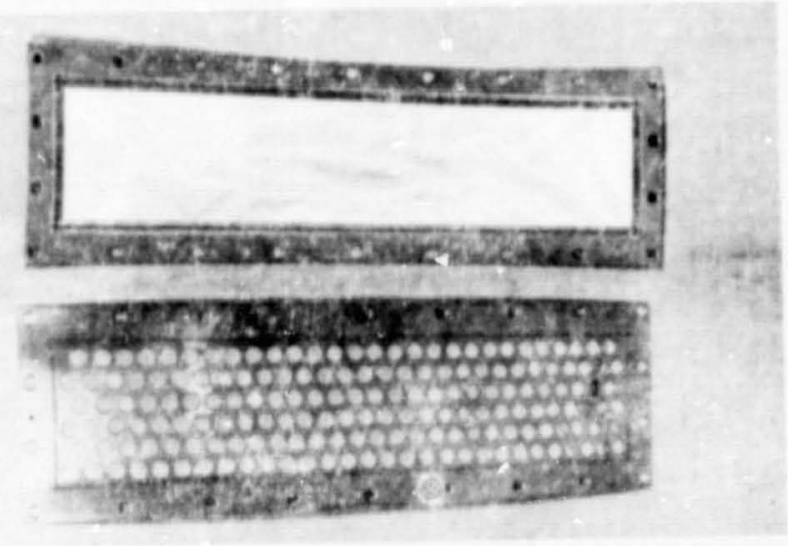

Figure IV-7. Supported by Perforated Plate

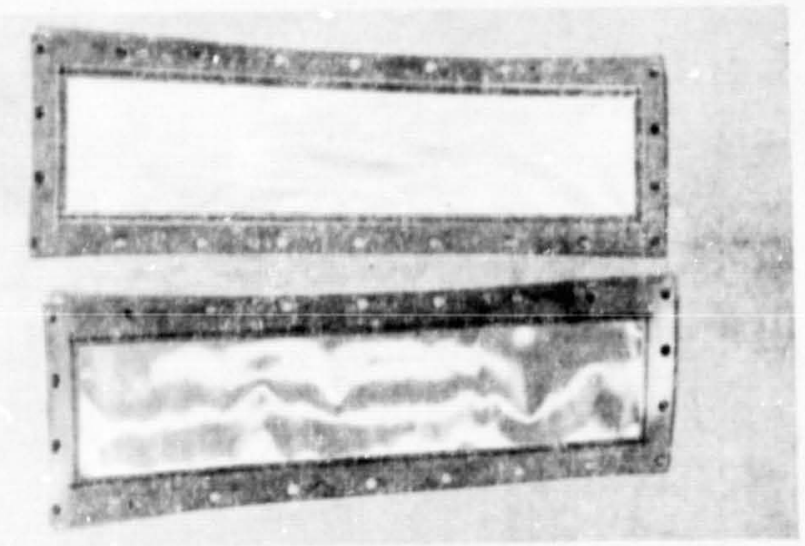

Figure IV-8. Unsupported
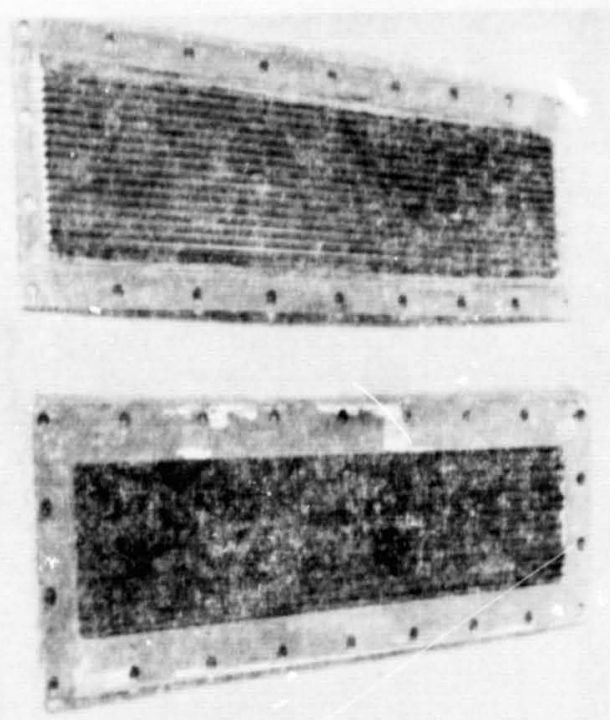

Figure IV-9. Pleated Screen 


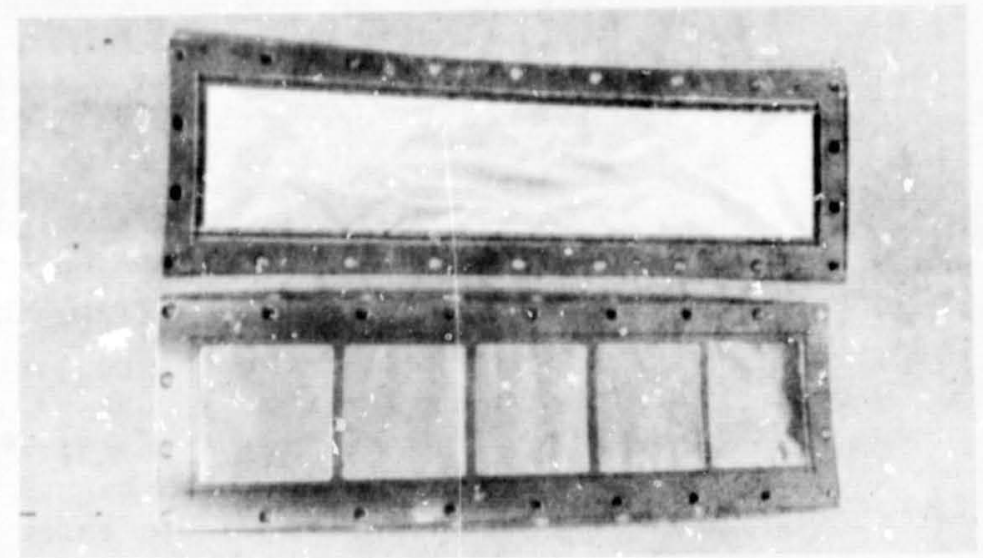

Figure IV-10. Internal Ribs

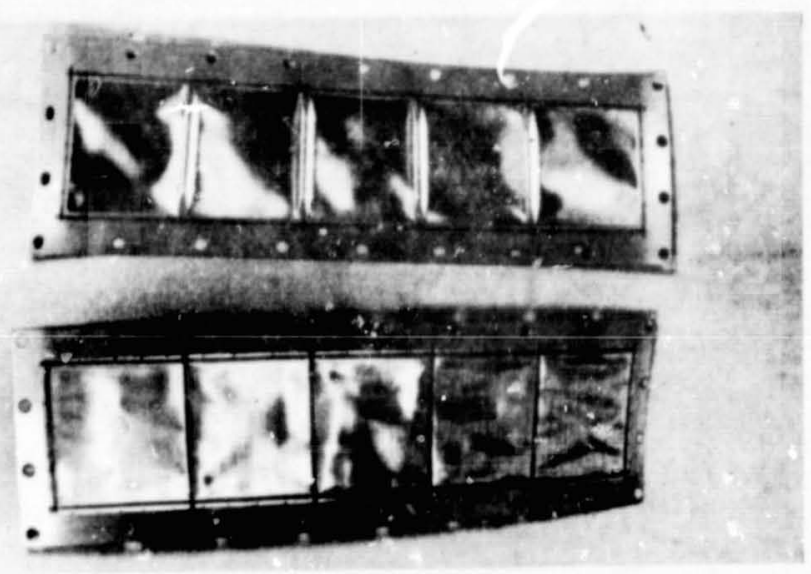

Figure IV-11. Externa1 Rib

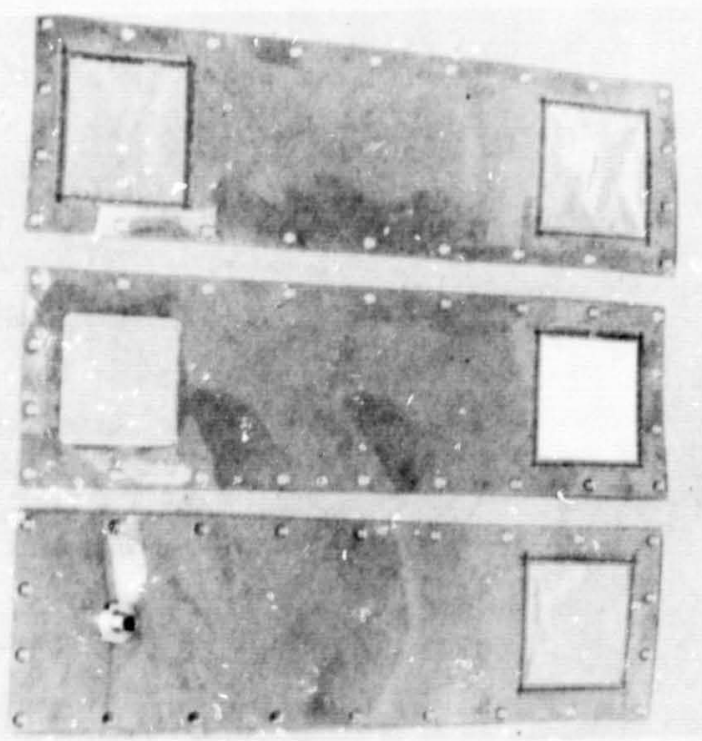

Figure IV-12. Specimens 1, 2 and 3 (from Left to Right) 
The pleated screen specimens, st.jwn in Figure IV-9, were fabricated differently. The pleats ran the longer length of the specimen. A pleat geometry of 6 pleats per inch and a pleat ratio (length of screen before pleating to length after pleating) of 2 was used. After pleating, the screen was soldered to the frame, eliminating the need to crimp the pleats to make the joint.

The three special specimens are shown in Figure IV-12.

The bubble point of each of the screen specimens was measured after they were fabricated using the standard bubble point test method. The screen was oriented horizontally and covered with a thin layer of isopropyl

alcohol. The wet screen was then pressurized from below and the differential pressure requir ${ }^{\circ}$ o cause the first gas bubbles to pass through the screen was recorded. After the testing was complete the bubble point was rechecked to determine if any screen degradation had occurred.

2. Test System - The test model was directly mounted to the shaker so that the vibration applied to the model was the same as the output of the shaker. The model was either mounted to the face plate of the shaker or to a mounting plate that was perpendicular to the face plate. With these two possible mountings and by orienting the shaker axis either vertical or horizontal, the six different orientations were achieved.

The model is shown mounted in orientation 1 , with the vibration and one-g accelezation vectors parallel to screen surface, in Figure IV-13. A closer view of the model is presented in Figure $I V=14$.

The necessary plumbing for the non-flow tests is shown in Figure IV-13. A supply tank gravity fed the bulk region of the model and gas was purged from the controlled region through the vent line. A vent port in the window allowed purging of the controlled region when the model was oriented horizontally.

Outflow was simulated by recirculating the test liquid through the model as shown in Figure IV-15.

The shaker used to perform the testfing was a Ling Electronics, Inc. Model 249. It has a force output of $133,000 \mathrm{~N}(30,000 \mathrm{lbs})$ and a frequency range of 5 to $2000 \mathrm{~Hz}$ with a sweep rate of 0.09 to 22.9 octaves/minute. The output can be either sine or random with a maximum acceleration of $75 \mathrm{~g}$ and a maximum displacement of $2.5 \mathrm{~cm}(1.0 \mathrm{in})$ peak-to-peak.

3. Instrumentation - Sczeen breakdown was tha key piece of data acquired during the testing. The passage of gas through the screen was visually detected. In addition to relating the point of breakdown to the applied vibration, the location of the breakdown on the screen and an estimate of the quantity of gas was noted.

The shaker control system provided the basic monitoring of the input frequency and amplitude of the applied vibration. The output of the accelerometer on the shaker that was used to control the shaker operation was used to determine the input vibration level. 


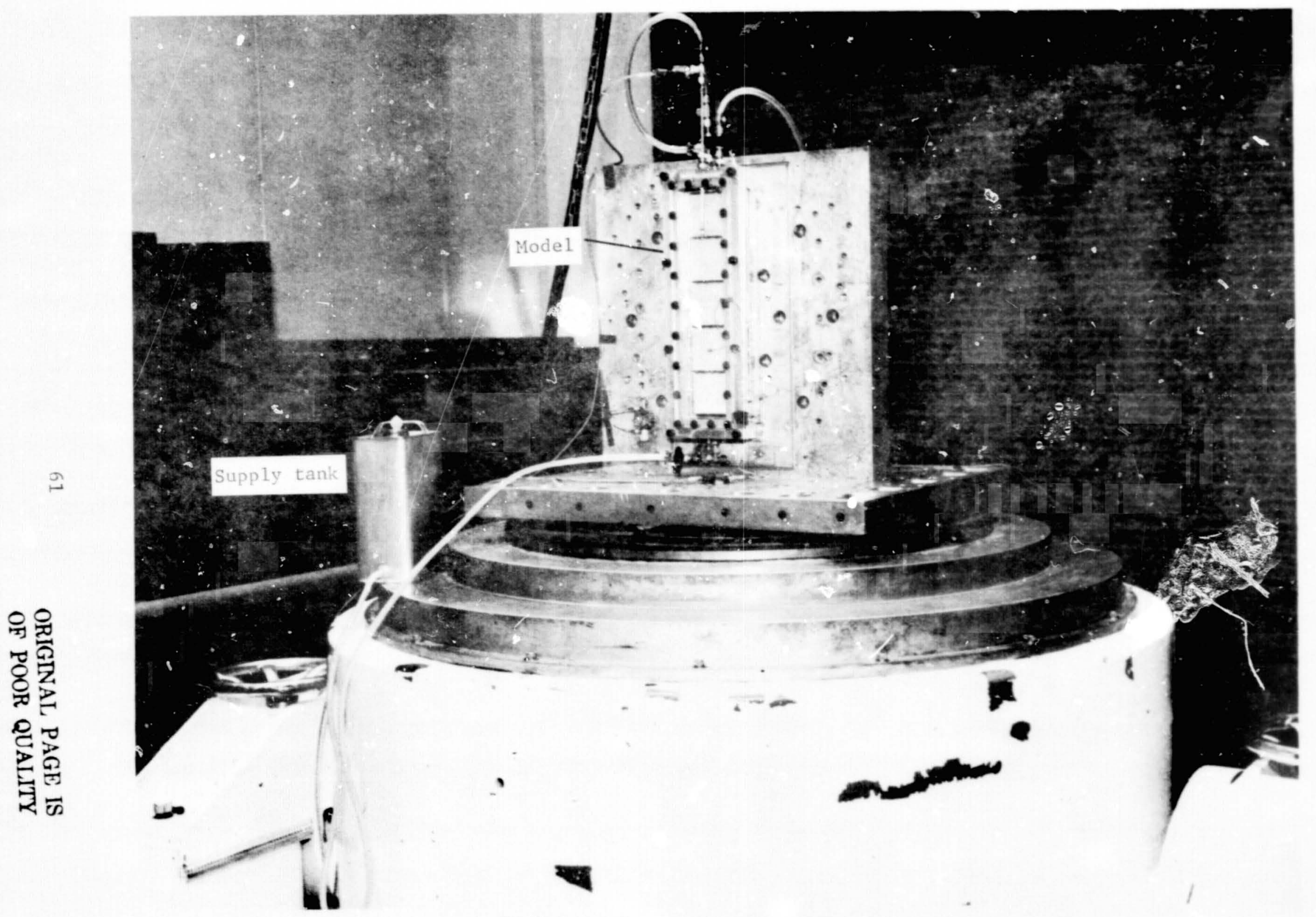

Figure IV-13. Model Mounted on Shaker 


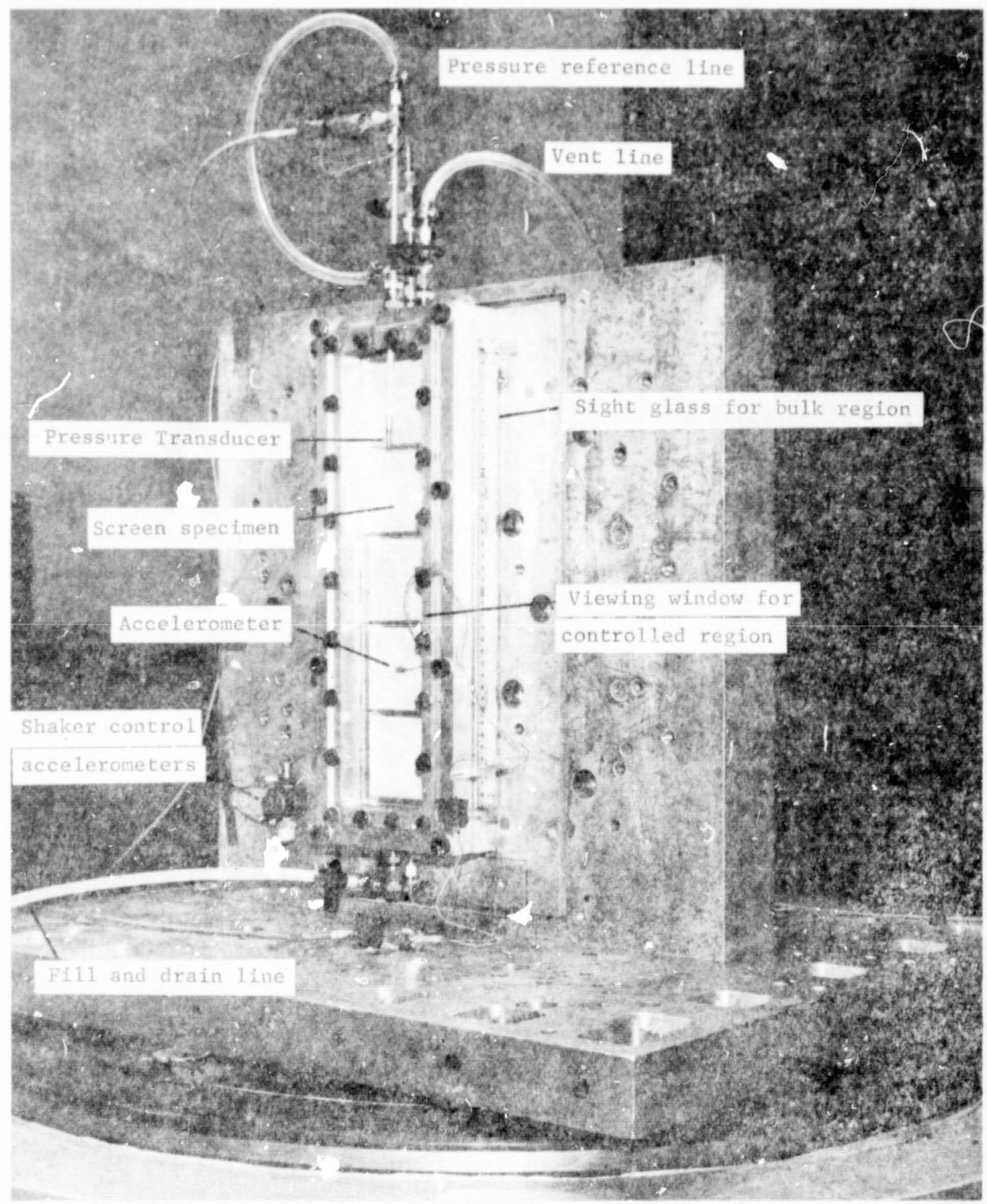

Figure IV-14. Close Up View of Model 


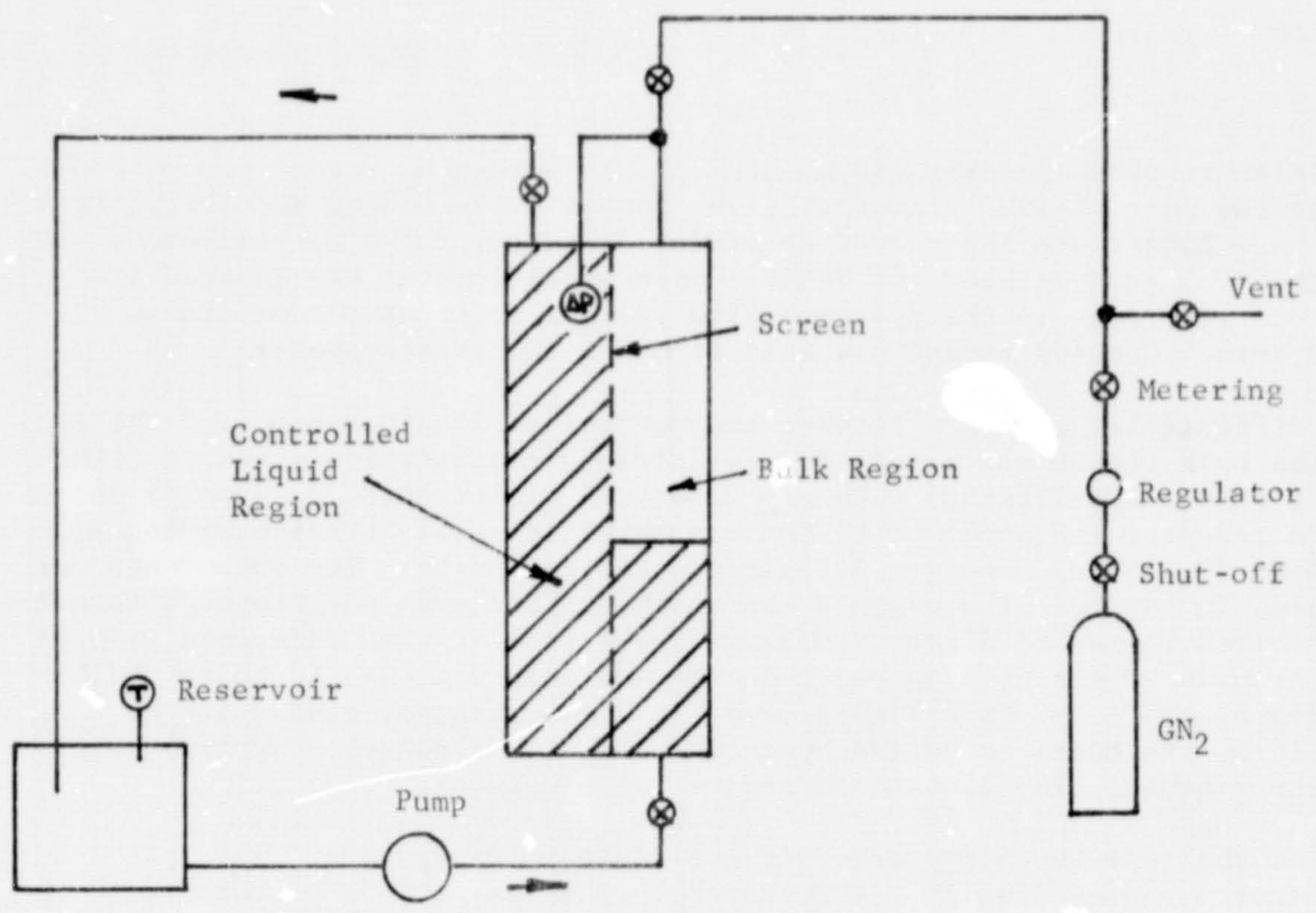

a. Single Element Configuration

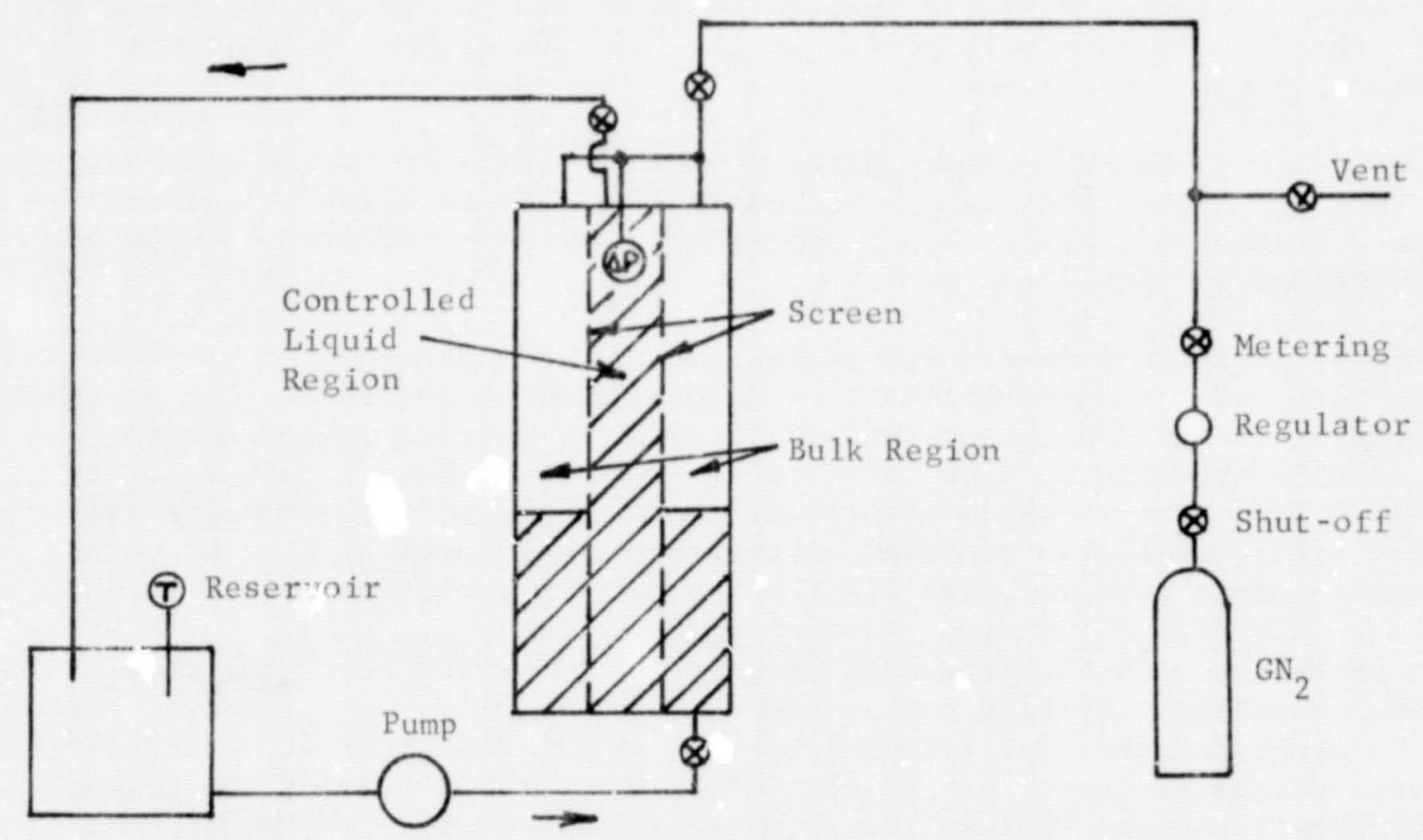

b. Dual Element Configuration

Figure IV-15. Flow Test Schematic 
A miniature accelerometer was mounted on the screen to record its response. An Entran EGA-125-250D piezoresistive, hermetically scaled accelerometer with a $\pm 250 \mathrm{~g}$ range and a $1000 \mathrm{~Hz}$ useful. frequency range was selected. It weighed $0.5 \mathrm{gram}$ without the leads. This accelerometer was mounted in various locations on the specimen with various orientations of its sensitive axis. Contact cement was used to mount the accelerometer.

The differential pressure between the controlled liquid region and the gas in the bulk region was measured. An Entran piezoresistive pressure transducer (Model EPA-125E-5D) with a $\pm 3.5-\mathrm{N} / \mathrm{cm}^{2}$ differential ( \pm 5 psid) range and a resonant frequency of $60 \mathrm{kHz}$ was selected. This transducer has a $3.18-\operatorname{mm}(0.125-i n)$ diameter stainless steel diaphragm. The transducer was mounted in the end of a tube so the diaphragm could be positioned within the controlled region to directly measure the pressure. The reference side of the transducer was open to the tube and the tube was coupled to the bulk region of the model (see Figure IV-14). Tests were performed with no liquid in the model to verify that the pressure transducer was insensitive to the vibration levels used during the testing.

A11 of the tests were performed at the ambient temperature. The test Iiquid was stored and used at that temperature. The temp srature of the liquid in the reservoir was monitored, When required for flow tests or the subcooled liquid tests, the model was pressurized with gaseous nitrogen. A dialtype pressure gage monitored the model pressure.

A sight glass was used to measure the liquid level in the bulk region of the mode1. This was a simple tube, mounted on the outside of the container wall, that entered the bulk region at the top and bottom. A scale was mounted alongside the tube.

For the flow tests, a constant flow rate, as established by the pump output and the flow system resistance, was used. The flow rate was calculated by using a graduated cylinder and a stopwatch. The time required to flow a given volume of liquid was measured.

The ontputs of the pressure transducer and the specimen-mounted accelerometer were fed through amplifiers to an oscillograph recorder. The pressure transducer was AC-coupled so that the static pressure component due to hydrostatic pressure or flow losses was eliminated. When a tape recorder was also used, the shaker monitor accelerometer output and an analog frequency signal were also recorded. Vibration power spectral density versus frequency plots were made for all the random vibration tests.

Some of the usual data processing methods for vibration test data were tried. For sine vibration tests, pressure amplitude versus frequency plots can be generated and, for random vibration tests, the pressure spectral. density versus frequency can be plotted. This data processing was found to be unsatisfactory because the pressure is processed as an RMS signal. The key component of the pressure, the positive peak value, was lost in the processing. The best data were the oscillograph records since they showed the actual pressure waveform. 
Motion pictures of selected tests were made. the breakdown of the screen during the test.

A high-speed camera recorded

c. Test Progrem

In this section the screen specimens and the tests that were performed are presented. The general test procedures are outlined.

1. Test Matrix - A preliminary test matrix was formulated when the tests were planned. This matrix was laid out by selecting the more significant test conditions from the multitude of possibilities indicated in the Approach, discussed previously. As the testing proceeded, the matrix was expanded and modified based on the results of the tests.

One of the first steps in defining the test matrix was to identify the screen specimens. A total of 27 specimens were fabricated and tested. Four specimens were added during the testing to further explore certain vibration effects. The specimens tested are listed in Table IV-3. Specimens of each of the support methods using a single screen mesh $(325 \times 2300)$ and specimens of various meshes using a single support method (external rib) were required so that these effects of mesh and support could be compared. The $325 \times 2300$ was selected because it gave the best resolution of the vibration effects due to its high bubble point. The external rib structure was selected because it was judged to provide the most basic response of the support methods.

The special specimens ( 1,2 and 3 ) were made using the $325 \times 2300$ screen, aga in to improve resolution. Two specimen pairs (Specimens 4 and 5 , and Specimens 24 and 25 ) had opposite weave orientations to evaluate that effect. The remainder of the specimens were selected to aid in further investigating the effects of screen mesh and support method.

Table IV-4 is the matrix of the test program, as performed. Each test consisted of a number of individual runs. Sine sweeps over a frequency range with various acceleration amplitudes and ullage heights were performed as part of each test. Sine dwell runs and random vibration runs were also incluad in many of the tests. A total of 551 vibration runs were performed.

The tests were laid out such that new variables were introduced one at a time. The intention was to perform tests that were identical, except for a single variable, so the effect could be established by a direct comparison of the data.

Tests 1 through 6 were aimed at establishing the basic vibration characteristics, so these tests incorporate a large number of runs ( $\sim 120$ runs). Tests 7 through 13 investigated the effects of weave orientation and model orientation. Tests 14 through 21 considered the influence of the various support methods. Tests 22 through 51 brought the effects of screen mesh and liquid outflow into the investigation. Tro element models were tested for tests 52 through 57. Finally, the effect of liquid subcooling was investigated in tests 58 through 65 . 


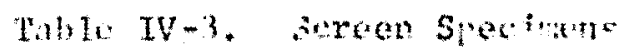

\begin{tabular}{|c|c|c|c|c|c|c|}
\hline & $\begin{array}{l}\text { A } \\
\text { Bonded to } \\
\text { Perf. plate }\end{array}$ & \begin{tabular}{|l} 
B \\
Supported by \\
Perf. Plate
\end{tabular} & $\begin{array}{l}\text { Un- } \quad \text { - } \\
\text { supported }\end{array}$ & $\begin{array}{c}\text { D } \\
\text { Pleated }\end{array}$ & $\begin{array}{l}\quad \mathrm{E} \\
\text { Internal } \\
\text { Rib }\end{array}$ & $\begin{array}{l}\quad \mathrm{F} \\
\text { Externa1 } \\
\text { Rib }\end{array}$ \\
\hline $3 x \div 2300$ & 6 & 7 & $1,2,3,4,5 *$ & 8 & 9 & 10,27 \\
\hline $000 \times 1400$ & & & 20 & & & 11 \\
\hline $165 \times 800$ Dutcin & 18 & & 21 & & & 12 \\
\hline $105 \times 800$ Whain & & $19 \%$ & $22 x$ & & $23 *$ & $13 *$ \\
\hline $80 \times 700$ & & & & 26 & & 14 \\
\hline $50 \times 250$ & & & & & & 15 \\
\hline $850 \times 155$ & & & $24 *, 25$ & & & 16 \\
\hline $200 \times 200$ & & & & & & 17 \\
\hline
\end{tabular}

a: Screen weave orientated with the warp in the long direction for those specimans with $*$, all others bave the weave nriented with the warp in the short direction. 
Table IV-4. Test Yatrix

\begin{tabular}{|c|c|c|c|c|c|c|c|c|c|c|c|}
\hline \multirow{2}{*}{$\begin{array}{l}\text { Tast } \\
\therefore \text { :0. }\end{array}$} & \multirow{2}{*}{$\begin{array}{l}\text { Screen } \\
\text { Specimen }\end{array}$} & \multirow{2}{*}{$\begin{array}{l}\text { Number } \\
\text { of } \\
\text { Elements }\end{array}$} & \multicolumn{3}{|c|}{ Test Liquid } & \multirow[b]{2}{*}{$\begin{array}{l}\text { Out- } \\
\text { F1ow }\end{array}$} & \multicolumn{5}{|c|}{ Orientation } \\
\hline & & & $\begin{array}{l}\text { Lsopropy } \\
\text { Alcohol }\end{array}$ & $\begin{array}{c}\text { Freon } \\
113\end{array}$ & $\begin{array}{c}\text { Freon } \\
11\end{array}$ & & 1 & & 4 & & 16 \\
\hline 1 & 1 & 1 & $\mathrm{x}$ & & & No & $x$ & & & & \\
\hline 2 & & & & $X$ & & & & & & & \\
\hline 3 & 1 & 1 & $\mathrm{x}$ & & & No & & & & $x$ & \\
\hline 4 & 2 & 1 & $\mathrm{X}$ & & & NO & $x$ & & & & \\
\hline 5 & 3 & 1 & $\mathrm{x}$ & & & No & $x$ & & & & \\
\hline 6 & $3 \mathrm{~A}$ & 1 & $\mathrm{x}$ & & & NO & $\mathrm{x}$ & & & & \\
\hline 7 & 4 & 1 & $\mathrm{x}$ & & & No & $\mathrm{x}$ & & & & \\
\hline 8 & 5 & 1 & $x$ & & & NO & $x$ & & & & \\
\hline 9 & & & & & & & & & & & \\
\hline 10 & & & & & & & & 2 & ) & & \\
\hline 11 & & & & & & & & & $x$ & & \\
\hline 12 & & & & & & & & & & $x$ & \\
\hline 13 & & & & & & & & & & & $x$ \\
\hline 14 & 6 & 1 & $\mathrm{X}$ & & & No & $\mathrm{x}$ & & & & \\
\hline 15 & $7 \mathrm{~A}$ & 1 & $\mathrm{x}$ & & & No & $\mathrm{x}$ & & & & \\
\hline 16 & & & & $\mathrm{x}$ & & & $x$ & & & & \\
\hline 17 & 7 & 1 & $\mathrm{x}$ & & & NO & $\mathrm{x}$ & & & & \\
\hline 18 & & & & $X$ & & & $\mathrm{x}$ & & & & \\
\hline 19 & 8 & 1 & $\mathrm{x}$ & & & NNo & $\mathrm{x}$ & & & & \\
\hline 20 & 9 & 1 & $x$ & & & NO & $x$ & & & & \\
\hline 21 & 10 & 1 & $\mathrm{x}$ & & & No & $\mathrm{x}$ & & & & \\
\hline 22 & 1 & 1 & $x$ & & & YES & $\mathrm{x}$ & & & & \\
\hline 23 & 1 & 1 & & $\mathrm{X}$ & & YES & $x$ & & & & \\
\hline 24 & 11 & 1 & $x$ & & & No & $x$ & & & & \\
\hline 25 & 11 & 1 & $X$ & & & YES & $\mathrm{x}$ & & & & \\
\hline 26 & 12 & 1 & $\mathrm{X}$ & & & No & $\mathrm{x}$ & & & & \\
\hline 27 & & 1 & $X$ & & & YES & $x$ & & & & \\
\hline
\end{tabular}


Table IV-4. Test :fatrix (continued)

\begin{tabular}{|c|c|c|c|c|c|c|c|c|c|c|c|}
\hline \multirow[b]{2}{*}{$\begin{array}{l}\text { Test } \\
\text { No. }\end{array}$} & \multirow[b]{2}{*}{$\begin{array}{l}\text { Screen } \\
\text { Specimen }\end{array}$} & \multirow{2}{*}{$\begin{array}{l}\text { Number } \\
\text { of } \\
\text { slements }\end{array}$} & \multicolumn{3}{|c|}{ Test Iiruid } & \multirow[b]{2}{*}{$\begin{array}{l}\text { Out- } \\
\text { Flow }\end{array}$} & \multicolumn{5}{|c|}{ Orientation } \\
\hline & & & $\begin{array}{l}\text { Isopropyl } \\
\text { Alcoho1 }\end{array}$ & $\begin{array}{c}\text { Freon } \\
113\end{array}$ & $\begin{array}{c}\text { Ereon } \\
11\end{array}$ & & 1 & 2 & $3 / 4$ & 5 & 6 \\
\hline 28 & 13 & 1 & $\mathrm{x}$ & & & NO & $\mathrm{x}$ & & & & \\
\hline 29 & & 1 & $\mathrm{x}$ & & & XES & $\mathrm{x}$ & & & & \\
\hline 30 & 19 & 1 & $\mathrm{x}$ & & & No & $x$ & & & & \\
\hline 31 & & 1 & $\mathrm{X}$ & & & YES & $x$ & & & & \\
\hline 32 & 22 & 1 & $x$ & & & NO & $x$ & & & & \\
\hline 33 & & 1 & $\mathrm{x}$ & & & YES & $x$ & & & & \\
\hline 34 & 18 & 1 & $\mathrm{x}$ & & & NO & $x$ & & & & \\
\hline 35 & & 1 & $\mathrm{x}$ & & & YES & $\mathrm{x}$ & & 1 & 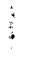 & \\
\hline 36 & 26 & 1 & $x$ & & & No & $\mathrm{x}$ & & & 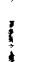 & \\
\hline 37 & 23 & 1 & $\mathrm{x}$ & & & NO & $x$ & & & & \\
\hline 38 & & 1 & $\mathrm{X}$ & & & YES & $\mathrm{x}$ & & & & \\
\hline 39 & 21 & 1 & $\mathrm{x}$ & & & No & $x$ & & & & \\
\hline 40 & & 1 & $\mathrm{x}$ & & & YES & $\mathrm{x}$ & & & & \\
\hline 41 & 20 & 1 & $x$ & & & No & $x$ & & & & \\
\hline 42 & & 1 & $\mathrm{X}$ & & & YES & $x$ & & & & \\
\hline 43 & 14 & 1 & $\mathrm{x}$ & & & No & & & & $x$ & \\
\hline 44 & & 1 & $\mathrm{x}$ & & & No & $x$ & & & & \\
\hline 45 & & 1 & $x$ & & & YES & $x$ & & & & \\
\hline 46 & 15 & 1 & $x$ & & & NO & & & & $\mathrm{x}$ & \\
\hline 47 & 17 & 1 & $x$ & & & NO & 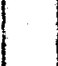 & & & $\mathrm{x}$ & \\
\hline 48 & & 1 & $\mathrm{x}$ & & & YES & & & & $\mathrm{x}$ & \\
\hline 49 & 16 & 1 & $x$ & & & NO & $x$ & & & & \\
\hline 50 & 24 & 1 & $\mathrm{x}$ & & & NO & $x$ & & & & \\
\hline 51 & 25 & 1 & $x$ & & & No & $x$ & & & & \\
\hline 52 & $10-27$ & 2 & $\mathrm{X}$ & & & No & x & & & & \\
\hline 53 & & 2 & $x$ & & & YES & $x$ & & & & \\
\hline 54 & & 2 & $X$ & & & No & & & & $x$ & \\
\hline
\end{tabular}


Table IV-4. Test Matrix (concluded)

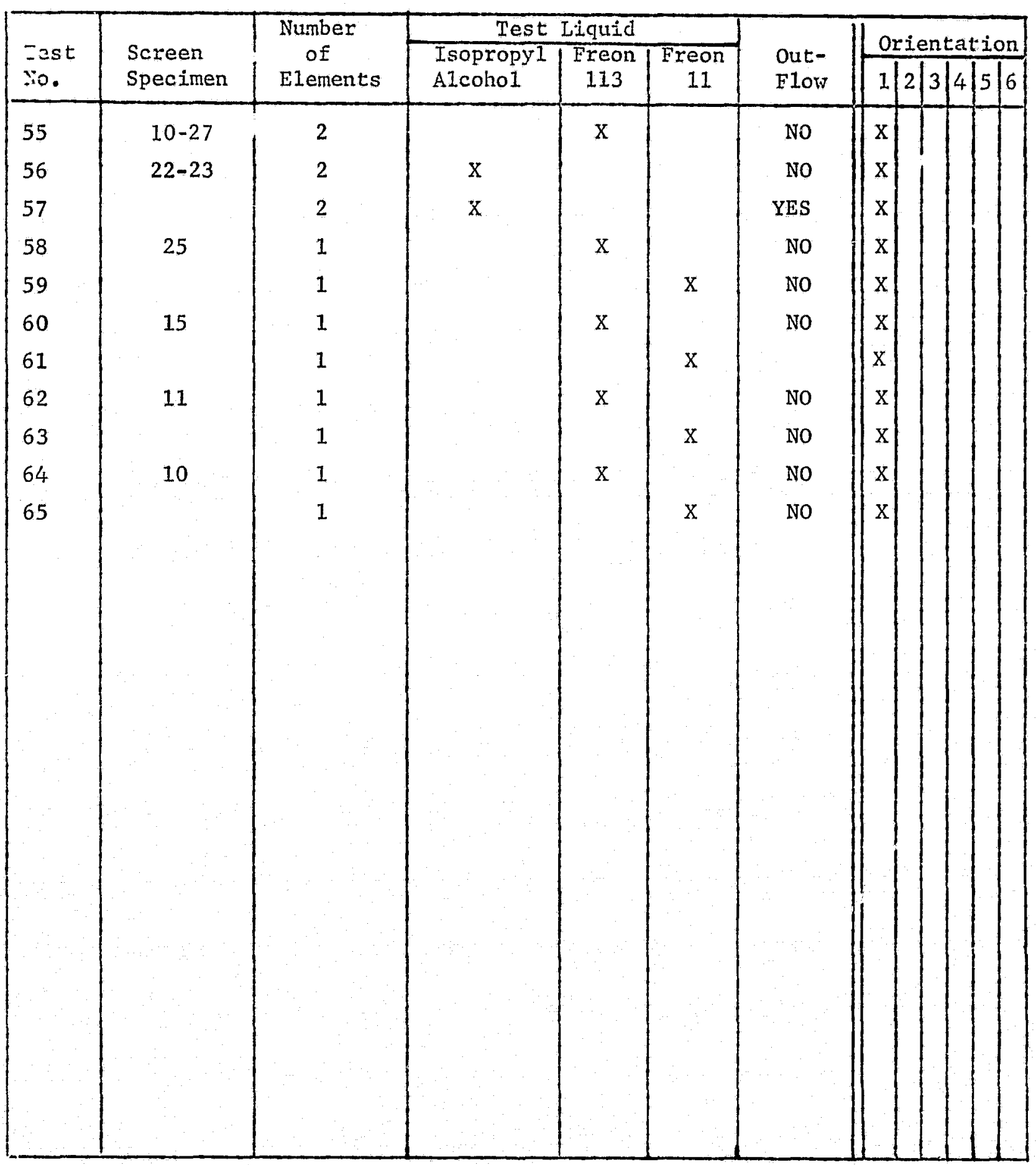


2. Test Procedure - Prior to each test the initial conditions were estabished. The controlled liquid side of the model was filled rompletely with 11quid and the vent was closed. The liquid level on the bulk side of the model was set. If it was a flow test, the pump would be started and a steady flow condition was established. The ullage was pressurized to obtain the correct bulk liquid height under flow conditions. Liquid temperature, pressure, ullage height and liquid flow rate were recorded.

Three basic tests were performed: sine vibration sweep, sine vibration dwell and random vibration tests. For a sine sweep test, the amplitude of the vibration was held constant while the frequency was varied. The test always began at $5 \mathrm{~Hz}$, the minimum shaker frequency. The frequency was increased at a constant rate. Most of the sine sweep tests were performed using a sweep rate of 2 octaves per minute, which means that the frequency doubles every 30 seconds. An upper frequency limit of $100 \mathrm{~Hz}$ was used most of the time, but $50 \mathrm{~Hz}$ and $500 \mathrm{~Hz}$ were used depending on how well the harmonics of the system were known. Usually the frequency was swept back down to $5 \mathrm{~Hz}$ after reaching the upper limit, to determine if decreasing the frequency changed the response. The pressure differential and the screen acceleration were recorded throughout the test. The occurrence of screen breakdown, the frequency, severity, and location on the screen were recorded. Screen breakdown was usually avoided for the sine sweep tests by using lower accelerations and ullage heights because it made the determination of the harmonic peaks in the pressure data more difficult (see the discussion of the pressure data in Chapter $V$ ).

Sine vibration dwell tests held the acceleration level and frequency constant, while the ullage height was varied during the test. These tests best establish the conditions under which screen breakdown would occur. The ullage height at which screen breakdown first began was determined, and transducer output was recorded at that condition.

Random vibration tests were similar to the sine dwell tests. For a fixed random vibration spectrum and overall g RMS level, the ullage height was varied to find the point of screen breakdown. It was found that no useful data was obtained from the transducers during the random vibration test due to the natura of the random excitation.

The specific procedures used during the testing are further discussed along with the test results in Chapter $V$. 
This chapter presents the results of the screen vibration tests. As discussed under the test approach in the previous chapter, the test program was set up to achieve two objectives. It provided the vibration data for al1 the various screen meshes, support methods, and test conditions that were used in performing the analytical correlation. In addition, the test program was composed so as to permit direct comparison of the same test data to establish vibration effects, independent of the analytical models. The following discussion in Section A presents the results of those comparisons. In Section $B$ the correlation between the data and the predictions of the analytical models is presented.

\section{A. Discussion of Results}

The vibration tests provided a large quantity of data on the general effects of vibration on screen acquisition systems. The initial specimens tested were used to make a detailed study of the pressure differentials produced by vibration. As the test progiam progressed and various screen specimens were tested, many effects, such as the support method and liquid flow, were evaluated. I'hese results were derived from the measured pressures and accelerations, and by comparing the screen response between the various tests.

1. Basic Screen Response - The data obtained with the pressure transducer provided information on the basic response of the screen specimens to vibration. This pressure transducer measured the vibration produced pressure differential between the liquid in the controlled region and the gas in the bulk region of the model. Signal conditioning removed a11 steady pressure differentials (due to liquid flow and hydrostatic pressure) so only the vibration produced pressure differential was recorded.

Specimen 1, the first specimen tested, was used to make a study of the characteristics of the pressure differential due to vibration. This specimen had two $7.6-\mathrm{cm}(3.0-\mathrm{in})$ square openings covered with $325 \times 2300$ screen and located at the top and bottom of the specimen. Due to its simple structure, the re ponse of Specimen 1 was more basic in nature than the other ful1 length specimens The pressure data obtained from Specimen 1 is smoother and has more distinct trends than the data from the other specimens. At the same time, the response of Specimen 1 is representative of the typical resporse of the other specimens.

The first part of this discussion concentrates primarily on tests performed with the model mounted with the vibration axis and one-g Earth gravity acting parallel to the length of the screen specimen (Orientation 1). As is discussed later in this chapter, this orientation made the screen the most sensitive to the applied vibration. Isupropyl alcohol was used as the test liquid for these tests since it yields relatively high retention capability and therefore improved the resolution of the vibration effects. 
a. Differential pressure Waveform - The mexzurec pressure differential due to the vibratiun hud a wiveform that vari... it the frequency of the applied vibration. How the amplitude of the pressure differential varied vill be discussed in the following section, but the basic form of the pressure differential will be considered here.

For most of the screen specimens, the pressure differential had a definite positive bias, where positive is defined to mean that the ullage pressure in the bulk region is greater than the pressure of the liquid in the controlled region. Near the harmonic frequency, large positive peaks developed, but the negative component of the differential pressure did not change significantly. For the full length specimens, some variation of the negative component of the pressure differential was seen.

The specimens that had the screen bonded to perforated plate were the only exception to the above described pressure bias. The pressure differential was symmetrical, with equal amplitude negative and positive pressures, over the fill range of frequencies. With the bonded support method, the screen could only displace as much as the perforated plate. None of the other support methods limited the screen displacement to the extent of the bonded specimens.

Since the screen displacement had little involvement in the response of the bonded specimens, the pressure differential was primarily due to only the coupling between the liquid mass and the molel vibration. There was nothing to bias the response of the system and the pressure differential due to the vibration was symmetrical. For the other specimens, the displacement of the screen caused the positive bias to the pressure. Negative pressure differentials were relieved by the displacement of the screen.

The development of the pressure waveform with frequency is shown by Figure $\mathrm{V}-1$. This is a typical plot derived from the data for specimen 1 . The frequency has been normalized in making the figure so that only two cycles are illustrated, regardless of the actual frequency of the waveform. The differential pressure is positive upwards. The applied acceleration of the model is shown at the bottom of the figure with positive acceleration being upwards.

At $5 \mathrm{~Hz}$, the pressure differential was sinusoidal in form and was in phase with the applied acceleration. A positive acceleration of the model lowered the pressure of the liquid in the controlled region with respect to the gas in the bulk region, producing a positive pressure differential. The relationship is the same as if the model was given a sceady acceleration and the hydrostatic pressure of the controlled liquid was measured.

As the first harmonic was approached, but before any amplification of the pressure had occurred, the positive differential pressure developed some small peaks (Figure $\mathrm{V}-1 \mathrm{a}$ ). These peaks developed into two distinct peaks at a slightly higher frequency and some amplification became evident (Figure $V-1 b$ ). The second of the two peaks gradually receded as the first grew, giving a waveform that was basically a series of positive pulses at the first harmonic (Figure $V-1 C$ ). At this harmonic, the pressure lagged the applied acceleration by a phase angle of 90 degrees. 


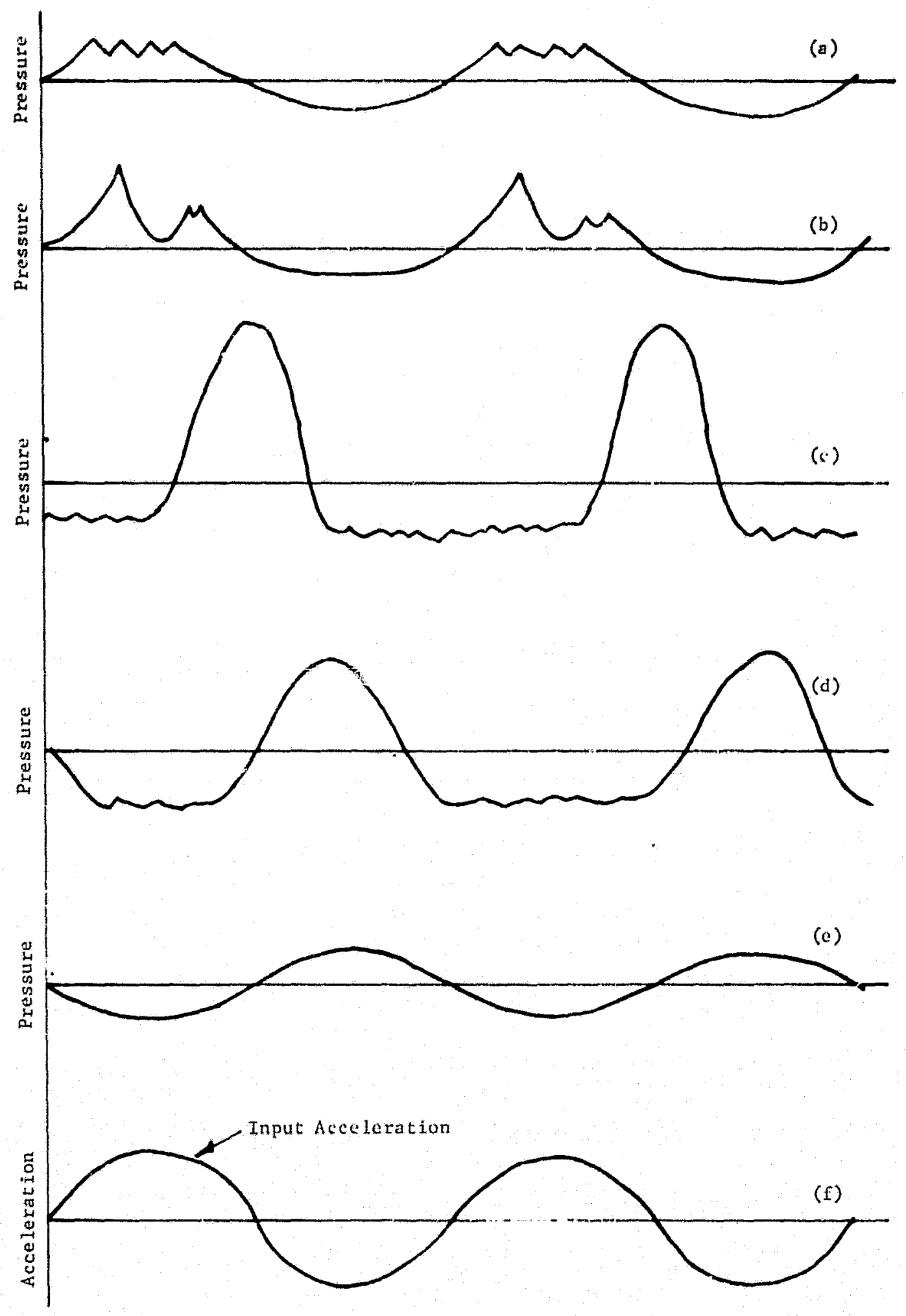

Eigure V-1, Pressure Waveforms 
At the harmonic the combined response of the liquid and the screen, due to the vibration, was a maxinum. Bistei un a comparison of the presaure differential data from the rigfd and loose screen specimens, the form of the positive component of the pressure differential was essentieliy the same. The method of screen support does influence the amplitude $c 1$ the positive pressure differential, as is discussed later in this chapter. The negative component of the pressure differential, as shown by Figure $V-1$, is small in comparison to the positive component. Apparently the motion of the screen reduces the amplitude of the negative component of the pressure differential. It is not clear why the screen movement does not influence the pesitive component of the pressure differential as stromgly.

At a frequency above the harmonic the amplitule of the pulses decreased and the phase lag continued to incyase (Figure $V-1 d$ ). Then at some higher Frequency the waveform was again sinusoidal and the anplitude was small. The pressure now lagged the applied acceleration by a phase angle of 180 degrees (Figure $V-I e$ ). The phase lag of the pressure described above is typical of the phasing of the iaput and output of a classical spring-mass system. This transition in the waveform of the pressure with frequency could be observed in the test data for most of the specimens. The most distinct characteristic was the growth of one pulse as the other recedes.

Sereen breakdown significantly altered the form of the measured differential pressure. If the breakdown was not significant, the pressure oscillax wions due to the vibration developed a Jower frequency component. Differential pressure transients in excess of the screen bubble point were observed. If excessive screen breakdown occurred, the pressure measurement became very erratic. Sine sweep tests, in which no breakdown occurred, provided the best data regarding the peak differential pressures and the harmonic frequencies. Sine dwell data were acquired just as treakdown occurred so that valid differential pressure data could be obtaineri.

This response was partly due to the direct interaction of the bubbles prowaced by the screen breakdown with the pressure transducer. Bubbles passing by or hitting the transducer wil1 produce transients. The gas that accumulated within the controlled region oscillated with the applied vibration, adding to the measured differential pressure.

b. Differential Pressure Variation with Frequency - A typical plot of the variation of the differential pressure with frequency for Specimen $I$ is shown in Figure $V-2$. The pressure afferential plotted is the positive zero-to-peak pressure. The positive pressure differentials act so as to cause screen breakdown (see discussion of screen breakdown in this chapter).

At frquencies near $5 \mathrm{~Hz}$ t, ninimum shakex operating frequeticy), the differential pressure was $d j$, hat responding to the applied acceleration, since the test model $d f^{f}, \ldots$, , the any ampliftcation of the input vibration. The differential presuare rapidly increases, achieving a maximum value at the harmonic frequency. At frequencies above the harmonic the differential pressure decreases, approaching zero. The model also has second and higher harmonic modes. Usually the first mode produces the maximum pressure differential and the higher modes are lesn significant, but a lew exceptions were noted during the testing. 


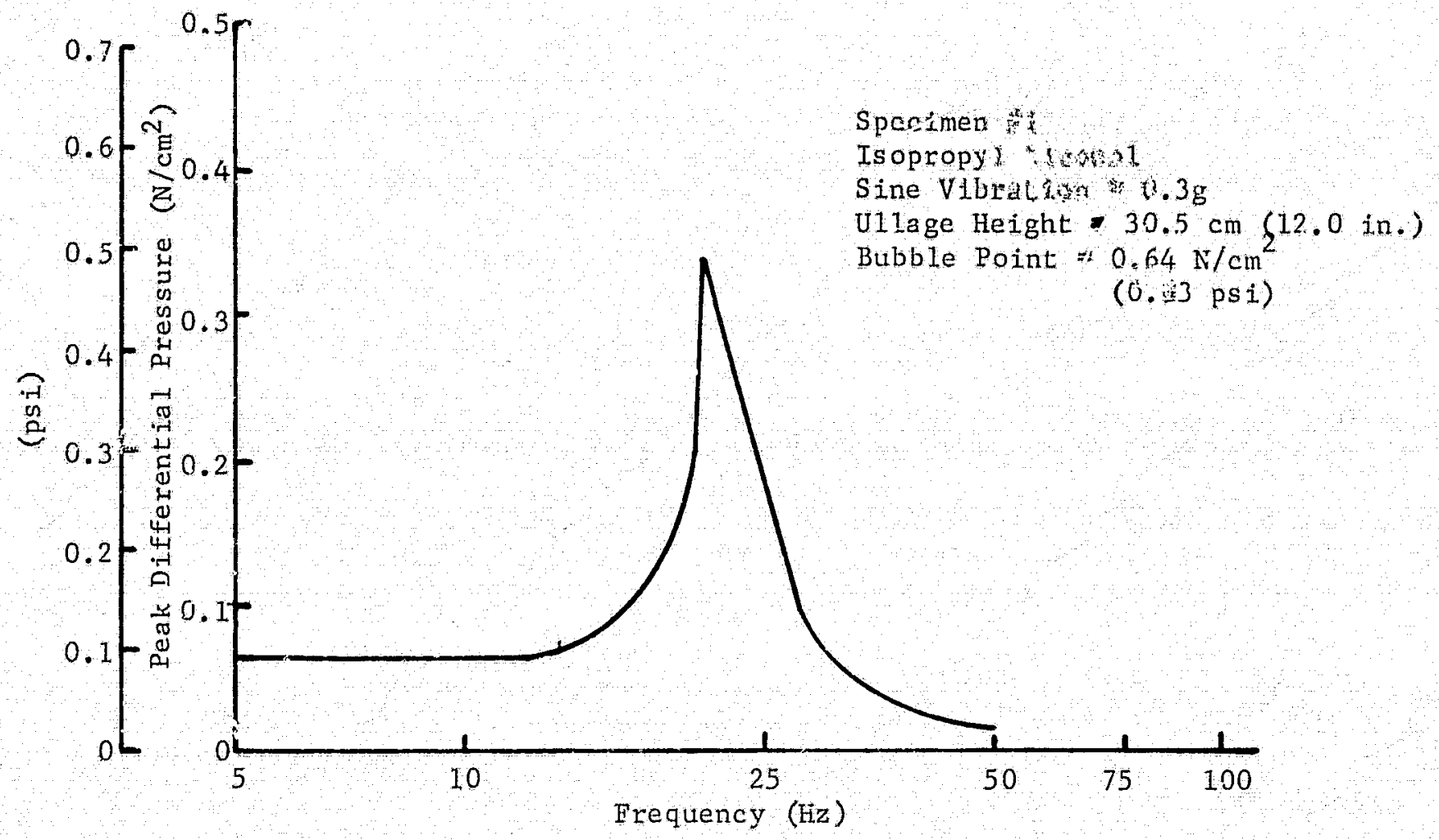

Figure V-2. Veriation of Differential Pressure with Frequency 
Specimen I had the most basic response of the specimens, giving a well defined first mode response. The full length specimens and the various support methods gave the screen many degrees of freerlom. Depenaing on the amplitude and frequency of the applied vibration and the ullage height, the relative signifiance of the modes changed. In many tests, the first mode was not distinct. The differential pressure folld gradually rise, remain at some higher level over a range of trequencies and then begin to decrease. Sometimes there would be a smal. I peak in the differential pressure at a low frequency, followed by a distinct differential pressure rise more typical of the first mode.

When many of the coarser screens were tested, it was found that the maximum differential pressure occurred at $5 \mathrm{~Hz}$ and then decreased as frequency was increasei? This appears to indicate that the first mode frequency was less than $5 \mathrm{~Hz}$. These specimens had to se tested at small uIlage heights, due to the low retention capability, and the large liquid mass in the model tends to decrease the harmonic frequency.

c. Differential Pressure Variation with Position - The location of the pressure transducer could be varied along the length of the mode1, but was always centered with respect to the model width. With the model mounted in Orientation 1 (refer to Figure IV 4 for the mode1 orientations), the maximum pressure differential due to vibration was found to be at the top of the most. Figure $\nabla-3$ is a plot of the pressure field measured for Specimer: 4, a full length unsupported $325 \times 2300$ screen. The amount of liquid mass being vibrated was the maximum at the top of the model, producing the maximum differential pressure dut to the vibration.

In Orientations 5 and 6 , the same response with transducer position was recorded. The maximum differential pressure was measused at the top of the node1. In all three of these orientations the model vas vertical so the result is consistent. For Orientations 2 and 4 no significant differences in differential pressure with transducer position were measured, which would be as expected due to the orientation of the vibration. When the model was mounted in vrientation 3 , interference btween the pressure transducer tube and the siaker permitted the pressures to only be measured at the center of the model.

d. Softenth Spring Effect - When the sine sweep tests were performed t.ey were sitarted at $5 \mathrm{~Hz}$, the frequency was increased to a selected value and then wis decreased back to $5 \mathrm{~Hz}$. At low acceleration 1. yels, the differential pro sures measured when sweeping up and down were the same. Figure $\mathrm{V}-2$ is $n$ example where the differential pressure was the same regardless of whether the frequency was increasing or decreasing.

When sine sweep tests were performed, using specimen 1 and applying accelerations of $0.75 \mathrm{~g}$ or greater, the hysteresis effect shown in Figure $V-4$ was observed. As frequency was increased, one path on the pressure versus frequency plot was foliowed (indicated by arrows), and when frequency was decreased, another path was followed. Above and below the harmonic the path was the same regardless of whether frequency was increased or de- 


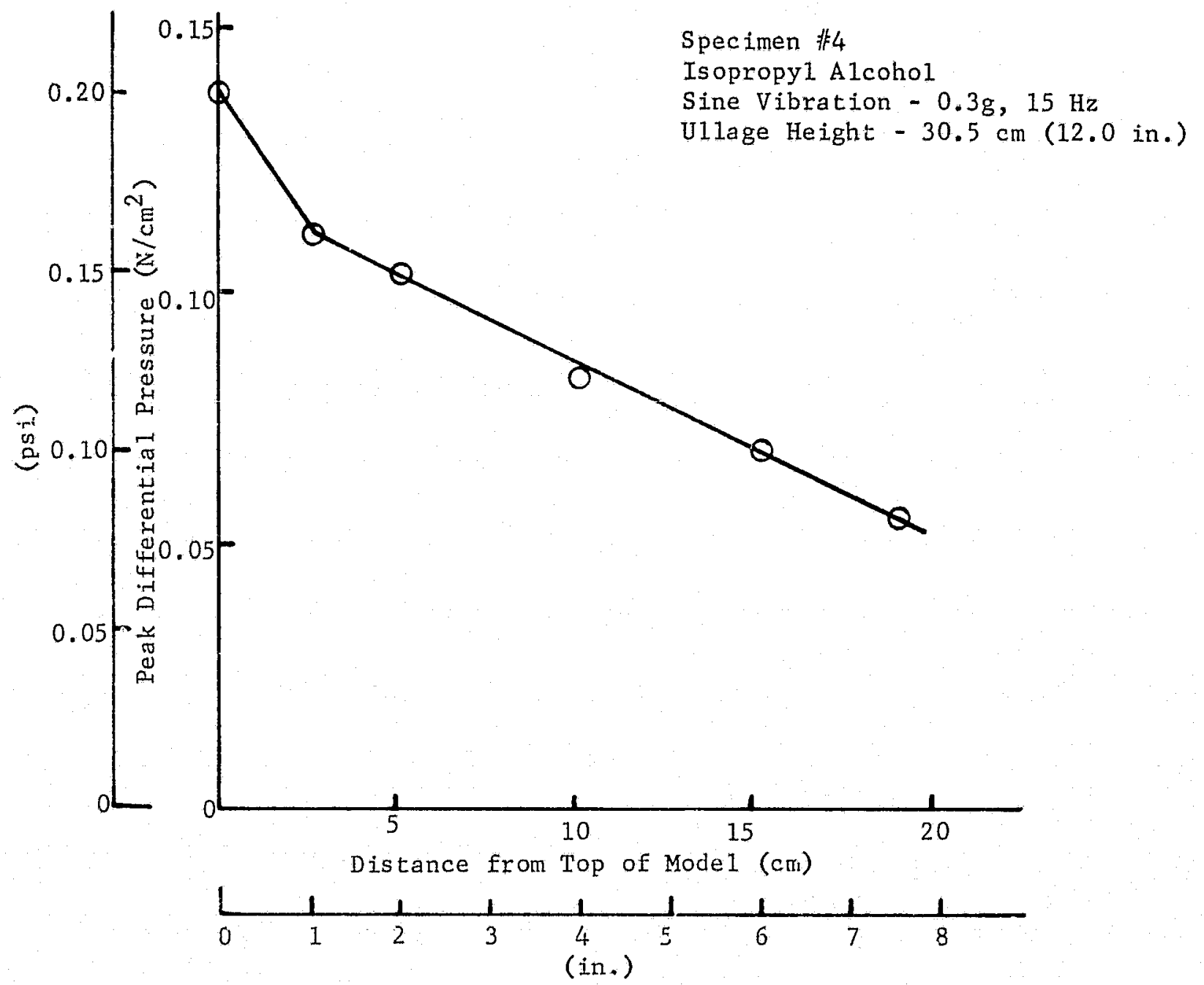

Figure V-3. Variation of Pressure with Position in Liquid 


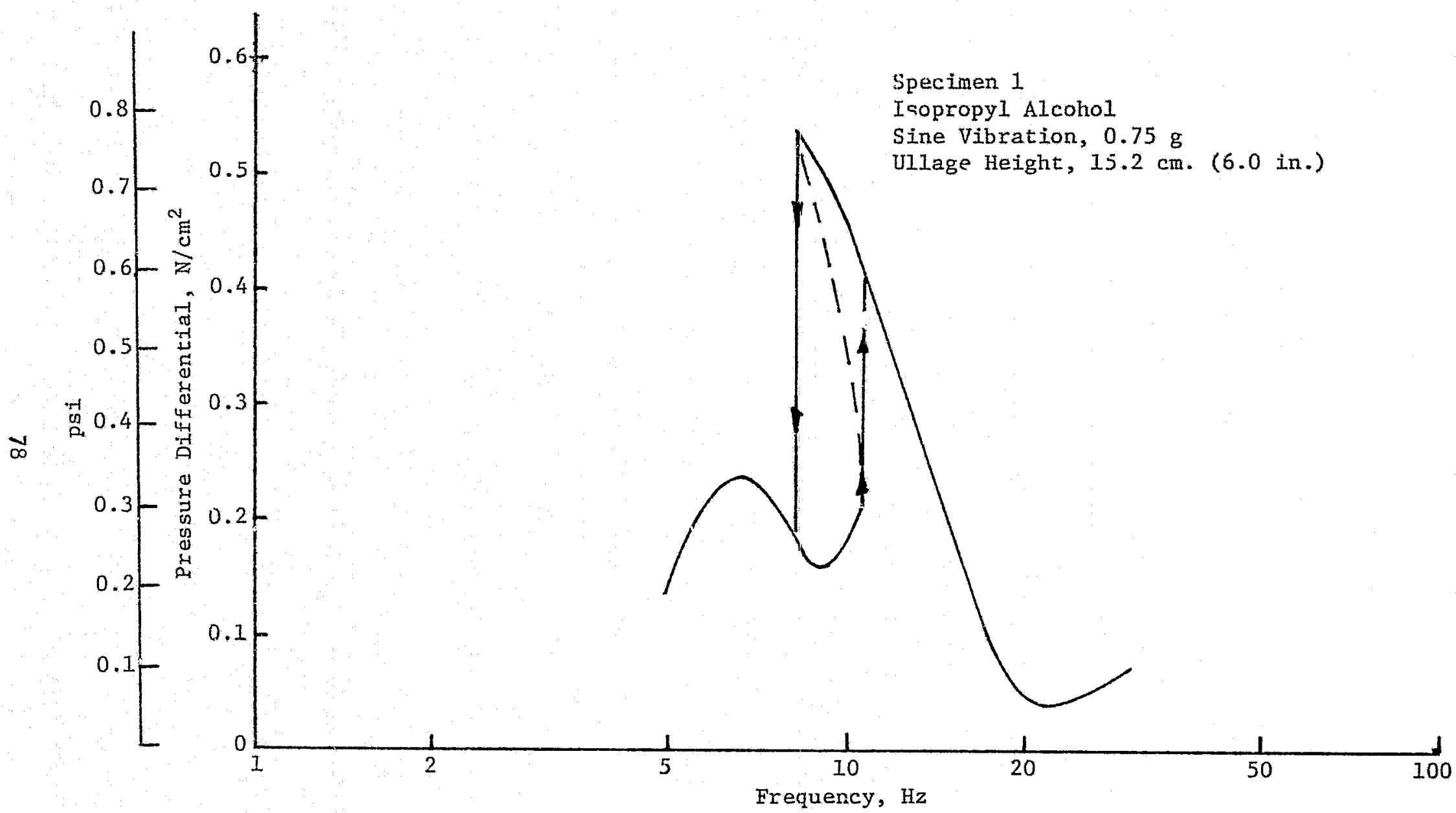

Figure V-4. Screen Response to Sinusoidal Vibration 
creased. The actual form of the curve just below the harmonic is indicated by the dashed curve. Since the curve is double valued over a range of frequencies the differential fressure jumps from a low to high value as the frequency increases or vice versa, giving the observed hysteresis. The response curve is similar in form to the one shown in Figure $V-2$, except that it leans over towards lower frequencies.

This hysteresis effect caused the peak differential pressure at the harmonic to be greater when the frequency was being decreased. This effect was directly observed when screen breakdown occurred during the sine sweep. For example, if the screen breakdown was slight and took place over only a small frequency range $(\sim 5 \mathrm{~Hz})$ as the frequency was increased, then as frequency was decreased breakdown began, became excessive and continued over a wider frequency range.

This type of response is typical of a "softening spring," that is, a spring that becomes less stiff as it is displaced. An actual metal spring usually has the opposite characteristic, it becomes harder as it is displaced. The sane would be expected of a screen membrane: displacing the screen would make it stiffer. Another mechanism must be involved to cause the softening effect. This mechanism must be the gas/liquid interface within the screen pores.

The interface within the screen has the form of: a gas bubble at each pore. While these gas bubbles are attached to a surface, their response is similar to a free gas bubble. The response of a single gas bubble to a sinusoidally varying pressure field has been analyzed and it has been found that it has the softening spring characteristic (Ref. $V-1$ ). The gas/liquid interface must contribute to the stiffness of the screen. The bubbles at each pore are small, having a diameter that is on the order of the pore diameter, but there are many pores per unit area. For Specimen 1, the contribution of the interface was enough to overwhelin any hardening spring effect from the screen wires and give the softening spring response. The harmonics of the gas bubbles are not involved, they have a very high harmonic frequency (order of $10^{5} \mathrm{~Hz}$ ), it is only their stiffness characteristic that influences the response.

Specimens 1 and 2 were the only specimens that exhibited this distinct softening spring effect. These two specinens had the effect of the vibration concentrated on a single screen window, while it was distributed over the full length of the other specimens. Also, the high retention capability of the $325 \times 2300$ screen used in these specimens permitted larger accelerations and ullage heights that could not be used with the coarser screens. These factors made the softening spring effect more obvious. For the other specimens, the effect was not sufficient to produce a measurable difference in the frequency of the harmonic due to increasing and decreasing frequency.

e. Ullage Effects - The pressure transducer measured the differential pressure between the bulk ullage and the liquid in the controlled region. An evaluation was performed to determine the contribution of the ullage region to the differential pressure. Three sine sweep tests, with varied 
accelerations nnd ullage heights, were selected for this evaluation. Tests in which che pressures were significant, but no screen breakdown occurred (which would produce erratic pressures) were selected. After performing the test with the transducer properly connected, tle test was repeated with the reference side of the transducer disconnected from the ullage side and left open to atmospheric pressure. Two conditions were considered, the bulk side sealed (the normal condition) and the bulk side open to the atmosphere.

For each pair of tests, the measured pressure differential was the same regardless of whether the reference line was connected or disconnected. The fact that the transducer was AC coupled eliminated the static pressure differences that would normally be observed when the reference line was disconnected. These results indicate that the effect of the vibration is to vary the pressure of the liquid in the controlled region. The ullage pressure, even with the relatively small volume of the model, remains constant and does not contribute to the pressure differential due to vibration.

2. Screen Breakdown - Most of the tests that were performed had the objective of causing screen breakdown so that the contribution due to vibration could be established. For the sine dwell and the random vibration tests the vibration environment was held constant and the hydrostatic pressure was increased, by draining liquid from the bulk region, until screen breakdown occurred. In many of the sine sweep tests, screen breakdown occurred at a specific value of frequency.

a. Manner of Screen Breakdown - The degree of screen breakdown, the rate at which gas passes through the screen, can cover a wide range. For the purpose of this discussion, breakdown can be classified as slight, significant and excessive. Slight breakdown is defined as the initial onset of breakdown, when very small bubbles penetrated the screen and continued breakdown was necessary before any real accumulation of gas bubbles could be observed. The amount of brealcdown is small enough to be neglected. Thiss type of breakdown occurred when the total pressure differential was closp the screen bubble point and a few pores were made to breakdown. The of of slight breakdown could be localized screen vibration effects, norials womponts of the random vibration that make the differential presmit. caced the bubble point, a few pores that are somewhat larger than adjartiti pores, or some similar effect.

Significant breakdown is due to readily observable bubbles being detached from the screen and resulted in a definite accumulation of gas in the controlled region. This type of breakdown is similar to the first breakdown of a screen when a conventional bubble point test is performed. Over a small area of the screen, the total pressure differential slightly exceeds the bubble point of the screen.

Excessive breakdown results when a large quantity of gas abruptly passes through an area of the screen and begins to fill the controlled region. To produce this condition, the total pressure differential acting over an area of screen much exceeds the bubble point of the screen. These are only qualitative definitions and the boundaries separating them are not well defined. 
This range of screen breakdown rates was best demonstrated by the random vibration tests. As the hydrostatic pressure was increased a distinct transition from slight to signiffcant to excessive breakdown could always be observed. This transition conld not be observed during the sine tests and in many cases the first indication was excessive breakdown. With sine vibration, breakdown was usually associated with a system harmonic, that involved a rapid change in amplification with either frequency or ullage height. With random vibration, a range of frequencies are being excited so a more gradual approach to the point of screen breakdown was possible.

When slight breakdown began, the bubbles were difficult to see. Their size is estimated to be on the order of $0.2 \mathrm{~mm}(0.01 \mathrm{in})$ diameter. After the breakdown had continued for about one minute, coalescence of the bubbles would result in the collection of gas bubbles on the order of $5 \mathrm{~mm}(0.2 \mathrm{in})$ diameter. For the random vibration tests, performed with $325 \times 2300$ screen (isopropyl alcohol, Orientation 1), there was a significant span in ullage height between the first indication of slight breakdown and excessive breakdown. Spans between slight and significant breakdown ranged from $2 \mathrm{~cm}$ $(0.8 \mathrm{in})$ to $10 \mathrm{~cm}(4 \mathrm{in})$, which corresponds to between 2 and 12 percent of the screen bubble point. From slight to excessive breakdown, spans as much as $15 \mathrm{~cm}$ ( 6 in) were measured ( $18 \%$ of the bubble point).

Slight breakdown during the sine vibration tests was more of a short duration, transient breakdowi. The very small bubbles observed during the random vibration test were not observed during the sine vibration tests. The span in ullage height between slight and excessive breakdown for a sine dwell test was smal1, on the order of $2 \mathrm{~cm}(0.8 \mathrm{in})$.

It was also possible in a sine diveli test to have breakdown begin at some ullage height and then as the uliage height was further increased, breakdown can cease. The results shown in Figure $V-5$ are an example of this phenomena. There was a harmonic peak in the effect of the vibration that is a function of liquid mass, which was varied by the ullage height. The sum of the hydrostatic pressure differential plos the pressure differential due to vibration shows that the total pressure differential exceeded the bubble point at ullage heights of $23 \mathrm{~cm}$ (9 in) and $38 \mathrm{~cm}$ (15 in), where screen breakdown was observed.

Under all conditions of screen breakdown, the breakdown would continue as long as the condition that caused breakdown was sustained. Once the vibration conditions had been changed to sufficiently reduce the pressure differential acting on the screen, breakdown ceased. When breakdown stopped, the screens always regained their retention capability and under even the most excessive breakdown conditions, some liquid height was still being retained by the screen. There was no catastrophic breakdown of the screens, where all retention capability was lost. This type of response, as it app ${ }^{7}$ es to liquids with various amounts of sutrooling, is discussed later iri this chapter.

b. Localized Effects - It was found that the manner in which the screen was supported influenced where the screen broke down. Consider the basic case where the model was in Orientation 1 (vibration and one-g parallel to 

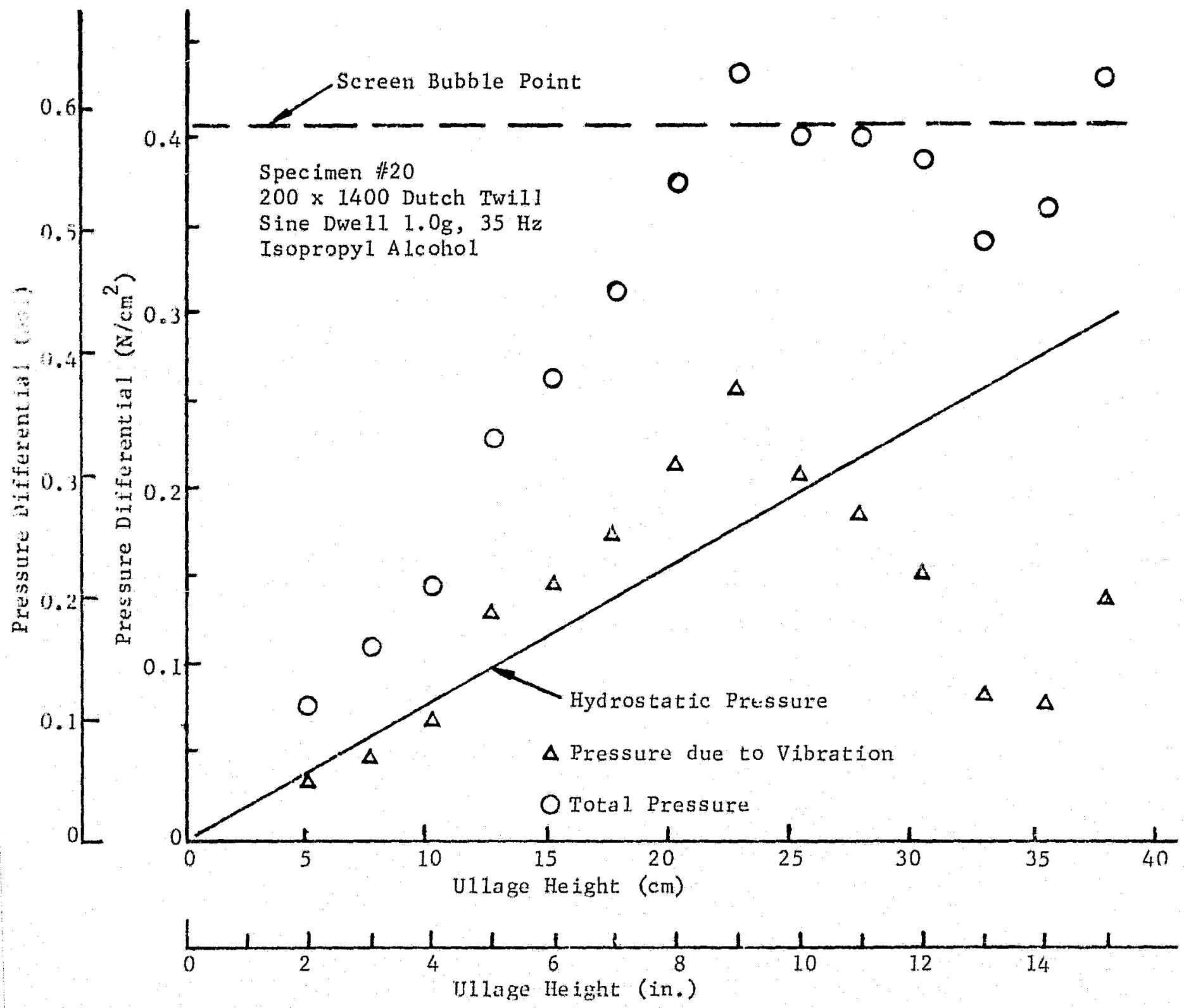

Eigure V-5. Effect of Liquid Height on Screen Response 
the longer length of the screen). The pressure differential across the screen due to hydrostatic pressure differential was the maximum at the top pores of the screen. The measured pressure differential due to the vibration was aiso a maximum at the top of the screen. Therefore, screen breakdown would be expected to first occur at the top of the screen. The screen breakdown observed during the tests did usually occur at the top of the screen for this orientation. For the more rigidly supported screen specimens, such as the ones that had the screen bonded to a perforated plate and the ones that had pleated screen, screen breakdown always occurred at the top of the screen. However, for the more loosely supported screens, screen breakdown was observed at various locations on the portior the screen that was exposed to the ullage. When breakdown first occ red at locations other than the top of the screen, it was very localized. Only small patches of screen, about $1 \mathrm{~cm}(0.4 \mathrm{in})$ in diameter or less break down. The breakdown would be classified as slight. The occurrence and location of the breakdown was a function of frequency and ullage height. As either factor was varied, breakdown would occur and cease at various locations on the screen. It was also observed that the finer mesh screens, that are thinner and lighter, are more likely to break down at locations other than the top of the screen.

The combination of the loose support method and the thin screen material permitted portions of the screen to flutter, independent of the net oscillation of a screen panel. Small wrinkles were present in the screen material as a result of the fabrication process. Typical fabrication methods do not include any means of holding the screen taut, so these wrinkles are inherent in the non-rigid support methods. These wrinkles could be observed to flutter under various vibration conditions and the wrinkles were the positions where the localized screen breakdown did occur. Apparently, the rapid movement of the screen due to this localized flutter, produced a fluctuation in the liquid pressure in the vicinity of the flutter. This localized pressure oscillation, added to the bulk pressure oscillation from the screen panel vibration, was sufficient to cause the localized screen breakdown, even though the hydrostatic pressure differential was less than it was at the top of the screen.

The pressure transducer could only measure the bulk effect of the screen vibration. While the transducer could be moved up and down within the controlled region of the model, the diaphragm was always $1.2 \mathrm{~cm}(0.48 \mathrm{in})$ away from the screen. At that distance the pressure oscillations due to the flutter could not be mearured.

Some measurements made using Specimen 4 (unsupported $325 \times 2300$ screen) illustrate this effect very well. For a sine dwell at $1.0 \mathrm{~g}$ and $20 \mathrm{~Hz}$, screen breakdown was first observed at a point $10 \mathrm{~cm}$ (4 in) down from the top of the screen, in the center of its width, when the ullage height was $20 \mathrm{~cm}(7.9 \mathrm{in})$. With the pressure transaucer positioned at the top of the screen, a pressure differential due to vibration of $0.43 \mathrm{~N} / \mathrm{cm}^{2}(0.62$ psi) was measured. Added to the hydrostatic pressure differential, the total pressure differential at the top pores of the screen was $0.58 \mathrm{~N} / \mathrm{cm}^{2}$ (0.84 psi), which is close to the bubble point of $0.62 \mathrm{~N} / \mathrm{cm}^{2}(0.90 \mathrm{psi})$. When the pressure transducer was positioned opposite the point of screen 
breakdown, a pressure differential due to the vibration of only $0.25 \mathrm{~N} / \mathrm{cm}^{2}$

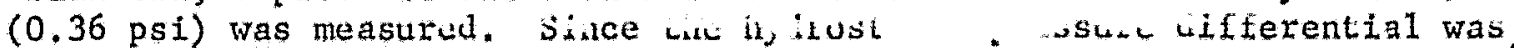
also less at that position, the total pressure differential was $0.32 \mathrm{~N} / \mathrm{ch}^{2}$ ( $0.47 \mathrm{psi}$ ), which is only half the bubble point. The localized flutter must be creating the additional pressure differential to cause screen breakdown. The above described conditions are typical of many similar measuraments that were made. The pressure differential acting on the screen at the top of the model (Orientation 1) is usually near to the bubble point (about $20 \%$ less) when localized breakdown occurs elsewhere.

c. Contribution of Vibration to Screen Breakdown - The primary purpose of the sine dwell tests was to determine how the measured pressure differential due to vibration contributed to the breakdown of the screens. Conditions were produced at which the screen began to break down and the pressure differential due to the vibration was measured. This measured pressure differential due to yibration was then added to the hydrostatic pressure differential, calculated from the ullage height and the liquid density, and the sum was compared to the bubble pcint of the screen.

These sine dwell tests were performed on all the screen meshes, using a range of vibration accelerations and frequencies. The analysis of this data shows that screen breakdown can be predicted based on the sum of the vibration and hydrostatic pressure differentials. The pressure differential due to vibration that causes screen breakdown is the positive peak of the time varying pressure differential. A positive pressure differential lowers the pressure of the liquid in the controlled region with respect to the ullage.

For the finer mesh screens that were rigidly supported and the coarser screen meshes, the sine dwell data repeatedly demonstrated that the sum of the measured pressure differential due to vibration and the calculated hydrostatic pressure differential, equalled the bubble point when screen breakdown was occurring. For those cases where localized screen flutter was adding to the vibration produced pressure differential, the pressure transducer was not measuring the local effects. It can only be presumed that if the true pressure differential due to the vibration wa. known, the sum of the pressure differentials would yield the bubble point when screen breakdown occurred. As previously discussed, the bulk vibration effect that was measured gave a total pressure differential that could be about $20 \%$ less than the bubble point.

This result established that the frequency of the pressire oscillations due to the vibration was low enough to allow the screen to respond to the peak pressure differential of the oscillations. Sine dwel1 testo at frequencies up to $50 \mathrm{~Hz}$ were performed to determine if the pressure osci.1.lation frequency influenced the effect of the vibration. Around a $50 \mathrm{~Hz}$ frequency and above, the pressure differential due to vibration was usually so small that it was difficult to resolve it from the hydrostatic pressure differential needed to produce screen breakdown. The significant effects of sine vibration occurred in the range of 10 to $20 \mathrm{~Hz}$, where the first: harmonics for the specimens tested fall. At these $10 \mathrm{w}$ frequencies the screen does not have the accumulator effect that is considered by the Bubble Growth Mode1 discussed in Chapter III. 
3. Effect of Weave Orientation - Most of the screens used in acquisition devices have a different number and configuration of their wires in the warp and shute directions. The only exception is the square weave screuns that have an identical warp and shute configuration. The differences in screen geometry can influence the structural properties of the screen in opposite directions. Since the response of a screen to vibration irrolves the deflection of the screen, which is a function of the structural properties, it might be expected that the orientation of the screen thave within the screen speciman could influence the screen response.

Four af the screen specimens were specifically intended to investigate the effects of screen weave orientation. Each of these screen specimens had the "unsupported" structural configuration. The screen was only supported at the seim weld around the edges, leaving the $7.6 \mathrm{~cm}(3.0$ in) by $38.1 \mathrm{~cm}$ (15.0 in) center span unsupported. Two specimens were made for each of the screen weaves considered, one with the warp wires running in the short direction and the other with the warp wires running in the long diraction. This configuration should produce the most significant difference in response between two specimens of the same weave, within the geometric constraints of the test mode1. The narrow dimension could have been reduced, but the deflection of the screen would have been too limited to provide adequate screen response.

The Hiffnes of the screens in the warp and shute directions was estimated to determine which screens would most show the effects of weave orientation. This was done by calculating an average thickness of the screen in the warp and shute directions, based on the volume of the wires per unit length. If it is assumed that the stiffness of the screen in one direction is independent of the loading in the other direction, then the stiffness is given by the product of the modulus of elasticity and the average thickness. Tensile test data for some of the screens used here is available (Ref. $V-2$ ) that shows that there is a reduction in the stiffness due to the bending of the slightly curved wires. The shute wires are usually more curved than the warp wires and the reduction is most pronounced in that direction. When measured values for the effective stiffness were not available, a reduction factor was estimated.

Presented in Table $V-I$ are the estimated stiffness values. These stiffness values indicate that there is little difference in the screen stjefness between the warp and shute directions. One exception is the $850 \mathrm{x}$ 155 scris:. Due to the unusual Robusta weave, this screen was predicted to have a factor of 8 difference in stiffness between the warp and shute directions.

Based on this evaluation, two screen meshes were selected to establish if an effect of weave orientation exists. One set of samples was made of the $850 \times 155$ screen, since it was predicted to be the most sensitive to orientation. The other set was made of $325 \times 2300$, which was predicted to have a stiffness independent of orientation. The high bubble point of 
Table V-1. Predicted Screen Stilfness

\begin{tabular}{|c|c|c|c|c|c|c|c|}
\hline \multirow{2}{*}{$\begin{array}{l}\text { Screen Mesh } \\
\text { (wires } \\
\text { per inch) }\end{array}$} & \multirow[b]{2}{*}{ Weave } & \multicolumn{2}{|c|}{$\begin{array}{c}\text { Wire Diameter } \\
\text { man (in.) }\end{array}$} & \multicolumn{2}{|c|}{$\begin{array}{l}\text { Actual Stiffness } \\
\mathrm{N} / \mathrm{cm} \text { (1bs/in.) }\end{array}$} & \multicolumn{2}{|c|}{$\begin{array}{c}\text { Eefective Stiffness } \\
\mathrm{N} / \mathrm{cm}(\mathrm{Ib} / \mathrm{in} .)\end{array}$} \\
\hline & & Warp & Fhute & Warp & Sharea & Warp & Shute? \\
\hline $325 \times 2300$ & Dutch Twi11 & $\begin{array}{c}0.038 \\
(0.0015)\end{array}$ & $\begin{array}{c}0.025 \\
(0.0010)\end{array}$ & $\begin{array}{c}27,800 \\
(15,900)\end{array}$ & $\begin{array}{c}80,900 \\
(46,200)\end{array}$ & $\begin{array}{c}19,400 \\
(11,100)\end{array}$ & $\begin{array}{c}20,300 \\
(11,600)\end{array}$ \\
\hline $200 \times 1400$ & Dutch Twi11 & $\begin{array}{c}0.071 \\
(0.0028)\end{array}$ & $\begin{array}{c}0.041 \\
(0.0016)\end{array}$ & $\begin{array}{c}60,400 \\
(34,500)\end{array}$ & $\begin{array}{l}133,000 \\
(76,000)\end{array}$ & $\begin{array}{l}49,600 \\
(28,300)\end{array}$ & $\begin{array}{c}33,300 \\
(19,000)\end{array}$ \\
\hline $165 \times 800$ & Dutch Twill & $\begin{array}{c}0.071 \\
(0.0028)\end{array}$ & $\begin{array}{c}0.051 \\
(0.0020)\end{array}$ & $\begin{array}{l}49,700 \\
(28,400)\end{array}$ & $\begin{array}{l}123,000 \\
(70,400)\end{array}$ & $\begin{array}{c}33,800 \\
(19,300)\end{array}$ & $\begin{array}{l}29,600 \\
(16,900)\end{array}$ \\
\hline $165 \times 800$ & Plain Dutch & $\begin{array}{c}0.051 \\
(0.0020)\end{array}$ & $\begin{array}{c}0.036 \\
(0.0014)\end{array}$ & $\begin{array}{l}25,400 \\
(14,500)\end{array}$ & $\begin{array}{c}00,400 \\
(34,500)\end{array}$ & $\begin{array}{c}17,300 \\
(9,900)\end{array}$ & $\begin{array}{c}14,500 \\
(8,300)\end{array}$ \\
\hline $80 \times 100$ & Dutch Pwill & $\begin{array}{c}0.102 \\
(0.0040)\end{array}$ & $\begin{array}{l}0.076 \\
(0.0030)\end{array}$ & $\begin{array}{c}49,200 \\
(28,100)\end{array}$ & $\begin{array}{l}243,000 \\
(1.39,000)\end{array}$ & $\begin{array}{c}39,400 \\
(22,500)\end{array}$ & $\begin{array}{c}60,900 \\
(34,800)\end{array}$ \\
\hline $50 \times 250$ & Plain Dutch & $\begin{array}{c}0.127 \\
(0.0050)\end{array}$ & $\begin{array}{c}0.114 \\
(0.0045)\end{array}$ & $\begin{array}{c}48,200 \\
(27,500)\end{array}$ & $\begin{array}{c}194,000 \\
(111,000)\end{array}$ & $\begin{array}{c}33,800 \\
(19,300)\end{array}$ & $\begin{array}{c}48,700 \\
(27,800)\end{array}$ \\
\hline $850 \times 155$ & Rrsusta & $\begin{array}{c}0.030 \\
(0.0012)\end{array}$ & $\begin{array}{c}0.102 \\
(0.0040)\end{array}$ & $\begin{array}{c}47,100 \\
(25,900)\end{array}$ & $\begin{array}{c}95,400 \\
(54,500)\end{array}$ & $\begin{array}{l}8,060 \\
(4,600)\end{array}$ & $\begin{array}{c}66,900 \\
(38,200)\end{array}$ \\
\hline $200 \times 270$ & Square & $\begin{array}{l}0.053 \\
(0.0021)\end{array}$ & $\begin{array}{c}0.053 \\
(0.0021)\end{array}$ & $\begin{array}{c}34,000 \\
(19,400)\end{array}$ & $\begin{array}{c}34,000 \\
(19,400)\end{array}$ & $\begin{array}{l}10,500 \\
(0,000)\end{array}$ & $\begin{array}{l}10,50 r \\
(6,000)\end{array}$ \\
\hline
\end{tabular}


the $325 \times 2300$ aids in data resolution, so as to better indicate any effect of orientation. Orientation 1 (vibiation and one-g parallel to the long axis of specimen), which is the most sensitive axis and isopropyl alcohol, which also aids in resolution, were used in performing these tests.

Identical sine sweep tests were performed on both of the samples of a given mesh. For the two $850 \times 155$ specimens (specimens 24 and 25) $0.5 \mathrm{~g}$ with a $15.2 \mathrm{~cm}(6.0 \mathrm{in})$ and $20.3 \mathrm{~cm}(8.0 \mathrm{in})$ ullage height, and $0.75 \mathrm{~g}$ with a $15.2 \mathrm{~cm}(6.0 \mathrm{in})$ ullage height were used. The two $325 \times 2300$ specimens (specimens 4 and 5) were tested with identical $0.3 \mathrm{~g}, 30.5 \mathrm{~cm}(12.0 \mathrm{in}$ ) ullage height and $1.0 \mathrm{~g}, 20.3 \mathrm{~cm}(8.0 \mathrm{in})$ ullage height sine sweeps. The frequency, amplitude and form of the measured pressure differential at the first harmonic of the system were used to perform the comparison.

In al1 cases the observed results, occurrence and amount of screen breakdown, if any, were the same for all the pairs of tests. For the $850 \times 155$ screen, ioth specimens had a first karmonic that occurred at the same frequency (within $1 \mathrm{~Hz}$ ) and the peak pressure differentials were essentially the same (within $0.03 \mathrm{~N} / \mathrm{cm}^{2}(0.05 \mathrm{psi})$ ). The first harmonics for the pair of $325 \times 2300$ screen were also alike. While the peaks were the same, some minor differences in the way the pressure varied with frequency were noted. These differences are attributed to the localized effects that were discussed earlier in this section. The "unsupported" screen support method, while being of the needed length and width to indicate weave orientation effects, introduces localized effects that are difficult to control. Typical fabrication methods were used in making the specimens, so there was no way to accurately duplicate the screen tautness bitween the two specimens in the pair.

It is concluded from these tests that the effect of weave orientation is negligible. If there were any significalt differetces there would have been a noticeable change in the frequency and amplitute of the first harmonic. If there were differences, they were of the same order of magnitude as the localized effects caused by the differences in screen tautness between the specimen pairs.

This result is consistent with data gathered under a prior study (Ref. $V-3)$. Various screen specimens were pressurized as a membrane and the deflection with pressure was measured. It was found that the screen behaved as an isotropic mediun (uniform in all directions) and could be modeled as such.

4. Effect of Mode1 Orientution - Some of the specimens were tested in varied orientations. Specimen 5 (unsupported $325 \times 2300$ screen) was usiad to perform an investigation of the effect of the orientation of the screen surface with respect to both the vibration and one-g. Six possible mode! orientations, shown in Figure IV-4 wert considered (the screen specimen is parallel to the largest face of the mocial).

In each orientation sine sweeps and dwells with various aceelerations were performed. The ullage height could be varied when the model was tested in 
Orientations 1.5 and 6 . In Orientations 2,3 and 4 the liquid in the controlled region was supported above the screen and the liquid in the bulk region was drained away, completely exposing that side of the screen to gas.

The tests established that the affect of the vibration is directly proportional to the length of the liquid column being supported by the scieen, parallel to the direction of the vibration. The model had a similar response and was most sensitive to vibration in orientations 1 and 3 . Orientation 3 made the model the most sensitive since the vibration always acted over the ful1 $38 \mathrm{~cm}$ (15 in) length of the screen specimen. In Orientation 1 the sensitivity of the screen was varied by changing che ullage height, which varied the height of the liquid column on which the vibration acts and changed the hydrostatic pressure differential acting on the screen. Accelerations as low as $0.5 \mathrm{~g}$ readily produced screen breakdown in these two orientations.

Orientations 2 and 5 made the model the least sensitive to vibration. Accelerations greater than $2 \mathrm{~g}$ were needed to cause breakdown of the screen. In Orientation 5 the thickness of the controlled region $(2.4 \mathrm{~cm}(0.95 \mathrm{in}))$ plus a contribution of the liquid column in the bulk region, was the liquid column on which the vibration acted. The vibration only acted over the thickness of the controlled region in orientation 2, making the model least sensitive in that orientation.

Orientations 4 and 6 were intermediate in sensitivity. The liquid column was determined by the width of the model for Orientation 4 and a contribution due to the bulk liquid column was added for Orientation 6 .

The liquid column upon which the vibration can be defined to act in each orientation can be estimated by evaluating the pressure differential due to vibration at low freguencies. At the minimum test frequency of $5 \mathrm{~Hz}$, the screen and the structure did not appreciably amplify the pressure differential due to the vibration. This pressure differential can be calculaced based on a purely pgh hydrostatic relationship where the asceleration is the zero-to-peak amplitude of the sine vibration and the $h$ is the above ciscussed colum height. These calculations indicated that the liquid column height for Orientations 2,3 and 4 , where there was no bulk Iiquid height, was close to the dimension of the controlled liquid mass paralle1 to the direction of the vibration. The presence of bulk liquid on one side of the screen made the column height approximateiy equal to the ullage height, based on the data for Orientation 1. For Orientations 4 and 5 , the contribution of the bulk I Iquid was not as atsitent,

Based on this evaluation of the etract of inodel orientation, Orientation 1 was selected as the primary orientation for the remainder of the testing. This orientation was the critical condition for the effect of vibration on the model. Orientation 3 , which was the most sensitive to vibration, can be considered to be only a special case of Orientation 1. Since the ullage height could be varied in orientation 1 , the test conditions could be controlled to establish the point of screen breakdown for a given input 
acceleration. Most of the testing was performed using orientction 1. When some of the coarser mesh screens were tested, Orientation 5 was also used. In orientation 5 the ullage height could still be varied, but the nor i was much less sensitive to the vibration. This was desired due to ti: ow retention capability of the coarse screens.

Win. ofe dual element modeI with the $325 \times 2300$ Dutch twill screen was trat. Orientations 1 and 5 were used. On a relative basis, the response was:; nilar to that with a sinqle screen element. This comparison established that the orientation e ects investigated with the single element model were not unique to that configuration.

5. Effeat of Screen Support Method - The screen of each specimen was supported by one of six methods. These support methods are typical of star lard screen fabrication methods used in current development and flight acquisition systems. The six methods were:

(1) Bonded to Perforated Plate - ty a diffusion welding process the screen was bonded to a perforated plate.

(2) Supported by Perforated Plate - the screen rested on perforated plate, with the screen facing the bulk liquid side of the model.

(3) Unsupported - the screen was attached to an open frame around its periphery.

(4) Pleated - the screen was pleated prior to attaching it to an open frame.

(5) Internal $R i b$ - the screen rested on ribs that were located on the controlled liquid side of the screen.

(6) External Rib - tive screen was attached to ribs located on the bulk side of the scretn.

The details of the fabrication of the specimens were presented in chapter IV. These support methods gave a wide range of variation to the rigidity of the screen support.

Six screen specimens (Specimens 5 through 10) were made using each of the support methods, but with the same screen mesh, to perform a relative evaluation of the support methods. The $325 \times 2300$ Dutch twill screen and isopropyl alcohol as a test liquid were selected to give a large retention capability and therefore improve the resolution of the effects of the vibration. Orientation 1 was used for all the tests. The controlled region was completely filled with liquid, random vibration was applied to the model and the bulk region was drained until screen breakdown was detected. The ullage height al wich slight, significant and excessive screen breakdown (see the screen breakdown discussion) occurred was identified for various vibration levels. The point of significant breakdown was used in this comparison since it was the most well defined breakdown condition. 
A random vibration spectrum with a constant power spectral density over a renge of frequencies was selected for these tests (Figure $V-6$ ).

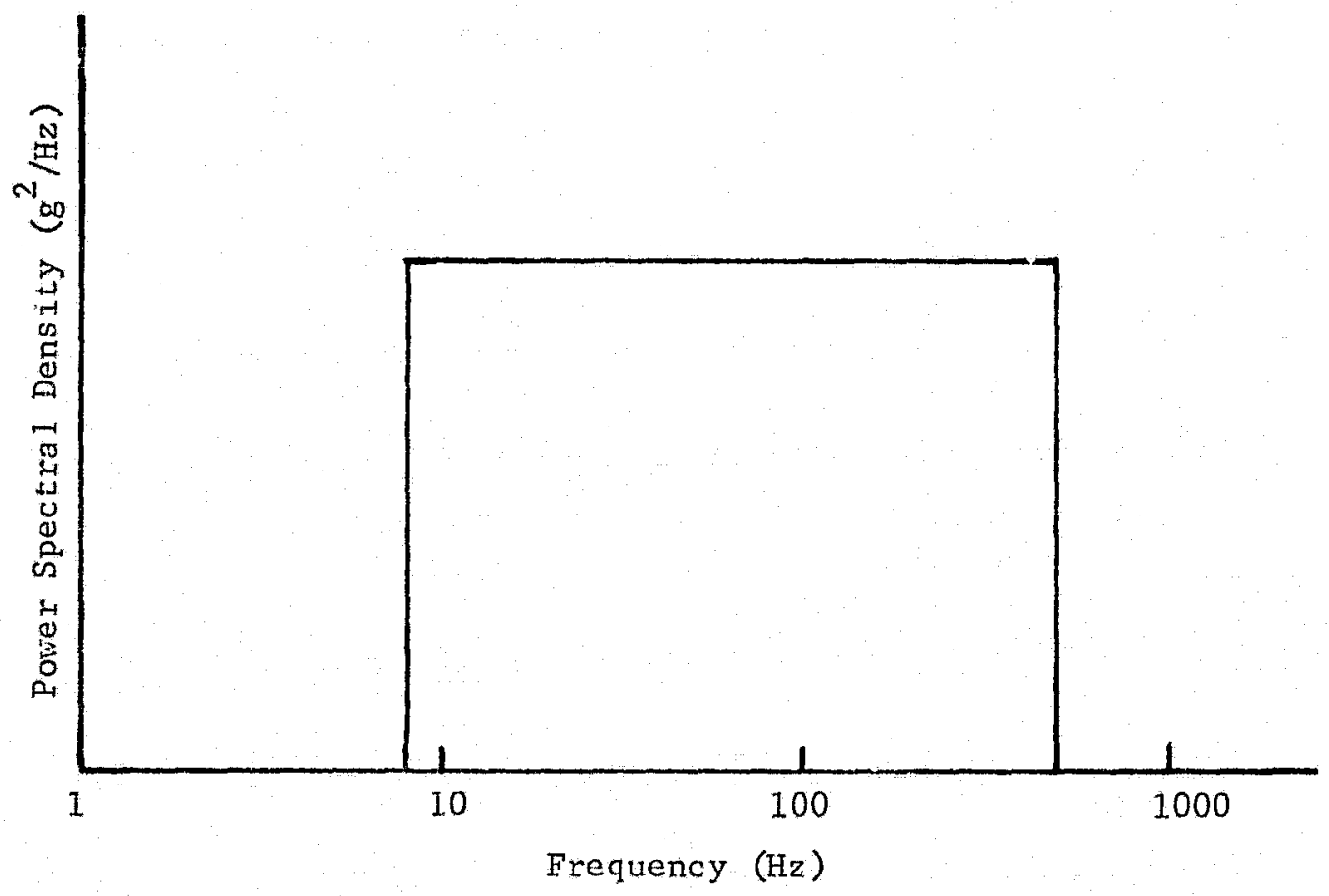

Figure V-6, Random Vibration Spectrum

The spectral density of this spectrum can be shifted either up or down to change the applied overall gRMS level, Such a spectrum adequately excited the lower frequencies where the harmonics of the model lay. A lower limit of $8 \mathrm{it} z$ for the frequency range extended the spectrum below the harmonic frequercies. By setting an uppe: frequency limit of $500 \mathrm{~Hz}$, the resolution of the spectrum at the low frequency end was improved. This is due to the Iogarithmic frequency increments of the filters used to form the spectrum. The resolution of the logarithmic increments to the spectral density, provided with this spectrum, also fit the total test system sensitivity. It was also found that this spectrum could be accurately reproduced each time a test was performed.

The objective of these tests was to establish a constant set of conditions under which each support method could be evaluated. For each support method the same range of gRMS levels were applied and the liqu'd retention 
height for each level was established. In effect, these testi simulated various surface tersion levices in the same spacecraft, with a given vibration environment, and the available retention capability of the screen was established.

The results of these comparative tests are shown in Figure $V-7$. The powex spectral density defines the level of the vibration and the ullage heitht: is the point at which the screen breakdown becane signilicant.

The general trend in the curves indicates that as the ullage height increases, the screen was more sensitive to vibration. This is consistent with the previous discussi n of the effects of model orientation. Increasing the ullage heignt, increased the liquid column on which the vibration acted and produced greater pressure differentials due to vibation.

The curves show that there was a definite effect due to the screen support method. The two extremes caused a difference in retention capability that amounted to around $15 \mathrm{~cm}$ ( 6 in) in ullage height. All six curves are similar in form. The curve for the external rib support method has more curvature than the others, causing it to be the only one that crosses another, There is an unusual bend in the curve for the pleated support method.

The curves converge at small values of ullage height. This is to be expected because the influence of the support method will become less as the amount of screen exposed is less. The support method lost its influence when the screen was subnerged in the liquid. For the same reasons the trends of the curves are most varied at large ullage heights, when the effect of the support method was most pronounced. If all the curves are extrapolated in the region of small values of ullage height, they almost intersect at a point on the zero ullage height axis. If this truly did happen, it would imply for this model that the screen would always break down if the spectial density was greater than about $0.1 \mathrm{~g}^{2} / \mathrm{Hz}$.

The pleated support method made the screen the least sensitive to the vibration environment. The bonded to perforated plate support method was next in sensitivity. These are the two methods that most rigidly support the screen. The external rib support method or the supported by perforated plate support method make the screen the most sensitive to vibration, depending on the range of the ullage height.

It is hypothesized that the support method influences the sensitivity of the screen to vibration in two ways. One factor is the bulk displacement of the screen that occurs when the entire screen panel or the individual windows of the specimen displace in response to the vibration. The other factor is the localized displacement of only a small area of the screen. This localized displacement occurs due to any looseness of the screen, which is inherent in the typical fabrication methods that were used. When localized displacement did occur it could be observed and did lead to screen breakdown in those same areas (see Screen Breakdown discussion). 


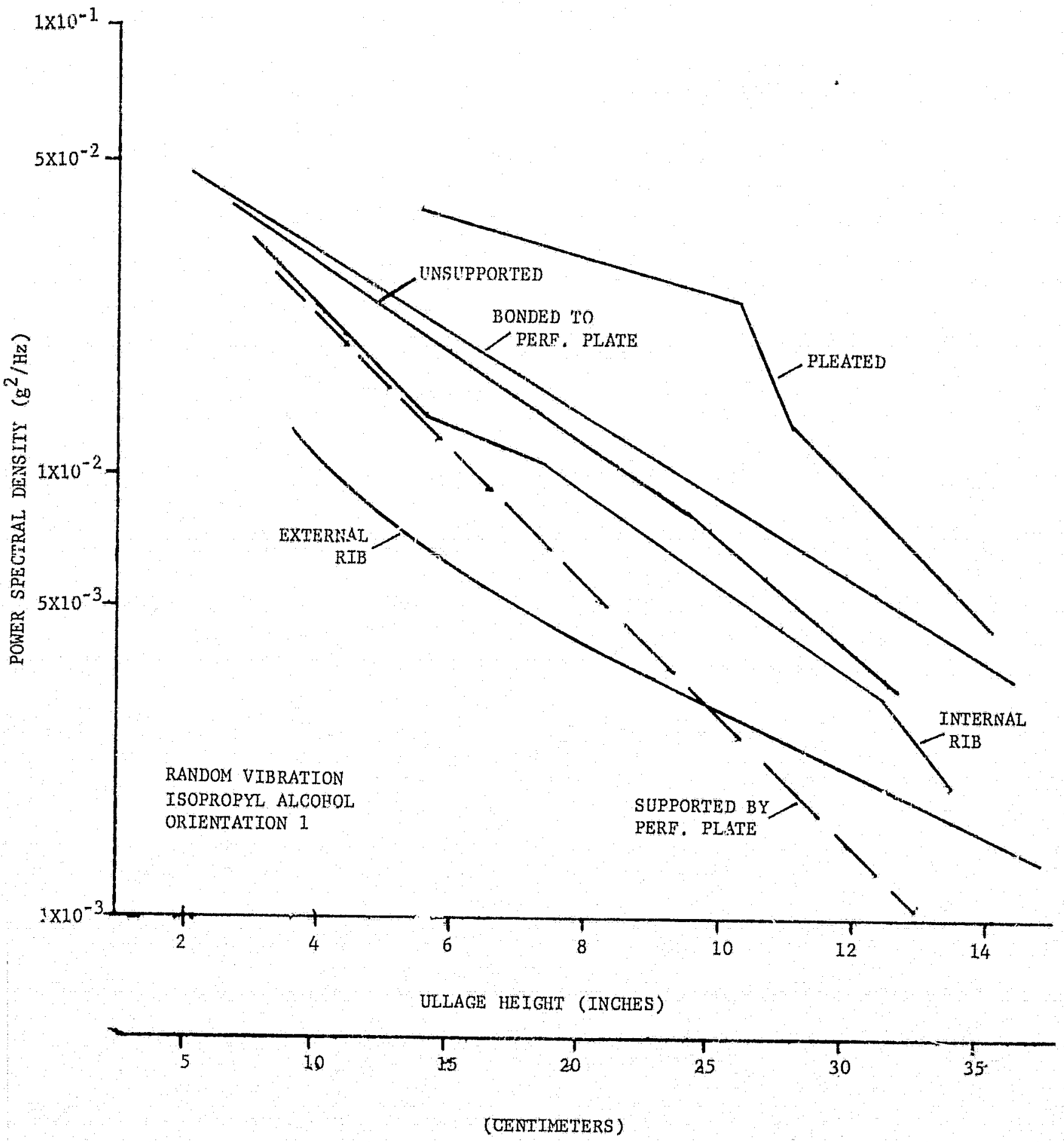

Figure $V-i$. Influence of Screen Support Method on Response to Vibration 
Bulk displacement of the screen permits the controlled liquid volume to change with very little hinderance, therchy relieving the pressure differentials that could ba created by the vabration. Displacement of the screen toward the controlled liduiti side of the model acts to relleve a lowering of the pressure In that region which is tending to cause screen breakdown. wowever, the localized dinglitweme produccs pressure gradients in the area of the oscillation that add to the pressure differential produced by the bulk displacement, increasing the total pressure differential acting on the screen.

This hypothesis is appliet to the test results as described in the rollowing paragraphs. The specimein with the pleated support method had the pleats runnine, the long direction of the specinen, This pleat configuration allowed arsidcrable bulk tollection of the screen. Approximately $0.7 \mathrm{~cm}$ $(0.3 \div n)$ of displacement of tho screes at its center occurred during the bubble point test. The displarenent was constrained more by the flexibility of the screen ploats than by the stiffness of the screen material. The pleat geometry rigidly construined the screen with respect to localized displacement and no localized screen breakdown was observed. This combination of bulk flexibility and localized rigidity made the pleated specimen least sensitive to the vibration. As the ullage height varied, there must have been a change in the node of the bulk displacement which would account for the slope changes in the curve for this specimen. If the pleats of the specimen ran in the oprosite direction (the width of the specimen) the bulk displacement would bo much $1 \mathrm{sss}$. is would be expected that its response would be similar to that of the bonded specimen.

The bonded specimen a? so was lucal screen ricidity. The small unsupported span of $0.95 \mathrm{~cm}(0.38 \mathrm{in})$ liminates the local screen displacement effects. No localized screen breikdown was observed with this specimen. Bulk displacement of this sereen was limited by the perforated plate. This lack of bulk displacement incre lsed the sensitivity of the screen to vibration. However, the lack of localized displacement made this specimen less sensitive to vibration than the remaining specimens.

The unsupported speciman had considerable bulk displacement, but there was some localized displacement. The two effects balanced out to make it somewhat more sensitive than the bonded specimen.

The internal ribs limited the bulk displacement of the screen as it deflected towerd the controlled liquid side of the model, increasing the sensitivity in comparison to the unsupported specimen. When the screen was supported by perforated plate, nn displacement toward the controlled region was possible making this specimen more sensitive than the internal rib specimen.

The external ribs limited the bulk displacement in both directions because the screen was attached to the ribs. The addel seam welds across the ribs introduced more wrinkles, which are the cause of the localized displacement. Localized screen brealedown was the most pronounced with this support method. As the ullage height increased, the bulk displacement of the external rib specimen improved since more panels were exposed. In comparison, 


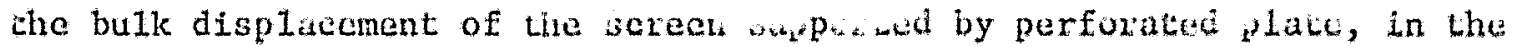
direction of the controlled 1tyuid region (the critical direction), could not change the ullage height. These effects explain why the curves for the external rib and the supported by perforated plate specimens cross.

At suall ullage heights the bulk effect was essentially the same for all specimens since most of the screen is submerged. Localized displacement was somewhat independent of ullage height, especialiy in the case of the external rib specimen. For these reasons, the external rib specimen was woh more sensitive to vituation in comparison to the other specimens at low ullage heights.

Sine sweep tests were also performed on each of the six above discussed specinens. These tests aid in substantiating the above conclusions derived from the random vibration tests. By comparing the results of sine sweeps at various accelerations and ullage heights a relative ranking of the sensitivity of the specimens can be established. The occurrence of screen breakdown of the peak pressure amplitude are the data used to make the comparison.

The plented and bonded specimeis were again shown to be least sensitive, but there were not anough tests to clearly define the relative raiking af the other four specimens. It was noted that Specimen 1 would be ranked as more sensitive to vibration than the external rib specimen. Specimen 1 was supported similar to the external rib method, except that specimen 1 had only two rindows at top and bottom, instead of five. Specimen 1 would have less bulk displacement makir $g$.t more sensitive to vibration.

During the sine sweep tests the specimen with the screen supported by perforated plate was tested in two different ways. First, the screen was installed in the model as intended with the ferforated plate on the controlled region side of the model. Then the same tests were repeated with the specimen reversed so the perforated plate was facing the bulk side of the model. Under identical test conditions the pressure differential amplitudes were found to be about fifty pereent greater when the perforated plate was facing the controlled region of the model. When bulk displacement into the con " trolled recion was permitted (perforated plate on bulk side) the screen was less sensitive to vibration.

A similar substantiation was achieved with the sine sweep data for the other screen meshes. The $325 \times 2300$ screen mesh was the only mesh for which a11 the support methods were tested. This was done so that the above described comparisons could be made. To verify the effect of the support: method, only a few selected support methods were used for the samples of the other screen meshes. As a minimum, an external rib specimen was fabricated for each screen mesh.

Two $200 \times 1400$ specimens were tested: one that was unsupported (Specimen 20) and one with external ribs (Specimen 11). From the four sine sweeps that could be directly compared, little difference $n$ their response was 
measured. In one test the pressure differential peaks were treater for one specimen, but the oppositn $y$ trae for mothar tast. The oceurionce and degree of screen breakdown was the sme lor all four tests. yue to the way that externa rib spcimen was fabricated the localized effects must have been much less, moking tle two specimens similar in response. Since the $200 \times 1400$ sereen has thiclear wires than the $325 \times 2300$ seretn,

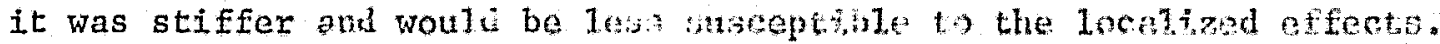

Three $165 \times 800$ Dutch twil1 scresu specinen vere tegted bonded co frerm forated plate (Specimen 18), unsupported (Specinen 21) and external rib (Specimen 12). The data were lituted, but the same ranking obtained from the $325 \times 2300$ tests was indicated.

Four 165 x 800 plain Duteh screan specmens tere testod supported by

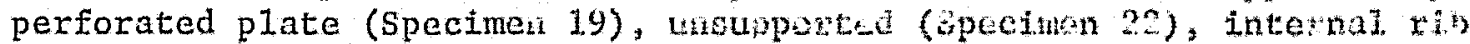
(Specimen 23) and external rib (specimen 13). The two specimsns with ribs were similar in response, both being more sensitive to vibration than the others. Based on the measured pressure differentials the unisupported specimen was more sensitive to vibration than the supported by perforated plate specimen. However, the male varlation in buble point for these $165 \times 800$ plain butch spaciner (1\%) male tix ir omparion difficule.

A pleated $80 \times 700$ screen specimen (Specimen 26) was tested in addition to an external rib specimen (Specimen 14). Their sensitivity was essentially the same. The pleated specinen had a lower bubble point due to the screen pleating operation. This screen mesh, and sone of the other coarse screens, did not display the harmonics that were present with the finer screens. The peak pressure differential amplitude occuried at $5 \mathrm{~Hz}$ and decreased as the frequency increased during the sine sweep. This type of response is a function more of the liquid mass than tre support structure. The low bubble point required that low acoeleration values $(0.5 \mathrm{~g})$ and low ullage heights $(\ll 13 \mathrm{~cm}(5 \mathrm{in}))$ be used, further reducing the structural contribution. In addition, the stiffness of the coatse screens eliminated any localized screen oscillation effects.

Three $850 \times 155$ screen specimens were tested o lwo were unsupported with opposite weave orfentations (Specimens 24 ans 25 ) and the third was an external rib (Specimen 16). In four 1 the tiatis lifexernal rib specimen was definitely more sensitive to vibution thin the others. As previously discussed, weave orientation did not influence the response.

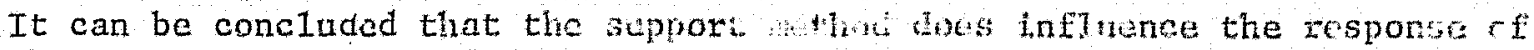
the screen to vibration. A structural sumport method that allowe bulk displactment of the screen, makes the sureen lese sensitive to vibration. Displacement into the controlled region acts to relieve the pressure differential due to the vibration. This approach conflicts with the need to limit deflection into the controlled region so that the chanel flow area is not constricted. Localized displacement of the screen increases its senstivity to vibration. Certain support methode indree localised displacement due to screen wrinkling that is inherent in the fabrication process. The coarser mesh screens are less likely to exhibit this localized displacement because of their greater stiffness. 
6. Effect of Screen Mesh - The bubble point of a screen determines the capacity of a screen to maintain its retention capability in a vibration environment. Ancther factor is the structural stiffness of the screen material which influences the dynamic response of the screen to vibration. Eight different: screen meshes were evaluated in the course of the testing. ihe vartous meshes, listed in order of decreasing bubble point, were:

$\begin{array}{ll}325 \times 2300 & \text { Dutch twill } \\ 200 \times 1400 & \text { Dutch twil1 } \\ 850 \times 155 & \text { Robusta } \\ 165 \times 800 & \text { Plain Dutch } \\ 165 \times 800 & \text { Dutch twi11 } \\ 80 \times 700 & \text { Dutch twi11 } \\ 50 \times 250 & \text { Plain Dutch } \\ 200 \times 200 & \text { Square }\end{array}$

These screens are representative of the full span of available fine-mesh screens. Most of the above screens are or soon will be used in flight qualified surface tension devices.

A set of eight screen specimens, all usirg a common support method, were fabricited and tested. The external rib support method was used since it was judged to provlde a representative, b't basic in nature, response. Specinens using the "unsupported" support method for five of the screen meshes tere also testied, permitting further comparison.

It was found that the iner mesh screens were more likely to exhibit localized screen breakdown (see Screen Breakdown discussion). Localized screen oscillation and breakdown did not occur with the $50 \times 250$ and $80 \times 70$ screens, both of which have relatively large wire dlameters and are stiff. Localizcd effects were most prevalent with the very fine $325 \times 2300$ screen and it was noticed to some degree in the other meshes.

The $200 \times 200$ screen also displayed localized effects, but this was due to its open and flimsy structure. It could also be observed that the impact of sloshing liquid on the bulk side caused gas penetration with this screen.

When significant or excessive screen breakdown occurred with the $200 \times 1400$ screen it had a characteristic difference from the other screens. Breakdown would produce lines of bubbles, aligned with the shute wires of the screen. This effect was not observed during the bubble point test.

It is difficult to draw very many conclusions regarding the effects of screen mesh from a direct comparison of the data. Depending on the retention capability of the screen, different acceleration and ullage heights had to be used. These data were primarily intended for the analytical model development.

One direct comparison that was performed was to compare the peak differential pressures and the occurrence of breakdown for all the external rib specimens. Most of the specimens were tested in Orientation 1 and isopropy 1 
alcohol was used as the test liquid. Tha $50 \times 250$ and $200 \times 200$ screens were only tested in Orientation 5 due to their low retention capabizity.

The relative ranking of the screen specimens, based on their sensitivity to vibration is the same as their rank based on bubble point. One exception could be the $325 \times 2300$ screen, but there was not sufficient data to be sure. In one pair of tests ( $1.0 \mathrm{~g}$ sine sweep with $20.3-\mathrm{cm}(8.0-\mathrm{in})$ vilage height) there was excessive breakdown with the $325 \times 2300$ screen, but only silight breakdown with the $200 \times 1400$ screen. In two nther pairs of tests, the $325 \times 2300$ and $200 \times 1400$ screens had no breakdown in one case and significant breakdown in another case. The $325 \times 2300$ screen had a bubble point that is $50 \%$ greater than the $200 \times 1400$ screen, but the data irdicate that they were approximately equal in their sensitivity to vibration or the $200 \times 1400$ may be 1 ess sensitive (based on the one data point). This may be due primarily to the influence of the Lccalized effects on the response of the $325 \times 2300$ specimen. The external rib support method was found to make the screen more sensitive to vibration because the localized effects were most ronounced with this support mathod (see discussion of the effect of support method). The $200 \times 1400$ screen, being somewhat stiffer, was not as strongly influenced by the external rib support method.

A similar comparison was performed using data from the various mesh unsupported specimens. Again, the ranking of their vibration sensitivity was consistent with their retention capability, except for the $325 \times 2300$ screen. These results indicate that the $325 \times 2300$ screen was more sensitive to vibration than the $200 \times 1400$ screen. For one set of 1 ike conditions, the screen breakciown was mure severe with the $325 \times 2300$ screen. For another set of like conditjons the peak differential pressure amplitude, with no screen breakdown, was about twice as great with the $325 \mathrm{x}$ 2300 screen.

7. Effect of Liquic Flow - Many of the screen specimens were tested under the combined conditions of vibcation and outflow. The approach was to first perform a sine sweep test of the specimen with no flow and then to repeat the test with outflow. Outflow was simulated using a flow loop that was described in Chapter IV (see Figure IV-15). Basically, liquid was pumped from a reservoir into the model and then returned to the reservoir. This flow loop made the bulk region of the model equivalent to an infinite reservoir of liquid. The ullage region was pressurized, balancing the pressures so that a selected value of ullage height could be maintained during the test. The flow conditions remained constant during the test so the only variable was the frequency of the sine vibration.

Flow tests were performed with isopropyl alcohol and Freon 113, usiug Orientations 1 and 5, and using the single and double element models. A11 of the tests were sine sweeps since effects of the flow on the harmonics of the system were desired. A single flow rate of $20 \mathrm{ml} / \mathrm{sec}\left(1.2 \mathrm{in}^{3} / \mathrm{sec}\right)$ was used for all the tests. This flow rate was adequate to produce an effect on the vibration response without causing significant flow losses within the model. By using this approach, the flow 1 osses did not complicate the interpretation of the test results. 
Some selected flow tests are shown in lable $V-2$. All of these tests were performed using Orientation 1 and with isopropyl alcohol as the test liquid. The effect on the serecn response is shorn in this table by comparing the frequency and amplitude of the first harmonic with both flow and no flow.

In general, it was found that the effect of the flow was to increase the frequency at which the first harmonic occurred, which resulted in the peak differential pressure either remaining the same or decreasing. There are a few exceptions to the above conclusions which will be discussed later. The alift in the frequency ranged from only 1 th: (the dual element model test with Spectmens 10 and 27) to one test with specimen 1 where it changed by almost a factor of 3 . The shift in frequency appears to be a function of the screen flow area, with the frequency shift being greater for a small area. For the test with the dual element model (Specimens 10 and 27) the screen flow area was $271 \mathrm{~cm}^{2}\left(42 \mathrm{in}^{2}\right)$ and a small frequency shift resulted, specimen 1 had only a $58 \mathrm{~cm}^{2}\left(9.0 \mathrm{in}^{2}\right)$ screen flow area, which gave the largess frequency shift. The other data points also fit this trend.

When the outflow caused a decrease in the peak differential pressure, the non-flow case was the worst case test condition. For example, during the first test listed in the table, slight screen breakdown occurred when the non-flow test was performed. Under flow conditions Iiquid was expelled from the top of the model so the flow losses added to the hydrostatic pressure, making the screen more susceptible to breakdown. However, the pressture differential due to vibration was reduced by the flow such that no screen breakdown occurred during thri flow test.

lests were performed using Specimen 1 to determine if the flow path through the model influenced the response of the screen to vibration. For an actual surface tension device in a tank, liquid in the bulk region flows through the screen and out of the tank through the device. In the model this was simulated by flowing liquid into the bulk region at the bottom of the model and expelling from the top of the controlled region. In the other case, the model simulates a portion of a surface tension revice in which the flow is just passing through the controlled region. The flow entered the controlled region at the bottom and left at the top. Some ullage height was matintained in the bulk region to control the hydrostatic pressure differential acting on the screen.

The first two tests listed in Table $\mathrm{V}-2$ show the results of this comparison. With identical vibration conditions, the flow path did alter the response to vibration. When the flow enters the bul side and must pass through the screen, the response was as described above. When the flow entered the controlled region and did not pass through the screen, the response was different. The frequency of the harmonic was slightly reduced ( $1 \mathrm{~Hz}$ ) and the peak differential pressure increased somewhat.

There are three exceptions listed in Table $V-2$ to the above conclusions regarding the effect of flow. One is the test with specimen 11 , a $200 \mathrm{x}$ 1400 screen, in which no change in either frequency or pressure differential between the non-flow and flow condition was detected. Compared to the 
Table $V-2 . \quad$ Effect of Flow on Screen Response

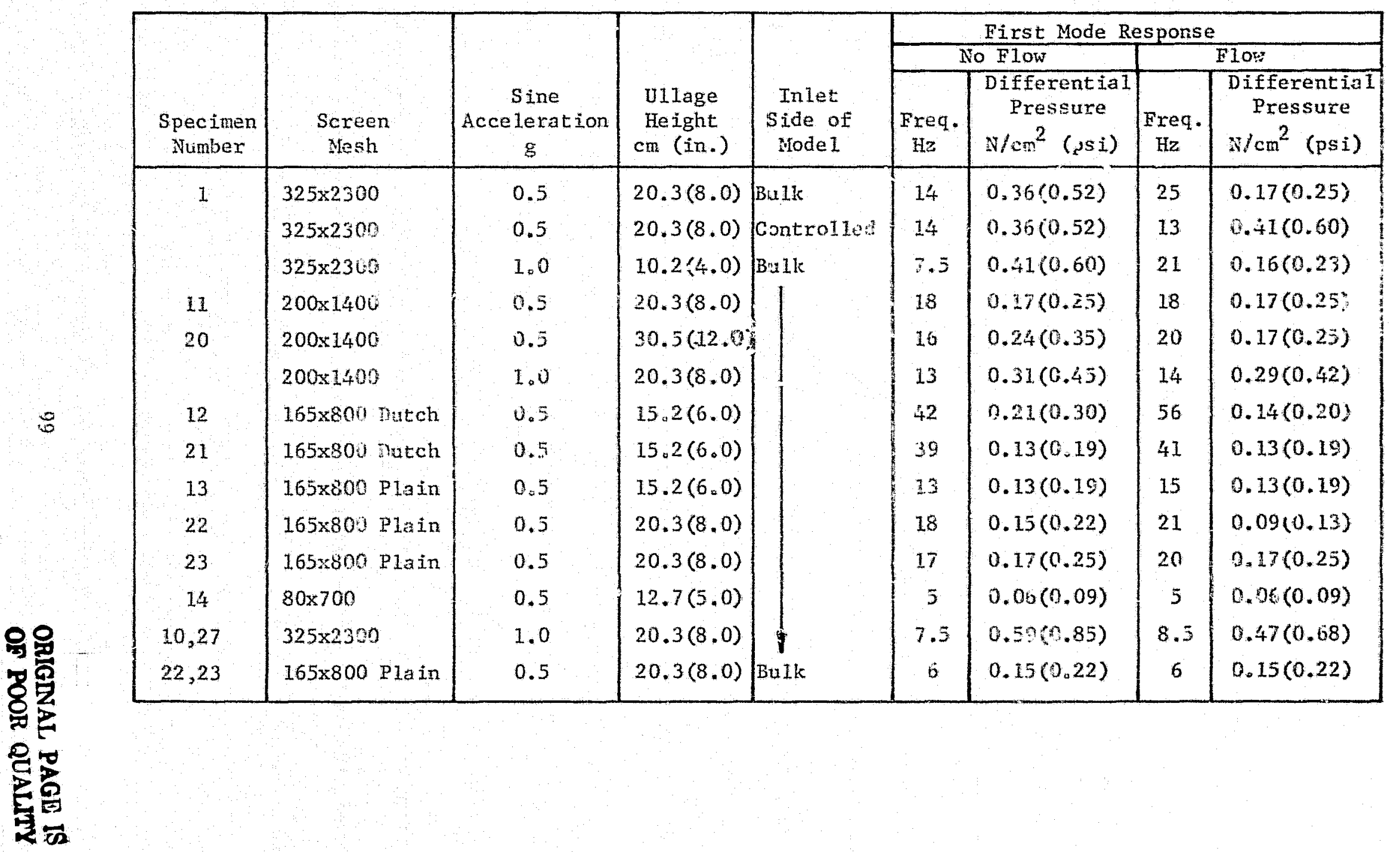


results with specimen 20 , another $200 ; 1400$ sexts, this result would be expected. The effect on frequency was small with the greater $1.0 \mathrm{~g}$ acceleration and the same ullage height and llow arca. With the greater ullage height and ruch smallex flow area, the frequency shtit was still only $4 \mathrm{~Hz}$ for the other $0.5 \mathrm{~g}$ test.

The other two exceptions are tir results with specinen 4 and the dual elenent tests with Specimens 22 and 23. In these two cases the system did not have a true harmonic frequency. The pressure differential was a maximum near the minimum shaker frequency of $5 \mathrm{~Hz}$ and decreased at higher frequencies. Flow did not change this condition, either in frequency or amplitude. With this type of response the flow condition will be the worst case. The effect of vibration remains constant, but the flow losses will increase the pressure differential acling on the screen.

To summarize, this eviluation indicates that the effect of liquid flow is to either not change the effect of vibration or to reduce the effect. A reduction in the vibration effect is accompanied by an increase is the harmonic frequency, that is a function of the flow area through the screen. If the pressure differential due to vibration was known under static conditions, a conservative approach would be to use the same differential for the flow condition, but also consider the flow losses. No explanation for the mechanisms of the flow effects can be given.

8. Effect of Dual Screen Elements - Two basic model configurations were tested. The previous discussion th this chapter has considered the single element model, with a bulk region and a controlled region separated by the screen specimen. The other model configuration used two screen specimens to form the controlled liquid region. This configuration simulated a channel of a surface tension device having screen panels on opposite sides.

There were three regions to the dual element model: a controlled region in the center and a bulk region on each side of the controlled region. The two bulk regions were externally coupled so they had the same pressure and ullage height (a complete description of the dual element model was presented in Chapter IV). The tests with the dual element model were performed in the same manner as the single element tests.

Some of the dual element data has already been discussed in this chapter. It was found that the effect of model orientation on the sensitivity of the model to vibration was the same for the dual element model as it was for the single element model. The effects of flow on the response to vibration were also similar.

The response meas,ured during the single element tests could be compared with the results of the dual element tests. Specimen 10 was tested as a single element and then Specimens 1.0 and 27 were tested as dual elements. Both Specimens 10 and 27 were $325 \times 2300$ screen and were supported using the external rib method. The ribs of the two specimens were aligned so that they were staggered. The ribs of one were positioned so that they were located between the ribs of the other specimen. 
The comparison of four common sine sweep tests between the single and dual eiement models shows that the dual elment ras less sensitive to the same vibration environment. Comparing the occurrence of screen breakdown showed that efther breakdown occurred with the single element while it did not with the dual elements or breakdown was more severe with the single element model.

This direct comparison may not be valid because there was a difference in the liquid mass in the controlled reglons of the two configurations. For the single element model, the thickness of the controlled region was $2.4 \mathrm{~cm}$ $(0.95 \mathrm{in})$. The length and width of the controlled region for the dual element model was the same, but it was only $1.3 \mathrm{~cm}(0.50 \mathrm{in})$ thick. It would be expected that the pressure differential due to vibration would decrease as the mass being vibrated is decreased. Based on the conclusions for the effect of the support method, the increase in screen area, due to two screen specimens instead of one, would peruit more bulk deflection and also reduce the sensitivity to the vibration. The contributions of each of these aspects in reducing the vibration sensitivity in zhe dual element configuration cannot be established by a direct comparison.

A similar comparison can be actempted, considering the other screen mesh that was tested in the dual element conflguration. Specimens 22 and 23, both 165 x 800 plain Dutch screen, were tested individually and then were tested in the dual element model. They have different support methods, unsupported for Specimen 22 and internal rib for Specimen 23. A comparison, based on the occurrence of screen breakdown, of five common sine sweep tests does not indicate any pionounced difference between the single and dual element results. There vas a definite decrease in the harmonic frequency, going from about 15 to $20 \mathrm{~Hz}$ as a single element to $6 \mathrm{~Hz}$ in the double element configuration.

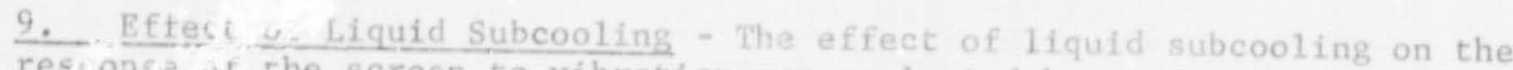
resjonse of the screen to vibration was evaluated by performing identical tests wich two different test 1iquids. The two liquids used were Freon 113 and Freon 11. They both have similar densities and surface tensions (see Table IV - 1), but their saturation curves are quite different (Figure V-8). At $20^{\circ} \mathrm{C}\left(68^{\circ} \mathrm{F}\right)$ Freon 113 has a vapor pressure of $3.7 \mathrm{~N} / \mathrm{cm}^{2}$ absolute (5.3 psia) while for Freon 11 it is $8.8 \mathrm{~N} / \mathrm{cm}^{2}$ absolute (12.8 psia). With a local atmospheric pressure of about $8.3 \mathrm{~N} / \mathrm{cm}^{2}$ absolute $(12.0 \mathrm{psia})$, Freon 11 is boiling at room temperatire. In tems of subcooling, at a temperature of $20^{\circ} \mathrm{C}\left(68^{\circ} \mathrm{F}\right)$ and with the model pressurized to $3.4 \mathrm{~N} / \mathrm{cm}^{2}$ gage $(5.0$ psig) the Freon 11 would be $8.3^{\circ} \mathrm{C}\left(15^{\circ} \mathrm{F}\right)$ subcooled and the Freon 113 would be $32^{\circ} \mathrm{C}\left(58^{\circ} \mathrm{F}\right)$ subcooled. The results for these liquids could also be compared with the results from the isopropyl alcohol tests, which would be $70^{\circ} \mathrm{C}$ $\left(126^{\circ} \mathrm{F}\right)$ subccoled under the same conditions. However, the different density and surface tension of the alcohol does not permit the direct comparison possible witli the Freons.

Under conditions in which no screen breakdown occurred, no difference in the response would be expected between the two test liquids. As long as there is an adequate reservoir of liquid on one side of the screen (provided by the controlled region in this case), the retention capability of 


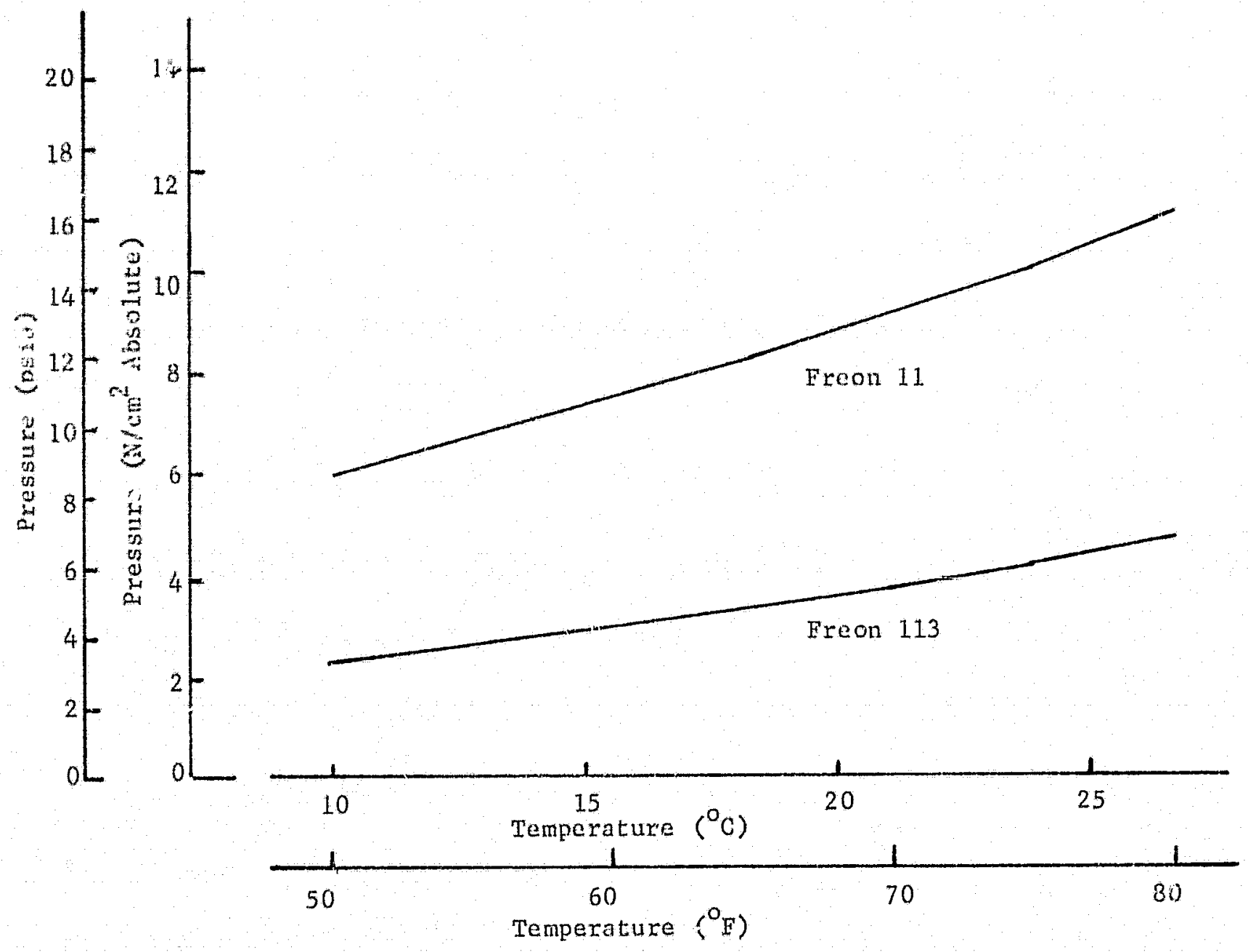

Figure V-8. Saturation Curves for Freon 11 and Freon 113 (Ref. V-4) 
the screen is not influenced until very high heat fluxes are applied and the liquid is at saturation (Ref. V-5). However, in the case where? wetted screen is exposed to gas on both sides, its retention capability is highly dependent on the pressurant saturation and thermodynamic effects (Ref. V-6). The objective of these tests was to evaluate the response of the sc:een when breakdown occurred due to vibration, to determine if the amount of subcooling had an effect.

The approach was to find sine sweep test conditions, first using the Freon 11.3, that cause excessive screen breakdown resulting in the exposure of the controlled 1iquid side of the screen to gas. Since the screen was being exposed to gas during the test and continued to be vibrated, the test was primarily evaluating the effects of vibration on its retention capability and not screen dryout due to thermodynamic effects. Up to five sine sweep tests producing the conditions described above were identified. Then the tests were repeated using the Freon 11 as the test liquid.

Four screen specimens were used in this evaluation: Specimen 10, $325 \times 2300$; Specimen 11, $200 \times 1400$; Specimen 25, $850 \times 155$; and Specimen 15, $50 \times 250$. Al1 of these tests were performed using model Orientation 1 . The model was pressurized to $3.4 \mathrm{~N} / \mathrm{cm}^{2}$ gage $(5.0 \mathrm{psig})$ and the room temperature was used to establish the saturation condition. The sine sweep started at $5 \mathrm{~Hz}$ and when the frequency reached $100 \mathrm{~Hz}$ the shaker was shut off and the liquid levels in the bulk and controlled region were monitored for about one minute to determine if the screen still had any retention capability. Screen break= down usually commenced at or near $5 \mathrm{~Hz}$ and had ceased by $100 \mathrm{~Hz}$.

With only a few exceptions, there was no difference in the screen response between the Freon 113 and Freon 11 tests, regardless of acceleration level, ullage height and screen mesh. The volume of gas that passed through the screen as it broke down was approximately the same for both test liquids. At the end of the test the screen vas still supporting some hydrostatic pressure differential, as indicated by the difference in liquid levels between the bulk and controlled regions,

The exceptions occurred during the tests of the $50 \times 250$ screen, which was the most susceptible to dryout of the screens tested. At the end of the test the liquid levels were equal in two out of three of the Freon 113 tests. For the same conditions bui using Freon 11, which would be more likely to cause screen dryout, the screen still had some retention capability at the end of the test.

These results indicate that the amount of liquid subcooling did not effect the screen response to vibration. If there was an effect there would have been a significant difference in the response with the Freon 11 test liquid. The unusual results with the $50 \times 250$ screen are due to the minimal wicking carability of this screen rather than the subcooling of the liquid.

10. Miscellaneous Effects - A few other factors regarding the response of the screen to vibration which were derived from the test data are noted in this section. 
a. Screen Acceleration - In all the tests it muniature accelerometer was mounted somewhere on the screen specimen. Various mounting locations and orientations of the accelerometer's axis were used.

In the early tests with Specimen 1 , the acceleroneter was mounted on the frame of the specimen and its axis was parallel with the vibration axis. In this mounting the accelerometer output was the same as that of the shaker control and monitor accelerometers. This arrangement permitted the pressure response to be compared with the input acceleration. As previously discussed, the phasing between the pressure and acceleration, as influenced by the harmonics, was established with these measurements.

The accelerometer was then mounted in the center of the $7.6 \mathrm{~cm}(3.0 \mathrm{in})$ screen panel of Specimen 1, with the accelerometer axis perpendicular to the screen. Comparisons of the pressure data showed that the small accelerometer did not change the response of the screen. It was also found that the accelerometer could be glued to the screen and removed without causing any screen damage or bubble point degradation. In all the subsequent tests the accelerometer was mounted on the screen.

There was no requîrement for the accelerometer to provide data to perform the data correiation. The pressure differential due to the vibration was the primary masurement and the screen acceleration was just supporting data,

The accelerometer showed that there was a definite relationship between the screen acceleration and the pressure differential due to vibration. At the harmonic frequency indicated by the pressure there was a peak in the acce1eration. However, the maximum acceleration was not always at the frequency of the maximum pressure differential. Large screen accelerations occurred at higher frequencies, accompanied by only a small or no increase in the pressure differential. This indicates that the screen can respond at high Erequencies, but the liquid does not, and the 1 iquid response produces the pressure differential.

The accelerometer, due to its small size, also indicated the localized screen oscillation effects. In some cases accelerations that were in excess of 30 times the input were measured by the accelerometer. The localized motion of the screen was rotating the accelerometer in addition to translating it, giving the unreasonably large outputs. For this reason, the data from the accelerometer were not a true indication of the screen response.

b. Screen Structural Integrity - The vibration tests provided a qualitative assessment of the capability of screen structures to withstand vibration. A surface tension device must be structurally designed to withstand the vibration loads applied throughout its operational life. The structural effects of vibration were determined by rechecking the bubble point of all the screens, using the standard bubble point test method, after the testing was complete. 
Only one of the screen specimens showed any degradation in bubble point. The pleated $325 \times 2300$ screen (Specimen 8) had a bubble point of $61.5 \mathrm{~cm}$ (24.2 in) of water before the testing and $32.3 \mathrm{~cm}$ (12.7 in) of water (using isopropyl alcohol at $20^{\circ} \mathrm{C}\left(68^{\circ} \mathrm{F}\right)$ after the testing, a very significant change. The pleating operation by itself caused some deiradation of the screen bubble point, about $3.8 \mathrm{~cm}(1.5 \mathrm{in})$ of water. The pleats had a fairly sharp bend radius and screen breakdown during the bubble point test occurred at the bends of the pleats. The pleats ran the long direction of the pecimen, giving the entire screen considerable flexibility. As the screen flexed, both in the vibration tests and due to handling, bending of the screen occurred at the bends in the pleats which increased the pore size at that location.

This specimen was subjected to consjderable vibration. Ten sine sweeps were performed at accelerations of $0.5 \mathrm{~g}, 1.0 \mathrm{~g}$ and $2.0 \mathrm{~g}$, with half of them being at the $2.0 \mathrm{~g}$ level. The sine sweeps were from $5 \mathrm{~Hz}$ to $100 \mathrm{~Hz}$ and back to $5 \mathrm{~Hz}$ at 2 octaves per minute, which subjected the screen to about 4.5 minutes of vibration each time it was performed. Sine dwells at 2.0g were performed. Finally, the random vibration tests applied levels between $0.2 \mathrm{~g}$ RMS and $4.4 \mathrm{~g}$ RMS over a period estimated to be about 1.5 hours. When the random vibration tests were performed the vibration was continuously applied. After draining to find the point of screen breakdown, the model was refilled and the acceleration level was increased without stopping the shaker.

By avoiding long pleat spans and using larger bend radij, the pleated screen would not be as likely to be degxaded by the vibration. Regardless, the effects of vibration on the structural interrity of pleated screen is more of a concern, due to the sharp radius bends, than it is with flat screen.

Specimen 1, which had only two $7.5 \mathrm{~cm}(3.0$ in) square screen openings, experienced the most vibration. One of the screen windows was usually submerged in liquid, so the other was subjected to the full effect of the vibration. With the full length specimns, the effect of the vibration was distributed over the exposed length of the screen. Many days of testing were performed on Specimen 1 because it was used to establish the basic effects of vibration. No record was kept of the actual amount of vibration time specimen 1 experienced, but it is estimated to be about 20 hours. Sine vibration up to $5.0 \mathrm{~g}$ and random vibration up to $3.0 \mathrm{~g}$ RMS was applied. No degradation of this specimen was measured.

A11 of the screen, with the exception of the $50 \times 250$, was used "as received" and the only operations performed on it being the attachment of the screen to the frame. The available $50 \times 250$ screen that was used had been annealed.

\section{B. Data Correlation}

In this section the specific results obtained through the correlation of the test data with the predictions of the analytical models are presented. Two models are considered: the hydrostatic model, developed under prior studies, and the structural dynamics model developed as part of this study. 
1. Hydrostatic Model - Prior to the beginnıng of this program the stateof- the-art for vibration modeling was what is referred to as the hydrostatic model. A complete description of the prior work related to the effects of vibration can be found in the Introduction. The hydrostatic model is described as part of the Chapter III, Vibration Effects Analysis.

The hydrostatic model is primarily applicable to predicting the effiects of random vibration. The prior correlations were based on random vibration data. A similar correlation was performed using the random vibration data collected in this study.

The first series of randon vibration tests was aimed at evaluating the influence of the vibration spectrum. The hydrostatic model does not consider either the harmonic frequencies of the system or the frequency of the applied vibration. These tests were performed to determine the validity of this approach.

As presented in Chapter II, Survey of Vibrational Effects, random vibration is specified by the power spectral density as a function of frequency. An overall g RMS level can be derived from any given spectrum. The three spectra shown in Figure $V-9$ were used to perform this evaluation. The first spectrum (Figure V-9a) has a constant power spectral density over a wide range of frequency, 4 to $2000 \mathrm{~Hz}$. The second spectrum (Figure $\mathrm{V}-9 \mathrm{~b}$ ) applied a constant spectral density at the higher frequencies from 100 to $2000 \mathrm{~Hz}$, with no input at the lower frequencies. The third spectrum (Figure $V-90)$ has a constant spectral density at low frequencies (4 to $100 \mathrm{~Hz}$ ) and no input at higher frequencies. In reality, the portions of the latter two spectra that were intended to have no input, did have a low power input due to shaker harmonics and noise. While these cantrihutions cannot be ignored, their influense on this evaluation were minimal.

The constant spectral density of each of these spectra can be adjusted so that a selected value of the overall vibration input, expressed in $g$ RMS, can be obtained. The shape of the spectrum remains constant and only the spectral density level is shifted. In the hydrostatic model, the $g$ RMS value is used to describe the applied random vibration.

The $100 \mathrm{~Hz}$ division between the low and high frequency spectra was selected based on the known range for the first harmonic of the screen specimens tested. The harmonic was always less than $100 \mathrm{~Hz}$, so the low frequency spectrum applied vibration at the resonant frequency, while the high frequency spectrum did not.

Screen Spucimen 1 (two $7.6 \mathrm{~cm}$ ( $3.0 \mathrm{in}$ ) square, $325 \times 2300$ Dutch twill screen windows) was subjected to these random vibration environments. It was positioned in orientation 1 (vibration and one-r parallel to the long length of the specimen) and isopropyl alcohol was used as the test liquid. The tests were performed by applying one spectrum, with a selected power spectral density and while maintaining that vibration environment, increasing the exposed screet height until screen breatiown was detected. The same test was repeated for various values of the spectral density and for each of the spectra. 


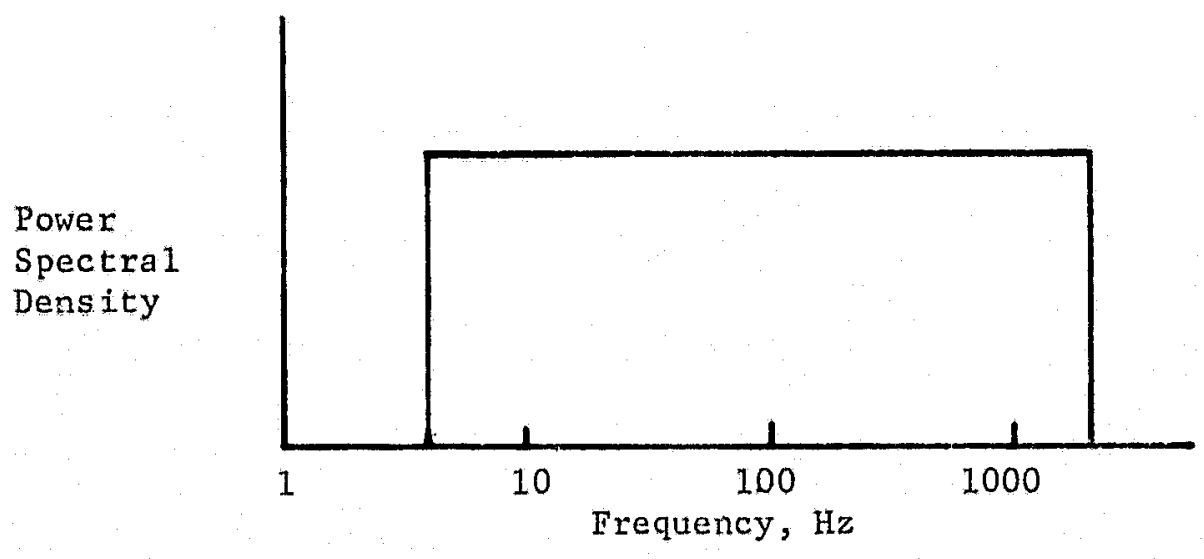

a. Flat Spectrum

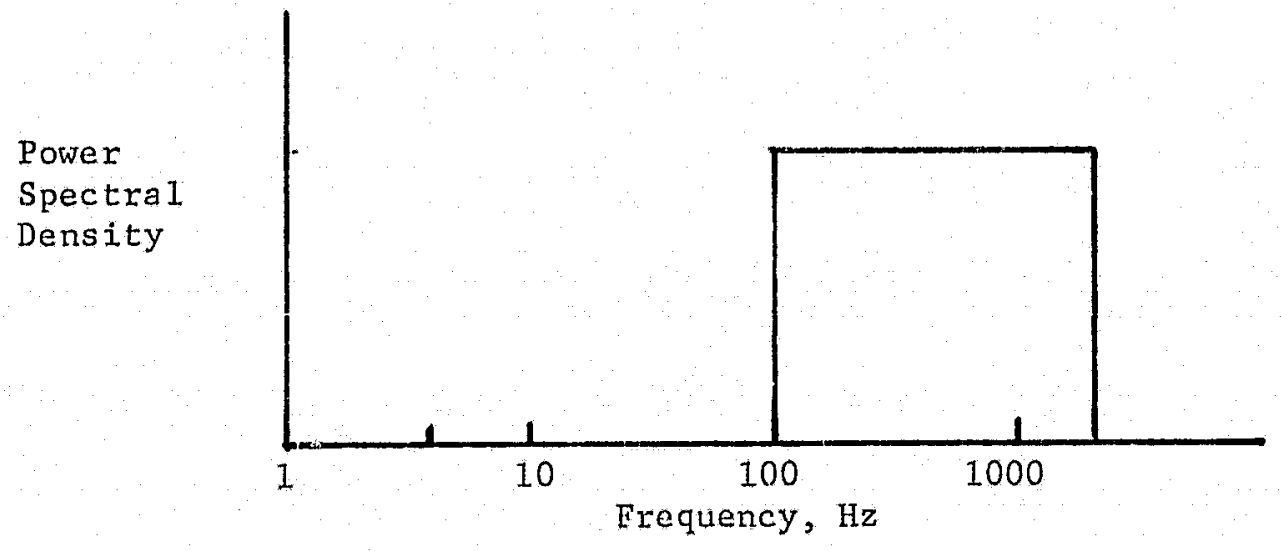

b. High Frequency Spectrum

Power

Spectral Density

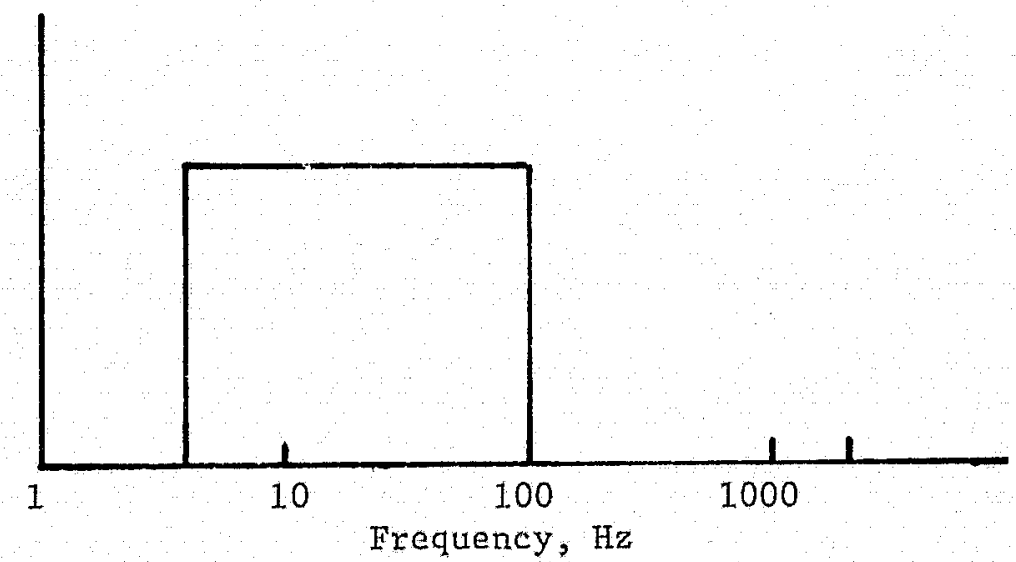

c. Iow Frequency Spectrum

Figure V-9. Random Vibration Spectra 
The effect on the scicuit rention capabilit; is

in in Figure V-10. Eich of the data points represents the ullage height at which significant screen breakdown was observed for the applied vibration, as defined by the overall $g$ RMS. The point at which slight, significant and excessive screen breakdown began was nottd for each test (see discussion of screen breakdown in the first section of this chapter). The amount of gas penetrating the screen during the slight breakdown was negligible. Significant breakdown was the most distinct condition, permitting better definition of the ullage height.

The results as presented in Figure $V-10$, show a definite effect of the frequency content of the spectrum. When the vibration energy was concentrated near the harmonic frequency of the specimen, the screen was the most sensitive to the random vibration. For a given value of $g$ RMS there was a large difference in the ullage height at which screen breakdown occurred. From these results it is obvious that frequency must be considered in addition to $g$ RMS in predicting the effects of random vibration.

In performing a correlation of this data the hydrostatic model predicts the contribution due to vibration based on the applied $g$ RMS acceleration and the ullage height:

$$
\Delta \mathrm{P}_{\mathrm{v}}=\rho \mathrm{g}_{\mathrm{rms}} \mathrm{h}^{\circ}
$$

For the test conditions, the sum of the hydrostatic pressure differential at the top of the screen, due to the bulk liquid level, and the contribution due to vibration should equal the screen bubble point at the point of screen breakdown, as follows:

$$
\Delta \mathrm{P}_{\mathrm{g}}=\Delta \mathrm{P}_{\mathrm{v}}+\Delta \mathrm{P}_{\mathrm{s}} .
$$

For the lower $\mathrm{g}$ RMS levels ( 1.2 and $1.5 \mathrm{~g}$ RMS) and the 4 to $2000 \mathrm{~Hz}$ spectrum the hydrostatic model predicted the effect of the vibration accurately ( $\pm 5 \%$ ). For the higher $g$ RMS levels the hydrostatic model predicted an effect due to vibration $\left(\Delta \mathrm{P}_{\mathrm{v}}\right)$ that was approximately one-half the measured effect. For the 100-2000 Hz spectrum the predicted effect was twice the measured and for the 4 to $100 \mathrm{~Hz}$ spectrum it was one-third.

One way to consider frequency in evaluating the effects of random vibration is to consider only the power spectral density at the harmonic frequency of the screen specimen. When the results shown in Figure $V-10$ are plotted as a function of the spectral density a more consistent result is obtained. The same data points now fall on one curve (Figure V-II), In the case of the 100 to $2000 \mathrm{~Hz}$ spectrum, the spectral density due to the inherent system noise, at the harmonic frequency of the specimen $(\sim 10 \mathrm{~Hz})$, was used. This factor, plus some uncertainty in defining the point of significant screen breakdown, cause some scatter in the data points. The results in Figure V-11 can only be applied, as they stand, to this specific set of test conditions (screen specimen, model orientation and test liquid). 


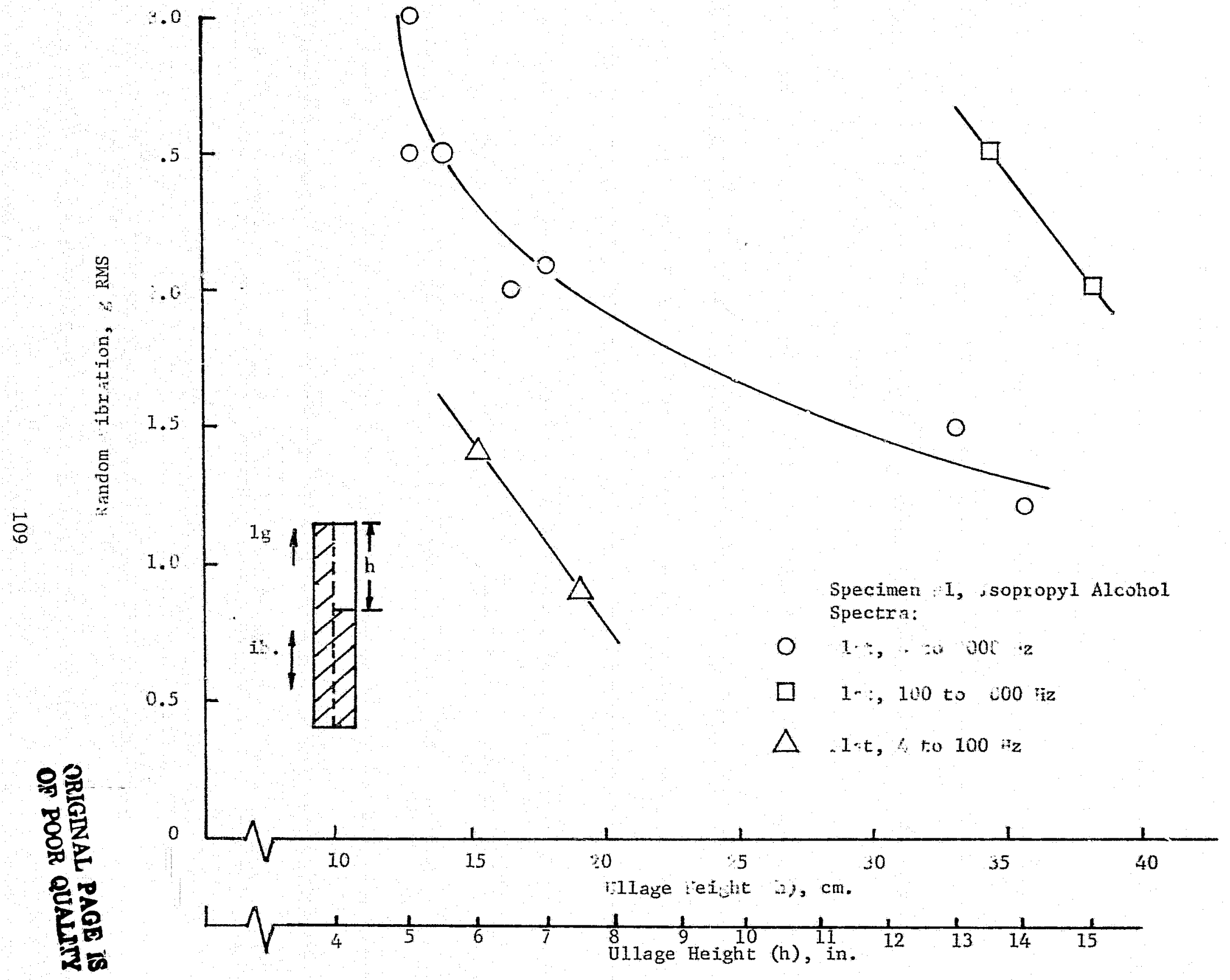

Figure V-10. Influence of Random Vibration Spectrum 


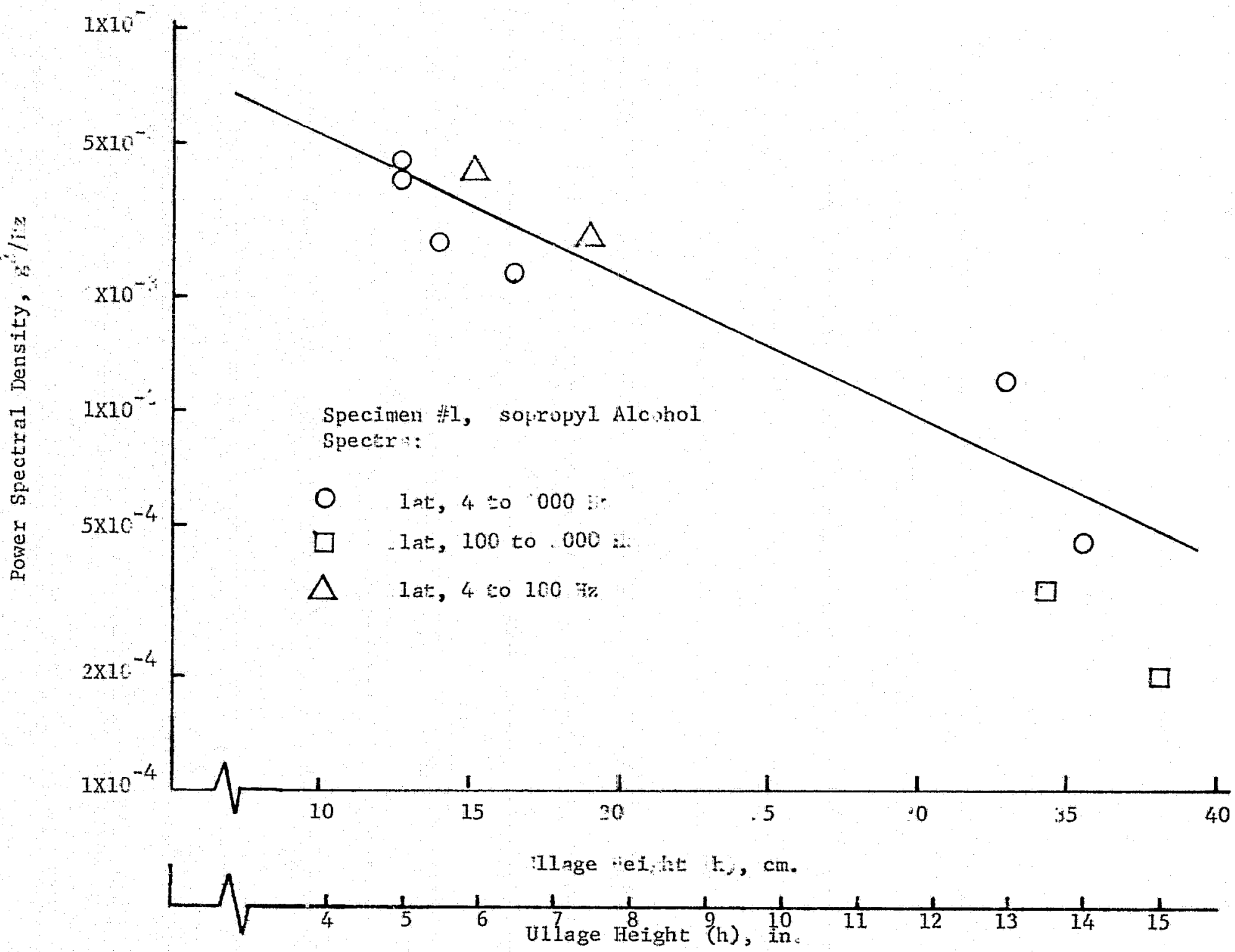

Figure V-11-Influence of Random Vibration Based on Spectra1 Density 
A large quantity of random vibration data was collected for screen specimens $5,6,7,8,9$ and 10 (these tests are also discussed under the effect of screen support method). Each of these screen specimens was made with $325 \times 2300$ Dutch twill screen, but each was supported in a different manner. A vibration spectrum with a constant power spectral. density between 8 and $500 \mathrm{~Hz}$ was used for these tests. Such a spectrum covers the range of possible screen specimen harmonic frequencies, provides good low frequency resolution and resolution of spectral density increments, and can be accurately reproduced throughout a series of tests. Again, model Orientation 1 was used and isopropy 1 alcohol was the test 1iquid. The various stages of screen breakdown were noted, but only the point of significant breakdown is considered in the correlation.

A somewhat differcut approach to using the hydrostatic model was used in correlating this random vibration data. The hydrostatic model was defined to include a coefficient, as follows:

$$
\Delta \mathrm{P}_{\mathrm{v}}=\mathrm{K}_{\mathrm{pg} \mathrm{rms}_{\mathrm{s}}} \mathrm{h}_{\mathrm{s}}
$$

Within the coefficient $K$ are all the influences of the specific screen geometry and the applied vibration spectrum. After the value of $\mathrm{K}$ has been establishea, the effect of the vibration can be predicted.

The test data in the form of the coefficient $\mathrm{K}$ versus the $\mathrm{g}$ RMS level is plotted in Figure $V-12$. This graph shows that the method of supporting the screen significantly influences the value of the coefficient $k$. The data for Specimen 6 (screen bonded to perforated plate) falls the closest to a value of $\mathrm{K}$ equal to 1 (giving the traditional form of the hydrostatic mode1), especially when the acceleration is less than $2.5 \mathrm{~g}$ RMS. At 4.5 $g$ RMS the value of $K$ must be 2.5 to predict the effect of vibration for this screen. The values of $\mathrm{K}$ for specimens 5,8 and 9 fall within $25 \%$ of $\mathrm{K}$ equal to one, below $2.5 \mathrm{~g}$ RMS, but the variation becomes wider at higher accelerations. Over the full range of the test accelerations, the value of $\mathrm{K}$ for Specimen 8 falls closest to one. Specimens 7 and 10 had the largest values for $k$.

The data appear to indicate a convergence toward $k$ equal to one as the acceleration approaches zero. Specimen 7 is the only exception, but per. haps could be discounted bissed on the erratic nature of the data for this specimen. This would indicate that the influence of the support method on the value of $\mathrm{K}$ vanishes at low random vibration levels which is typical of actual spacecraft vibration environments. However, this conclusion is only valid for the particular spectrum used in the test, as shown by the previous discussion of the effects of the vibration spectrum.

It is also interesting to note that the relative order of the curves for the specimens follows the same order as their sensitivity to vibration, as discussed in the first part of this chapter. The more sensitive the screen specimen is to vibration, the larger the value of $K$. 


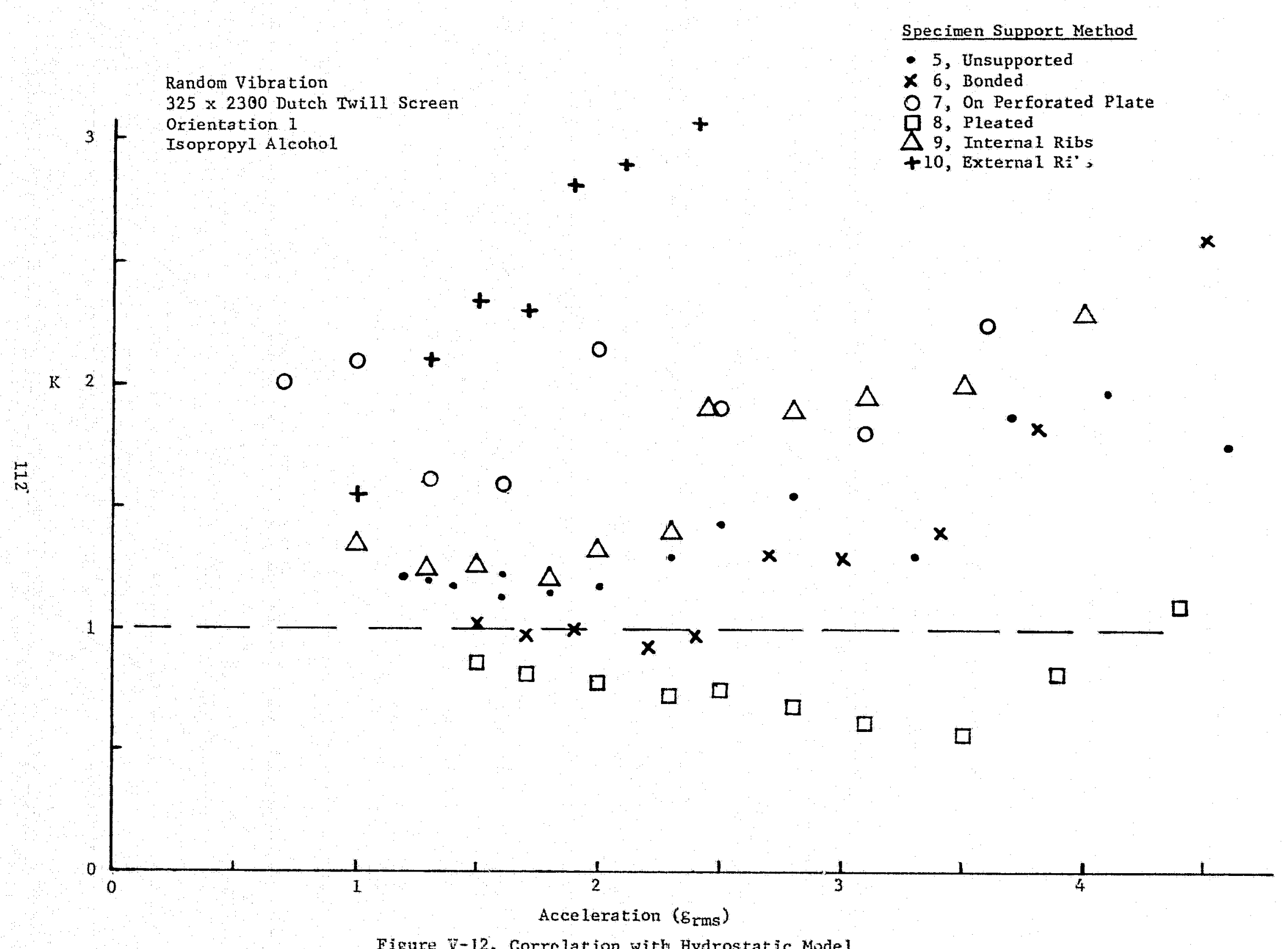


Specimen 1 is most similar to specimen 10 . Specimen 10 has five windows while Specimen 1 has only two of the same size. The results from the tests with Specimen 1 ( 4 to $2000 \mathrm{~Hz}$ constant spectral density spectrum) are similar to the results for Specimen 10 ( 8 to $500 \mathrm{~Hz}$ constant spectral density spectrum) shown in Figure $V-12$. For both specimens the value of $K$ was close to ore at low accelerations and became larger at larger acc lerations.

The hydrostatic model was also applied to the sine vibration tests. As discussed in the first part of this chapter, under the effect of model orientation, the pressure due to vibration at: low frequencies (near $5 \mathrm{~Hz}$ ) could be predicted with the hydrostatic model. In this application the acceleration was the zero-to-peak amplitude of the sine vibration, the height was the length of exposed screen parallel to the vibration axis, and the value of $K$ was one. To predict the pressure due to vibration at higher frequencies the amplification must be known. At the system harmonic, pressures of up to five times the low frequency value were measured.

Based on these tests and the prior vibration studies, it can be concluded that the hydrostatic model has some merit. The effect of vibration on the screen retention is hydrostatic in nature. The effect of frequency, due to the random vibration spectrum or sine vibration, has a significant effect on the ability of the hydrostatic model to predict the vibration effect. A11 of the screen spectmens had harmonic frequencies and the amount of vibration energy applied to the specimen at that harmonic frequency was . the primary factor influencing its response. This effect was clearly demonstrated by the tests using various rpectra.

The hydrostatic model can be used to make estimates of the effect of vibration if the above discussed factors concerning the screen support method and the vibration spectrum are given sonsideration. The $h$;drostatic model also serves as a method of presenting and interpolating random vibration data acquired for a specific screen acquisition device and Jution environment.

2. Structural Dynamics Model - As pointed out previously (Chapter III), the purpose of the tests performed on the initial three screen configurations was to establish the range of applicability of the single degree-offreedom slow model and, for this controlled set of test specimens, to establish a measure of mass, stiffness and cmping characteristics. It was anticipated that this information would then be extended to the more complex screen configurations (Specimens 4 through 27) and thus the model, if indeed valid for the control specimens, would be refined and extended to the more complex cases and, ultimately, used to predict the peak response pressure differential due to a vibration input for arbitrary screen acquisition system configurations.

The following discussion summarizes selected test results for several configurations. In general, three types of tests (sine sweep, sine dwe11 and random) were performed. As the intent of the structural dynamics model is to predict the peak vibration pressure differential (assumed to occur at the fundamental mode frequency), the sine dwell data have only limited 
applicabiltty. Further examination of the random respora data indicated that they are dif ficult to interpret with respect to establihing the presm sure differential of the fundamental resonance point.

Specimer 1 consisted of two approximately $7.6 \mathrm{~cm}(3.0 \mathrm{in})$ square screen covered openings with a $30.3 \mathrm{~cm}(12.0 \mathrm{in})$ distance between centers. Specimen 2 was identical except the submerged screen was removed. Specimen 3 reduced the size of the flow area to a $0.95 \mathrm{~cm}(0.375 \mathrm{in})$ diameter tube. A11 spectmens used $325 \times 2300$ screen. A majority of these tests were conducted with Orientation 1 and isopropanol as the test fluid.

Table V-3 summarlzes the results for Specimen 1 ; Table V-4 summarizes for specimen 2. The intent of these spocimens was to establish preliminary estimates of fluid mass, screen stiffness and system daming characteristics; this was the justification for use of the small screen window(s) and the Incorporation of a well defined flutd path. The intent of Specimen 3 was to lend additional insight into these results by providing a known variation in the system mass. This is in viet of the fact that the previous development of fluid effective mass was based on the assumption of unf form flow throughout the section $A B$ (see Chapter III, Section 13 ). However, it seems unlikely that truly uniform flow $c$ an be achieved due to boundary effects and the possible nonunifomity of screen motion and this implies that the actual system kinetic energy might be different than previously indieated. The intent of specimen 3 was then to provide a manner by which we soht assess this possible discrepancy, i.e., create a known "artificial mas "l ;y restricting the flow between the controlled bulk regions as shown in ... sketch. Here the system kinetie energy, with the additional energy due to the orifice flow (and assuming no outflow) is

$\mathrm{T}=\frac{\rho}{2}\left|\iiint_{V_{01}} \dot{\mathrm{q}}_{1}^{2} \mathrm{dV}+\iiint_{V 01} \dot{\mathrm{q}}_{3}^{2} \mathrm{dV}\right|$

where the second integration is over the volume of the tube. The integration yields

$T=\frac{\rho}{2}\left(A B L \dot{q}_{1}^{2}+A_{0} \lambda_{0}{\dot{a_{3}}}_{3}^{2}\right)$

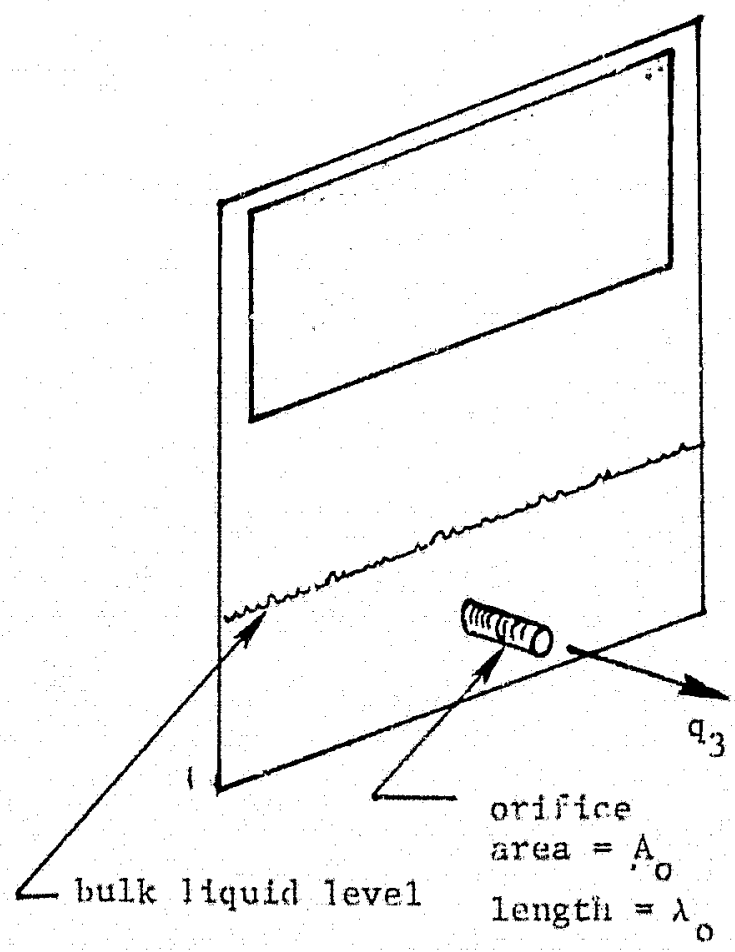


Table V-3. Sumury of Test Results, Specinen 1

\begin{tabular}{|c|c|}
\hline Date & Conditions and Observations \\
\hline $2 / 2 / 77$ & $\begin{array}{l}\text { Sine dwells at } 10-40 \mathrm{~Hz} \text {, input }=1.5 \mathrm{~g} \text {, initial head }=12.7 \mathrm{~cm}(5 \mathrm{in}) \\
\text { drain until breakdown } \\
\text { random at } 0.9-3.0 \mathrm{~g} \mathrm{rms} \\
\text { sweep } 5-20-5 \mathrm{~Hz} \text {, input }=1.5 \mathrm{~g} \text {, head }=12.7 \mathrm{~cm}(5 \mathrm{in}) \\
\Delta \mathrm{P}_{\mathrm{V}}=0.55 \mathrm{~N} / \mathrm{cm}^{2}(0.80 \mathrm{psi}) \text { at } 8.0-8.5 \mathrm{~Hz} \text { (upswp) } \\
\Delta \mathrm{P}_{\mathrm{V}}=0.55 \mathrm{~N} / \mathrm{cm}^{2}(0.80 \mathrm{psi}) \text { at } 8.0-8.5 \mathrm{~Hz} \text { (dnswp) }\end{array}$ \\
\hline $2 / 23 / 77$ & 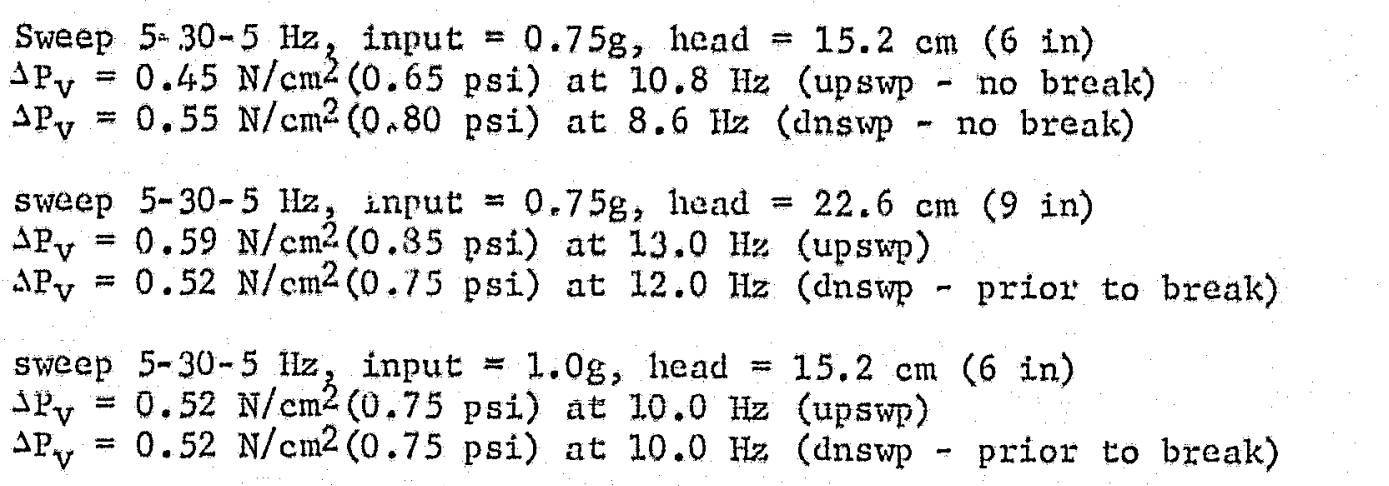 \\
\hline $2 / 24 / 77$ & $\begin{array}{l}\text { Sine dwcils at } 20-25 \mathrm{Il} \text {, input }=5.0 \mathrm{~g} \text {, initial head }=30.5- \\
38.1 \mathrm{~cm}(12-15 \mathrm{in}) \text {, orientation } k^{5} \\
\text { sweep } 5-30-5 \mathrm{~Hz} \text {, inmut }=3.0,5.0 \mathrm{~g} \text {, orientation 非 }\end{array}$ \\
\hline $3 / 4 / 77$ & $\begin{array}{l}\text { Sine dwells at } 15 \mathrm{~Hz} \text {, input }=0.5 \mathrm{~g} \text {, various initial heads } \\
\text { sweep } 5-50-5 \mathrm{~Hz} \text { input }=0.3 \mathrm{~g}, \text { hend }=30.5 \mathrm{~cm} \text { (12 in) } \\
\Delta \mathrm{P}_{\mathrm{V}}=0.31 \mathrm{~N} / \mathrm{cm}^{2}(0.45 \mathrm{psi}) \text { at } 21.0 \mathrm{~Hz} \text { (upswp - prior to break) } \\
\Delta \mathrm{P}_{\mathrm{V}}=0.34 \mathrm{~N} / \mathrm{cm}^{2}(0.50 \mathrm{psi}) \text { at } 21.0 \mathrm{~Hz} \text { (dnswp - prior to break) }\end{array}$ \\
\hline $3 / 10 / 77$ & $\begin{array}{l}\text { Sweep } 5-500-5 \mathrm{~Hz}, \text { input }=0.3 \mathrm{~g}, \text { head }=30.5 \mathrm{~cm}(12 \mathrm{in}) \\
\Delta \mathrm{P}_{\mathrm{v}}=0.41 \mathrm{~N} / \mathrm{cm}^{2}(0.60 \mathrm{psi}) \text { at } 2.0 \mathrm{~Hz} \\
\Delta \mathrm{P}_{\mathrm{V}}=0.31 \mathrm{~N} / \mathrm{cm}^{2}(0.45 \mathrm{psi}) \text { at } 21.0 \mathrm{~Hz} \\
\text { sweep } 5-500-5 \mathrm{~Hz}, \text { input }=0.5 \mathrm{~g}, \text { head }=20.3 \mathrm{~cm}(8 \mathrm{in}) \\
\Delta \mathrm{P}_{\mathrm{V}}=0.41 \mathrm{~N} / \mathrm{cm}^{2}(0.60 \mathrm{psi}) \text { at } 15.0 \mathrm{~Hz} \text { (dnswp }- \text { prior to break) } \\
\text { sweep } 5-500-5 \mathrm{~Hz}, \text { input }=1.0 \mathrm{~g}, \text { head }=10.2 \mathrm{~cm}(4 \mathrm{in}) \\
\Delta \mathrm{P}_{\mathrm{V}}=0.52 \mathrm{~N} / \mathrm{cm}^{2}(0.75 \mathrm{psi}) \text { at } 10.0 \mathrm{~Hz} \text { (upswp) } \\
\Delta \mathrm{P}_{\mathrm{V}}=0.41 \mathrm{~N} / \mathrm{cm}^{2}(0.60 \mathrm{psi}) \text { at } 10.5 \mathrm{~Hz} \text { (dnswp) }\end{array}$ \\
\hline
\end{tabular}




\begin{tabular}{|c|c|}
\hline Date & Conditions and observations \\
\hline $4 / 21 / 77$ & 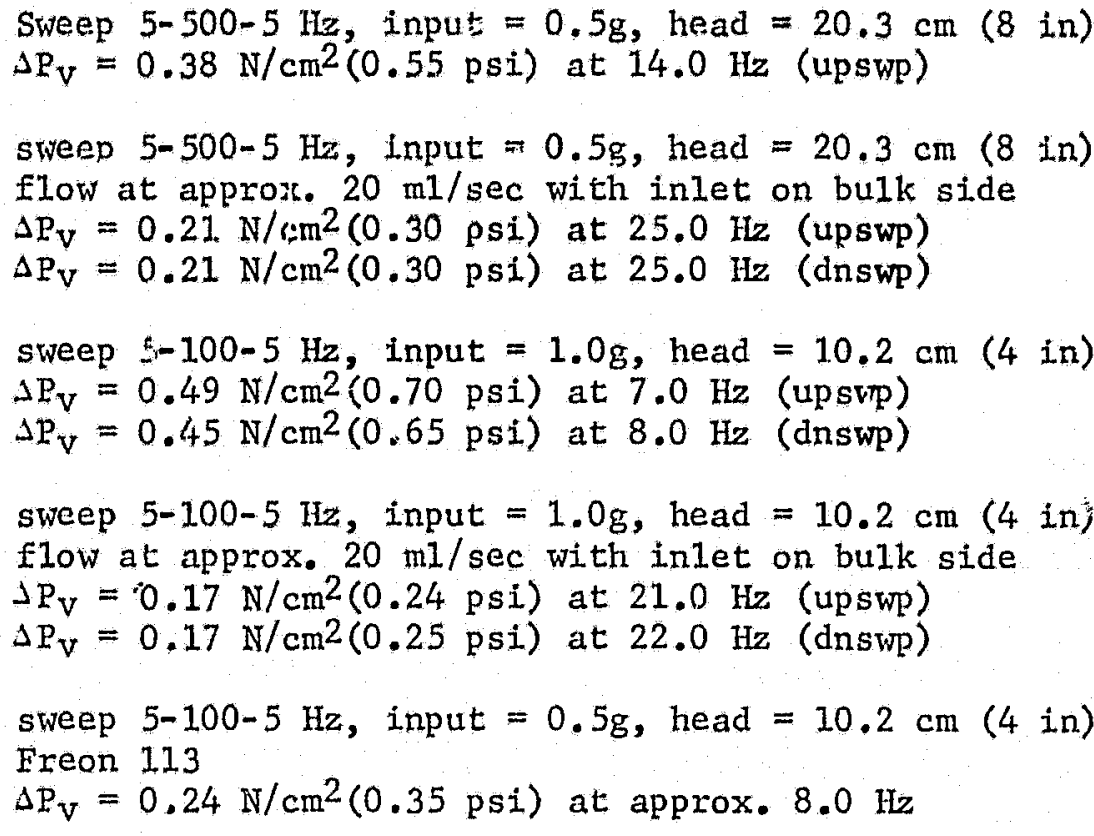 \\
\hline \multicolumn{2}{|c|}{$\begin{array}{l}\text { Orientation 非 unless noted } \\
\text { Isopropanol unless noted } \\
\text { No flow unless noted }\end{array}$} \\
\hline
\end{tabular}


Table V-4. Summary of Test Results, Specimen 2

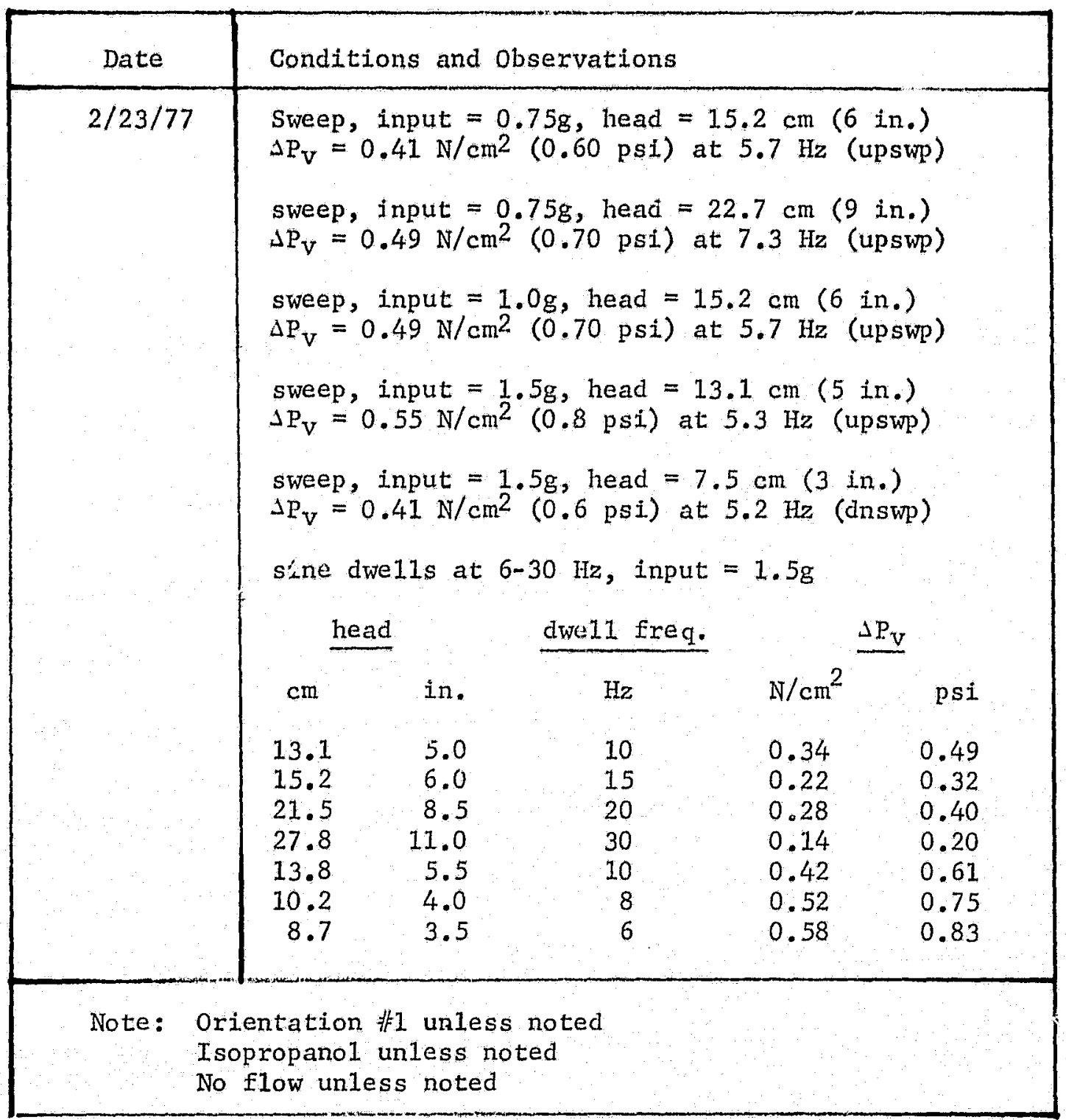


which, with the continuity expression

$$
\text { AB } \dot{q}_{1}=A_{0} \dot{q}_{3}
$$

becomes

$$
T=\frac{\rho}{2} A B\left[I+\frac{\lambda_{0} A B}{A_{0}}\right] \dot{\mathrm{q}}_{1}{ }^{2} .
$$

Application of Lagrange's equation to the above yields

$$
\frac{d}{d t}\left(\frac{\partial T}{\partial \dot{q}_{1}}\right)=\rho A B\left[L+\frac{\lambda_{0} A B}{\Lambda_{0}}\right] \ddot{q}_{1}=\vec{M}_{\text {eff }} \ddot{q}_{1}
$$

and $\dot{M}_{\mathrm{Cff}}=\rho A B\left[L+\frac{\lambda_{0} A B}{A_{0}}\right]=M_{e_{L} I}+\Delta M_{e f f}$

where the value of $\Delta M_{e f f}$ can, hopefully, be controlled by judicious selection of the orifice tube length and cross-sectional area.

Unfortunately, the test results for Specimen 3 are inconclusive as to whether the desired objective (increased fluid mass with corresponding reduced natural frequency) was, in fact, accomplished. Examination of the data indicates that the apparent primary response lies in the $40-50 \mathrm{~Hz}$ range which would seem to imply that the effect of adding the orifice was to reduce the effective mass. However, this may be totally misleading. The expected natural frequency range for Specimens 1 and 2 is approximately $8-15 \mathrm{~Hz}$ and, if the predicted mass variation was in fact achieved for Specimen 3 , it well may be that the resultant natural frequency lies below $5 \mathrm{~Hz}$, the threshold value of the excitation equipment. This inconsistency has not been resolved and further analysis and/or controlled tests appear to be justified.

In an attempt to better understand the results of specimens 1 and 2 , consider the peak vibrational pressure differential as a function of static head as shown in Figure $\mathrm{V}-13$ where the variation in the observed fundamental response frequency is also indicated. It is observed that increasing the static head, $h_{S}$, leads to an increase in the observed fundamental frequency. This is thought to occur through a combination, as yet undetermined, of two effects; increasing the static head decreases the effective flow length and increases the static pressure differential at the screen. Reduced effective flow length implies reduced effective fluia mass and increased pressure (static) differential applies a tension to the screen thus increasing its effective stiffness. The net result is the observed increase in the response frequency. Note also that for fixed static head, the observed vibrational 


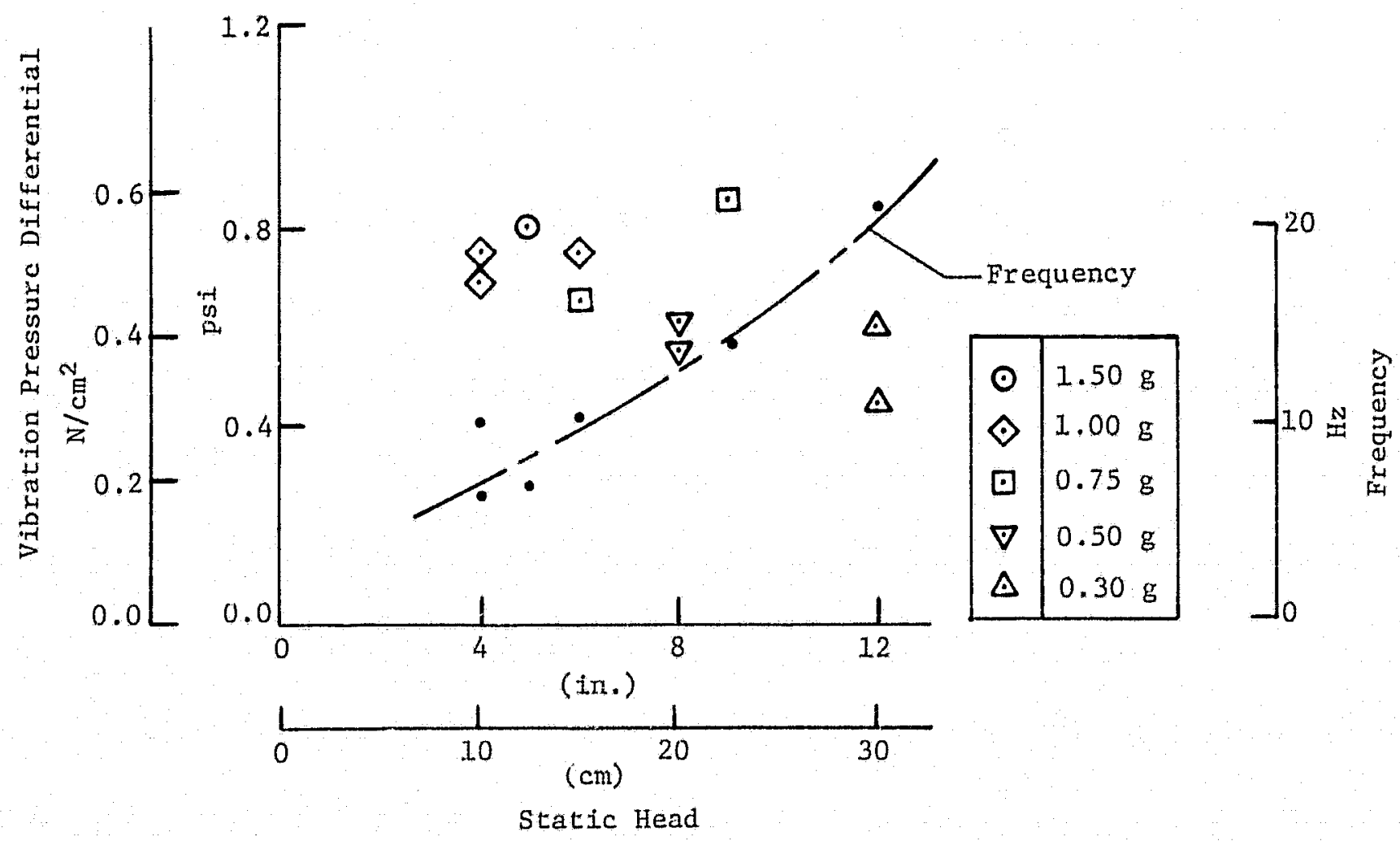

Figure V-13a. Test Results, Specimen 1
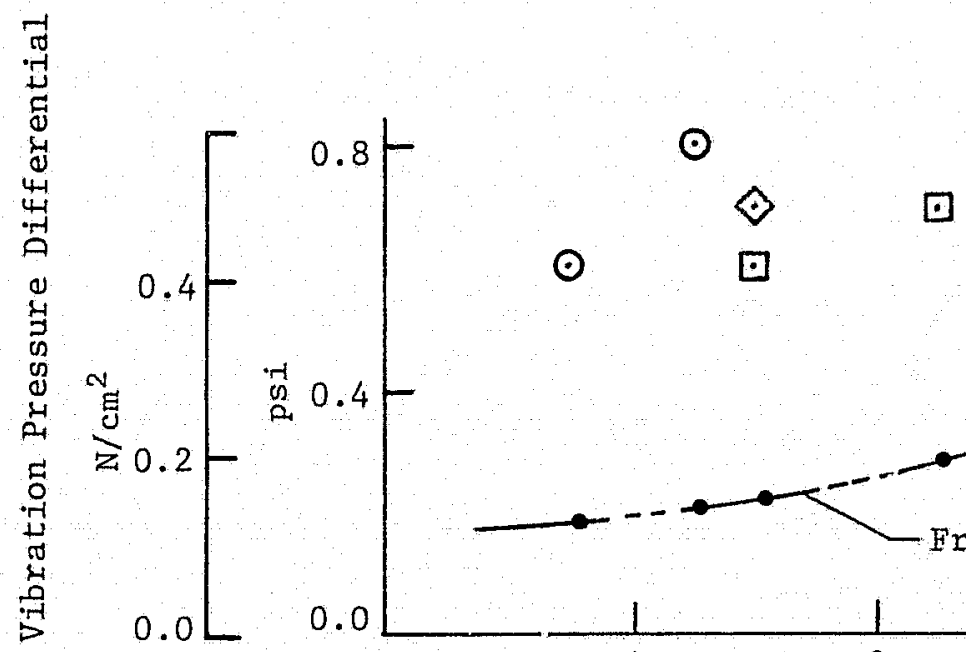
pressure differential increases with increasing input vibration level as would be predicted from the analysis presented previously.

Another interesting view of the test results for Specimens 1 and 2 can be constructed by returning to the analysis of Chapter III slightly modified to account for geometric characteristics of the particular test specimens. The total pressure differential can be expressed as

$$
\Delta \mathrm{P}_{t}=\Delta \mathrm{P}_{\mathrm{s}}+\Delta \mathrm{P}_{\mathrm{v}}
$$

with $\Delta \mathrm{P}_{\mathrm{S}}=\rho \mathrm{g} \mathrm{h}_{\mathrm{s}}$

and $\quad \Delta \mathrm{P}_{\mathrm{v}}=\frac{\rho \mathrm{g} \mathrm{QC}_{\mathrm{x}} \mathrm{h}^{2} \ddot{\mathrm{X}}}{\mathrm{L}}$

for acceleration in the vertical direction, $\mathrm{X}$.

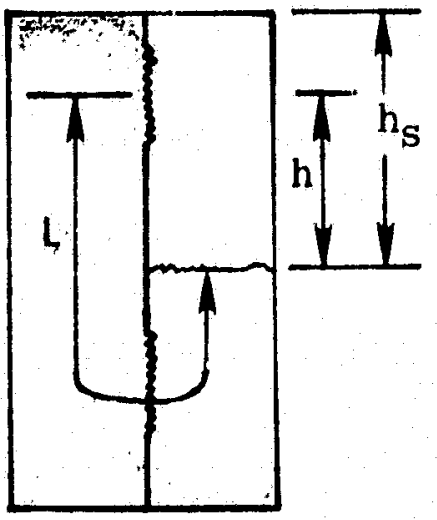

If we now say $\tilde{\mathrm{h}}=\mathrm{h} / \mathrm{h}_{\mathrm{S}}$, the above expression for pressure differential due to vibration becomes

$$
\Delta P_{v}=\frac{\rho g Q C_{x} \tilde{h}^{2} h_{s}^{2} \ddot{x}}{L}
$$

and it follows that the dynamic amplification can be expressed as

$$
Q C_{X}=\frac{\Delta P_{V} I}{\rho g \widetilde{h}^{2} h_{s}^{2} \ddot{x}} \simeq \frac{\Delta P_{v} L}{\rho g h_{s}^{2} \ddot{x}}
$$

for $h_{s}=h$. The results of this equation are depicted in Figure $V-14$ which indicates that some degree of correlation exists between the two test specimens with (perhaps) Specimien 2 exhibiting slightly higher damping characteristics. This would seem to indicate that the square fluid passageway, permitting lateral fluid motion, acts as a damping device and that, for Specimen 1, no flow passes through the screen mesh. It would have been interesting also to show results for specimen 3 at this point but, as mentioned previously, those results are not available. The figure indicates that a prediction of vibrational pressure differential is available for these two specimens but the extension to more complicated specimens is not yet evident. 


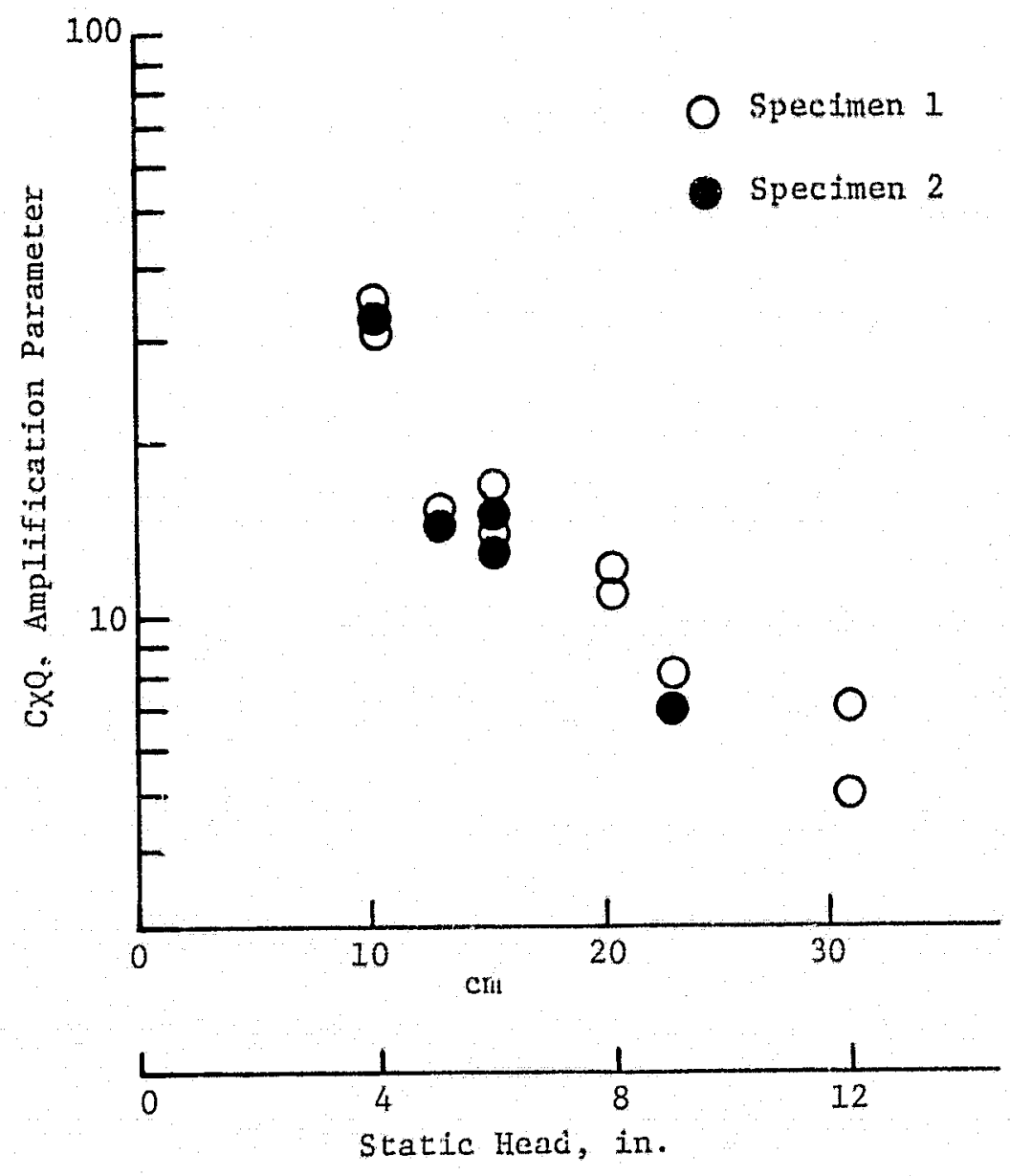

Figure V-14. Amplification Parameter, Speciment 1 and 2 
In an effort to extend the previous results, test data for other screen specimens were tabulated and examined in some detail. This examination was made difficult by the fact that the amount of available test data are iimited; there being only one or two pieces of data for some screen configurations. Further, the limited range of parameter values makes a graphical representation difficult. This is illustrated by examination of the data resulting from tests on several of the external rib configurations (Table V-5) where the peak vibrational pressure differential and observed fundamental frequency are tabulated for various static heads and input vibration levels. It is clearly evident that additional data are required before development of a fully test validated analytical model can be accomplished.

Table V-5. Test Results, External Rib Configurations

\begin{tabular}{|c|c|c|c|c|c|c|c|}
\hline Specimen & Screen & $\begin{array}{l}\text { Input } \\
\left(g^{\prime} s\right)\end{array}$ & \multicolumn{2}{|c|}{ (in) $)^{\text {Head }}(\mathrm{cm})$} & $\begin{array}{l}\text { Freq. } \\
(\mathrm{Hz})\end{array}$ & \multicolumn{2}{|c|}{$\begin{array}{c}\text { Peak Pressure } \\
\left(1 \mathrm{~b} / \mathrm{in}^{2}\right) \quad\left(\mathrm{N} / \mathrm{cm}^{2}\right)\end{array}$} \\
\hline $\begin{array}{l}12 \\
1.3\end{array}$ & $\begin{array}{l}325 \times 2300 \\
200 \times 1400 \\
\\
165 \times 800 \\
\text { (Dutch) } \\
165 \times 800 \\
\text { (Plain) }\end{array}$ & $\begin{array}{l}0.5 \\
0.5 \\
0.5 \\
0.5 \\
1.0 \\
1.0 \\
0.5 \\
0.5 \\
0.5 \\
0.5\end{array}$ & $\begin{array}{r}8.0 \\
8.0 \\
8.0 \\
12.0 \\
8.0 \\
6.0 \\
6.0 \\
6.0 \\
6.0 \\
6.0\end{array}$ & $\begin{array}{l}20.3 \\
20.3 \\
20.3 \\
30.4 \\
20.3 \\
15.2 \\
15.2 \\
15.2 \\
15.2 \\
15.2\end{array}$ & $\begin{array}{l}17 \\
18 \\
18 \\
21 \\
15 \\
14 \\
42 \\
56 \\
13 \\
15\end{array}$ & $\begin{array}{l}0.20 \\
0.22 \\
0.22 \% \\
0.32 \\
0.35 \\
0.25 \\
0.30 \\
0.30 \% \\
0.20 \\
0.25 \%\end{array}$ & $\begin{array}{l}0.14 \\
0.15 \\
0.15 \\
0.22 \\
0.24 \\
0.17 \\
0.21 \\
0.21 \\
0.14 \\
0.17\end{array}$ \\
\hline Note: & $\begin{array}{l}\text { ntation } \\
\text { ropanol } \\
\text { dicates }\end{array}$ & $\begin{array}{l}\text { t } \\
\text { w tes }\end{array}$ & & & & & \\
\hline
\end{tabular}


Thy.s study has invistigated the basic phenomena of the effects of vibration on the liquid retention capability of fine-mesl: screens. The problem of the response of a screen to vibration was analytically evaluated in detail. A test program considering a large number of variables that influence screen response was conducted, Data were acquired and analyzed from 551 individual vibration tests.

The pressure differential due to the vibration was measured during the tests. These data give a basic understanding of the amplitude, waveform and characteristics of the vibrational pressure. The key factor in the screen response is the amplification of the vibrational pressure due to harmonics of the screen-liquid system. It was found that the retention capability is influenced by the pos:tive peak pres sure (lowering the liquid pressure with respect to the gas on the other sidc of the screen) dwe to the vibration. These pressure data also displayed the non-linear characteristics of the screen specimeris. Loosely supported screens relieved the negative vibrational pressure, so the pressure was positively biased. A. "softening spring" stiffness was noted, indicating that the response of the screen is influenced by the gas/1iquid interface at the screen pores. Another non-linear effect was the localized scraen breakdown due to the oscillation of small portions of a screen panel. These results establish that the vibrational response of a typical surface tension device is a highly non-linear, multi-degree of freedom problem.

It was found that the effect of the surface tension device orientation with respect to the ribration axis was proportional to the length of the liquid column, supported by the screen, parallel to the vibration axis. The orientation of the screen weave had no noticeable effect.

The screen support method significantly affects the screen response. Bulk displacement of the screen, primarily when the screen can deflect into the controlled liquid region, reduces the sensitivity of the screen to vibration. A support method that allows or enhances the localized oscillation of the screen, increases the sensitivity of the screen to vibration. The finer mesh screens are more susceptible to the localized oscillation, increasing thto relative vibration sensitivity.

Liquid flow and dual screen elements can influence the harmonics and the response to vibration, in general decreasing the sensitivity in comparison to the single element, static case.

Prediction of the effects of vibration was most successful using the hydrostatic model that was developed in prior studies. This model can predict the effects of sine vibration at frequencies below the first harmonic of the system ( $\sim 5 \mathrm{~Hz}$ for the test model used here). Near the harmonics, the amplification would have to be known. The model predicts the effects of random vibration for rigid screen specimens and specific vibration spectra. The shape of the random spectrum and the screen support method definitely

$$
\begin{aligned}
& \text { ORIGINAL PAGE IS } \\
& \text { OF POOR QUALITY }
\end{aligned}
$$


influence the screen response, but are not directly considered by the hydrostatic mode1. It appears that successful use of the hydrostatic model will require that test data for a representative model, using the actual spectrum, be acquired. It would primarily serve as a means of scaling, based on the vibration level and liquid properties.

Limited verification of the structural dynamics mode1, developed under this program, was achieved. It was based on the premise that the effect of vibration is hydrostatic in nature, which was verified by the results of the hydrostatic model. However, the model dynamics were based on a linear, single degree of freedom system, which these tests have shown is not the case. The localized screen oscillation and other non-1inear effects made it impossible to sort out the coefficients for the model from the data acquired.

The investigation of the effects of vibration on surface tension devices should be continued. Two approaches are recommended. First, an empirical approach based on the hydrostatic model should be followed. This should be directed toward random vibration and typical surface tension devices. It should be established that test data can be gathered and applied to an actual surface tension device, installed in a tank.

The second approach is to continue to study the basic phenomena of the response of the screen to vibration. Basic specimens, similar to those tested under this program but free of the localized oscillation effects; should be tested and the verification of a dynamics model continued. Mass and flow effects need to be more extensively investigated. As confidence in the model is gained, the non-linear effects could then be considered.

Through these two approaches to the problem of screen vibration, reliable analytical methods of predicting the effects of vibration may then become available. 


\section{AEPENDIX A}

BUBBLE GROWTH MODEL

Presented in this appendix is a description of the bubble growth model and the development of this model that was performed under this program. The application of this mode 1 to the analys is of screen vibration is discussed in Chapter III.

The bubble growth model evaluates the response of the gas/liquid interface to pressure transients. Screen breakdown can be viewed as the growth and detachment of a gas bubble at a screen pore. The mode 1 is based on a theoretical derivation of the dynamic response of a gas bubbie. Each aspect influencing the response of the screen can be incorporated into the analysis. A detalled description of the model can be found in Reference III-2. During this program the bubble growth model was refined and adapted to the specific conditions of interest.

The structural dynamics model (see Chapter III) is essential to the use of the bubole growth model. The time varying pressure of the liquid, as calculated by the structural dynamics mode1, is input to the bubble growth model.

\section{A. SCREEN PARAMETERS}

Parameters that account fer the geometry of the screen are also input to the bubble growth model. The screen geometry determines the capillary pressure at a pore and the resistance to gas flow through the screen.

The capillary pressure at the pore must be defined as a function of the volume of the gas bubble. Only by simplifying the screen geometry, as shown in Figure $A-1$, can this capillary pressure be calculated.

The gap between the wires is the pore radius, which is derived from the bubble point of the screen (see Appendix $C$ for a list of symbols).

$$
r=\frac{2 \sigma}{\Delta P_{c}}
$$

The radius of the wire is the average of the warp and shute wire radii.

The contact angle is assumed to be zero, as it is for most propellants. Contact angles other than zero could be considered. Since the pores are very small, capillary forces will dominate gravity forces, even 


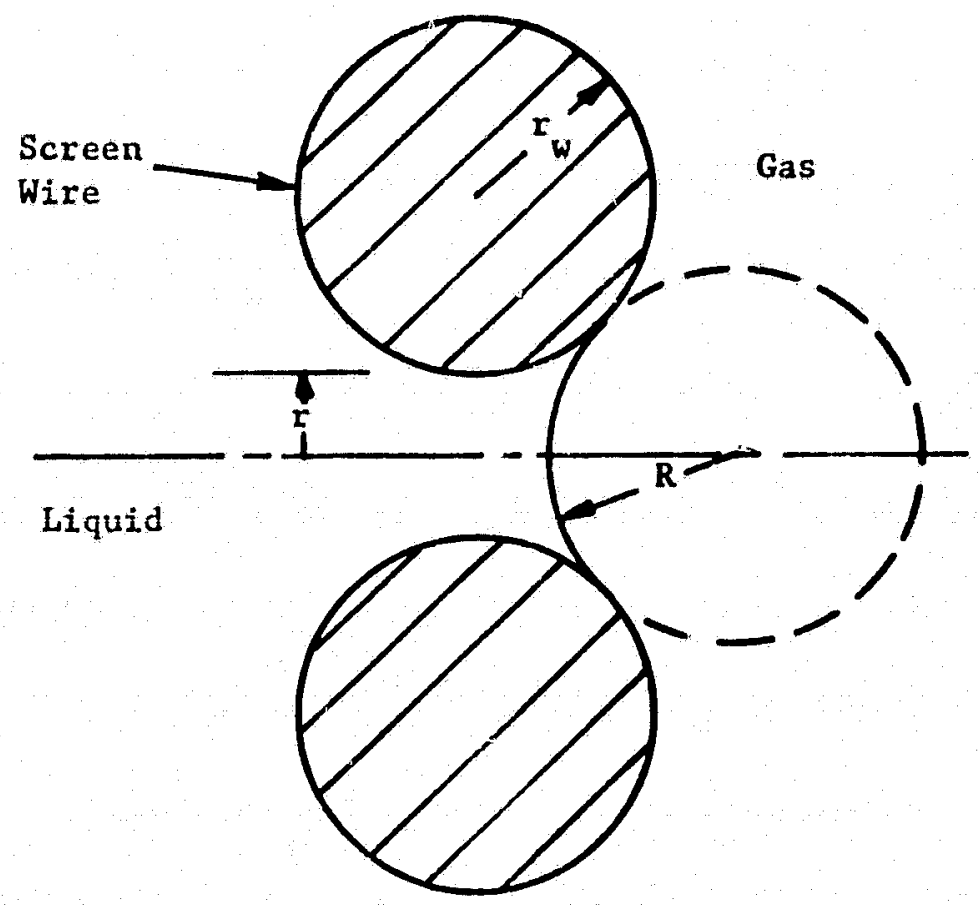

Figure A-1. Simplified Screen Pore 
in one-g, so a zero-g interface can be assumed\%. Therefore the interm face at the pore is a segment of a sphere with radius $R$, tangent to the wires. The capillary pressure across the interface can be expressed as

$$
\Delta \mathrm{P}=\frac{2 \sigma}{\mathrm{R}}
$$

In a dimensionless form, based on the minimum pore radius, the equation becomes

$$
\frac{\Delta \mathrm{Pr}_{\mathrm{r}}}{\mathrm{T}}=\frac{2 \mathrm{r}}{\mathrm{R}}
$$

Using the filat interface, having a capillary pressure of zero as a reference, the volume of the gas bubble can be calculated based on the defined screen geometry.

The parameters necessary to ealculate the capiliary pressure for each of the screens to be evaluated under this program are listed in Table A-1. The calculated variation of capilary pressure with bubble volume is shown in Flgurc $A-2$. The bubble volume $(\because n)$ is a lso placed in dimensiontess form.

It this dimensionless form al1 of the screens have a curve of the same basic shape. The relative size of the screen pore and the wires causes the differences becween the curves. Some interesting results can be noted in the figure. The progression of the curves from left to right is not the same order as based on increasing bubble point. The $50 \times 250$ anci $200 \times 1400$ screen are the most obvious exceptions. This may be an indication of the relative capability of the icreens in response to vibration.

Attempting to experimentally verify the curves in Figure A-2 would be difficult. Highly accurate measurements of the volume change related to a single pore would be required. There are factors that provide some confidenee that the curves properly represent the capillary passure. Obviuusly, the volume is zero when the capillary pressure is zero. The maximum capillary pressure is known from the bubble point.

The two dashed curves in Figure A-2 establish boundaries for the curves for any screen. One of the dashed curves is for a spherical

\footnotetext{
*For an extreme condition of oxygen (smallest kinematic surface tension of the liquids of interest), $200 \times 200$ screen (largest pore of the screens of interest), and a one $-g$ acceleration, the Bond number based on the pore radius is $2 \times 10^{-3}$. The Bond number would have to be greater than 0.1 before there would be anv significant change in the capillary pressure. Only whin the gas bubble becomes very large would any influence of the acceleration be noted.
} 


\begin{tabular}{|c|c|c|c|c|c|}
\hline \multirow[b]{2}{*}{$\begin{array}{c}\text { Screen } \\
\text { (Wires per Inch) }\end{array}$} & \multirow[b]{2}{*}{ Weave } & \multirow{2}{*}{$\begin{array}{c}\text { Bubble Point } \\
\text { with Isopropyl } \\
\text { Alcohol } \\
\text { cm. of } \mathrm{H}_{2} \mathrm{O} \\
\text { (in. of } \mathrm{H}_{2} \mathrm{O} \text { ) }\end{array}$} & \multirow{2}{*}{$\begin{array}{l}\text { Pore } \\
\text { Radius, } \\
\text { Microns } \\
\text { (Inches) }\end{array}$} & \multicolumn{2}{|c|}{ Wire Diameter } \\
\hline & & & & $\begin{array}{l}\text { Warp } \\
\text { mm } \\
\text { (in.) }\end{array}$ & $\begin{array}{l}\text { Shute } \\
\text { mm } \\
\text { (in.) }\end{array}$ \\
\hline $325 \times 2300$ & Dutch Twill & $\begin{array}{c}61.0 \\
(24.0)\end{array}$ & $\left(2.86 \times 10^{-4}\right)$ & $\begin{array}{l}.038 \\
(.0015)\end{array}$ & $\begin{array}{l}.025 \\
(.0010)\end{array}$ \\
\hline $200 \times 1400$ & Dutch Twill & $\begin{array}{c}41.4 \\
(16.3)\end{array}$ & $\left(4.21 \times 10^{-4}\right)$ & $\begin{array}{l}.071 \\
(.0028)\end{array}$ & $\begin{array}{l}.041 \\
(.0016)\end{array}$ \\
\hline $165 \times 800$ & Dutch Twill & $\begin{array}{l}19.6 \\
(7.7)\end{array}$ & $\left(8.94 \times 10^{-4}\right)$ & $\begin{array}{l}.071 \\
(.0028)\end{array}$ & $\begin{array}{l}.051 \\
(.0020)\end{array}$ \\
\hline $165 \times 800$ & Plain Dutch & $\begin{array}{l}24.1 \\
(9.5)\end{array}$ & $\left(7.53 \times 10^{-4}\right)$ & $\begin{array}{l}.051 \\
(.0020)\end{array}$ & $\begin{array}{l}.036 \\
(.0014)\end{array}$ \\
\hline $80 \times 700$ & Plain Dutch & $\begin{array}{l}15.5 \\
(6.1)\end{array}$ & $\left(1.12 \times 10^{-3}\right)$ & $\begin{array}{l}.102 \\
(.0040)\end{array}$ & $\begin{array}{l}.070 \\
(.0050)\end{array}$ \\
\hline $50 \times 250$ & Dutch Twill & $\begin{array}{l}8.9 \\
(3.5)\end{array}$ & $\begin{array}{l}51.8 \\
\left(2.04 \times 10^{-3}\right)\end{array}$ & $\begin{array}{l}.127 \\
(.0650)\end{array}$ & $\begin{array}{l}.114 \\
(.0045)\end{array}$ \\
\hline $850 \times 155$ & Robusta & $\begin{array}{c}28.4 \\
(11.2)\end{array}$ & $\left(6.12 \times 10^{-4}\right)$ & $\begin{array}{l}.030 \\
(.0012)\end{array}$ & $\begin{array}{l}.102 \\
(.0040)\end{array}$ \\
\hline $200 \times 200$ & Square & $\begin{array}{c}9.7 \\
(3.8)\end{array}$ & $\left(1.79 \times 10^{-3}\right)$ & $\begin{array}{l}.053 \\
(.0021)\end{array}$ & $\begin{array}{l}.053 \\
(.0021)\end{array}$ \\
\hline
\end{tabular}




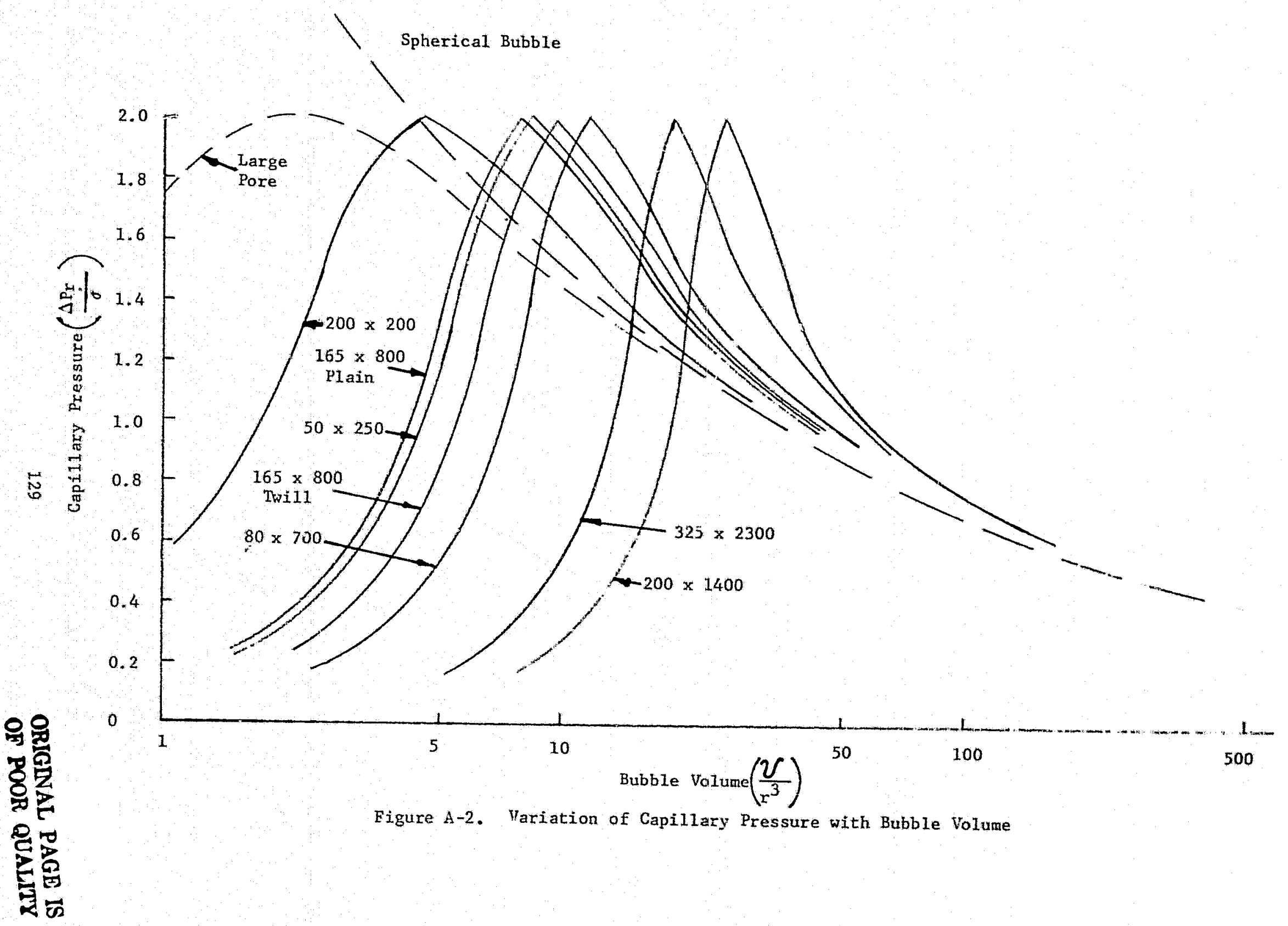


bubble, not attached to a surface. Al1 the curves are asymptotis to the spherical bubble curve and have essentially converged after the capillary pressure $(\Delta \operatorname{Pr} / \sigma)$ has fallen below about 0,6 . A boundary for bubble volumes after the maximum capillary pressure is estatished by this curve. The dashed curve for a large pore is based on the limiting condition that the wire radius is negligible in comparison to the pore radius. All curves for a real screen must be shifted to the right of this curve.

Bubble growth after the bubble point of the screen has been exceeded is of prime interest, since this is the condition under which screen breakdown can occur. For that reason, the shape of the curve up to the buinle point is not critical.

Based on the above factors, the only uncertainty lies in the volume of the bubble at the maximum capillary pressure. If it was known, the entire curve would then be adequately defined.

The other geometric parameter is the coefficient that defines the res is tanie to gas flow through the scresn. This flow res istance is one factor that limits the growth rate of the gas bubble due to an applied pressure differential. Based on Reference A-1, the flow resistance for a screen can be expressed as

$$
\Delta \mathrm{P}_{\mathrm{f}}=\pi p V^{2}+K_{\mu} V \text {. }
$$

This approach to characterizing the flow resistance has been widely used and verified.

For the screens, fluids and flow velocities of interest, the $\rho v^{2}$ term is negligible in comparison to the $\mu V$ term.

Therefore,

$$
\Delta \mathrm{P}_{\mathrm{F}}=\mathrm{K} \mu \mathrm{V}
$$

However, the equations in Reference A-1 apply to an area of screen. To apply the expression to a single pore a pressure balance:

$$
\Delta \mathrm{P}_{\mathrm{f}}=\mathrm{K} \mu \mathrm{V}=\mathrm{K}_{\mathrm{p}} \mu \mathrm{V}_{\mathrm{p}}
$$

(where the subscripted variab?es are for the screen pore) and continuity:

$$
\rho A V=\rho A_{p} V N
$$

(where $\mathrm{N}$ is the number of pores in area $\mathrm{A}$ ) must be considered. From the above two expressions

$$
\frac{K_{p}}{K}=\frac{A_{p} N}{A}
$$


By definition the righthand side of the equation, is the void fraction, ${ }^{*}$. Therefore

$$
\Delta \mathrm{P}_{\mathrm{f}}=\kappa \mathrm{K} \mu \mathrm{V}_{\mathrm{p}}
$$

The flow velocity can be expressed as a function of the bubble volume

$$
V_{p}=\frac{1}{A} \frac{d 1 S}{d t}
$$

where $A$ is now the orifice area.

Using expressions for $S$ and $A$, based on the pore and bubble geometry, the velocity is

$$
\mathrm{V}_{\mathrm{p}}=4\left(\frac{\mathrm{R}}{\mathrm{r}}\right)^{2} \frac{\mathrm{dR}}{\mathrm{dt}}
$$

The refore

$$
\Delta \mathrm{P}_{\mathrm{f}}=4 \div \mu\left(\frac{\mathrm{R}}{\mathrm{r}}\right)^{2} \frac{\mathrm{dR}}{\mathrm{dt}}
$$

The values of $K$ and $E$ can be calculated using equations provided in Reference A-1. Values of these coefficients for the screens of interest are listed in Table A-2. Equations for a Robusta weave are not provided in Reference $A-1$, so the equations for a plain Dutch screen were used, reversing the identificetion of the warp and shute wires (i.e., the $850 \times 155$ Robusta weave was assumed to be a $155 \times 850$ plain Dutch weave).

The accuracy of the coefficients in the bubble grow th model were evaluated in detail to establish the best approach to adjusting the model in the process of correlation with test data. The most uncertainty resides in the curve for the capillay pressure of a pore versus the bubble volume.

If the maximum capillary pressure (bubble point) and the general form of the curve are held constant, the curve can be shifted by varying the volume of the bubble at the maximum capillary presiane. A number of trial cases were computed to establish the influence of that volume on the response of the pore. The response of the screen is defined in terms of an effective pressuro, which is a steady pressure that produces the same effect on the screen retention as the transient applied pressure. The change in the effective pressure was less than $0.5 \%$ of the bubble point for an increase in $100 \%$ of the calculated volume. These results indicate that variations of this volume, over a reasonable range, does not provide a means of varying the response of the pore. 
Table A-2. Coefficients Fo Fion Ioss

\begin{tabular}{|c|c|c|c|}
\hline $\begin{array}{c}\text { Screen } \\
\text { (wires per inch) }\end{array}$ & Weave & $\begin{array}{c}\text { Void Fraction } \\
\in\end{array}$ & $\begin{array}{c}\text { Coefficient } \\
\mathrm{K} \\
1 / \mathrm{cm} \\
(1 / \mathrm{in} .)\end{array}$ \\
\hline $325 \times 2300$ & Dutch Twill & 0.297 & $\begin{array}{c}1.16 \times 10^{6} \\
\left(2.94 \times 10^{6}\right)\end{array}$ \\
\hline $200 \times 1400$ & Dutch Twi11 & 0.267 & $\begin{array}{r}9.49 \times 10^{5} \\
\left(2.41 \times 10^{6}\right)\end{array}$ \\
\hline $165 \times 800$ & Dutch Twill & 0.430 & $\begin{array}{l}1.77 \times 10^{5} \\
\left(4.51 \times 10^{5}\right)\end{array}$ \\
\hline $165 \times 800$ & Plain Dutch & 0.598 & $\begin{array}{c}5.08 \times 10^{4} \\
\left(1.29 \times 10^{5}\right)\end{array}$ \\
\hline $80 \times 700$ & Dutch Twil1 & 0.368 & $\begin{array}{c}2.09 \times 10^{5} \\
\left(5.32 \times 10^{5}\right)\end{array}$ \\
\hline $50 \times 250$ & Plain Dutch & 0.616 & $\begin{array}{c}1.41 \times 10^{4} \\
\left(3.58 \times 10^{4}\right)\end{array}$ \\
\hline $850 \times 155$ & Robusta & 0.503 & $\begin{array}{r}7.70 \times 10^{4} \\
\left(1.96 \times 10^{5}\right)\end{array}$ \\
\hline $200 \times 200$ & Square & 0.642 & $\begin{array}{r}1.60 \times 10^{4} \\
\left(4.08 \times 10^{4}\right)\end{array}$ \\
\hline
\end{tabular}


The coefficient for the flow loss through the screen pore should be used to achieve correlation. This was the approach used when predictions from this model were compared with the response of a screen to pulsed flow (Ref. III-2). The coefficient is based on the work of Armour and Cannon (Ref. A-1). Our experience, including recent tests as part of the Space Shuttle Reaction Control System Tank Program, has indicated that the Armour and Cannon relations are at most about $30 \%$ conservative (i.e. $e_{\circ}$ predicts a pressure differential greater than measured). Data from another experimental program covering a wide range of screen meshes tends to substantiate that result $(\operatorname{Ref}, A-2)$.

Therefore a certain range of variation of this coefficient is permis sible. Since the coefficient has been modified to account for a single pore, further uncertainty has been introduced. This coefficient is the only means of adjusting the model so it will inherently account for any other inaccuracies in the model, thus becoming more than a specifically identified orifice coefficlent. After correlation has been achieved, the coefficient will correct the screen response, as analytically defined, to the actual physical case.

\section{B. BUBBLE INERTIA}

From the previous development of the bubble growth model (Ref. III-2), the inertia of the liquid interface was described using the basic Rayleigh equation for a spherical bubble in an infinite liquid. The kinetic energy of the liquid mass for spherical bubble growth is represented as (Ref. $A-3$ ):

$$
\text { Kinetic energy }=2 \pi \rho\left(\frac{d R}{d t}\right)^{2} R^{3} \text {. }
$$

Equating the total kinetic energy to the work done by the liquid, yields the Rayleigh equation.

The bubble growth problem being analyzed here can be more accurately described by a spherical bubble attached to a flat surfaci. In this case, the kinetic energy has been calculated to be (Ref. A-4):

$$
\text { K.E. }=9.35 \rho\left(\frac{d R}{d t}\right)^{2} R^{3} .
$$

Therefore, the Rayleigh equation is modified by a coefficient to account for the presence of the surface.

$$
\Delta \mathrm{P}_{\mathrm{d}}=1.49 \rho\left[\frac{3}{2}\left(\frac{\mathrm{dR}}{\mathrm{dt}}\right)^{2}+\mathrm{R} \frac{\mathrm{d}^{2} \mathrm{R}}{\mathrm{dt}^{2}}\right]
$$

where $\Delta \mathrm{P}_{\mathrm{d}}=$ pressure differential due to inextia. This improvement has been incorporated into the model. 


\section{c. STATIC CONDITIONS}

Consideration was also given to incorporating all the variables that would be encountered during the testing into the model. Under nonilow conditions, an input steady pressure differential accounts for the hydrostatic pressure due to one-g. When flow takes place, tis same term can account for the sum of the steady pressure differentials acting at a screen pore. The magnitude of this differential is input to the model, based on a measured value or a separate calculation.

The thermodynamic state of the liquid is primarily accounted for by its pressure and temperature, and the saturation temperature at that pressure. Under non-equilibrium thermal conditions, vaporization of the liquid could contribute to the growth of a bubble at the screen pore. However, our primary interest here is in various conditions of liquid subcooling with thermal equilibrium. It was expected that the degree of subcooling would not strongly influence the point of first breakdown of the screen, but could significantly effect the screen response following initial breakdown. Once gas is on both sides of the screen pore, dryout may rapidly take place if there is li,tte subcooling.

\section{SAMPLE CASES}

Some trial cases were analyzed with the mode1, using the coefficients derived in the above. It was assumed that a sinusoidal vibration produced a sinusoidal variation of the liquid pressure adjacent to the screen. A $200 \times 1400$ Dutch twill screen and isopropyl alcohol liquid were selected. For this analys is the retention of the screen was based on either a stable or unstable response of the bubble growth at a screen pore. A stable response occurs as a periodic growth and collapse of the bubble, with no net increase in size. For now, it will be assumed that detachment of the bubble does not occur during a stable response.

An unstable response is the continued growth of the bubble. A typical unstable response is shown in Figure A-3. With each cycle of the pressure the bubble radius undergoes a net increase. Detachment of the bubble is inevitable in this case, so an unstable response always leads to screen breakdown.

An effective pressuge was calculated for an applied peak pressure over a range of frequencies. The results for two values of peak pressure, referenced to the bubble point, are shown in Figure A-4. These analytical results indicate that even at frequencies as low as $10 \mathrm{~Hz}$, the screen does not respond to the peak pressure of the transient. As frequency increases, the effective pressure continues to decrease. The difference between the effective pressure and the bubble point is the maximum amount of steady pressure differential. that can be applied in conjunction with the vibration, without caus ing screen breakdown. 


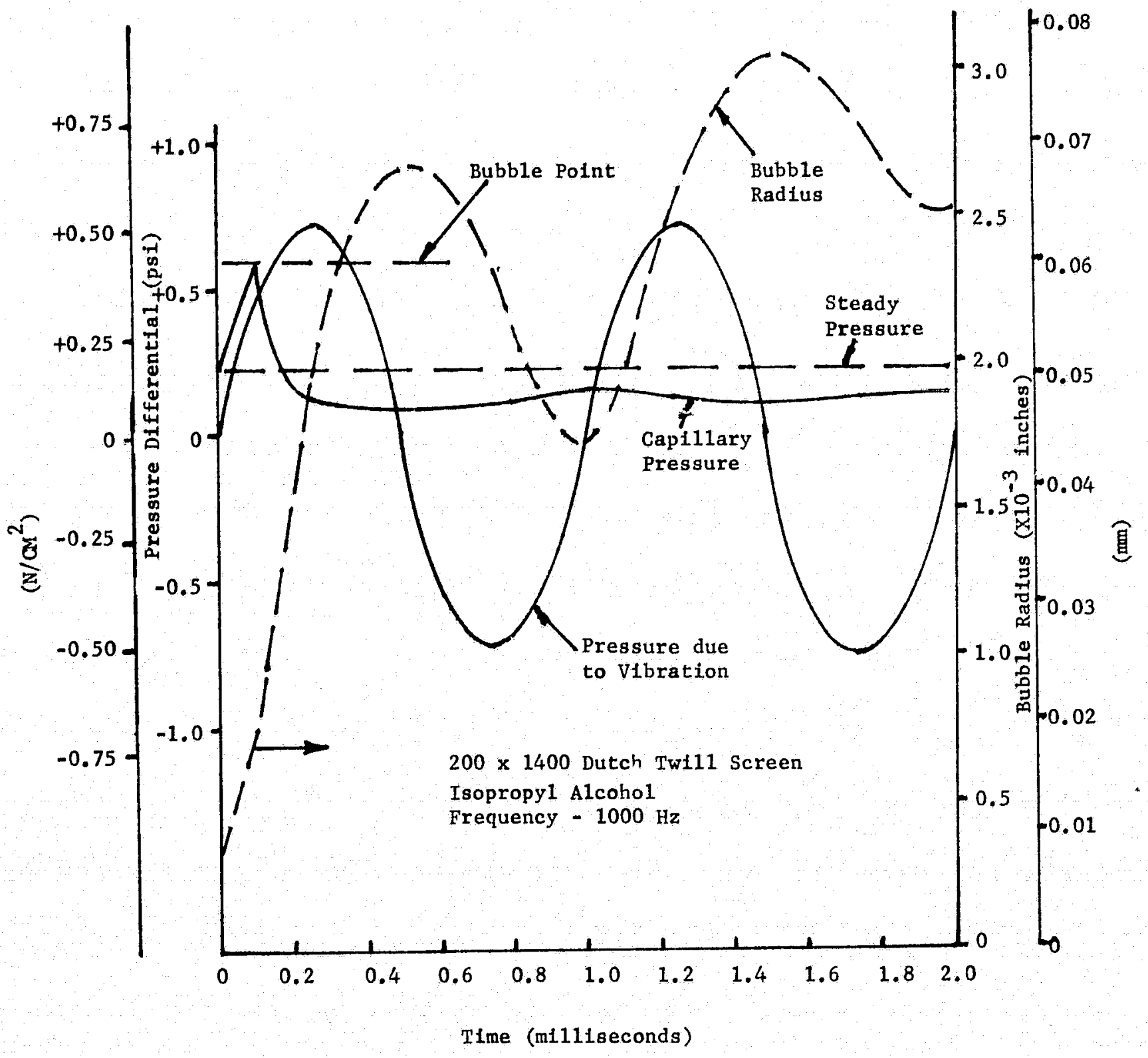

Figure A-3. Unstable Response to Sinusoldal Pressure Variation 


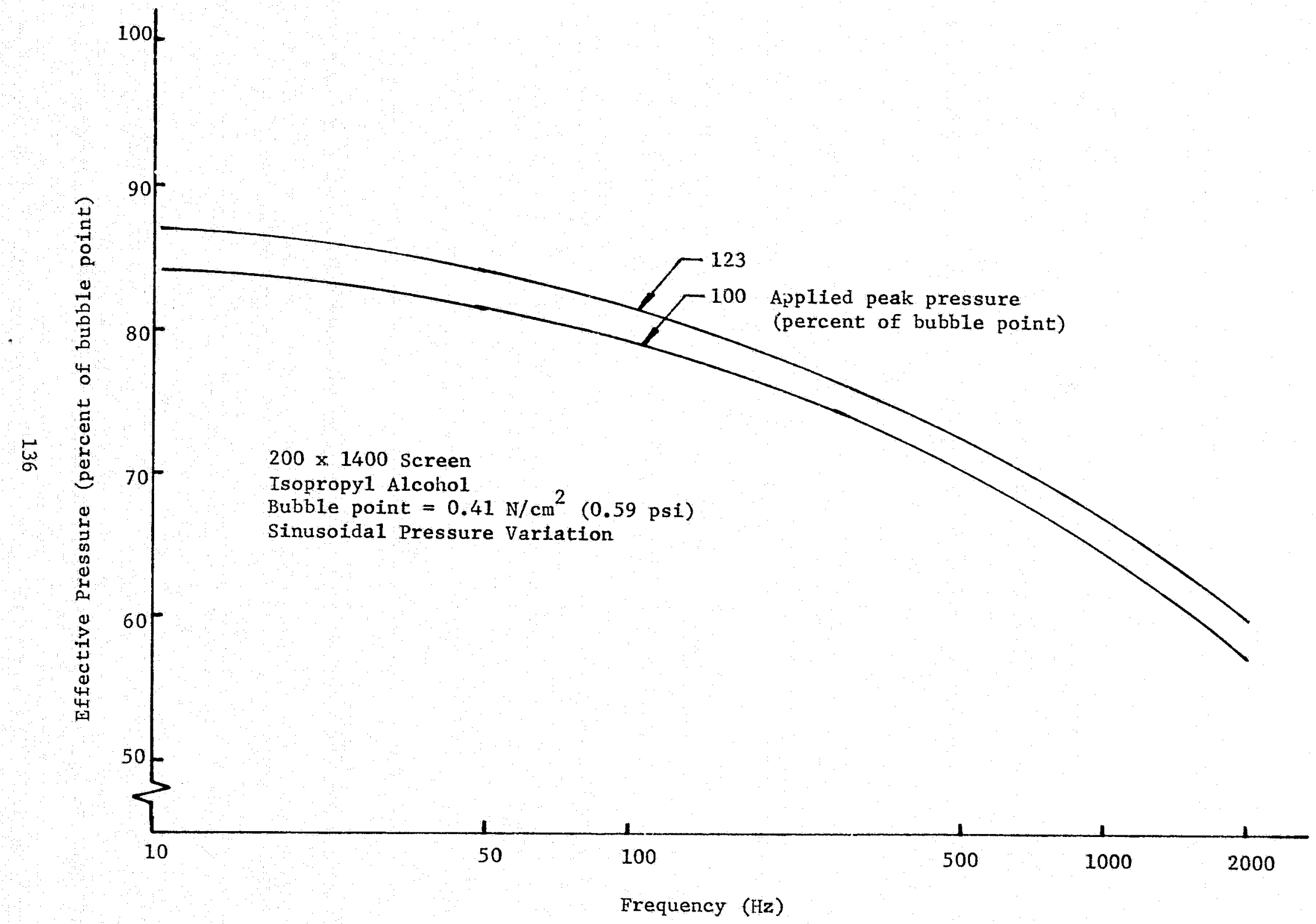

Figure A-4. Effective Pressure for Sinusoidal Pressure Variation 
The actual, passage of gas through the screen occurs when the gas bubble is detached from the screen pore. As discussed above, if the response is unstable, the bubble continues to grow and detachment (screen breakdown) is inevitable. If the growth of the bubble is stable, this does not necessarily mean that screen retention is maintained. During the stable response the bubble may reach a size such that the forces acting on the bubble will cause detachment.

\section{E. BUBBLE DETACHMENT}

The growth of a gas bubble at the screen pore, in response to a pressure transient, can be either stable or unstable. Unstable growth implies that the applied pressures will continue to cause a net increase in the bubble size with time. The actual passage of gas through the screen (screen breakdown) occurs when the gas bubble is detached from the screen pore. If the bubble growth response is unstable, the continued growth makes detachment inevitable. During the stable response of the gas bubble, detachment may or may not occur depending on the forces acting on the bubble.

In general, the interest is in the point of incipient screen breakdown, where only a few of screen pores have begun to break down. For this regime it can be assumed that there will be no influence from adjacent pores and the forces on the bubble produced by the dynamic interaction of the bubble and the surrounding liquid are negligible.

\section{Non-flow Condition}

Under non-flow conditions, gravity forces are the prime means of causing bubble detachment. The mass of liquid displaced by the bubble produces a buoyant force that is opposed by the surface tension force where the bubble contacts the screen. A balance of forces, making use of the defined bubble geometry yields the following expression for the radius at which the bubble will detach due to buoyancy:

$$
R=\left[\frac{3}{2} \frac{R_{0}}{B_{0}}\right]^{1 / 3}
$$

where $R_{0}$ is the radius of the line of contact between the bubble and the screen.

The variables $R$ and $R_{0}$ are dimensionless, being referenced to the minimum pore radius $(r)$. The Bond number is also referenced to the minimum pore radius as follows:

$$
\text { Bo }=\frac{P \mathrm{ar}^{2}}{\sigma} \text {. }
$$

The radius of the line of contact is defined as: 


$$
R_{0}=\frac{R\left(1+R_{w}\right)}{R_{w}+R}
$$

where $\mathrm{R}_{\mathrm{w}}$ is the dimensionless wire radius.

The possibility of bubble detachment due to buoyancy is evaluated by considering the maximum radius achieved by the bubble during a stable response. The value of $R_{O}$ is calculated for the maximum bubble radius using equation (18). A value for $R$ is then calculated using equation (16) and is compared to the original value for $R$. If the value from equation (16) is the smaller, the bubble does detach due to buoyancy. Screen breakdown does not occur as long as the maximum size ot the babble does not exceed the valus given by equation (16).

The grayity force can also oppose the surface tension force at the interface of the bubble, it the direction of the acceleration tends to cause flow of liquid through the pore. If the gravity force exceeds the surface tension force along the interface, the interface of the bubble will collapse upon itself, causing detachment. This mechanism of detachment was evaluated by calculating the shape of the intertace at the pore, as influenced by gravity forces, and establishing a limit for the existence of the interface. It was found that for a given liquid and acceleration level, buoyancy will cause detachment before that limit is reached.

The bubble radius for buoyant detachment was evaluated for a one-g acceleration. Of the typical propellants, liquid oxygen presents the worst case because of its low kinematic surface tension (Freon 11 , one of the test liquids, has similar properties). Three screens, representing the span of meshes being considered, were evaluated. The parameters calculated are listed in Table A-3. The point of detachment is best represented by calculating the capillary pressure of the bubble at the point of detachment and compaxing it to the bubble point of the screen. The values for capillary pressure listed in lable $A-3$ are relatively low. For such values of capillary pres m sure to be reached during stable bubble growth, the static pressure applied to the system would have to be of similar magnitude and the peak pressure of the transient would have to be much larger than the butble point. Under low-g condicions it can be seen that buoyant detachment becomes much less significant.

\section{Flow Condition}

When there is liquid flow, parallel to the screen surface within a surface tension device, the shear force acting on the bubble can cause detachment. A surface tension force again opposes the shear so the balance of forces yields:

$$
R=\left[\frac{4 R_{0}}{C_{D} W e}\right]^{1 / 2}
$$


Table A-3. Bubble Detachment for Iiquid Oxygen

\begin{tabular}{|c|c|c|c|}
\hline \multirow[b]{2}{*}{ Buoyancy } & \multicolumn{3}{|c|}{ Screen Mesh } \\
\hline & $\begin{array}{l}325 \times 2300 \\
\text { Dutch Twi11 }\end{array}$ & $\begin{array}{l}165 \times 800 \\
\text { Dutch Twi11 }\end{array}$ & $\begin{array}{l}200 \times 200 \\
\text { Square Weave }\end{array}$ \\
\hline Bond Number for one-g & $4.39 \times 10^{-5}$ & $4.30 \times 10^{-4}$ & $1.73 \times 10^{-3}$ \\
\hline $\mathrm{R}$ & 47.8 & 20.1 & 11.1 \\
\hline Percent of Bubble Point & 2.09 & 4.97 & 8.99 \\
\hline \multicolumn{4}{|l|}{ Shear } \\
\hline $\begin{array}{l}\text { Weber Number for } \\
U=.3 \mathrm{~m} / \mathrm{sec}(1 \mathrm{ft} / \mathrm{sec})\end{array}$ & 0.0574 & 0.179 & 0.359 \\
\hline $\mathrm{R}$ & 21.1 & 10.2 & 5.95 \\
\hline Percent of Bubble Point & 4.74 & 9.78 & 16.8 \\
\hline
\end{tabular}


The Weber number is referenced to the minimum pore radius.

$$
W e=\rho \frac{U^{2} r}{\sigma}
$$

where the flow velocity (U) is parallel to screen.

The drag coefficient $\left(C_{D}\right)$ is a function of the Reynolds number of the bubble and can be found in most fluid mechanics text books (e.g., Ref. $A-5)$.

The value of $U$ can cover a wide range, dependent on the flow rate from the tank and the configuration of the surface tension device. A value of $0.3 \mathrm{~m} / \mathrm{sec}(1.0 \mathrm{ft} / \mathrm{sec})$ was selected as a representative upper limit for the flow velocity. Having picked a velocity, oxygen would again give the worst case condition due to its small kinematic surface tension. The calculated values are again presented in Table A-3. At large flow velocities, shear is the more likely cause of bubble detachment. Liquid flow in a high-g environment would require the valuation of the cornbined effects of shear and buoyancy.

The theory mpon which the above described bubble detachment is based can be found in the literature regajing gas bubble generators (e.g. Ref. $A-6$ and $A-7)$, and has been well verified with experimental data. 


\section{APPENDIX B}

TEST DATA

The following table is a compilation of the measured data from selected vibration tests. These tests were selected from Table IV -4 as being representative of the total test program. Al1 of these selected tests were performed using the single element model and there was no outflow. The model was installed in orientation 1 on the shaker unless otherwise noted in the table, Most of the listed tests were performed using isopropyl alcohol as the test liquid, except for tests 62 (Freon 113) and 63 (Freon 11). Presented in this table are the specific conditions of each vibration test. The results of the test that are piesented are the frequency and peak positive amplitude of the pressure differential due to vibration at the first harmonic of the system, and the occurrence of screen breakdown is noted along with the degree of breakdown. 


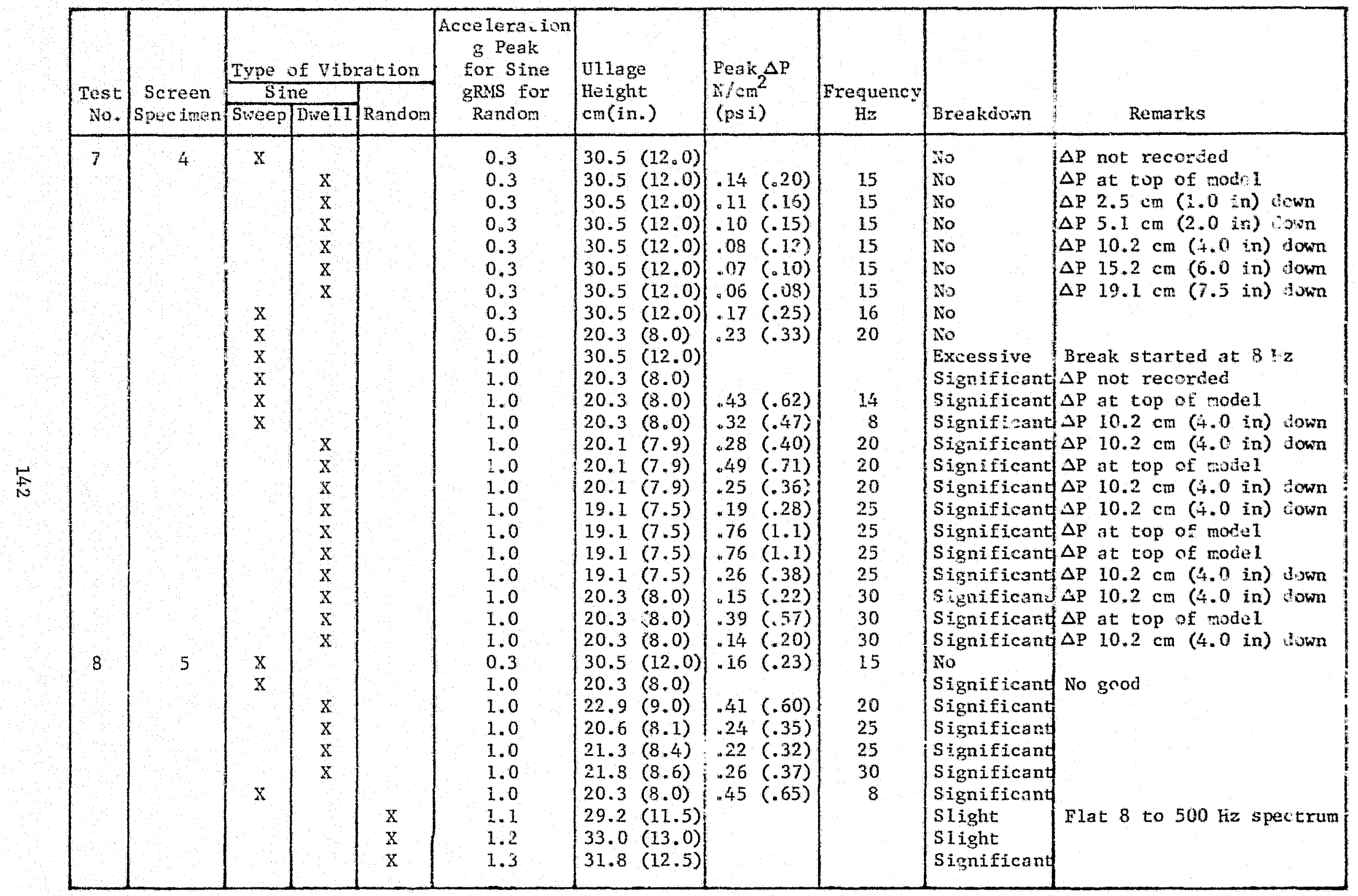




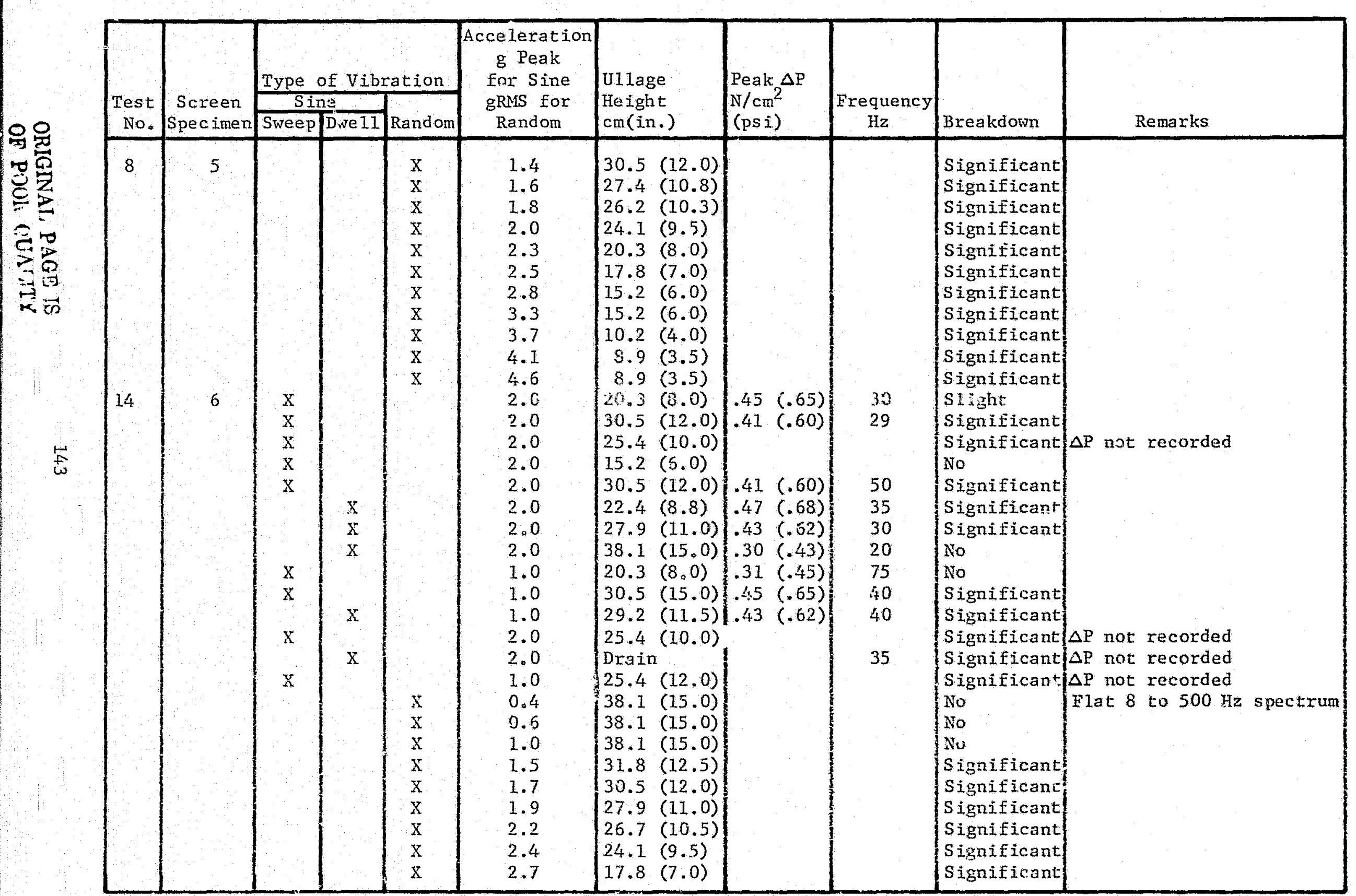




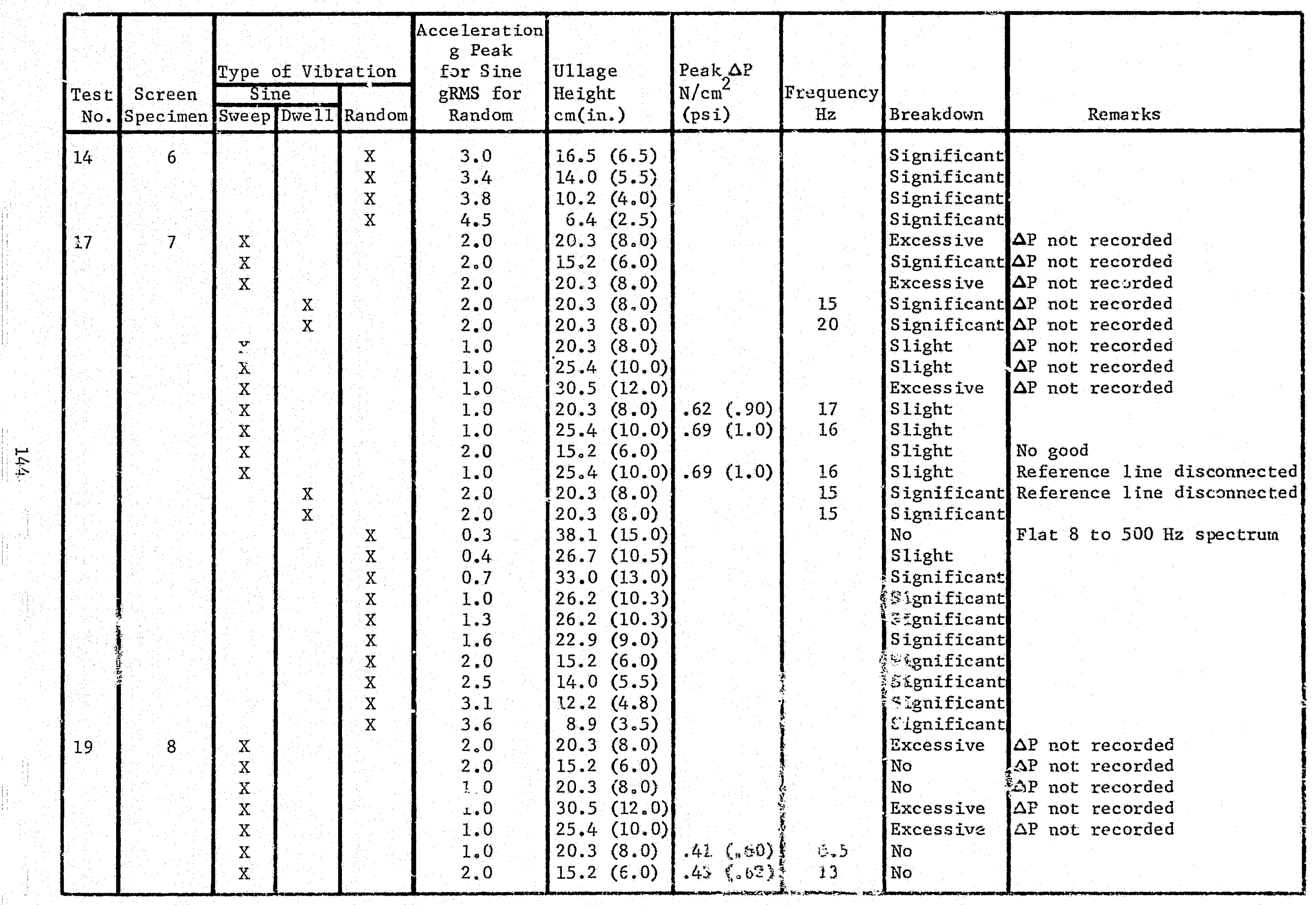




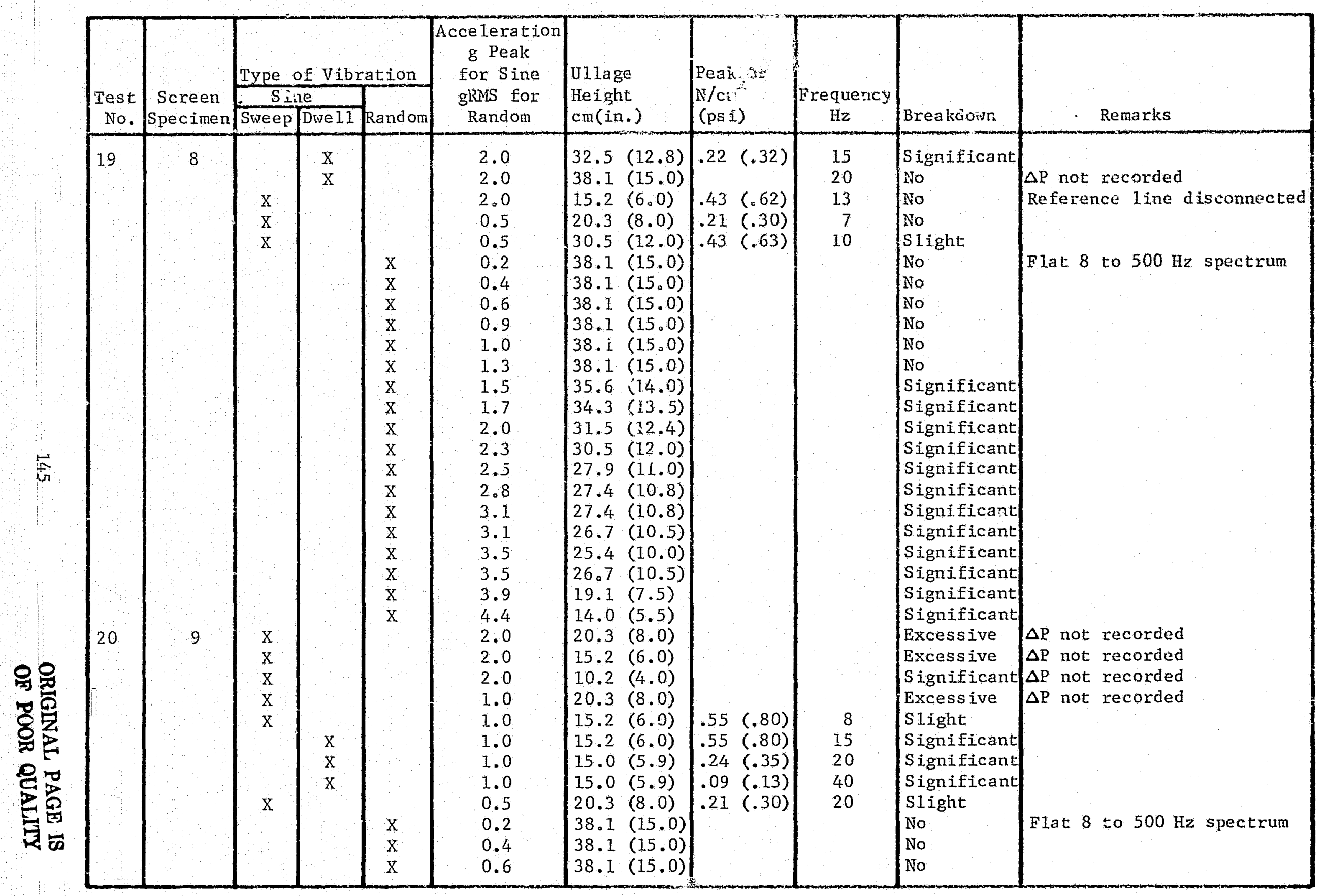




\begin{tabular}{|c|c|c|c|c|c|c|c|c|c|c|}
\hline $\begin{array}{c}\text { Test } \\
\text { No. }\end{array}$ & $\begin{array}{c}\text { Screen } \\
\text { Specimen }\end{array}$ & \multicolumn{3}{|c|}{ Type of Vibration } & $\begin{array}{c}\text { Acceleration } \\
\mathrm{g} \text { Peak } \\
\text { for Sine } \\
\text { gRMS for } \\
\text { Random }\end{array}$ & $\begin{array}{l} \\
\text { Ullage } \\
\text { Height } \\
\text { cm(in.) }\end{array}$ & $\begin{array}{l}\text { Peak } \Delta \mathrm{P} \\
\mathrm{N} / \mathrm{cm}^{2} \\
\text { (psi) }\end{array}$ & $\begin{array}{c}\text { Frequency } \\
\mathrm{Hz}\end{array}$ & Breakdown & Remarks \\
\hline 20 & 10 & $\begin{array}{l}x \\
x \\
x \\
x \\
x \\
\\
x \\
x \\
x \\
x\end{array}$ & $\begin{array}{l}\mathrm{x} \\
\mathrm{x}\end{array}$ & $\begin{array}{l} \\
\mathrm{X} \\
\mathrm{X} \\
\mathrm{X} \\
\mathrm{X} \\
\mathrm{X} \\
\mathrm{X} \\
\mathrm{X} \\
\mathrm{X} \\
\mathrm{X} \\
\mathrm{X} \\
\mathrm{X}\end{array}$ & $\begin{array}{l}1.0 \\
1.3 \\
1.5 \\
1.8 \\
2.0 \\
2.3 \\
2.5 \\
2.8 \\
3.1 \\
3.5 \\
4.0 \\
2.0 \\
2.0 \\
2.0 \\
1.0 \\
1.0 \\
1.0 \\
1.0 \\
0.5 \\
1.0 \\
1.0 \\
1.0 \\
0.2 \\
0.4 \\
0.6 \\
0.8 \\
1.0 \\
1.3 \\
1.5 \\
1.7 \\
1.9 \\
2.1 \\
2.4\end{array}$ & $\begin{aligned} & 34.3(13.5) \\
& 31.8(12.5) \\
& 27.9(11.0) \\
& 25.4(10.0) \\
& 21.6(8.5) \\
& 19.1(7.5) \\
& 14.0(5.5) \\
& 12.7(5.0) \\
& 11.4(4.5) \\
& 10.2(4.0) \\
& 7.9(3.1) \\
& 20.3(8.0) \\
& 15.2(6.0) \\
& 10.2(4.0) \\
& 20.3(8.0) \\
& 15.2(6.0) \\
& 9.1(3.6) \\
& 19.1(7.5) \\
& 20.3(8.0) \\
& 20.3(8.0) \\
& 15.2(6.0) \\
& \text { Dra.1n } \\
& 38.1(15.0) \\
& 38.1(15.0) \\
& 38.1(15.0) \\
& 38.1(15.0) \\
& 31.8(12.5) \\
& 29.2(11.5) \\
& 17.8(7.0) \\
& 16.5(6.5) \\
& 12.7(5.0) \\
& 11.4(4.5) \\
& 9.7(3.8)\end{aligned}$ & \begin{tabular}{|l|l|} 
& \\
& \\
& \\
& $.48(.70)$ \\
.17 & $(.25)$ \\
$.50(.73)$ \\
\end{tabular} & $\begin{array}{l}40 \\
40 \\
20\end{array}$ & $\begin{array}{l}\text { Significant } \\
\text { Significant } \\
\text { Significant } \\
\text { Significant } \\
\text { Significant } \\
\text { Significant } \\
\text { Significant } \\
\text { Significant } \\
\text { Significant } \\
\text { Significant } \\
\text { Significant } \\
\text { Excessive } \\
\text { Excessive } \\
\text { Excessive } \\
\text { Excessive } \\
\text { Signjicant } \\
\text { Significant } \\
\text { Significant } \\
\text { No } \\
\\
\\
\text { No } \\
\text { No } \\
\text { Slight } \\
\text { Significant } \\
\text { Significant } \\
\text { Significant } \\
\text { Significant } \\
\text { Significant } \\
\text { Significant } \\
\text { Significant } \\
\text { Significant }\end{array}$ & \begin{tabular}{|l} 
\\
\\
$\Delta \mathrm{P}$ not recorded \\
$\Delta \mathrm{P}$ not recorded \\
$\Delta \mathrm{P}$ not recorded \\
$\Delta \mathrm{P}$ not recorded \\
$\Delta \mathrm{P}$ not recorded \\
$\Delta \mathrm{P}$ not recorded \\
$\Delta \mathrm{P}$ not recorded \\
Flat 8 to $500 \mathrm{~Hz}$ spectrum \\
\end{tabular} \\
\hline
\end{tabular}




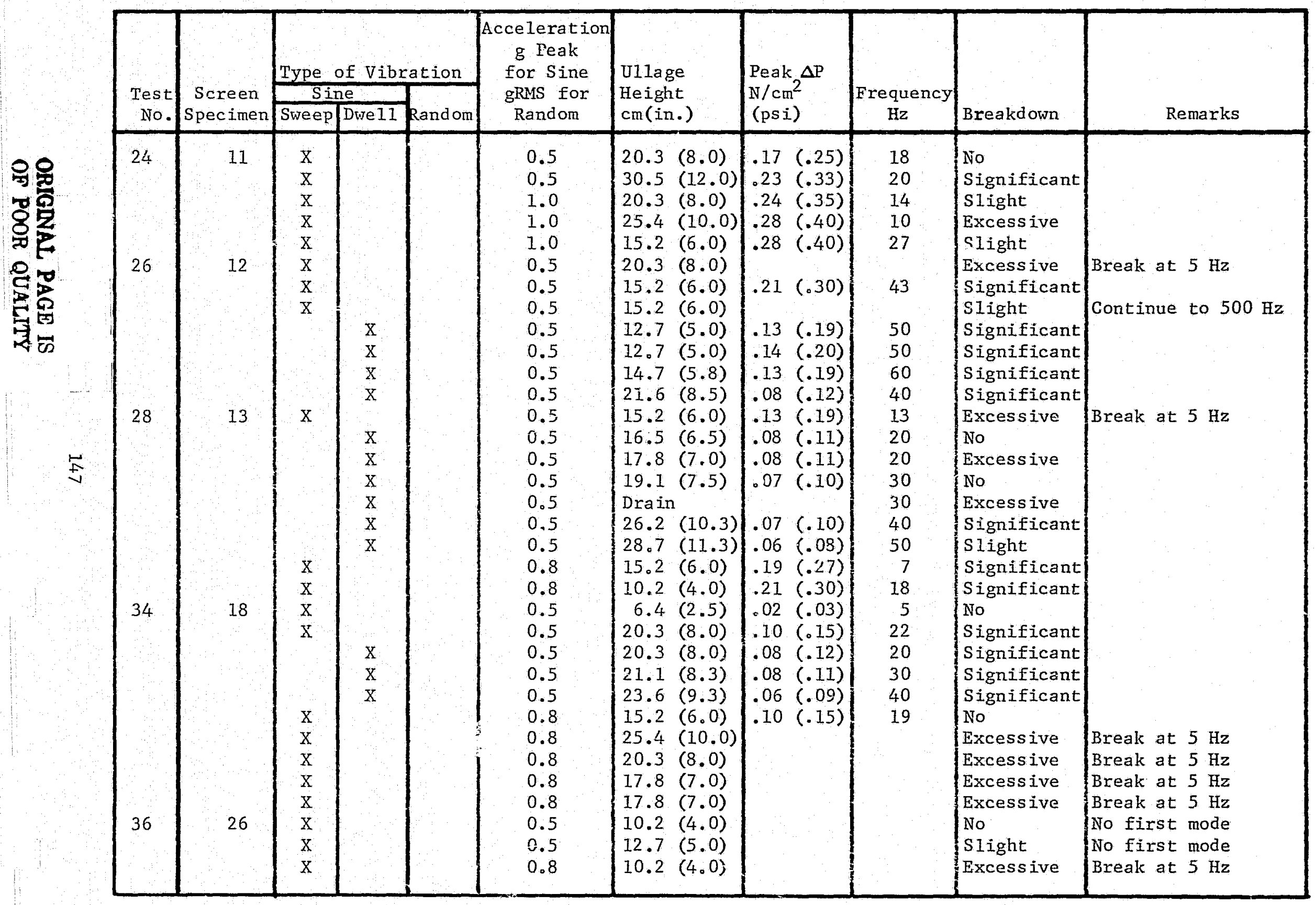




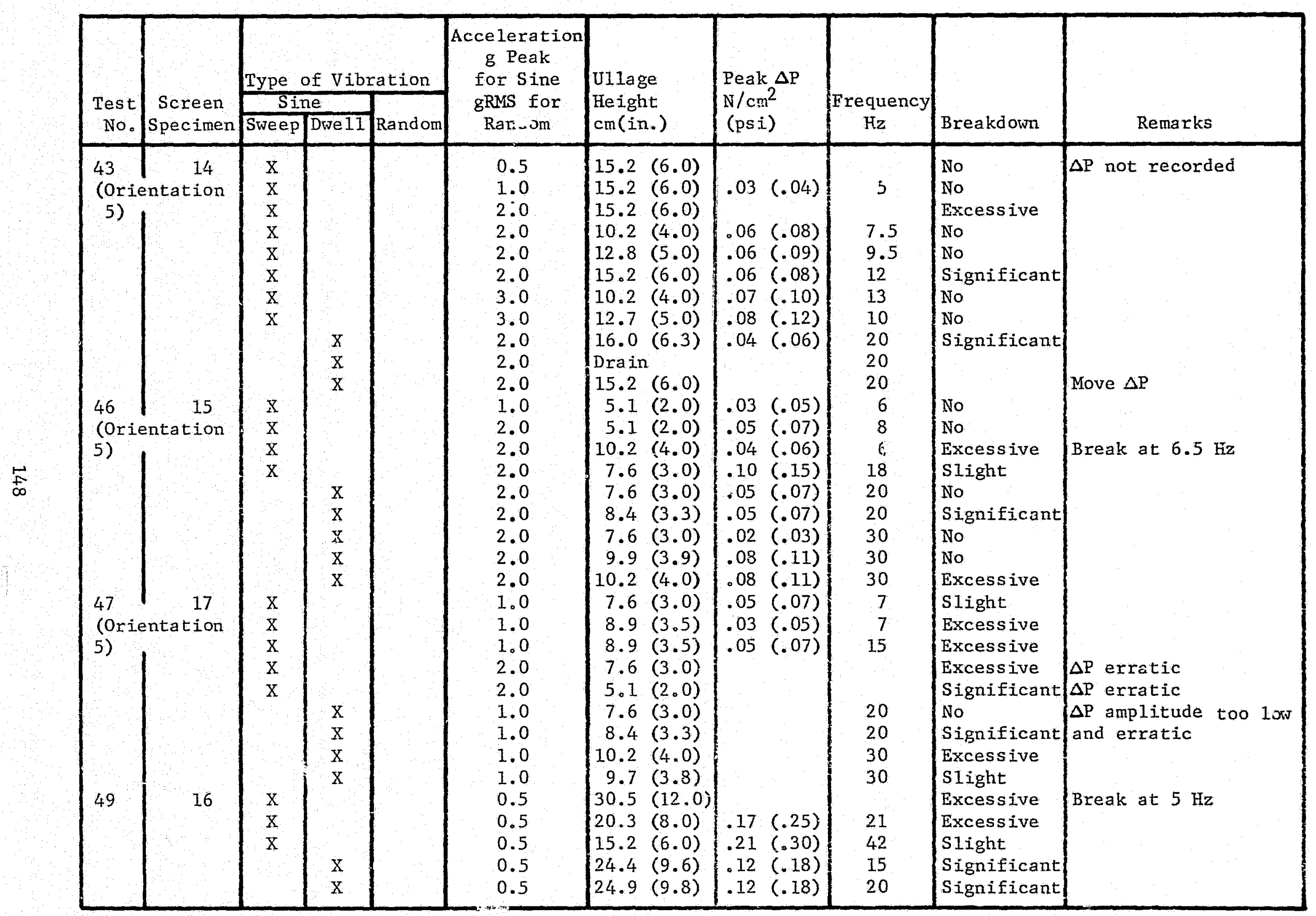




\begin{tabular}{|c|c|c|c|c|c|c|c|c|c|c|}
\hline \multirow[b]{2}{*}{$\begin{array}{r}\text { Test } \\
\text { No. }\end{array}$} & \multirow[b]{2}{*}{$\begin{array}{c}\text { Screen } \\
\text { Specimen }\end{array}$} & \multicolumn{3}{|c|}{ Type of Vibration } & \multirow{2}{*}{$\begin{array}{c}\text { Acceleration } \\
\text { g Peak } \\
\text { for Sine } \\
\text { gRMS for } \\
\text { Random }\end{array}$} & \multirow{2}{*}{$\begin{array}{l}\text { Ullage } \\
\text { Height } \\
\text { cm(in,) }\end{array}$} & \multirow{2}{*}{$\begin{array}{l}\text { Peak } \Delta \mathrm{P} \\
\mathrm{N} / \mathrm{cm}^{2} \\
\text { (psi) }\end{array}$} & \multirow[b]{2}{*}{$\begin{array}{c}\text { Frequency } \\
\mathrm{Hz}\end{array}$} & \multirow[b]{2}{*}{ Breakdown } & \multirow[b]{2}{*}{ Remarks } \\
\hline & & Sin & Dwe & Randon & & & & & & \\
\hline $\begin{array}{l}62 \\
\text { (Freo } \\
63 \\
\text { (Freo }\end{array}$ & \begin{tabular}{|l|r} 
& 16 \\
& \\
& \\
& \\
on 113$)$ & 11 \\
on 11$)$ & 11
\end{tabular} & $\begin{array}{l}\mathrm{X} \\
\mathrm{X} \\
\mathrm{X} \\
\mathrm{X} \\
\mathrm{X} \\
\mathrm{X} \\
\mathrm{X} \\
\mathrm{X}\end{array}$ & $\begin{array}{l}X \\
X \\
X \\
X \\
X \\
X\end{array}$ & & $\begin{array}{l}0.5 \\
0.5 \\
0.5 \\
0.5 \\
0.5 \\
0.5 \\
0.8 \\
0.8 \\
1.0 \\
1.0 \\
1.5 \\
1.0 \\
1.0 \\
1.5\end{array}$ & $\begin{array}{ll}19.8 & (7.8) \\
30.5 & (12.0) \\
29.2 & (11.5) \\
14.7 & (5.8) \\
18.5 & (7.3) \\
\text { Drain } \\
15.2 & (6.0) \\
10.2 & (4.0) \\
15.2 & (6.0) \\
10.2 & (4.0) \\
10.2 & (4.0) \\
15.2 & (6.0) \\
10.2 & (4.0) \\
10.2 & (4.0)\end{array}$ & $\begin{array}{ll}.16 & (.23) \\
.08 & (.22) \\
.08 & (.11) \\
.21 & (.31) \\
.17 & (.25) \\
.19 & (.27) \\
.26 & (.37)\end{array}$ & $\begin{array}{l}25 \\
30 \\
30 \\
40 \\
50 \\
30 \\
35 \\
29\end{array}$ & $\begin{array}{l}\text { Significant } \\
\text { Significant } \\
\text { Significant } \\
\text { Significant } \\
\text { Significant } \\
\\
\text { Excessive } \\
\text { Significant } \\
\text { Excessive } \\
\text { Significant } \\
\text { Excessive } \\
\text { Excessive } \\
\text { Significant } \\
\text { Excessive }\end{array}$ & $\begin{array}{l}\Delta \\
\Delta \mathrm{P} \text { not recorded } \\
\Delta \mathrm{P} \text { not recorded } \\
\Delta \mathrm{P} \text { not recorded } \\
\Delta \mathrm{P} \text { not recorded } \\
\Delta \mathrm{P} \text { not recorded } \\
\Delta \mathrm{P} \text { not recorded }\end{array}$ \\
\hline
\end{tabular}

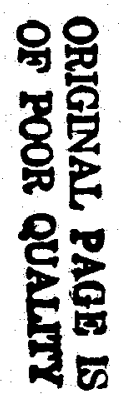


APPENDIX C

SYMBOLS

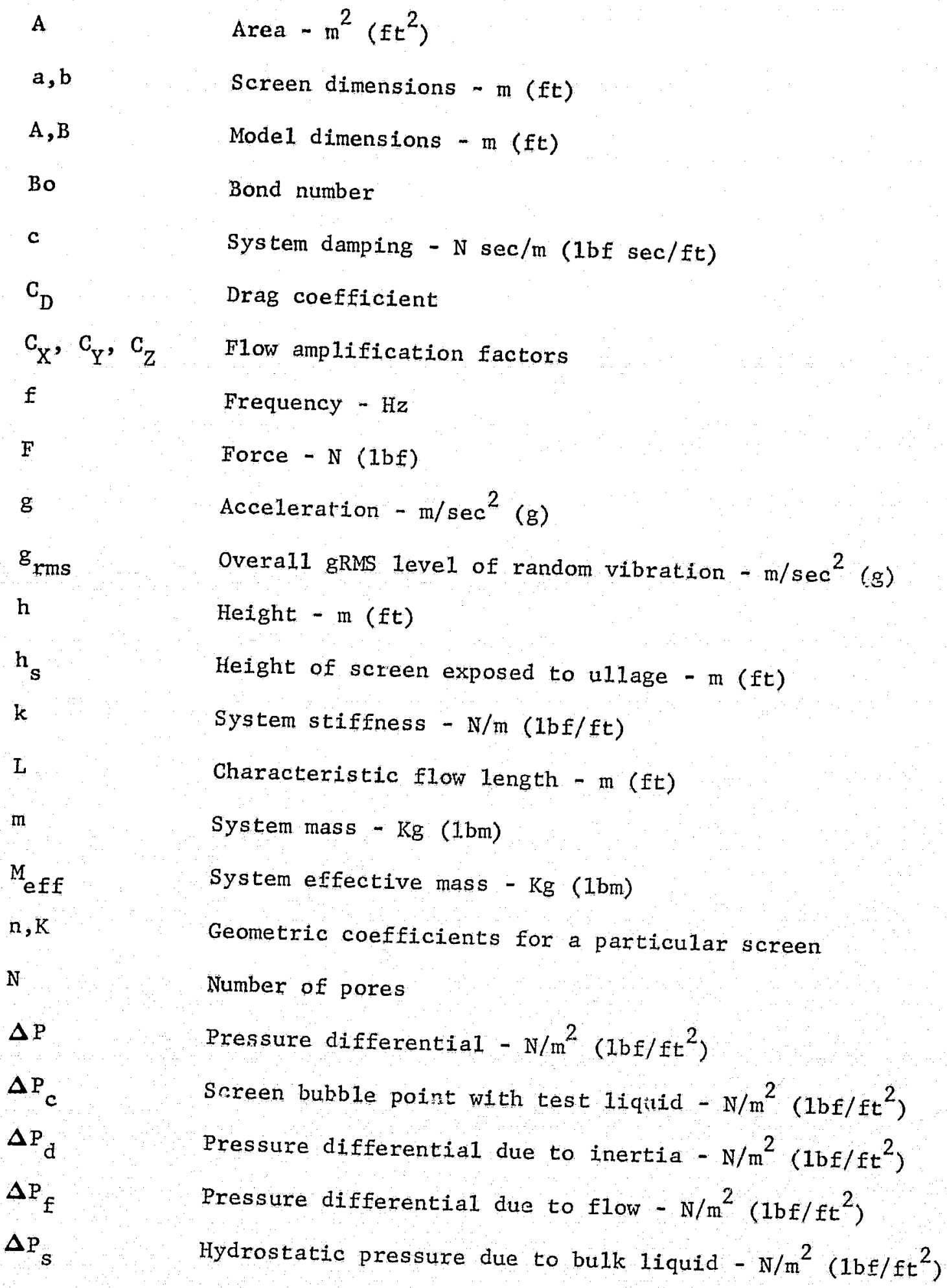




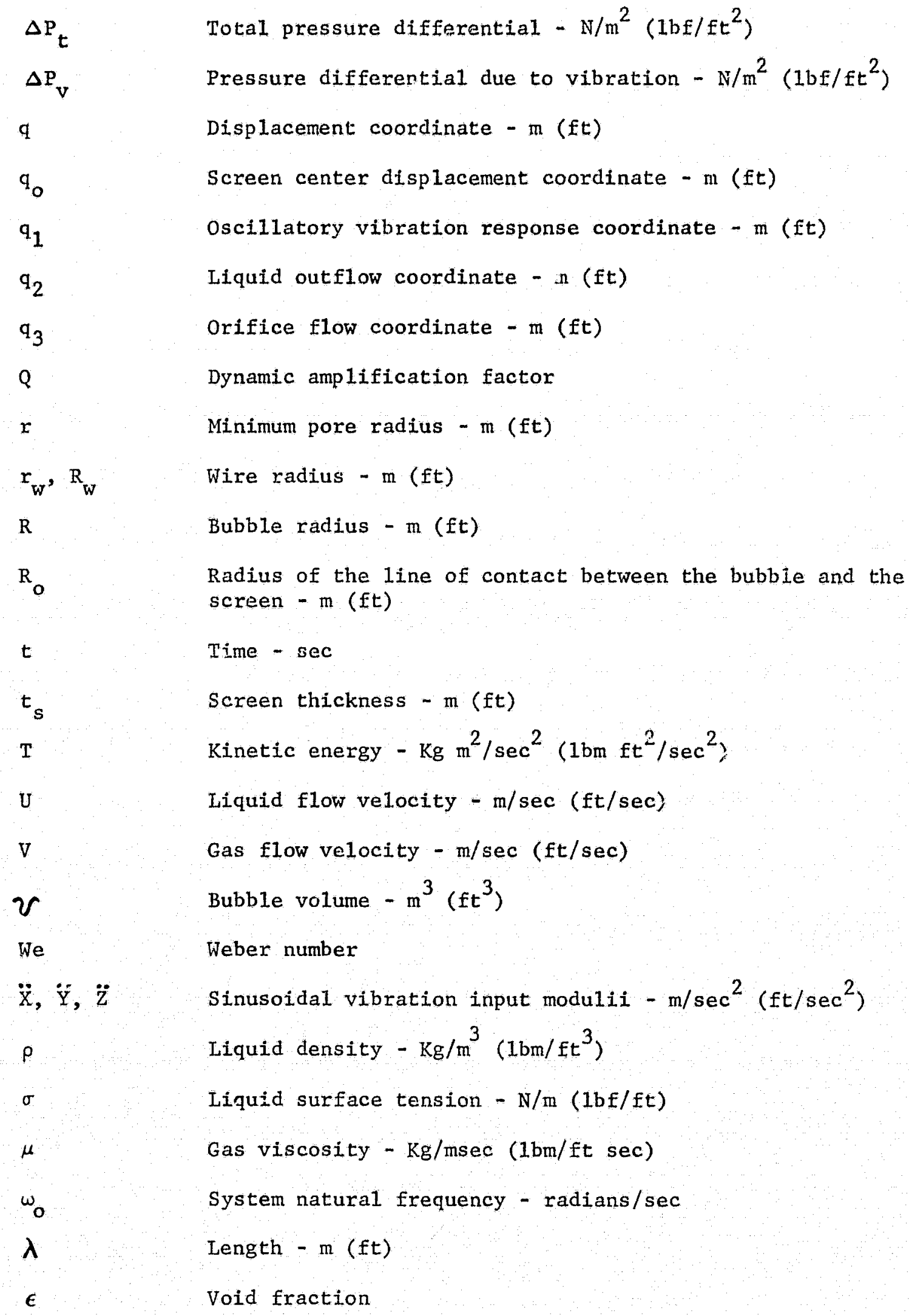


APPENDIX D

REFERENCES

I-1 George F. Orton: Simulated Flight Vibration Testing of a Surface Tension Propellant Expulsion Screen. Master's Thesis, Saint Louis University, 1971.

I-2 G. W. Burge and J. B. Blackmon: Study and Design of Cryogenic Propellant Acquisition Systems, Final Report, Volume II Supporting Experimenta 1 Program. MDC G5038. McDonne11 Douglas Astronautics Company, Huntington Beach, California, December 1973.

I-3 G. R. Page: Acquistion/Expulsion System for Earth-Orbital Propulsion System Study, Final Report, Volume III - Cryogenic Pest. MCR-75-171. Martin Marietta Corporation, Denver, Dolorado, October 1973. (Contract NAS9-12182)

I-4 D. A. Fester: SS/RCS Surface Tension Propellant Acquisition/ Expulsion Tankage Technology Fina1 Report. MCR-75-171. Mart in Marietta Corporation, Denver, Colorado, August 1975. (Contract NAS 9-13709)

I-5 J. R. Tegart: The Effect of Vibration on Surface Tension Devices. $\mathrm{R}-74-48602-001$. Martin Marietta Corporation, Denver, Colorado, June 1974 .

I-6 R. P. Warren: Acquisition System Environmental Efiects Study. MCR-75-21. Mart in Marietta Corporation, Denver, Colorado, May 1975. (Contract NAS8-30592)

II-1 D. A. Hess and G. F. Orton: Space Shuttle OMS Propellant Acquisition. Proceedings of the JANNAF 1975 Propulsion Meeting, Volume III, pp. 429-453.

II-2 Tank Propellant - Reaction Contro1 System. MC282-0061C, Rev. D. Rockwel1 International Space Division, 8 June 1975 (Space Shuttle RCS Tank Specification)

II-3 C. D. Brown: Viking Orbiter 1975, Propel lant Management Device, Final Report. SE010-47-01. Martin Marietta Corporation, Denver, Colorado, May 1973.

II -4 S. O. DeBrock and R. K. Grove: "Capillary Propellant Management for Integrated Primary and Secondary Propulsion Systems." Journal of Spacecraft and Rockets, May 1975, pp. 261-270. 
II-5 L. T. Park and J. D. Corbin: Titan Transtage Spacecraft Propu1sion System. AIAA Paper 73-1210. Presen ed AIM/SAE 9th Prom pulsion Conference, Las Vegas, Nevada, November 1973.

II-6 M. H. Blatt and M. D. Walter: Centaur Propellant Acquisition System Study. NASA CR-134811. General Dynamics Convair Division, San Diego, California, June 1975.

II-7 R. L. Chase, M. J. Cook and D. L. Young: Planetary Mission Applications for Space Storable Propulsion. AIAA Paper 74-1178, presented AIAA/SAE 10th Propulsion Conference, San Diego, California, October 1974.

II-8 J. R. Tegart and D. A. Fester: "Space Storable Propellant Acquisition System." Journal of Spacecraft and Rockets, Vo1. 12, No. 2, September 1975.

II-9 G. R. Page: Acquisition/Expulsion Orbital Propulsion System Study, Volume II, Cryogenic Design. MCR-73-97. Martin Marietta Corporation, Denver, Colorado, October 1973.

II-10 G. W. Burge, et a1.: Design of Propellant Acquisition Systems for Advanced Cryogenic Space Propulsion Systems. AIAA Paper 73-1287, presented at AIAA/SAE 9th Propulsion Conference, Las Vegas, Nevada, November 1973.

II-11 J. R. Owens: Intelsat Sate11ire Onboard Propulsion Systems, Past and Future. AIAA Paper 75-289. Pr ssented AIAA/CASI 6th Communications Satellite Systems Conference, Montreal, Canada, Apri1 1976.

II-12 Baseline Space Tug Configuration Definition. MSFC 68M00039-2, NASA George C. Marsha11 Space Flight Center, July 15, 1974.

II-13 G. R. Page: Acquisition/Expulsion System for Earth Orbital Propulsion System Study, Volume II, Cryogenic Design. MCR-73-97, Martin Marietta Corporation, Denver, Colorado, October 1973.

II-14 G. W. Burge and J. B. Blackmon: Study and Design of Cryogenic Propellant Acquisition Systans, Volume I. Design Studies. MDC G5038, MeDonne11 Douglas Astronatics Company, Huntington Beach, California, December 1973.

II-15 J. F. Nichols: Study of Liquid Oxygen/Liquid Hydrogen Auxiliary Propulsion Systems for the Space Tug. NASA CR-134790, Rockwel1 International Corporation, Seal Beach, California, June 1975.

II -16 S. C. DeBrock: Development and Flight Experience with a Capillary Propellant Management System for a Three Axis

Stabilized Vehicle. AIAA Jet Propulsion Specialists Conference, November 1972. 
II-17 D. L. Balzer, et al.: The Monopropellant Hydrazine Reaction Control System for the RCA Globcom/RCA Alascom Communication Satellite (RCA Satcom). AIAA Paper 76-631, presented AIAA/SAE 12th Propulsion Conference, Palo Alto, California, July 1976.

II-18 H. Himelblau, C. M. Fuller and T. D. Scharton; Assessment of Space Vehicle Aeroacoustic - Vibration Prediction, Design and Testing. NASA CR $\times 1596$. McDonnel1 Douglas Astronautics Company, Huntington Beach, California, July 1970.

II-19 Eunctiona1 Requirement Viking Orbiter 1975 Environmental Design Criteria. V075-3-240. Jet Propulsion Laboratory, Pasadena, Califirnia, 29 February 1972.

II-20 Rocket Engine Assemb1y, RCS. PD5000007. Martin Marietta Corporation, Denver, Colorado, July 1972 (Specification for Viking Lander Attitude Control Rocket Engine).

II-21 General Environmental Test Specification for Spacecraft Components. S-320-G-1. NASA Goddaro Space Flight Center, Greenbe1t, Maryland.

II-22 C.J. Beck, Jr. and D. N. Caba: "Vibration and Acoustic Environment Characteristics of the Saturn V Launch Vehicle." Shock and Vibration Bulletin, No. 39, Part 6, March 1969.

II-23 Agena Payload Users Handbook. LMSC-A981500. Lockheed Missiles and Space Company, Sunnyvale, California, I March 1971.

II-24 F. I. Marks: Titan III Common Core EnvironmentaI Specifications. Martin Marietta Corporation, Denyer, Colorado, January 5, 1967.

II-25 D. E. Newbrough, et a1.: "Development and Verification of the Apollo Lunar Module Vibration Test Requirements." Shock and Vibration Bulletin, No. 37, Part 5, January 1968.

II-26 L. R. Pendleton: "Sinusoidal Vibration of Poseidon Solid Propellant Motors." Shock and Vibration Bulletin, No. 42, Part 3, January 1972 .

II-27 J. R. Fow1er and J. S. Rosentha1: Missile Vibration Environment for Solid Propellant Oscillatory Burning. AIAA Paper No. 71-756, presented AIAA/SAE 7 th Propulsion Joint Specialist Conference, Sa1t Lake City, Utah, June 1971.

II-28 J. A. Schoenster and H. B. Pierce: Effects of Experimentally Measured Pressure Oscillations on the Vibration of a Solid Rocket Motor. NASA IN D6931, NASA Langley Research Center, Hampton, Virginia, November 1972. 
II-29 Conmunication Technology Satel1tte, Qun11fication Test Report. Thiokol Corporation, EIkton, Maryland, July 30, 1975.

II-30 E. M. Landsbaum: Solid Motor Spacecraft Interfaces. AIAA Paper No. 74-1051, presented AIAA/SAE 10th Propulsion Conference, San Diego, California, October 1974.

II-31 Private Communication with Oren B. Philifps, Manager, Space Systems, Thiokol Corporction, Elkton, Maryland, June 28, 1976.

II-32 B. A. Conway and T. C. Henricks; A Summary of the Skylab Crew/ Vehicle Disturbances Experiment $T-013$. NASA TN D-8128, NASA Langley Research Center, Hampton, Virginia, March 1976.

II-33 F. T. Dodge, et a1.: Fluid Physics, Thermodynamics, and Heat Transfer Experiments in Space. NASA CR-134742, Southwest Research Institute, San Antonio, Texas, January 1975.

II-34 E. C. Cady: Effect of Transient Liquid Flow on Retention Characteristics of Screen Acquisition Systems. NASA-CR-135218, MeDonne11 Douglas Astronautics Co., Huntington Beach, California, April 1977. (Contract NAS3-19719)

II-35 J. A. Stark: Low-G Fluid Transfex Technology Study. NASA GR-134911, General Dynamics Corporation, San Diego, California, May 1976.

II-36 Ivan Bekey and Harris Mayer: "1980 - 2000, Raising Our jights for Advanced Space Systems." Astronautics and Aeronautics, July/August 1976, pp. 34-63.

II-37 Outlook for Space. NASA SP-386, National Aeronautics and Space Administration, January 1976.

III-1 R. P. Warren: Acquisition System Environmenta1 Effects Study. MCR-72-21, Martin Marietta Corporation, Denver, Colorado, May 1975.

III-2 J. R. Tegart; Influence of Pressure Transients on the Performance of Capillary Propellant Acquisition Systems. AIAA Paper 76-597, presented AIAA/SAE 12th Propulsion Conference, Palo A1to, California, July 1976.

V-1 W. Lauterborn: "Numerical Investigation of Nonlinear Oscillations of Gas Bubbles in Liquids," J. Acoust. Soc. Am., Vol. 59, No, 2, February 1976, pp. 283-293.

V-2 E. C. Cady: Effect of Transient Liquid Flow on Retention Characteristics of Screen Acquisition Systems. Ninth Monthly Report, McDonne11 Douglas Astronautics Company-West, Huntington Beach, California, April 1976. (Contract NAS3-19719) 


\begin{tabular}{|c|c|}
\hline$V-3$ & 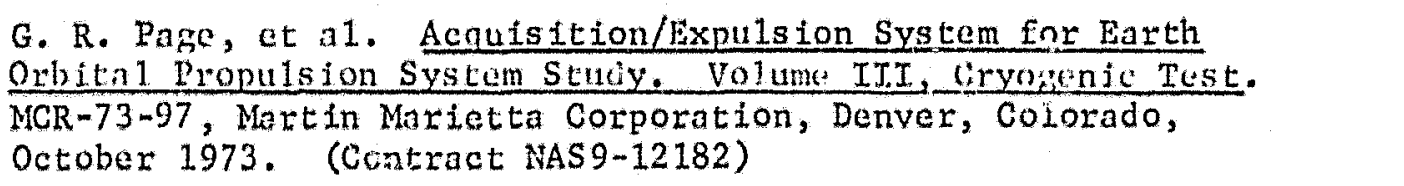 \\
\hline$v-4$ & $\begin{array}{l}\text { Freon Produce Information. B-2, E. I. duPont dexemouriz and co., } \\
\text { WiImington, Delaware, } 1969 .\end{array}$ \\
\hline$V-5$ & $\begin{array}{l}\text { F. C. Cady: Design and Evaluation of Thermodynamic Vent/Screen } \\
\text { Baffle Cryogenic Storage System. NASA CR-13480, McDonne11 } \\
\text { Douglas Astronautics Co,, Huntington Beach, California, June } 1975 .\end{array}$ \\
\hline$v-6$ & $\begin{array}{l}\text { P. E. Bingham and J. R. Tegart: Wicking in Fine Mesh Screens. } \\
\text { AIAA Paper } 77-849 \text {, presented AIAA/SAE } 13 \text { th Joint Propulsion } \\
\text { Conference, Orlando, Florida, July } 1977 \text {. }\end{array}$ \\
\hline$A-1$ & $\begin{array}{l}\text { J. G, Armour and } J_{0} \text { N. Crinon: "Fluid Flow through Woven Screens." } \\
\text { AIChE Journa 1, Vol. 14, No. 3, May } 1968 \text {, pp } 415-420 \text {. }\end{array}$ \\
\hline$A-2$ & $\begin{array}{l}\text { E. C. Cady: Study of The rmodynamic Vent and Screen Baffle } \\
\text { Integration for Orbjtal Storage and Transfer of Liquid Hydrogen. } \\
\text { NASA CR-13/4t32, McDonne11 Douglas Astronautics Company, Huntington } \\
\text { Beach, California, August } 1973 \text {. }\end{array}$ \\
\hline$A-3$ & $\begin{array}{l}\text { B. B. Mikic, Wo Mo Rohsenow and P. Griteith: "On Bubble Growth } \\
\text { Rates." Int. J. Heat Mass Transfer, Vol, 13, pp } 657-666,1970 .\end{array}$ \\
\hline$A-4$ & $\begin{array}{l}\text { C. P. Nitze, V. E. Schrock and P. L. Chambre: "Flow about a } \\
\text { Growing Sphere in Contact with a Plane Surface." Int. J. Heat } \\
\text { Mass Transfer, Vo1. 11, pp 1637-1652, } 1968 .\end{array}$ \\
\hline$\Lambda-5$ & $\begin{array}{l}\text { H. Schlichting. Boundary Layer Theory. McGraw-Hill Book } \\
\text { Company, 1960, page } 16 .\end{array}$ \\
\hline$A-6$ & $\begin{array}{l}\text { D. W. VanKrevelen and P. J. Hoftijzer: "Studies of Gas Bubble } \\
\text { Formation." Chemica1 Engineering Progress, Vol. } 46 \text {, No. 1, 1950, } \\
\text { pp } 29-35 .\end{array}$ \\
\hline $\mathrm{A}-7$ & $\begin{array}{l}\text { E. Silberman: Production of Bubbles by the Disintegration of } \\
\text { Gas Jets in Liquid. Procetdings of the Fifth Midwestern Confer- } \\
\text { ence on Fluid Mechanics, University of Michigan Press, April } \\
\text { 1957. }\end{array}$ \\
\hline
\end{tabular}

